UNIVERSITAS 



\section{UNIVERSITAS}

REVISTA DE CIENCIAS SOCIALES Y HUMANAS

Número 29 / septiembre 2018-febrero 2019

ISSN impreso: 1390-3837 / ISSN electrónico: 1390-8634

\section{Universitas está indexada en las siguientes}

Bases de Datos y sistemas de información científica:

\section{BASE DE DATOS INTERNACIONALES SELECTIVAS}

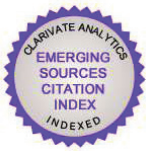

WEB OF SCIENCE

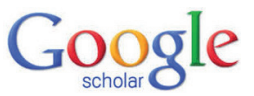

\section{BASE}

PLATAFORMAS DE EVALUACIÓN DE REVISTAS

\section{MIAR}

DIRECTORIOS SELECTIVOS
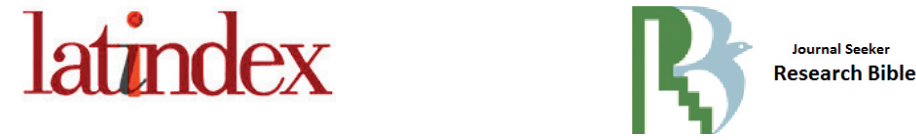

HEMEROTECAS SELECTIVAS

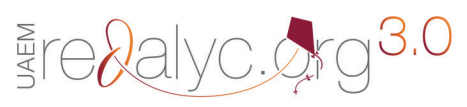

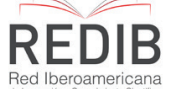

BUSCADORES DE LITERATURA CIENTÍFICA OPEN ACCESS
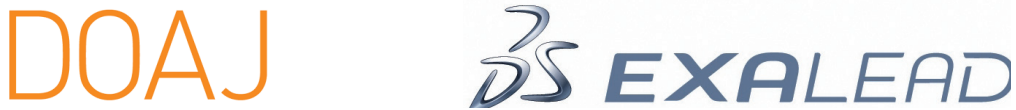


\section{○ं SHERPA/RøMEO}

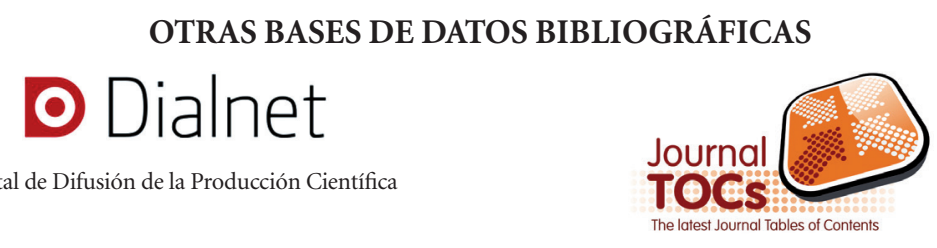

\section{CATÁLOGO DE BIBLIOTECAS INTERNACIONALES}

\section{Andes}

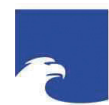

Ibero-Amerikanisches

Institut

Preußischer Kulturbesitz
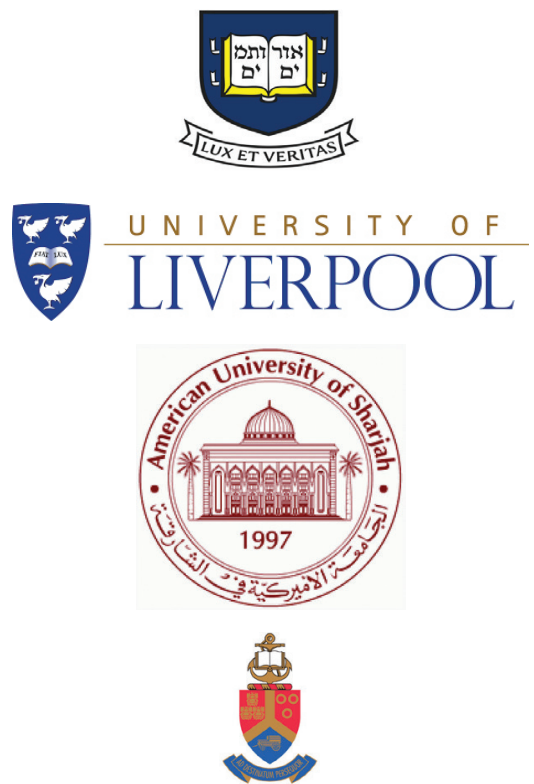

UNIVERSITEIT VAN PRETORIA

UNIVERSITY OF PRETORIA

YUNIBESITHI YA PRETORIA

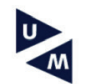

Maastricht University

Universidad de Navarra

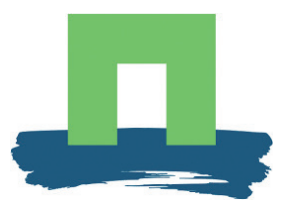

Wageningen University

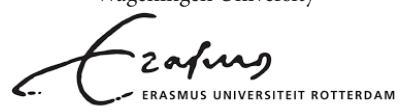

Hanzehogeschool

Groningen

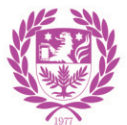

UNIVERSITY

OF SKÖVDE

BISHOP

GROSSETESTE

UNIVERSITY 


\section{Sainte Anne}

Plymouth State

MUHLENBERG

FRANLINCYARSHALL

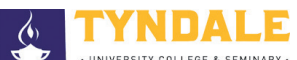

. University COLLEge \& SEMinary.

THE UNIVERSITY of NORTH CAROLINA

GREENSBORO

Virginia

$[|[\mid]|]$ Tech

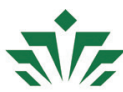

UNC CHARLOTTE

Depaul Dniversity

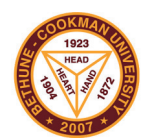

Nebraska

Omaha

Southwestern

University

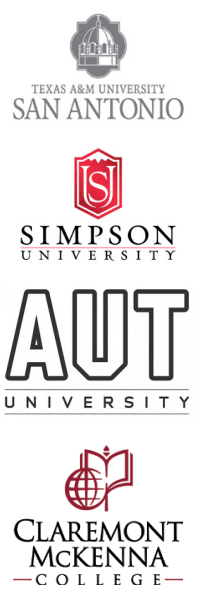

매 OFIIVERSITY

REVISTAS CONSORCIADAS

Comunicar

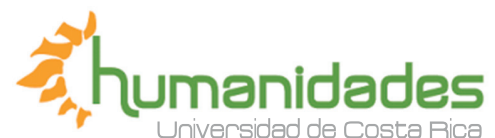


Universitas-UPS, Revista de Ciencias Sociales y Humanas de la Universidad Politécnica Salesiana del Ecuador, que se inicia en el año 2002, tiene una regularidad semestral.

El objetivo de Universitas-UPS es promover y difundir la publicación de textos científicos y críticos, inéditos y previamente evaluados, de carácter e interés actuales, en el campo de los conocimientos de lo social y humano y sobre problemáticas de alcance general, aunque privilegiando aquellos referidos en particular al Ecuador y América Latina.

La Revista presenta artículos y ensayos, investigaciones en curso o resultados de ellas, análisis y comunicaciones de perfil más coyuntural, y reseñas o recensiones de libros.

http://www.ups.edu.ec

Correo electrónico: revistauniversitas@ups.edu.ec

Rector

Javier Herrán Gómez, sdb

Vicerrector General Académico

Luis Tobar Pesántez

Vicerrector Docente

Fernando Pesántez Avilés

Vicerrector de Investigación

Juan Pablo Salgado Guerrero

Vicerrectores de sede

César Vásquez Vásquez (Cuenca)

José Juncosa Blasco (Quito)

Andrés Bayolo Garay (Guayaquil)

Universitas-UPS, Revista de Ciencias Sociales y Humanas, publicación semestral, No. 29, septiembre 2018-febrero 2019. Editor responsable: René Unda Lara. ISSN impreso: 1390-3837 / ISSN electrónico: 1390-8634. Diseño y corrección: Editorial Universitaria Abya-Yala. Domicilio de la publicación: Universidad Politécnica Salesiana del Ecuador. Casilla postal 2074, Cuenca-Ecuador. Centro Gráfico Salesiano: Vega Muñoz 10-68 y General Torres, Teléfono (+593 7) 2831745, Casilla 01-01-0275, Cuenca-Ecuador.

D.R. (c) Universitas. Revista de Ciencias Sociales y Humanas.

Impreso en Ecuador

UNIVERSITAS es una publicación semestral de la Universidad Politécnica Salesiana del Ecuador. Las ideas y opiniones expresadas en las colaboraciones son de exclusiva responsabilidad de los autores. 


\section{Consejo de Editores (Editors Board)}

\section{Editora (Editor)}

Dra. Amor Pérez Rodríguez, Universidad de Huelva, España

\section{Editores Adjuntos (Assistant Editors)}

Dr. René Unda Lara, Universidad Politécnica Salesiana, Ecuador

Dr. Saúl Uribe Taborda, Universidad Politécnica Salesiana, Ecuador

\section{Consejo Científico (Advisory Board)}

Dr. Alberto Acosta, FLACSO, Ecuador

Dr. Oscar Aguilera Ruiz, U. de Chile, Chile

Dra. Sara Victoria Alvarado, CINDE Universidad de Manizales, Colombia

Dr. Alejandro Cussianovich, U. Mayor de San Marcos, Perú

Dr. Eduard Arriaga, Universidad de Western Ontario, Canadá

Dr. Luis M. Romero-Rodríguez, Universidad Internacional de La Rioja, España

Dr. Jorge Baeza, U. Católica Silva Henríquez, Chile

Dr. Jorge Benedicto, UNED, España

Dr. Héctor Fabio Ospina,CINDE Universidad de Manizales. de Manizales, Colombia

Dra. Silvia Borelli, Pontificia Universidad Católica de Sao Paulo, Brasil

Dr. Luis Bruzón Delgado, Fundación DEMUCA (AECID), Costa Rica

Dra. Alida Carloni, Universidad de Huelva, España

Dra. Rita María Cassia de Oliveira, PUCSP, Brasil

Dr. José Rubén Castillo, U. Autónoma de Manizales, Colombia

Dr. Manuel Cebrián de la Serna, Universidad de Málaga, España

Dr. René Ceballos, Universidad Católica Boliviana. La Paz, Bolivia

Dra. Ma. Isabel Domínguez, Centro Investigaciones Psicológicas y Sociológicas, Cuba

Dr. Carles Feixa, Universidad de Lleida, España

Dra. Bertha García, Pontificia Universidad Católica del Ecuador

Dra. Claudia García Muñoz, Universidad de Pereira, Colombia

Dr. David González Cruz, Universidad de Huelva, España

Dr. Rafael Grasa, Universidad Autónoma de Barcelona, España

Dr. José Luis Guzón, Universidad Pontificia de Salamanca, España

Dr. Antonio Hermosa, Universidad de Sevilla, España

Dr. François Houtart, Universidad de Lovaina, Bélgica

Dr. Xavier Izko, Universidad Politécnica Salesiana, Ecuador

Dr. Manfred Liebel, Universidad de Berlín, Alemania

Dr. Jesús Leal, Universidad Complutense de Madrid, España

Dr. Fernando López Noguero, Universidad Pablo de Olavide, España

Dra. Valeria Llobet, Universidad Nacional San Martín, Argentina

Dr. Fernando Mayorga, Universidad Mayor de San Simón, Bolivia 
Dr. Julio Mejía, Universidad Nacional Mayor de San Marcos, Perú

Dr. Ángel Montes, Universidad de Murcia, España

Dr. Germán Muñoz, U. Distrital Fco. José de Caldas, Colombia

Dra. María Elena Ortiz, Universidad Politécnica Salesiana, Ecuador

Dr. Lucas Pacheco, Pontificia Universidad Católica del Ecuador

Dr. Franklin Ramírez, FLACSO, Ecuador

Dr. Juan Romero, Universidad de La República, Uruguay

Dra. Florencia Juana Saintout, Universidad Nacional de La Plata, Argentina

Dr. Giampietro Schibotto, Universidad de Bologna, Italia

Dr. José Manuel Valenzuela, Colegio de la Frontera Norte, México

Dr. Manuel Ángel Vázquez Medel- Universidad de Sevilla, España

Dra. Melina Vázquez, Universidad de Buenos Aires, Argentina

Dr. Gaitán Villavicencio, Universidad de Guayaquil, Ecuador

Dr. Pablo Vommaro, Universidad de Buenos Aires, Argentina

Dra. Isabel Yépez, Universidad de Lovaina, Bélgica

Dr. Hernán Reyes. Universidad Andina Simon Bolívar, Ecuador

Dr. José Machado Pais, Universidad de Lisboa, Portugal

Dra. Mariana Chaves, Universidad Nacional de La Plata, Argentina

Dra. Teresa Viera Hernández, Centro de Estudios de Juventud, Cuba

Dr. David Acosta, Corporación Universitaria Unitec, Colombia

Dra. Verónica Filardo, Universidad de la República, Uruguay

Dr. Geoffrey Pleyers, Universidad Católica de Lovaina, Bélgica

Dr. Benjamín Tejerina, Universidad del País Vasco, España

Dr. Alberto Riella, Universidad de la República, Uruguay

Dr. Ivaldo Gelhen, Universidad Federal de Río Grande do Sul, Brasil

Dra. Lourdes Gaitán, Universidad Complutense de Madrid, España

Dr. Pedro Núñez, FLACSO, Argentina

Dra. Silvia Guemureman, Universidad de Buenos Aires, Argentina

Dr. Gomer Betancor, UNED, España

Dra. Kim Clark, Universidad de Western Ontario, Canadá

Dra. Beatriz Juárez. Universidad de Western Ontario, Canadá

Dra. Maria del Rosario Chacón, Universidad Pedagógica Experimental

Libertador"Rafael Alberto Escobar Lara", Venezuela

\section{Consejo Internacional de Revisores (International Reviewers Board)}

Dra. Alexandra Agudelo, Universidad Autónoma Latinoamericana, Colombia

Dr. Jaime Brenes Reyes, Western Ontario University, Canadá

Dr. Emilio Álvarez Arregui, Universidad de Oviedo, España.

Dra. Catarina Alves Costa, Universidade Nova de Lisboa

Dra. Ana Paula Alves Ribeiro, Universidade do Estado do Rio de Janeiro 
Dr. Xavier Andrade, Universidad de los Andes, Colombia

Dra. Karen Andrade Mendoza, Universidad Central del Ecuador

Dra. Elisenda Ardevol, Universidad Abierta de Cataluña, Barcelona

Dra. Inmaculada Berlanga, Unir, España

Dra. Patricia Bermúdez, FLACSO, Ecuador

Dr.César Bernal, Universidad de Almeria, España

Dr. Hugo Burgos, Universidad San Francisco de Quito, Ecuador

Dra. M. Carmen Caldeiro, Universidad Pública de Navarra, España

Dr. Gastón Carreño, Centro de Estudios en Antropología Visual, Chile

Dra. Patricia de Casas Moreno, Universidad de Huelva, España

Dra. Ana Castro Zubizarreta, Universidad de Cantabria, España

Dr. Manuel Cebrián de la Serna, Universidad de Málaga, España

Dr. David Chávez, Universidad Central del Ecuador

Ddo. Hugo Chávez, Universidad Autónoma Metropolitana Unidad Iztapalapa, México

Dra. Paloma Contreras Pulido, Universidad de Huelva, España

Dra. Rocío Cruz Díaz, Universidad Pablo de Olavide, España

Dr. José M. Cuenca, Universidad de Huelva, España

Dra. Agueda Delgado Ponce, Universidad de Huelva, España

MSc. Holger Díaz, Universidad Politécnica Salesiana, Ecuador

Dr. Manuel Fandos, Unir, España

Dra. Monica Fantin, Universidade Federal de Santa Catarina, Brasil

Dra. Soraya Ferreira Vieira, Universidade Federal de Juiz de Fora, Brasil

Dr. Carlos Flores, Universidad Autónoma del Estado de Morelos, México

Dra. Margarita García Candeira, Universidad de Huelva, España

Dr. Blas Garzón, Universidad Politécnica Salesiana, Ecuador

Dr. Manuel González Mairena, Universidad Pablo de Olavide, España

Dr. Ricardo Green, Goldsmiths, University of London.

Dra. Anne Gustavsson, Universidad Nacional de San Martín, Argentina

Dr. Lizardo Herrera, Universidad de Pittsburg, EEUU

Dra. Mónica Hinojosa Becerra, Universidad Nacional de Loja, Ecuador

Dra. Débora Lanzeni, Universidad de Buenos Aires, Argentina

Dr. Christian León, Universidad de Buenos Aires, Argentina

Dr. Edizon León, UASB, Ecuador

Dra. Rosalba Mancinas Chávez, Universidad de Sevilla, España

Dr. Rafael Marfil Carmona, Universidad de Granada, España

Dr.Isidro Marín Gutiérrez, Universidad de Huelva, España

Dra. Carmen Marta Lazo, Universidad de Zaragoza, España

Dr. Jorge Eliécer Martínez, U. La Salle, Colombia

Dr. Javier Marzal Felici, Universitat Jaume I, Valencia, España

Dr. Pedro Núñez, FLACSO, Argentina

Dr. Xaquín Núñez, Universidade do Minho, Portugal 
Dr. Miguel Ángel Ortiz Sobrino, Universidad Complutense, España MSc. Franco Passarelli, FLACSO Ecuador

Dr. Francisco Pavón Rabasco, Universidad de Sevilla, España

Dra. Paz Guarderas, Universidad Politécnica Salesiana, Ecuador

Dra. Alicia Peñalva, Universidad Pública de Navarra, España

Dr. David Londoño, Institución Universitaria de Envigado, Colombia

Dra. Liliana Ávila, Universidad Pedagógica, Colombia

Dra. Bárbara Catalano, Universidad Metropolitana para la Educación y el Trabajo, Argentina

Dra. Sarah Pink, University of Kent, Inglaterra.

Dra. Armanda Pinto Matos, Universidade de Coimbra, Portugal

Dra. Ma del Mar Ramírez Alvarado, Universidad de Sevilla, España

Dra. Antonia Ramírez García, Universidad de Córdoba, España

Dr. Jordi Grau Rebollo, Universidad Autónoma de Barcelona, España

Dra. Paula Renés Arellano, Universidad de Cantabria, España

Dra. Mariana Rivera, Escuela Nacional de Antropología e Historia, México

Dr. Juan Ignacio Robles, Universidad Autónoma de Madrid, España

Dr. Alejandro Rodríguez Martín, Universidad de Oviedo, España

Dra. M. Mar Rodríguez Rosell, Universidad Católica San Antonio, España

Dra. Sara Román García, Universidad de Cádiz, España

Dra. Charo Sádaba, Universidad de Navarra, España

Dra. Yamile Sandoval, Alfamed, Colombia

Dra. María Fernanda Soliz, UASB, Ecuador

Dr. Santiago Tejedor Calvo, Universidad Autónoma de Barcelona, España

Dra. Simona Tirocchi, Università di Torino, Italia

Dr.Vitor Tomé, Universidade do Algarve, Portugal

MSc. Christian Troya, FLACSO, Ecuador

Dra. María Fernanda Troya, Escuela de Altos Estudios en Ciencias Sociales, Paris

Dr. Ulises Unda, Universidad de Western Ontario, Canadá

Dra. Gabriela Zamorano, El Colegio de Michoacán, México

Dr. Antonio Zirión, Universidad Autónoma Metropolitana Unidad Iztapalapa, México

\section{Consejo Editorial Institucional UPS (Publishers Council UPS)}

\section{Consejo de Publicaciones (Board of Publications)}

Dr. Javier Herrán Gómez, sdb.Universidad Politécnica Salesiana, Ecuador

Dr. Juan Botasso Boetti, sdb.Universidad Politécnica Salesiana, Ecuador

Dr. Juan Pablo Salgado, GuerreroUniversidad Politécnica Salesiana, Ecuador

Dr. Luis Álvarez Rodas, Universidad Politécnica Salesiana, Ecuador

Msc. Fabricio Freire, Universidad Politécnica Salesiana, Ecuador

Dr. José Juncosa Blasco, Universidad Politécnica Salesiana, Ecuador 
MSc. Jaime Padilla Verdugo, Universidad Politécnica Salesiana, Ecuador Dra. Floralba Aguilar Gordón, Universidad Politécnica Salesiana, Ecuador MSc. Sheila Serrano Vincenti, Universidad Politécnica Salesiana, Ecuador MSc. John Calle Sigüencia, Universidad Politécnica Salesiana, Ecuador Dr. René Unda Lara, Universidad Politécnica Salesiana, Ecuador Msc. Betty Rodas Soto, Universidad Politécnica Salesiana, Ecuador MSc. Andrea De Santis, Universidad Politécnica Salesiana, Ecuador MSc. Mónica Ruiz Vásquez, Universidad Politécnica Salesiana, Ecuador

\section{Editor General UPS (General Editor UPS)}

Dr. Luis Álvarez-Rodas

\section{Consejo Técnico (Board of Management)}

MSc. Tania X. Barrezueta

Dr. Ángel Torres-Toukoumidis

\section{Servicio de Publicaciones (Publications Service)}

Hernán Hermosa (Coordinación General)

Marco Gutiérrez (Soporte OJS)

Paulina Torres (Edición)

Martha Vinueza Manosalvas (Maquetación)

Raysa Andrade (Maquetación)

Traductor (Translator)

Adriana Curiel

\section{Editorial}

Editorial Abya-Yala (Quito-Ecuador)

Avenida 12 de octubre N422 y Wilson,

Bloque A, UPS Quito, Ecuador. Casilla 17-12-719

Teléfonos: (593-2) 3962800 ext. 2638

Correo electrónico: editorial@abyayala.org

\section{Figura de portada}

Motivos indígenas del antiguo Ecuador de Frederick W. Shaffer. Motivo 126 Lechuza, pág 43. 



\section{DOSSIER}

Internacionalización de la educación y movilidad:

reflexiones a partir del caso argentino

Liliana Mayer y Bárbara Catalano

La propiedad intelectual y la mercantilización forzada

del conocimiento

Pablo Míguez

A cien años de Córdoba: entre imperativos tecno-económicos

y la reelaboración de conocimientos

Alexis Mercado

Hacia una política pública del bioconocimiento:

ciencia, tecnología e investigación

Pablo Samaniego Ponce

Políticas públicas de retorno del talento humano

calificado de Ecuador y su inserción internacional:

el caso de los becarios de doctorado

Verena Hitner y Jesús Tapia López.

\section{MISCELÁNEA}

Análisis comparativo del framing mediático en agencias internacionales de noticias Oriente-Occidente.

Estudio de caso: Atentado al aeropuerto de Estambul

Sabina Civila de Dios y Luis M. Romero-Rodríguez. 
Acceso a la educación superior: Uruguay y Ecuador

Estudio de derecho comparado

Rina Pazos

Club de periodismo como incidente comunicacional en el proceso educativo

Jefferson J. Sandoval G. y Tomás H. Rodríguez C.

Aprendizaje ubicuo, interfaces de comunicación

y las competencias mediáticas

Soraya María Ferreira Vieira y Luana Castilho

Tendencias globales que marcan el desarrollo de la educación superior en el Ecuador: pertinencia, regionalización

y expansión de la oferta académica

José A. Flores y Endel D. Pernía

\section{NORMAS EDITORIALES}

Normas de publicación en «Universitas» 


\section{DOSSIER}

Internationalization of education and mobility:

an analysis upon the argentine case

Liliana Mayer y Bárbara Catalano

Intellectual property and the forced commodification

of knowledge

Pablo Míguez

A hundred years of Córdoba: between techno-economic imperatives and the re-elaboration of knowledge

Alexis Mercado

Towards a public policy of bio-knowledge:

science, technology and research

Pablo Samaniego Ponce

Public policies for the return of qualified human talent

in Ecuador and its international insertion:

the case of PhD scholars

Verena Hitner y Jesús Tapia López.

\section{MISCELÁNEA}

Comparative analysis of media framing in international news agencies east-west. Case Study: Attack at Istanbul airport

Sabina Civila de Dios y Luis M. Romero-Rodríguez. 
Access to higher education: Uruguay and Ecuador Comparative Law study

Rina Pazos

Journalism club as a communicational incident in the educational process

Jefferson J. Sandoval G. y Tomás H. Rodríguez C.

Ubiquitous learning, communication interfaces and media skills

Soraya María Ferreira Vieira y Luana Castilho

Global trends marking the development of Ecuador's

higher education: relevance, regionalization and expansion

of the academic market

José A. Flores y Endel D. Pernía

\section{NORMAS EDITORIALES}

Publication guidelines in «Universitas» 


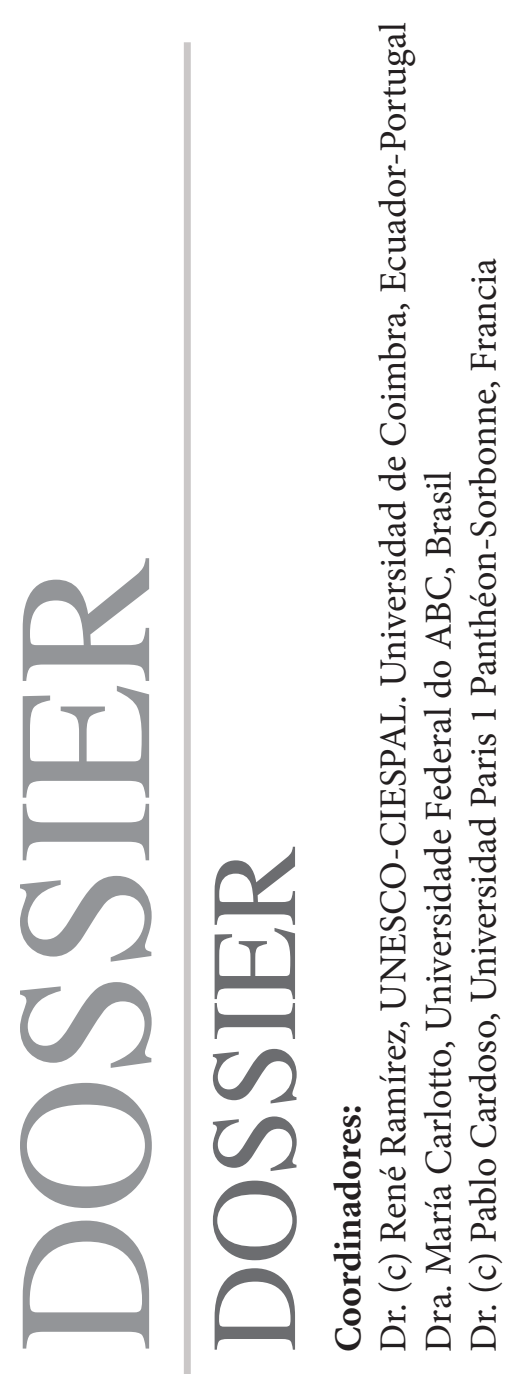





\title{
Internacionalización de la educación y movilidad: reflexiones a partir del caso argentino
}

\author{
Internationalization of education and mobility: \\ an analysis upon the argentine case
}

\author{
Liliana Mayer \\ CONICET. Sede en la Universidad Nacional de Misiones \\ lzmayer@gmail.com \\ Código Orcid: https://orcid.org/0000-0002-7364-4048 \\ Bárbara Catalano \\ Universidad Metropolitana para la Educación y el Trabajo (UMET) \\ Universidad Argentina de la Empresa (UADE) \\ Instituto Gino Germani de la Facultad de Ciencias Sociales de la UBA \\ catalano81@gmail.com \\ Código Orcid: https://orcid.org/0000-0002-7565-8451
}

\begin{abstract}
Resumen
La internacionalización de la educación es un tema de creciente interés. En la actualidad, refiere a diversos esquemas de relaciones de poder, así como a la acumulación de ventajas y vicisitudes vinculadas a las movilidades en la modernidad y fundamentalmente los efectos de la globalización en las sociedades contemporáneas. En este artículo analizamos, por un lado, la evolución de este fenómeno educativo, focalizando en el caso argentino, en particular, en de la ciudad de Buenos Aires. Se plantea como elemento subyacente a la movilidad académica las desigualdades existentes y los problemas vinculados a la exclusión social y a las (des)ventajas que repercuten en los inequitativos accesos a la educación en este marco internacional. Asimismo, la inminente globalización que permea las diversas esferas de la vida social también tiene su correlato con el incremento de las movilidades y la diversificación de los viajes entre los que se encuentran los viajes por motivo de estudio, tal como se mostrará a continuación con datos precisos sobre las llegadas de no residentes a Argentina. Finalmente, se enumeran ciertos factores decisorios a la hora desarrollar los viajes por estudios por parte de los no residentes que ingresan al país en general y la ciudad de Buenos Aires en particular. Entre ellos se destacan: la gratuidad, la universidad democrática, ciertos discursos sobre calidad y las referencias y tradiciones.
\end{abstract}

\section{Palabras clave}

Internacionalización de la educación, movilidad académica, acumulación de ventajas y globalización.

Forma sugerida de citar: Mayer, Liliana y Catalano, Bárbara (2018). Internacionalización de la educación y movilidad: reflexiones a partir del caso argentino. Universitas, 29 , pp. 19-41. 


\begin{abstract}
The internationalization of education is a topic of growing interest. It refers to various patterns of power relations, as well as the accumulation of advantages and changes linked to the mobilities in modernity and fundamentally the effects of globalization in contemporary societies. In this article we analyze, on the one hand, the evolution of this education phenomenon, taking into account the Argentine case, particularly in the city of Buenos Aires. The existing inequalities and the problems linked to social exclusion and to the (dis) advantages that have an impact on the inequitable access to education in this international framework are considered as an underlying element of academic mobility. Likewise, the imminent globalization that permeates the different spheres of social life also has its correlation with the increase in mobility and the diversification of travel, among which are trips for reasons of study, as will be shown below with precise data on arrivals of non-residents to Argentina. Finally, certain decision factors are listed when developing study trips by non-residents entering the country in general and the city of Buenos Aires in particular. Among them stand out: the gratuity, ta democratic university ethos, certain discourses on educational quality, and references and scholastic traditions.
\end{abstract}

\title{
Keywords
}

Internationalization of education, scholastic mobilities, accumulation of advantages, and globalization.

\section{Introducción}

En las ciencias sociales, existe un consenso al afirmar que los sistemas de educación superior nacionales fueron creados para una elite en sus orígenes - varones, urbanos y de los sectores más favorecidos de las sociedades - (Bourdieu y Passeron, 2009; Buchbinder, 2005; Herrero, 2010) y luego, la procedencia social de su público, al tiempo que el género, se fue modificando con la incorporación de estudiantes provenientes de sectores sociales medios y bajos. Estas transformaciones en el alumnado se corresponden con los cambios en las legislaciones educativas que, primero en los países centrales - luego de la Segunda Guerra Mundial - y luego en América Latina en los últimos veinte años, fueron modificando las legislaciones educativas, extendiendo la obligatoriedad de los niveles secundarios y 
ampliando así la base de reclutamiento para la educación superior ${ }^{1}$ (Pochulu, 2004; Ezcurra, 2011; García de Fanelli y Jacinto, 2010). Así, el Instituto Internacional para la Educación Superior en América Latina y el Caribe (IESALC) de la UNESCO, indica que entre 1994 y 2006 la matrícula de la educación superior mostró una tasa de crecimiento sobresaliente del 126\%, pasando de albergar aproximadamente a 7544000 estudiantes a alrededor de 17017000 (Gazzola y Didriksson, 2008). ${ }^{2}$

De esta manera, en nuestro continente, desde las últimas décadas del siglo XX, se registra una tendencia sostenida a la democratización y masificación de la educación superior. Como sostiene Rama (2009), es previsible que este crecimiento continúe con un corrimiento ascendente hacia la educación permanente y los estudios de posgrado en todos sus niveles. La dinámica de la universalización de la educación superior - que en nuestro continente está en proceso con distintas problemáticas y vacancias - presenta aristas positivas, como el aumento de la matrícula universitaria en sectores vulnerables (Mayer y Cerezo, 2016, 2018a y 2018b), lo que significa una democratización del saber junto con una tendencia a sociedades más igualitarias (Mayer y Núñez, 2016). Sin embargo, a su vez - y en paralelo a estos procesos - , presenciamos lo que se ha dado en llamar como "democracia segregadora" (Merle, 2009), que supone que una vez alcanzados niveles altos o totales de cobertura, se generan movimientos internos de diferenciación horizontal (Braslavsky, 1985), es decir, propuestas diferenciadas hacia dentro un mismo nivel educativo. Dicho de otra manera, las tendencias hacia la universalización de un nivel educativo, sea esta cual sea, devienen en ciertos niveles de devaluación, que generan estrategias de distinción en los agentes, para lograr trayectorias educativas (Mayer y Núñez, 2016) - y biográficas (Beck y Beck, 2001) - diferenciadas. En este sentido, una de las posibles estrategias cada vez más frecuente entre estudiantes y profesionales consiste, o bien en internacionalizar sus estudios obteniendo titulaciones en el extranjero, o bien en incorporar movilidad a sus trayectorias realizando una parte de sus estudios o estudiando el idioma del país hospedante $-\mathrm{y}$

1 Para un análisis de los cambios en las legislaciones educativas en nuestro continente, ver N. López, Las nuevas leyes de educación en América Latina. Una lectura a la luz del panorama social y educativo de la región (2007, Buenos Aires: IIPE UNESCO).

2 Esta matrícula se concentró principalmente en los estudios de grado (96\%) y en instituciones de gestión pública gratuita. 
viviendo - en otro país por un tiempo determinado, que suele tener como mínimo un cuatrimestre académico.

La educación internacional, o siguiendo los términos aquí planteados, la internacionalización de la educación son procesos de larga data. La historia de los procesos educativos observa estudiantes nómades o móviles, asociados a familias de diplomáticos, o de diversas áreas que suponían desplazamientos por determinadas partes del globo (Gessaghi, 2016; Larrondo y Mayer, 2018). Sin embargo, lo que sí se presenta de un modo nuevo - y novedoso - es lo que entendemos en la actualidad al asociar la educación internacional con la globalización, concibiendo a la misma no solo como un reordenamiento de las relaciones económico-financieras, sino como una reorganización de todas las esferas de la vida social dentro de las que se incluye la educativa. En este sentido, existe un consenso al afirmar que el reordenamiento global redescubre lo local como una dimensión de lo global, por lo que los procesos de internacionalización conducen a preguntas sobre la creación de espacios que se sitúan tanto a nivel nacional como global y los modos en que se revelan sistemas, prácticas y políticas que fomentan los privilegios sociales, culturales y económicos de grupos dominantes (Howard y Gatzambide- Fernández, 2010). En este marco, un punto de inflexión para los estudios es desde la década de los noventa hasta la fecha, por el fin de la Guerra Fría y la redefinición de las relaciones de poder (Resnik, 2012). Koh y Kenway (2012) exploran la creación de órdenes educativos que incentivan la formación de líderes nacionales a partir de la internacionalización de sus trayectorias educativas. Resnik (2012) sostiene que a partir de los procesos de internacionalización de la educación se generan currículos con visiones internacionales y que esta orientación afecta, inclusive, a quienes no salen de su lugar de residencia habitual. Por otro lado, Nogueira y Aguiar (2012) muestran cómo los sectores acomodados de Brasil invierten cada vez más en recursos internacionalizados, en particular en los viajes educativos y el aprendizaje de segundas y terceras lenguas.

\section{Consideraciones metodológicas, aproximaciones teóricas y datos relevantes}

Este artículo se nutre de una profunda revisión teórica respecto de la temática en cuestión en relación con la problemática social y educativa con- 
temporánea, particularmente en lo que respecta a las dimensiones de la globalización y su impacto en el ámbito educativo (Resnik, 2015). En este sentido, el abordaje supone que si bien existen movilidades y procesos de internacionalización de la educación desde hace larga data, lo que aquí está en cuestión es su interrelación con los procesos globalizadores y la economía global. Las reflexiones teóricas de este trabajo se componen de entrevistas realizadas en el marco de la tesis de doctorado de una de las autoras (Catalano, 2017), cuyo tema versa sobre la integración y prácticas socioculturales de turistas de los países Mercosur y Chile en la ciudad de Buenos Aires. En ese marco, se realizaron 28 entrevistas a profundidad durante 2016 y se re-trabajaron datos cuantitativos provistos por el Ministerio de Turismo de la Nación (MINTUR).

La elección de la metodología cualitativa a partir de entrevistas a profundidad se debe a que la misma permite comprender los modos de sentido y representaciones de los actores en cuestión y la multiplicidad de dimensiones y explicaciones que los mismos conciben para dar cuenta de su situación y experiencia. Nos interesa acercarnos a la perspectiva del actor en su contexto abandonando el punto de vista "único" en beneficio de la pluralidad de puntos de vista coexistentes (Bourdieu, 2000). La entrevista debe ser entendida como el marco de una elaboración teórica conjunta en la que no necesariamente surgirán acuerdos totales o aprovechamientos semejantes, pero sí interpretaciones que no existían antes de la relación (Saltalamacchia, 1992).

Si bien más adelante brindaremos las especificidades del concepto de globalización y sus implicancias en la vida cotidiana de los sujetos, resulta pertinente precisar aquí el sentido de los procesos de internacionalización de la educación. El mismo se describe - desde los organismos internacionales - como el proceso de integrar una dimensión internacional, intercultural y global a los objetivos y la enseñanza/aprendizaje. La internacionalización, entonces, refiere a la relación entre naciones, personas, culturas y sistemas, que a través de esfuerzos normativos se "armonizan" (Ball y Youdell, 2008), teniendo un espacio educativo común. La referencia a los procesos de internacionalización es indisociable a la Declaración de Bolonia, ${ }^{3}$

3 La Declaración de Bolonia refiere a un proceso de convergencia entre universidades de los países de la Unión Europea y otros fuera de ese espacio como Rusia y Turquía, que tiene como objetivo estandarizar los contenidos de carreras universitarias para facilitar el intercambio de titulados y la movilidad académica. Además de los actores públicos específicos en materia de comunicación, en este proceso participaron - y participan - actores diversos como empresas y organismos interna- 
que en 1999 prestó el marco normativo y de convergencia dónde desarrollar las iniciativas tendientes al fortalecimiento de este proceso. Si bien el espacio educativo común es europeo - relacionado con la Comunidad Europea y otros países adherentes - , el proceso de Bolonia impulsa por un lado una "dimensión externa" (Zgaga, 2006) y, por otro lado, tendencias a emular con las dificultades de cada caso - estas experiencias fuera de los límites del espacio común creado. ${ }^{4}$

De este modo, la movilidad deviene en un aspecto intrínseco al fenómeno de la internacionalización de la educación. Mientras que este binomio - educación y movilidad - da pie al abordaje de las movilidades como parte de una constelación entre movimientos, significados, experiencias, ritmos y prácticas (Cresswell, 2008), sumado al hecho de considerar al movimiento en el centro de las realidades sociales. El movimiento físico de las personas que implica un origen y un destino acarrea un conjunto de fenómenos que circulan satelitalmente sobre los sujetos, sus interacciones y significados, perceptible desde el nivel individual y también desde una escala de sociedad.

En la relación movilidad y educación, se subraya el desplazamiento de sujetos de un lugar de residencia hacia un lugar de destino, por un periodo de tiempo determinado y por un motivo que tiene que ver con el estudio, la formación, la especialización y la complementariedad académica. El motivo formación, intercambio y titulación, es lo que caracteriza a este tipo de sujeto móvil, que a su vez lo diferencia de cualquier otro tipo, ya sea migrante o turista (Catalano, 2017); a su vez, en otros contextos este fenómeno es tratado como movilidad académica (Tremblay, 2005).

En las líneas que siguen, analizaremos los procesos de internacionalización y movilidad académica, anclando nuestro estudio al área metropolitana de la Buenos Aires (AMBA). Nuestro análisis se nutre, por una parte, de datos primarios obtenidos a través de entrevistas realizadas a estudiantes de la región ${ }^{5}$ durante 2016 y 2017, ${ }^{6}$ y de datos provistos por el MINTUR respec-

cionales, lo que origina también debates respecto a la mercantilización y commoditization de la educación superior, y que supone la competitividad de las universidades y su modernización, para "adaptar" sus currículos a las necesidades del "mercado global", por sobre las necesidades locales.

4 Para un análisis respecto de las dificultades en la emulación de esta Declaración en América Latina, ver J. Brunner, "El proceso de Bolonia en el horizonte latinoamericano: límites y perspectivas" (2008, Revista de Educación, pp. 119-145, España: MECD).

5 El trabajo de campo incluyó entrevistados de Chile, Paraguay, Brasil y Uruguay.

6 Las entrevistas fueron realizadas en el marco de la investigación doctoral Turismo y MERCOSUR, prácticas socioeculturales de integración en la Ciudad de Buenos Aires, de Bárbara Catalano. 
to del ingreso de turistas al país. Estos datos fueron provistos a partir de la Encuesta de Turismo Internacional (ETI) y su sistematización en el Anuario Estadístico de Turismo (AET), que desde 2011 incluyó la categoría de estudio para explicar los motivos para arribar al país. ${ }^{7}$

Tal como se observa en la tabla 1 , en el conjunto de extranjeros que ingresan al país se distinguen anualmente la cantidad de los turistas no residentes que llegan cuya principal motivación es el estudio, en relación a la totalidad de los datos recolectados por la ETI. Si bien el número absoluto de llegadas de turistas merma levemente en los últimos años, es dable destacar que las participaciones en torno al total de turistas por estudio han manifestado un leve aumento que va desde el 3,48 \% en 2012 hasta el 3,82 \% en 2015. Sin embargo, estos datos merecen algunas consideraciones: muchos turistas pueden no mencionar al momento de ser encuestados que ingresan por motivos educativos; la causa de ello radica en considerar perjudicial declarar tal fin por cuestiones reglamentarias y burocráticas. Otra de las razones de dicha omisión se debe a que la decisión de estudiar puede no estar tomada al momento de ser entrevistados. Por último, consideramos que ante las estigmatizaciones emergentes respecto a la cuestión de los migrantes, muchos ingresantes pueden no querer develar la finalidad real de su estadía en el destino.

Tabla 1

Turistas no residentes que llegan a Argentina cuya principal motivación es el estudio

\begin{tabular}{|l|l|l|l|l|}
\hline \multicolumn{1}{|c|}{ Año } & \multicolumn{1}{|c|}{$\mathbf{2 0 1 2}$} & \multicolumn{1}{c|}{$\mathbf{2 0 1 3}$} & \multicolumn{1}{c|}{$\mathbf{2 0 1 4}$} & \multicolumn{1}{c|}{$\mathbf{2 0 1 5}$} \\
\hline $\begin{array}{l}\text { Cantidad de turistas no residentes que } \\
\text { llegan a los aeropuertos y puertos de } \\
\text { Buenos Aires y aeropuerto de Córdoba }\end{array}$ & $\begin{array}{l}2904452 \\
(100 \%)\end{array}$ & $\begin{array}{l}2761563 \\
(100 \%)\end{array}$ & $\begin{array}{l}2828771 \\
(100 \%)\end{array}$ & $\begin{array}{l}2640394 \\
(100 \%)\end{array}$ \\
\hline $\begin{array}{l}\text { Cantidad de turistas no residentes cuyo } \\
\text { motivo principal es el "estudio" }\end{array}$ & $\begin{array}{l}85184 \\
(3,48 \%)\end{array}$ & $\begin{array}{l}85717 \\
(3,21 \%)\end{array}$ & $\begin{array}{l}77630 \\
(3,64 \%)\end{array}$ & $\begin{array}{l}68975 \\
(3,82 \%)\end{array}$ \\
\hline
\end{tabular}

Fuente: las autoras adaptado de AET-Mintur 2012-2015

7 Dentro del marco regulatorio de estos estudiantes que vienen a Argentina, se estipula que pueden ingresar al país como "turistas" y tramitar su residencia como estudiantes en la Dirección Nacional de Migraciones (DNM) dentro de los 30 días de la inscripción a la universidad. Esta aparente inadvertida normativa sobre la regularidad de los estudiantes, tiene incidencia en la recopilación de las estadísticas oficiales. Una característica particular de este tipo de estudiante que viaja por cuestiones académicas es que presenta un promedio de permanencia de 50 días para el año 2014 (MINTUR), lo que refleja un desenvolvimiento particular en el espacio. 


\section{La acumulación de ventajas}

La literatura existente en las ciencias sociales ha abordado de manera profunda la acumulación de desventajas, que derivan en procesos de vulnerabilidad y exclusión social (Castel, 1997), reconociendo la base material para tales situaciones pero anclando también en la densidad de los tejidos sociales. Esta acumulación de desventajas tiene su correlato en procesos estudiados en menor profundidad que conllevan a la acumulación de ventajas. Aquí citamos la preeminencia de Bourdieu (2000), que ha estudiado los campos del poder y las distintas estrategias de los sectores acomodados para mantener sus posiciones y la de los sectores medios para (re)enclasarse. Para el caso de los jóvenes - en este caso estudiantes - ambos procesos son fundamentales, ya que se trata de los esfuerzos que realizan - muchas veces en soledad, otras con su familia - para evitar caer en situaciones desventajosas y valerse de estrategias que desemboquen en situaciones privilegiadas. En palabras de Saravi (2010), acumular ventajas supone la participación en eventos, situaciones, experiencias y procesos que afianzan situaciones sociales y colaboran en la reafirmación de privilegios motorizados en otros momentos del ciclo de vida propio o inclusive, previo al individuo en cuestión. Entonces, si el análisis se centra en la acumulación de ventajas, adquieren primacía las experiencias biográficas y los períodos transicionales, donde la condición juvenil y estudiantil ocupa un lugar fundamental. ${ }^{8}$

Como sostiene Saravi (2015), universalizar la educación básica y extender la cobertura y los años de obligatoriedad, son políticas consensuadas por todos los sectores sociales y políticos, ancladas en las narrativas del "ejemplo" de los países avanzados que cuentan con altos niveles educativos en sus poblaciones, con estándares de vida y de desarrollo igualmente altos. Sin embargo, en nuestro continente esta expansión no es homogénea y se ancla sobre exclusiones o desigualdades preexistentes - niveles de ingresos del hogar, localización geográfica, el clima educativo del hogar y la pertenencia o no a grupos étnicos y/u originarios, solo por citar algunas - que representan ventajas o desventajas significativas sobre las que se desarrollan los procesos de inclusión. Estas desigualdades, ventajas o desventajas no desaparecen

8 Esping Andersen (2002) sostiene que este hilvanamiento de eventos, situaciones, experiencias y procesos, en la medida en que las condiciones de bienestar de un momento dado presuponen otras previas y habilitan a otras futuras, permite distinguir desventajas transitorias de las que calarán más hondo y por largos períodos en las biografías singulares. 
porque vastos sectores de la población hayan sido "incluidos" (Saravi, 2015, p. 11). Esto nos lleva a plantear las primeras líneas de nuestro artículo: la tendencia a masificar el nivel universitario - al ampliar su base de reclutamiento debido a la universalización de los niveles previos - si bien sostiene los anhelos por la inclusión y la constitución de sociedades más igualitarias - procesadas a través de la educación - no elimina las desigualdades sociales, sino que muy por el contrario, genera mecanismos para el desarrollo de nuevas formas de diferenciación social. Aquí es donde las instituciones educativas - en este caso las de educación superior - cobran importancia: no solo para producir y reproducir posiciones, sino como un entramado donde los actores puedan influir - o así creerlo - en sus futuras determinaciones.

\section{Globalización, educación, internacionalización y movilidad: algunas aproximaciones}

Beck y Beck (2001) sostienen que la globalización cambia las formas de pensar y percibir el mundo y las respuestas que los agentes sociales e instituciones intentan dar a un mundo que se torna cada vez más incierto e inestable, con la necesidad de responder a múltiples desafíos, corroídos los reaseguros del Estado de Bienestar (Mayer, 2012). Si entendemos que la globalización - en tanto reordenamiento y liberalización de todas las esferas - cala en todos los niveles de la vida social, más allá de las reformas y esfuerzos normativos — que describiremos más adelante-, es importante poner atención a los cambios - en este caso los educativos - , ya que las trayectorias vitales se ven afectadas por ideas y decisiones que crean audiencias para la implementación de determinados marcos normativos y reformas. En este sentido, los cambios educativos, si bien encuentran condiciones de posibilidad en las reformas, muchas veces derivan de virajes y desplazamientos sociales más generales que circulan en las sociedades, consensos de organismos internacionales o discursos supranacionales, y que derivan en prácticas determinadas. Se trata, entonces, de dinámicas y cambios inmediatos que tienen significado nacional y global no solo en términos de política educativa, sino también en términos de igualdad de oportunidades, y que con su implementación pueden redefinir las prácticas educativas. Vale decir que ante una igualdad formal de las credenciales, los agentes sociales despliegan estrategias para diferenciarse, en un mundo cada vez más incier- 
to y desigual (Beck y Beck, 2001; Mayer, 2009) para intentar obtener ventajas comparativas respecto de sus pares (Larrondo y Mayer, 2018). Es en este contexto donde cobra relevancia el concepto de internacionalización de la educación, entendiendo a la misma como un proceso que se relaciona con la globalización, por una parte, y con normativas y acuerdos educativos, por otra. Ahora bien, ¿por qué se elige el destino que se elige? Y luego, más específicamente, ¿por qué Buenos Aires?

\section{La elección del destino: estudiar y vivir en Buenos Aires}

En los párrafos anteriores enfatizamos cómo los procesos de movilidad e internacionalización están atravesados por nuevas desigualdades o, dicho de otra manera, estrategias de distinción que despliegan los agentes sociales para lograr - o proyectar lograr - ventajas distintivas en sus biografías. Sin perder este eje de análisis, es lícito mencionar que dentro de los repertorios que organizan la acción de quienes optan por estas modalidades, se registra también una respuesta a una forma de percibir y vivir la vida social en la que las fronteras entre el trabajo y el ocio son porosas, y el espacio y tiempo están cada vez menos diferenciados. En este sentido, sobreviene una desorganización de los ritmos habituales junto a una flexibilización de la vida social, en la que se entreveran las obligaciones y el placer. Producto también de los modos de acumulación flexibles (Harvey, 1998), los individuos organizan su tiempo y sus actividades como un rompecabezas en el que todo parecería encajar milimétricamente, calculando los tiempos, las dedicaciones al ocio, al trabajo y a la socialización y el descubrimiento de "nuevas culturas".

Algunos expertos (Botto, 2015; Solanas, 2014) han abordado exhaustivamente las etapas de los procesos de acreditación universitaria, los avances y retrocesos que este fenómeno acarrea a nivel mundial $-\mathrm{y}$ en particular en ciertos procesos de integración regional - , así como también la efectividad de las políticas públicas construidas en cada bloque y desde los diferentes modelos de concebir a la integración regional, desde la cooperación binacional, el "intergubernamentalismo", las redes de políticas públicas, etc. También se ha tratado la presente dualidad entre la perspectiva de cooperación solidaria de acreditación universitaria y otra contrapuesta que se observa más orientada a la visión mercantilista de la educación y la concepción de la profesión como un recurso a ser transable, devaluando las fuerzas que aca- 
rrean los colectivos de profesionales de distintas disciplinas. ${ }^{9}$ No obstante, cabe destacar una significativa correlación entre el reconocimiento y la acreditación de carreras con la movilidad de estudiantes dentro de los procesos de integración regional (Botto, 2015).

En esa línea, más allá del arduo trabajo que implica la armonización de normas y regulación de acreditaciones, reconocimiento, homologación de títulos, así como también la incorporación por parte de los organismos gubernamentales como de las instituciones universitarias de las políticas suprarregionales, se evidencia que educación y movilidad profesional y de saberes es un tema de prioridad y en agenda dentro del bloque del Mercosur.

Argentina devino en un destino estratégico para completar estudios universitarios, sobre todo a nivel regional, a la vez que se manifiesta una creciente importancia que ha tenido la educación en el marco de los regionalismos como se manifestó en los casos de la Unión Europea o el Mercosur. En relación a esto, en los últimos años se gestaron programas de fomento a la movilidad por estudio, lo que propició un espacio regional común para la educación superior, fomentó la movilidad estudiantil, un sistema de transferencia de créditos y el intercambio entre profesores e investigadores (Perrotta, 2014). Dentro de ellos, Argentina implementa el Programa de Promoción de la Universidad Argentina a partir de 2006 (Oregioni y López, 2011), lo que agiliza la información a los extranjeros que desean estudiar en Argentina e se incentiva el flujo de estudiantes a través de la promoción y el relanzamiento de la calidad de la educación argentina, no obstante, es muy difícil obtener datos precisos sobre los flujos de este tipo de movilidad de sujetos (Botto, 2015).

Dentro de la población extranjera (50 000 estudiantes) sobresalen primero los estudiantes de nacionalidad peruana seguidos por sus pares de Brasil. También tienen participación estudiantes de Paraguay, Bolivia, Colombia y Chile. En menor medida se registra una presencia de estudiantes provenientes de Europa y Estado Unidos (La Nación, 2017).

Además de los procesos políticos específicamente delineados en los párrafos anteriores que refieren a los acuerdos normativos en desarrollar facilidades para la internacionalización, debemos incorporar las relaciones de poder que existen en la región. Aquí cobra importancia el concepto de “di-

9 Estas ideas son desglosadas a profundidad en investigaciones específicas sobre la educación superior y el marco internacional de la globalización y los regionalismos que tienen en su agenda esta temática (Botto, 2015; Perrotta, 2014; Solanas, 2014). 
plomacia cultural" (Fierro Garza, 2008), que si bien no se trata de un término nuevo, sí lo es su importancia como campo de acción y espacio privilegiado de la política exterior. Este concepto se refiere a la promoción de los valores que nutren una identidad nacional y de la historia, política y características socioeconómicas de un país en el extranjero. Las relaciones culturales permiten el acercamiento entre los diversos sectores políticos, económicos y sociales de los diferentes países (Cummings, 2003). ${ }^{10}$

Esta perspectiva se diferencia de las lecturas respecto de la educación en el extranjero como herramienta de venta de "marca país" (Mongiello, 2012), por su énfasis en el marketing y lo comercial, pero también por su carácter reductivo y la pobre interpretación de la identidad de los países, mientras que tanto la diplomacia cultural como la pública incorporan la idea del soft power. Es decir, los esfuerzos específicos se encuadran en lógicas de geopolítica previa, en las que intervienen relaciones de poder asimétricas (Sidicaro, 2003, p. 132). Además de los esfuerzos normativos arriba descritos y las cuestiones específicamente referidas a lo educativo - a lo que nos referiremos a continuación: la elección de Argentina y específicamente de Buenos Aires - , estará definida también por la estructura de relaciones de poder regional - en donde Argentina sobresale.

Los procesos de internacionalización y movilidad, como venimos sosteniendo hasta aquí, son indisociables de los relacionados a la globalización y modernización. En estos, las capitales o "grandes ciudades" ocupan un lugar privilegiado, donde lo nacional se vincula con lo global. Siguiendo el clásico análisis de Borja y Castells (1998), ciudades como Buenos Aires se constituyen en "ciudades nodales", que expresan la acumulación de estos procesos y los cambios que derivan de ellos: estas ciudades representan las principales aglomeraciones ya sea por su población o por su tamaño, así como también por las relaciones socioeconómicas que se generan en su interior. Este espacio geográfico condensa relaciones de nuevo tipo entre la sociedad civil y la sociedad política, así como nuevos ámbitos participativos diferentes de los tradicionales. En el caso de Buenos Aires, desde sus inicios se constituyó como una ciudad que amalgama lo tradicional con lo moder-

10 El concepto de "diplomacia cultural" no puede comprenderse sin el de "diplomacia pública", que refiere al conjunto de acciones mediante las cuales los Gobiernos se dirigen directamente a la población de otro país. Mientras la "diplomacia tradicional" puede ser descrita como las relaciones que se establecen entre instituciones al más alto nivel, la diplomacia pública se encarga de cómo un país se comunica con la ciudadanía de otras latitudes. Es por ello que la diplomacia pública basa su fuerza en la atracción. 
no, en un marco de diversidad cultural que se observa en aspectos cotidianos como la gastronomía y en su morfología urbana. Así, el paisaje muestra una ciudad "moderna", inscripta en una "economía global" y "sociedad de flujos", que impacta en la dinámica social y en la reestructuración del tiempo y el espacio. ${ }^{11}$ Pero, además de estos factores, la Reina del Plata conjuga una reputación específica dentro del sistema universitario nacional.

\section{Gratuidad}

Las dificultades - económicas - de acceso a los estudios superiores - en particular los universitarios - es uno de los motivos principales que impulsa el desplazamiento de los jóvenes que desean realizar sus estudios en el exterior. Para ello realizan, en primer lugar, un diagnóstico en el que evalúan las posibles opciones, donde entran las variables vinculadas al costo, distancia y afinidad sociocultural. La decisión del lugar donde van a pasar un tiempo considerable de sus vidas no es una tarea fácil ni aleatoria; existen innumerables dudas y reflexiones antes de elegir el destino y la universidad, aspectos que contribuyen a darle una significativa impronta emocional a esas experiencias posteriores.

En el proceso de evaluativo, para el caso de los estudiantes regionales, una de las particularidades observadas en las entrevistas es que Argentina aparece como una de las opciones que más ventajas traería, ya que la universidad pública es gratuita y la mayoría de las de gestión privada tienen cuotas más convenientes que sus pares latinoamericanas. Si bien, como veremos más adelante, esto no es el único factor explicativo de la elección de destino educativo, sí influye de manera importante.

\section{La universidad "democrática"}

[Elegí Argentina] porque yo quería hacer medicina y, bueno, la forma de ingreso en Brasil en medicina es difícil. Tenemos una prueba que es un día es-

11 Las articulaciones e interacciones entre lo global y lo local se tornan explícitas en los procesos de transformación urbana, en la modificación de la estructura espacial y social de las ciudades. Buenos Aires se presenta inmersa en una serie de transformaciones que evidencian la lógica de nuevos procesos de acumulación, de organización de la producción, de comunicación de los mensajes y de ejercicio del poder, simultáneamente incluyente y excluyente de la "sociedad de flujos" (Borja y Castells, 1996). 
pecífico y cae todo lo que estudiaste en el fundamental y medio. No sé si se dice así pero en Brasil es así, es el fundamental medio. Y mucha gente y poquísimas vacantes y también las facultades privadas es re caro y yo no tenía plata y cuestiones para pagar yo no iba a tener. Y acá la UBA es una buena facultad y acepta a los extranjeros, la forma de ingreso es buena también. Y nada, decidí venir acá.

En la presidencia de Juan D. Perón en 1949, con el Decreto 29337, se derogaron los aranceles universitarios. A partir de entonces, las universidades públicas e institutos de formación superior son gratuitos, al igual que las instituciones de los demás niveles que componen el sistema educativo nacional. Esto presenta una gran ventaja para los extranjeros, ya que facilita el estudio ante las realidades adversas en sus propios países. Varias naciones de la región - siendo Chile el caso emblemático - suponen, además de un proceso de selección universitaria, altos costos de matriculación y el desarrollo de "cuasimercados educativos" (Ball y Yourdell, 2008; Gamallo, 2015). Si bien en la primera década del nuevo milenio los Estados de la región - muchos de ellos bajo el paraguas de las reformas de los "gobiernos progresistas" - han ampliado sus presupuestos en educación, muchos de ellos limitan su participación a la escolarización obligatoria y luego están presentes en el nivel superior facilitando becas y financiamientos individuales a altas tasas de interés. Inclusive en países donde se está en proceso de eliminación de las cuotas, las plazas suelen definirse según pruebas preuniversitarias para un número de vacantes menor al número de postulantes.

En Argentina, esta lógica aparece invertida. Ya la Reforma de 1918, al apelar a diversos canales de participación del estudiantado en el gobierno universitario, genera un punto de inflexión, aun cuando permaneciera un ethos elitista en la composición social del mismo. Es a partir del Decreto arriba mencionado cuando sucede lo que Chiroleu (2009) denomina "democratización externa", con la gratuidad y el ingreso irrestricto. A partir de entonces, se diversifica la población estudiantil, que luego con los gobiernos dictatoriales intentan limitar con un sistema de cupos. La vuelta de la democracia suprimió las restricciones de ingreso ${ }^{12}$ en la mayoría de las universi-

12 La Ley de Educación Superior, sancionada en 1995 y actualmente vigente, contenía dos artículos que permitían modos de arancelamiento. Si bien esto no llegó a ponerse en práctica, esos artículos se derogaron en el año 2015, garantizando la gratuidad y la responsabilidad del Estado en los procesos formativos superiores. 
dades del país, junto con los aranceles. En tal sentido, la construcción de la universidad pública en Argentina - a diferencia de muchos de los países de origen de nuestros entrevistados - se vinculó siempre con la igualdad y la democracia, siendo estas una arena de constante expresión y lucha de y por esos emblemas. Esto es lo que muchos autores han remarcado al señalar el rasgo "plebeyo" de la universidad argentina (Krotsch, 2014). Esto último es importante al momento de explicar los motivos por los que los estudiantes optan por formarse en Argentina cuando las erogaciones que realizan son, tal vez, inclusive más altas que de quedarse en su propio país. En varios trabajos (Mayer y Cerezo, 2016; Mayer y Cerezo, 2018a y 2018b) se demostró cómo el pasaje hacia la universidad supone la puesta en funcionamiento de determinados saberes y capitales que permiten el logro de afiliación institucional y académica. El ethos democrático y diverso culturalmente de "larga data" en las universidades nacionales puede ser un factor explicativo importante que genere atracción en los estudiantes extranjeros, frente a procesos de selección y de exclusión en sus instituciones locales, aun cuando puedan ingresar a las mismas. Esto puede pensarse inclusive para las universidades argentinas más elitistas, como la Universidad de Buenos Aires, que pese al prestigio y reputación - que analizaremos a continuación - no se presenta como espacio de elite. ${ }^{13}$

\section{Los discursos sobre la "calidad"}

Los discursos respecto de la "calidad" universitaria existen desde sus comienzos. Sin embargo, como toda práctica social, se trata de un discurso socialmente situado que debe contextualizarse no solo en términos históricos, sino según sus enunciantes. Así, Fernández Lamarra (2005) sostiene que para los académicos su significado estará asociado a los saberes, para los empleadores a competencias, para los estudiantes a la empleabilidad y para el Estado puede referirse desde a aspectos asociados al desarrollo social, a la ciencia o a los costos y requerimientos del "capital humano". Sin entrar en el debate respecto de la "calidad universitaria", reconoceremos el

13 La expansión de la matrícula fue acompañada por el desarrollo de las "universidades del conurbano" (Mayer y Cerezo, 2016), que fueron la respuesta del Estado para albergar "nuevos públicos", en su mayoría primera generación de estudiantes, y nacen con un espíritu más inclusivo que las universidades "tradicionales". 
significado que le otorgan los estudiantes - a modo de categoría nativa-, relacionado a cierta instrumentalidad para su desarrollo presente y futuro, pero que se ancla en los pilares construidos desde organismos y agencias gubernamentales e internacionales, en los que la acreditación y la evaluación son fundamentales.

Vine en agosto 2013, más que nada por la UBA, por el ranking, creo que la UBA estaba en segundo lugar de América Latina. Primero pensé Santo Tomé, al sur de Brasil. Pero después me di cuenta de que esa universidad no era tan buena. Entonces vi la UBA, y entonces pensé: que si voy para algo y que todavía no estoy tan segura de qué rumbo quiero seguir mejor me voy para algo más garantizado... Entonces voy para la UBA que es buena. Porque digo... ya que voy a pasar tanto tiempo afuera, para que me den un título que tal vez no sé si me va a servir o que no sea reconocido. Entonces, bueno... voy a la UBA. Y de ahí me vine directamente a Buenos Aires, tanto Buenos Aires es el primer destino extranjero que conozco.

\section{Las referencias}

Líneas arriba, al relatar las relaciones de poder existentes que delimitan las elecciones, $\mathrm{o}$ al menos que están presentes en tal delimitación, nos referimos al concepto de diplomacia pública. Esto supone que las experiencias previas, relatos y comentarios se convierten en reservorios sobre el lugar a elegir, a modo de referencia. Estos embajadores legos, ya sea porque tuvieron experiencias previas en Buenos Aires o bien por su reputación, son un factor importante al explicar las motivaciones de la elección. En ese sentido, se contemplan las imágenes que sus allegados tienen no solo sobre el lugar, sino también por la sociedad de acogida, es decir, los residentes que viven en el lugar.

Las experiencias en el exterior son un valor adicional en la formación de los estudiantes, esto no solo se observa al considerar los requerimientos en cualificaciones por parte de aspirantes a puestos de trabajo, sino también en el imaginario social sobre lo que representa "tener una experiencia afuera".

"Yo había terminado la carrera y en el trabajo siempre me decían: "no, pero tú tienes que ir a estudiar afuera, pasar por la experiencia". Y me había presentado a una beca en Chile que no me salió hasta que un compañero, me dijo, “¡no!, pero esta es muy buena tiene el enfoque más o menos que tu trabajas, la teoría que te interesa". Él era mi compañero de trabajo, habíamos 
comentado en la oficina y yo tenía que presentar una sola carta de admisión o pre admisión y presenté ahí en UBA y en diciembre salió la lista y me salió"

Aquí se refleja claramente la imposición que muchas veces se presenta en el momento de la decisión de realizar algún estudio de posgrado o especialización en el exterior. Esto también se manifiesta en un aspecto de tradición, en mirar hacia el exterior que en ocasiones se observa en sociedades con sistemas educativos - y universitarios - de poco desarrollo o reservado para elites, aun cuando hayan democratizado su acceso.

\section{Tradición, modernidad y perspectiva académica}

Los enfoques de tradición y geopolíticos que reflejan vicisitudes históricas sobre las relaciones entre los Estados también comprenden un elemento clave - aunque a veces invisible o subyacente - que se presenta al momento de elegir el destino dónde estudiar.

Imagínate vos que la universidad paraguaya comienza a tener diversidad de carrera en la segunda mitad del siglo XX, todo el mundo venía acá o a Uruguay, o sea, la tradición paraguaya era mirar a Argentina, no es casualidad que yo mirara a Argentina, no es casualidad que yo haga un estudio de maestría en Paraguay y que haya tenido referencia y profesores argentinos porque es lo más cercano que tenías, entonces ahí había como una referencia argentina importante. Vos me decís “¿por qué Buenos Aires?” y fue digamos que era lo mejor que tenía a mano, evaluando ahora me parece muy bueno que haya elegido Buenos Aires, en un momento me pareció que quería ir a EE.UU. de manera muy fuerte, porque era la única oferta que tenía, posibilidad de hacerlo súper dedicado y los gringos una vez que vas allá te ponen todo, como vos me explicabas, pero analizando los enfoques que yo quiero ver y la libertad intelectual que yo tengo acá... Hoy en día estoy contento de estar acá, me gusta la UBA, me gusta el nivel de discusión, estoy viendo, estoy entendiendo Argentina de una manera que no la había entendido antes (a estudiante de Paraguay).

Las diferencias en las oportunidades de desarrollo laboral también son un elemento que los potenciales viajeros jóvenes tienen en cuenta a la hora de decidir sobre dónde estudiar afuera, lo que saca a la luz las diferencias en los niveles de desarrollo productivo y económico de los distintos países 
y ciudades que están al alcance de ser elegidos, así como también las ventajas y desventajas de los mercados de trabajo característicos de cada área.

\section{A modo de conclusión}

Los procesos educativos, pese a las rigideces propias de los sistemas en los que están insertos, presentan una dimensión de adaptabilidad y respuesta a los cambios sociales. De esta manera, a lo largo del artículo, hemos analizado los procesos de internacionalización en clave sociológica, es decir, en su relación con las sociedades contemporáneas. En primer lugar, el análisis mostró la relación de los fenómenos aquí estudiados con la desigualdad social y educativa, la universalización y masificación del nivel medio, y su implicancia en el nivel superior. Tal como sucede en otros niveles, la mayor cobertura incorpora nuevas desigualdades, que antes quedaban por fuera de las instituciones educativas, surgen entonces estrategias de diferenciación - en los actores legos - para sobresalir. En segundo lugar - y ligado a las transformaciones sociales - , la internacionalización y movilidad educativa son indisociables de la economía de la pos-organización, la reflexividad, la des-diferenciación de la sociedad, los flujos y la ampliación de los viajes producto de la organización social y pericia profesional (Urry y Lash, 1998), y sobre los regímenes de movilidad (Glick Schiller y Salazar, 2013), así como de las relaciones de poder. De este modo, los flujos sociales manifiestan comportamientos que se acoplan a las diferencias estructurales existentes entre los países emisores y receptores de estudiantes vinculados a los diversos niveles de desarrollo de las sociedades. Las movilidades académicas pertenecientes a la esfera de la educación parecerían replicar las diferencias entre las regiones desarrollados versus las regiones en desarrollo. Pero no solo entre países y regiones, sino también - y principalmente - entre los estudiantes: poder acceder a las experiencias derivadas de los fenómenos aquí estudiados, supone el despliegue de una serie de recursos — principalmente económicos, aunque no exclusivamente - que no están disponibles por igual en todos los sectores sociales. En este sentido, la todavía baja proporción de estudiantes internacionales, si bien puede entenderse por lo novedoso de estos procesos en nuestro continente, también puede explicarse por las desigualdades que lo atraviesan y que dejan en evidencia estas modalidades. Además, existen factores como las distancias geográficas y las 
dificultades de conectividad que muestran una contracara frente al proceso homólogo en Europa.

Un último punto que nos interesa retomar en esta instancia, es el referido a la valoración de la internacionalización como la "experiencia" que otorga. Aquí, como hemos visto en los fragmentos de las entrevistas citadas, se ponderan igualmente las vivencias y aprendizajes que estos desplazamientos suponen como la "calidad" académica. Estos enunciados aparecen como recomendaciones sociales - es decir de pares, familia y/o familiares - o bien porque luego "el mercado" capitalizaría la movilidad. Esta dimensión nos parece crucial, en la medida en que la ganancia de experiencia supone la adquisición de un capital específico, que trasciende los contenidos de la formación académica, para englobarse en los aprendizajes generales que se obtienen viviendo en el exterior: "contacto" con otras culturas, vivir solo, flexibilidad al desplazarse, etc. En una palabra, habilidades relacionadas a lo emocional o las habilidades soft. Mientras las hard son las habilidades y conocimientos específicamente relacionados al área de incumbencia académica, las soft son las habilidades vinculadas a la experiencia en un contexto de fuertes y constantes cambios en "el mercado". De otro modo, en la apuesta por el estudio - y la elección de carrera - se incluye la incertidumbre por lo necesario - o no - que pueda ser ese profesional al cabo de su graduación. Las experiencias de internacionalización, al introducir un capital relacionado a habilidades transversales y poco presentes en los planes de estudio las soft-, darían (la impresión de) más seguridad, al ser valoradas tanto social como mercantilmente.

\section{Bibliografía}

Ball, S. y Youdell, D. (2008). Hidden Privatization in public Education. Londres: University of London.

Beck, U. y Beck, E. (2001). La individualización. Buenos Aires: Paidós.

Borja, J. y Castells, M. (1998). Local y global: la gestión de las ciudades en la era de la información. Madrid: Taurus.

Botto, M. (2015). La transnacionalización de la educación superior: ¿qué papel juegan los nuevos regionalismos en la difusión de estas ideas ? El caso del Mercosur (1992-2012). Revista Iberoamericana de Educación Superior, 6, 90-109. 
Bourdieu, P. (2000). Poder, derecho y clases sociales. Buenos Aires: Descle.

Bourdieu, P. y Passeron, J. C. (2009). Los herederos: los estudiantes y la cultura. Buenos Aires: Siglo XXI.

Braslavsky, C. (1985). La discriminación educativa en Argentina. Buenos Aires: Miño y Dávila.

Buchbinder, P. (2005). Historia de las universidades argentinas. Buenos Aires: Sudamericana.

Castel, R. (1997). La metamorfosis de la cuestión social. Buenos Aires: Paidós.

Catalano, B. (2017). Turismo y Mercosur: prácticas socioculturales de integración en la ciudad de Buenos Aires. Buenos Aires: UBA-Facultad de Ciencias Sociales.

Cresswell, T. (2008). Constellations of mobility. Londres: Department of Geography-University of London. Recuperado de https://bit.ly/2nnwE0E/

Cummings, M. (2003). Cultural Diplomacy and the United States Government: A Survey. Washington, DC: Center for Arts and Culture.

Esping Andersen, G. (2002). Why we need a welfare state. Oxford: Oxford University Press.

Ezcurra, A. M. (2011). Igualdad en educación superior: un desafío mundial. Buenos Aires: UNGS/IEC-CONADU.

Fernández Lamarra, N. (2005). La evaluación de la calidad y su acreditación en la educación superior en América Latina y en el Mercosur. En G. Mora y N. Fernández Lamarra (eds.), Educación superior: convergencia entre América Latina y Europa (procesos de evaluación y acreditación de la Calidad). Buenos Aires: Universidad Nacional Tres de Febrero.

Fierro Garza, A. (2008). La diplomacia cultural como elemento privilegiado de la política exterior. Revista Mexicana de Política Exterior, 85, 23-28.

Gamallo, G. (2015). La "publificación” de las escuelas privadas en Argentina. Revista SAAP, 9(1), 43-74.

García de Fanelli, A. y Jacinto, C. (2010). Equidad y educación superior en América Latina: el papel de las carreras terciarias y universitarias. Revista Iberoamericana de Educación Superior, 1(1), 58-75.

Gazzola, A. y Didriksson, A. (2008). Tendencias de la educación superior en América Latina y el Caribe. Superior, 1(1), 58-75. Caracas: IESALC/UNESCO.

Gesaghi, V. (2016). La educación de la clase alta en Argentina. Buenos Aires: FCE. Glick Schiller, N. y Salazar, N. B. (2013). Regimes of Mobility Across the Globe. Journal of Ethnic and Migration Studies, 39(2), 183-200. 
Guevara, H. M. (2009). Identidades estudiantiles, conocimiento y cultura: percepciones de jóvenes universitarios y universitarias de Cuyo, Argentina. Revista Latinoamericana de Ciencias Sociales, Niñez y Juventud, 7(1), 209-234.

Harvey, D. (1998). La condición de la modernidad: investigación sobre los orígenes del cambio cultural. Buenos Aires: Amorrortu.

Herrero, A. (2010). Una aproximación a la historia de la educación argentina entre 1862 y 1930, en los niveles primario y secundario. En D. Toribio (ed.), La universidad en la Argentina: miradas sobre su evolución y perspectivas. Lanús: Universidad Nacional de Lanús-Departamento de Planificación y Política Pública.

Howard, A. y Gatzambide-Fernández, R. (2010). Educating Elites. Class Privilege and educational advantage. Londres: R\&L Education.

Koh, A. y Kenway, J. (2012). Cultivating national leaders in an elite school: Deploying the transnational in the national interest. International Studies in Sociology of Education, 22(4), 333-351.

Krotsch, P. (2014). Los universitarios como actores de reformas en América Latina: ¿han muerto los movimientos estudiantiles? En S. Carli (ed.), Universidad pública y experiencia estudiantil: historia, política y vida cotidiana. Buenos Aires: Miño y Dávila.

La Nación. (9 de noviembre de 2017). ¿Cuántos extranjeros estudian en universidades argentinas y de qué países vienen? Recuperado de https://bit. ly/2yiEOMq/

Larrondo, M. y Mayer, L. (2018). Juventud y educación: las otras desigualdades. Buenos Aires: Grupo Editor Universitario/CLACSO.

Mayer, L. (2009). Hijos de la democracia: ¿cómo viven y piensan los jóvenes? Buenos Aires: Paidós.

Mayer, L. (2012). La conflictividad escolar cotidiana: estrategias para su minimización (tesis doctoral, Universidad de Buenos Aires). Mimeografiado.

Mayer, L. y Cerezo, L. (2016). Tutorías y estipendio mensual: contribuciones a la trayectoria universitaria de jóvenes en situación de vulnerabilidad. Revista Latinoamericana de Ciencias Sociales, Niñez y Juventud, 14(2), 1421-1433.

Mayer, L. y Cerezo, L. (2018a). Análisis de las contribuciones de un programa social a la trayectoria universitaria de jóvenes en situación de vulnerabilidad social. Páginas de Educación, 11. Montevideo.

Mayer, L. y Cerezo, L. (2018b). Ser becario en la universidad: un análisis desde lo vincular. Revista de Debate Universitario, (en prensa). Buenos Aires: Universidad Abierta Interamericana. 
Mayer, L. y Núñez, P. (2016). Desigualdades en la educación juvenil en América Latina. Temas, 87-88, 12-19.

Merle, P. (2009). La democratización de la enseñanza. París: La Decouverte.

Mongiello, E. (2012). Cambios en la relación escuela y nación: las escuelas italianas en el exterior. El caso argentino (tesis de maestría en ciencias sociales, FLACSO-Buenos Aires).

Nogueira, M. A. y Aguiar, A. (2008). La formation des élites et l'internationalisation des études: Peut-on parler d'une "bonne volonté internationale"? Education et Societes, 21, 105-120.

Oregioni, M. S. y López, M. P. (2011). La gestión de la cooperación internacional en la universidad argentina: el papel de los investigadores locales y del Área de Relaciones Internacionales. El caso de la Universidad Nacional del Centro de la Provincia de Buenos Aires (1999-2010). RAES, 3, 49-72.

Perrotta, D. (2014). La educación superior en el Mercosur: la acomodación entre las políticas domésticas y la política regional. Revista Perspectivas de Políticas Públicas, 6, 177-206.

Pochulu, M. (2004). La educación superior argentina hoy: entre instituciones que se transforman y relaciones que se modifican. Revista Iberoamericana de Educación, 33(9), 2-10.

Resnik, J. (2012). The Denationalization of Education and the Expansion of the International Baccalaureate. Comparative Education Review, 56(2), 248-269.

Resnik, J. (2015). The development of the International Baccalaureate in Spanish speaking countries: a global comparative approach. Globalisation, Societies andEducation, 14(2),298-325.doi: 10.1080/14767724.2015.1051951

Saltalamacchia, H. (1992). La historia de vida: reflexiones a partir de una experiencia de investigación. Puerto Rico: Ediciones SIJUP.

Saravi, G. (2015). Juventudes fragmentadas: socialización, clase y cultura en la construcción de la desigualdad. México DF: FLACSO/CIESAS.

Saraví, G. A. (2010). Transiciones vulnerables: juventud, desigualdad y exclusión en México. México DF: CIESAS.

Sidicaro, R. (2003). Consideraciones sociológicas de la segunda modernidad. Revista Estudios Sociales. Rosario, Argentina.

Solanas, F. (2014). El Mercosur, la educación superior y la circulación de profesionales frente al desafío de la globalización. En M. Panaia (ed.), Mercosur: la integración regional en tensión (pp. 49-75). Buenos Aires: La Colmena. 
Tinto, V. (2006). Research and practice of student retention: What is next? Journal of Collegestudent Retention, 8(1), 1-19.

Toribio, D. (2010). La expansión de la educación superior en contextos de crisis sociales y políticas. En D. Toribio (ed.), La universidad en la Argentina: miradas sobre su evolución y perspectivas. Buenos Aires: UNLA.

Tremblay, K. (2005). Academic mobility and immigration. Journal of Studies in International Education, 9(3), 196-228.

Urry, J. y Lash, S. (1998). Economía de signos y espacios: sobre el capitalismo de la posorganización. Buenos Aires: Amorrortu.

Vellas, F. (2004). Economía y política del turismo internacional. Madrid: Síntesis.

Zgaga, P. (2006). External Dimension of the Bologna Process. Working Group on the external dimension of the Bologna Process: First Report. Recuperado de https://bit.ly/2B9Vg6K/

Fecha de recepción: 2018/04/15; Fecha de aceptación: 2018/08/0I;

Fecha de publicación: 2018/09/01 



\title{
La propiedad intelectual y la mercantilización forzada del conocimiento
}

\section{Intellectual property and the forced commodification of knowledge}

\author{
Pablo Míguez \\ Instituto de Industria. Universidad Nacional General Sarmiento \\ (IDEI-UNGS) \\ Instituto de Altos Estudios Sociales. Universidad Nacional de San Martín \\ (IDAES-UNSAM-CONICET) \\ pmiguez@ungs.edu.ar \\ Código Orcid: https://orcid.org/0000-0002-4359-7113
}

\begin{abstract}
Resumen
Este trabajo propone analizar la creciente mercantilización del conocimiento a través del refuerzo de los derechos de propiedad intelectual a escala global como una expresión de un cambio en la lógica de la producción y de la valorización del capital, que supone el pasaje del capitalismo industrial a un capitalismo cognitivo. Retomando los debates recientes sobre los bienes comunes y las tesis del capitalismo cognitivo, procuraremos mostrar la necesidad de correspondencia de las regulaciones internacionales y de los sistemas jurídicos nacionales, con las necesidades de la valorización del conocimiento. Estudiaremos el origen y la evolución histórica de los derechos de propiedad intelectual y, con apoyo en evidencias empíricas provenientes de estudios específicos y fuentes diversas, señalaremos algunas circunstancias concretas que favorecieron los cambios en las regulaciones e instituciones.
\end{abstract}

\section{Palabras clave}

Propiedad intelectual, conocimiento, bienes comunes, capitalismo cognitivo.

\section{Abstract}

This paper analyzes the growing commodification of knowledge through the reinforcement of intellectual property rights, on a global scale. This process is an expression of a change in the logic of capital's production and valorisation, in the switch from industrial to cognitive capitalism. We recover the recent debates on commons and the theories of cognitive capitalism to show the need for stablishing a correspondence between international regulations and national legal systems, in order to valorize knowledge. We will study the origin and historical evolution of intellectual property rights and, based on empirical evidence obtained from specific studies and diverse sources, we will point out some concrete circumstances that favored changes in regulations and institutions.

\section{Keywords}

Intellectual porperty, knowledge, commons, cognitive capitalism.

Forma sugerida de citar: Míguez, Pablo (2018). La propiedad intelectual y la mercantilización forzada del conocimiento. Universitas, 29, pp. 43-65. 


\section{Introducción}

La "propiedad intelectual" fue impulsada a nivel internacional desde 1967 por el Acuerdo General de Aranceles y Comercio (GATT) en su intento por generar acuerdos a nivel mundial sobre la protección de las producciones de las empresas multinacionales, predominantemente norteamericanas. Las leyes nacionales sobre patentes existen desde el siglo XIX y fueron cuestionadas desde su nacimiento - aún en los países donde se desarrollaban los principales inventos de la era industrial - a causa de los límites que estas imponían a las posibilidades de "innovación tecnológica". No obstante, aunque todos los países desarrollados fueron protegiendo la propiedad intelectual, la legislación de patentes, marcas y derechos de autor varía según los países.

Este trabajo propone analizar la creciente mercantilización del conocimiento a través del refuerzo de los derechos de propiedad intelectual a escala global, como una expresión de un cambio en la lógica de la producción y de la valorización del capital que supone el pasaje del capitalismo industrial a un capitalismo cognitivo. Retomando los debates recientes sobre los bienes comunes y las tesis del capitalismo cognitivo, procuraremos mostrar la necesidad de correspondencia de las regulaciones internacionales y del sistema jurídico nacional, con las necesidades de la valorización del conocimiento. Estudiaremos el origen y la evolución histórica de los derechos de propiedad intelectual y, con apoyo en evidencias empíricas provenientes de estudios específicos y fuentes diversas, señalaremos algunas circunstancias concretas que favorecieron los cambios en las regulaciones e instituciones.

El concepto "propiedad intelectual" engloba una serie de marcos regulatorios sustantivamente diferentes entre sí y que requieren un estudio por separado. La Organización Mundial de la Propiedad Intelectual (OMPI) en su Declaración Mundial de la Propiedad Intelectual del año 2000, la define como:

Cualquier propiedad que, de común acuerdo, se considere de naturaleza intelectual y merecedora de protección, incluidas las invenciones científicas y tecnológicas, las producciones literarias o artísticas, las marcas y los identificadores, los dibujos y modelos industriales y las indicaciones geográficas (OMPI, 2000).

Como señala Igor Sádaba, son las leyes las que determinan si un objeto específico pertenece al dominio público o al dominio privado: 
Gran parte de los debates sobre la Propiedad Intelectual puede ser reducida a la dicotomía siguiente: arbitran sobre la cuestión de dónde se sitúa un objeto (un gen causante de la obesidad, el software para predecir terremotos, una línea celular obtenida de un bazo humano, un medicamento que cura el paludismo, los compases de una melodía de Mozart, etc.) en el espacio público o en el terreno privado, del lado de la individualidad o del lado del al colectividad (Sádaba, 2008, p. 136).

Bajo este esquema, el dominio público se está volviendo cada vez más reducido y el avance del dominio privado sucede en todos los aspectos de la actividad económica, colonizando la dimensiones sociales, culturales y de la vida en general.

En el primer apartado realizaremos un pequeño recorrido por el origen y la evolución de la protección de la propiedad intelectual hasta inicios del siglo XX, cuando quedan configurados dos modelos de protección: el anglosajón y el europeo. En el segundo apartado analizaremos el cambio que supone el pasaje de la garantía de derechos para el autor/inventor hacia la empresa/corporación a comienzos del siglo XX. En el tercer apartado nos ocuparemos del cambio surgido a finales de los años setenta, cuando se desdibujan las fronteras entre lo que es un invento y lo que es un descubrimiento. En el cuarto apartado nos ocupamos del efecto de esta normativa como un nuevo orden global con consecuencias específicas en América Latina. Finalmente, analizaremos siguiendo a Karl Polanyi el hecho de que la propiedad intelectual supone la "mercatilización del conocimiento" por medio de "mercancía ficticias"; mientras que en las conclusiones nos ocuparemos de las consecuencias de estas regulaciones, los beneficiarios y los perjudicados de la privatización forzada de lo común.

\section{Breve recorrido por la evolución de los derechos de propiedad intelectual}

Existe un acuerdo tácito sobre el origen de la propiedad intelectual con la aparición de la imprenta en el siglo XV, donde los autores y los impresores se unían para protegerse de las falsificaciones, al mismo tiempo que el Estado aceptaba conceder derechos de monopolio por su utilidad para fiscalizar los contenidos de lo que se imprimía. Fue la Revolución Inglesa de 1688 la que permitió la impresión libre, sin previa autorización, de la mano 
de los pensadores liberales. Sin embargo, la proliferación indiscriminada de copias hizo que en 1709 se dictara el Estatuto de la Reina Ana, que protegía más al editor que al autor; este estatuto protegía solo las palabras escritas por un período relativamente extenso, pero limitado a 28 años, dando inició así a las leyes del copyright.

En los derechos de autor de una obra se reconocían derechos patrimoniales de posesión y propiedad, pero no derechos morales de reconocimiento de su autoría, es decir, se trataba más de privilegios para la explotación de libros que una protección al autor. Dicha protección apareció luego como resultado de la Ilustración y la Revolución Francesa. La Enciclopedia dejó claro que el "derecho de copia" se desprendía del derecho de propiedad del escritor sobre sus obras. Los escritores se agrupaban en sociedades para defender sus intereses corporativos y obtenían derechos morales sobre sus obras, que no podían ser representadas en el teatro o modificadas sin su permiso. El autor era valorado como un productor o creador que trabajaba intelectualmente.

La patente, por su parte, también se originó en la Inglaterra mercantilista en el siglo XV con la concesión de privilegios monopólicos a comerciantes y fabricantes de manufacturas, pero - a diferencia de los derechos de autor - estas no podían venderse o cederse y requerían una descripción muy detallada de la invención para poder ser registradas. Una vez expirado el plazo del monopolio, la patente pasa al dominio público, por eso se requería que el inventor expusiera de manera detallada su secreto. La primera presentación equivalía al descubrimiento del "invento", permitiendo incluso la importación de técnicas desde el extranjero. En la Francia revolucionaria también se pide que se reconozca al propietario del invento como su inventor, en sintonía con las leyes británicas. Estados Unidos es el primer Estado moderno que sanciona leyes de patentes en 1790, para beneficio de los inventores y de la sociedad; luego, en 1836, crea la Patent Office y en 1897 la American Patent Law Association (Sádaba, 2008, p. 47).

Quedan configuradas entonces dos modalidades típicas de protección de la propiedad intelectual: el modelo europeo continental y el modelo anglosajón:

El modelo inglés es aún muy deudor de la imprenta, de la posibilidad de producir copias exactas y difundirlas. El modelo francés, en cambio, incorpora la idea de que la sociedad está compuesta por individuos con sus propios derechos, más fuertes que los de la colectividad (Sádaba, 2008, p. 34). 
El primero tiene su origen en la Francia previa a la Revolución Francesa y consolida un derecho de autor. El segundo se origina en Gran Bretaña en el siglo XVIII y es reformulado por Estados Unidos a fines del siglo XVIII. Al incorporarse de manera tardía al mundo industrial, Estados Unidos se posicionó durante el primer siglo de su historia en contra los derechos de propiedad intelectual de Gran Bretaña y otros países industriales, ya que no se reconocían derechos de copyright extranjeros, incluso aunque esto significara que las obras estadounidenses quedaran desprotegidas en el extranjero. La protección se otorgaba para garantizar la explotación de las ideas y asegurar la continuidad de los procesos creativos no sobre la base de un derecho moral del autor en tanto "propietario" de su obra (Sádaba, 2008, p. 140).

Tras la revolución de 1775 se procura sancionar normas que compensen la creación artística a cambio del fomento del progreso colectivo de la sociedad. De esta forma la Federal Copyright Act, de 1790, accede a conceder un monopolio de manera limitada a cambio del fomento a la innovación. Como veremos luego, las diferencias entre estos dos modelos se van a ir reduciendo con la aceptación irrestricta del copyright por parte de ambos (y de manera drástica desde finales del siglo XX).

Durante el siglo XIX se fue consolidando la protección de la propiedad intelectual en numerosos países $\mathrm{y}$, como veremos seguidamente, en el derecho internacional. Este proceso de concesión de derechos intelectuales se acelera a comienzos del siglo XX con la llegada del cine y con la posibilidad de la reproducción masiva de obras de arte, lo que genera la necesidad de una compensación económica para los autores y propietarios (de los financiadores antes que directores o realizadores), por lo cual se da la sanción de una nueva ley estadounidense, la Copyright Act, en 1909. El posterior auge de la radio y la televisión volverá más compleja todavía la asignación de derechos de autor. Como bien explica Sádaba:

Si en su momento la imprenta fue clave, no menos importante va a ser la aparición del fonógrafo, el cinematógrafo, la radio, el vídeo, Internet y todos los medios a través de los cuales tradicionalmente se han comunicado o se han transmitido contenidos en información (2008, pp. 36-37).

En el mismo sentido, Scout Forsyth señala que:

El cine es la avanzada estratégica - para decirlo en términos de la nueva jerga del negocio del espectáculo, la nave insignia - de un circuito de mer- 
cancías de consumo que incluye videos, televisión, Internet, historietas , novelas, juegos, juguetes, ropa comida rápida, parques y paseos temáticos. En este momento, las industrias del entretenimiento lideran las exportaciones de Estados Unidos (Forsyth, 2005, p. 145).

\section{Del inventor a las corporaciones}

A fines del siglo XIX existían diferentes formas de proteger la propiedad intelectual, cuya relevancia creciente llevó a la implementación a nivel internacional de las legislaciones, desde la Convención de Berna de 1886. Allí se reconoció internacionalmente el derecho de autor al creador y a sus derechohabientes hasta 70 años después de su muerte. No obstante, el derecho internacional sobre la propiedad intelectual va a tender a acercarse cada vez más al esquema del copyright (Sádaba, 2008, pp. 55-59).

Acorde con las transformaciones de la producción de la "gran empresa" del capitalismo industrial en ascenso, la innovación se desplazará desde el inventor a las corporaciones empresariales, a partir de las primeras décadas del siglo XX. En el capitalismo industrial, el mecanismo de producción de conocimientos se concentraba en los departamentos de investigación - tanto teórica como aplicada - de los organismos públicos y de las oficinas de Métodos y de I+D de la "gran empresa". El modelo de propiedad intelectual era coherente con un esquema donde la apropiación privada del saber se fundaba en recursos materiales y en el ámbito espacial del Estado nacional, donde la invención debía:

- Representar una novedad.

- Poder ser aplicada a nivel de la industria.

- Poder conciliar la remuneración del acto inventivo privado con la difusión pública del conocimiento.

Joseph Schumpeter $(2002 / 1939 ; 1944)$ fue uno de los primeros en celebrar este pasaje de la invención a la innovación, adjudicándole al empresario - el entrepreneur - que toma riesgos un rol protagónico. La invención alude a la mera generación de nuevos conocimientos o adelantos científicos y/o tecnológicos, mientras que la innovación supone la introducción exitosa de dichos conocimientos en la producción por parte de los empresarios, ya sea que se trate de un nuevo producto, un nuevo método de producción, una 
nueva fuente de materias primas o un cambio en la organización industrial. Las innovaciones reflejan una visión idealizada del empresario innovador - se asocia con nuevos "liderazgos" - por parte de Schumpeter y constituyen la causa principal de los ciclos largos y desequilibrios que caracterizan al sistema capitalista a partir de sucesivas "revoluciones tecnológicas" (grandes saltos tecnológicos derivados de innovaciones como la máquina de vapor, el ferrocarril, la electricidad o el transporte motorizado).

El rasgo innovador luego será adjudicado a las "firmas" por los economistas neoschumpeterianos y evolucionistas (Nelson y Winter, 1982; Dosi, Freeman, Nelson, Silverberg y Soete, 1988; Lundvall, 1992), dado que las innovaciones son costosas y arriesgadas y requieren, por tanto, un alto grado de concentración, así como recursos financieros suficientes para ser llevadas a cabo. Ellas se producen en el marco de determinados "paradigmas tecnológicos", los que dirigen el cambio técnico en la medida que definen los problemas relevantes, los patrones de investigación y la tecnología a utilizar hasta que se agota dicha fase con la difusión de los conocimientos, se desacelera el cambio técnico y se reducen las oportunidades de inversión (López, 1996). Para ellos, las patentes aseguran la innovación, es decir, generan los incentivos necesarios para innovar, ya que la innovación depende de limitar la difusión de la tecnología hasta que la renta tecnológica permita recuperar ese esfuerzo innovador.

La propia historia económica norteamericana parece confirmar este punto, cuando el capitalismo corporativo acelera la separación entre propietarios y gerentes desde las primeras décadas del siglo XX. Como señala David Noble (1979) en American by design, el propio poderío económico norteamericano durante el siglo XX fue condicionado, en buena medida, por leyes de propiedad intelectual adaptadas al reconocimiento de la propiedad de los inventos científicos y tecnológicos a las firmas, a los laboratorios de las grandes compañías. Las patentes serán propiedad de las grandes corporaciones en lugar del inventor o científico empleado que las desarrolló, quienes a cambio solo recibían un ingreso regular en forma de salario.

En suma, a lo largo de la evolución de la protección a la propiedad intelectual podemos diferenciar dos modelos fundamentales: el modelo anglosajón de Inglaterra y Estados Unidos basado en el Common Law y el modelo europeo basado en el derecho continental. En el modelo jurídico norteamericano las leyes de patentes establecen los principios generales, pero es la Oficina de Patentes la encargada de dar su versión sobre la apli- 
cación de la norma, en última instancia es esta la que tiene la capacidad de crear jurisprudencia, pues la Corte Suprema interviene solo cuando ella misma lo decide, lo que sucede en algunos pocos casos. Los tribunales clásicos, formados en la doctrina antitrust, eran históricamente reacios a otorgar patentes, pero esta situación iba a cambiar con el surgimiento, a comienzos de los años ochenta, de numerosas leyes y varios fallos de la Corte Suprema de Justicia estadounidense que transformaron radicalmente la situación (como la decisión de patentar los genes, contra la opinión de la Oficina de Patentes), como veremos en el siguiente apartado (Coriat, 2008, p. 57).

Durante los primeros 100 años de aplicación de las leyes de patentes Estados Unidos desconocía los derechos de copyright otorgados en el extranjero, pero desde los años setenta, a partir de su influencia en los organismos internacionales, a instancias de este país se procura homogeneizar las legislaciones con marcos jurídicos de implementación única en todo el mundo para favorecer el despliegue de sus industrias, sobre todo en el plano cultural y del entretenimiento (Lessig, 2005, p. 84). Estados Unidos detenta un elevado número de otorgamiento de patentes sobre el total de patentes solicitadas y en su territorio se asiste a las mayores batallas judiciales en torno a violaciones a las leyes de patentamiento. Esto hace que muchas empresas se dediquen a la acumulación de patentes no para su utilización, sino para demandar a pequeños emprendedores o para negociar entre las grandes compañías acuerdos de uso de patentes en condiciones más favorables.

\section{Del invento al descubrimiento}

En la década de 1920 comienzan a darse los primeros pasos en el patentamiento de "descubrimientos" - ya no sólo de inventos - , cuando los conocimientos básicos - los originados por la ciencia básica sin haber sido aplicados (o desconociendo su potencial aplicabilidad) - comienzan a ser objeto de patentes. No importaba que ya existieran en la naturaleza y que no fueran, por lo tanto, una creación humana. Por ejemplo, en 1922 Pasteur había patentado un proceso sobre una bacteria dando comienzo a las "patentes sobre organismos vivos" y en 1930 Estados Unidos sanciona una ley de patentes sobre plantas. También hacen lo suyo los floricultores holandeses que reciben patentes con la promesa de no tocar la reproducción sexual de las semillas. Sin embargo, no será hasta la década de 1960 que la cuestión retoma- 
rá un verdadero impulso. Más emblemático aún es el caso de la industria del cine de Hollywood. La creación en California del complejo cinematográfico responde a la huída de empresarios de la costa este, donde debían respetar las patentes de Thomas Edison. La guerra de patentes duró hasta que nueve compañías se fusionaron en la Motion Picture Patents Company (MPPC) (Sádaba, 2008, p. 130).

Un momento importante se da en 1970, cuando Estados Unidos sanciona una nueva ley de patentes, en el mismo año que impulsa la OMPI. En esta década se producen cambios fundamentales desde que en 1975, por decisión de la Corte Suprema, los microorganismos pasan a ser patentables (caso "Bayer Yeats"). Sin embargo, estos cambios jurisprudenciales en el territorio estadounidense, si bien son importantes, no pueden ser vistos de manera aislada. En el capitalismo contemporáneo, el conocimiento pasa a ser central por razones sociales e históricas antes que tecnológicas, y preceden a la constitución del capitalismo cognitivo. Estos cambios se deben fundamentalmente a la democratización de la enseñanza - con la consecuente elevación del nivel general de formación-, que facilitó la constitución de una "intelectualidad difusa" que está en la base de la emergencia de una economía fundada en el rol motor del conocimiento (Lebert y Vercellone, 2006).

También debemos tener en cuenta la coyuntura del capitalismo fordista con su crisis de rentabilidad en los años setenta y con su necesidad de relanzar las bases de la acumulación. Según Coriat (2008), el despegue de la propiedad intelectual como factor decisivo de la valorización capitalista contemporánea debemos rastrearlo en la búsqueda por parte de Estados Unidos del restablecimiento de su competitividad erosionada por numerosos países - especialmente Alemania y Japón - , que lo desafiaban apoyándose en desarrollos tecnológicos basados en investigación básica, de la cual Estados Unidos era el responsable en un 50\% a nivel global. Estos cambios van a suponer una brutal aceleración de los procesos de mercantilización del conocimiento a comienzos de los años ochenta. En 1980 va a sancionarse la BayhDole Act, a partir de la cual los productos de la investigación desarrollados con fondos del Gobierno norteamericano pueden ser patentados y dejar, por tanto, de formar parte del dominio público. Adicionalmente, los propietarios de patentes podrán otorgar licencias exclusivas con la condición de que se realice a empresas ubicadas en el territorio norteamericano (sección 204). Se trata de una norma fundamental, que significó un punto de quiebre en muchos sentidos, especialmente debido a la obligación de la Secretaría de 
Comercio de informar al Congreso el listado de los países que no respetan la propiedad intelectual en perjuicio de las empresas estadounidenses (sección 301). Se preveía, además, la extensión de los plazos de protección de las patentes en numerosos sectores, así como la creación de tribunales arbitrales para dirimir este tipo de conflictos.

En rigor, será en 1980, con la obtención a favor de General Electric de la primera patente sobre un microorganismo - que fagocita las manchas de petróleo-, cuando se dé el verdadero golpe inicial a las patentes sobre la vida (el caso "Chakrabarti"). En pocos años, los hospitales y universidades se lanzaron en una carrera de solicitudes de patentes por "invenciones" que contenían material biológico, llegándose al caso extremo de científicos que patentaban sus descubrimientos aún antes de publicarlos. Este sistema creado para Estados Unidos se extendió a Europa, donde fue aceptado en el Parlamento Europeo con resistencias en puntos como la propiedad sobre los genes y los algoritmos, sin embargo, no pasó lo mismo en la Comisión Europea (Coriat, 2008, p. 59).

En suma, hay dos momentos claves a partir de la segunda posguerra: la creación de la OMPI en 1970 y el cierre de la Ronda Uruguay del GATT de 1986-1994, que creó la Organización Mundial del Comercio (OMC). Tras cada uno de estos acontecimientos asistimos a una relanzamiento de las solicitudes de protección de la propiedad intelectual que condicionan actualmente la innovación tecnológica. La década de los noventa trajo una explosión de la propiedad intelectual, pues las empresas transnacionales (ETN), especialmente norteamericanas, se lanzaron a obtener patentes de todo tipo para beneficiarse de la denominada "globalización". En 1994, en el cierre de la Ronda Uruguay del GATT, los países consideraban un asunto comercial bajo la protección de la naciente OMC, donde los firmantes debían comprometerse, entre otras cosas, a la protección de la propiedad intelectual de todo tipo por la vía de los Acuerdos sobre Aspectos de Propiedad Intelectual Relacionados al Comercio (AADPIC). En fin, el boom de la biotecnología de los años ochenta, el auge de la manipulación genética y de la industria farmacéutica, le deben mucho a la evolución de las patentes, pues estas áreas ya no se van a ver obligadas a realizar sus propias investigaciones para desarrollar productos, sino que pueden obtener licencias de universidades, instituciones públicas o pequeñas empresas tecnológicas surgidas generalmente como un spin off de las primeras.

En Europa las objeciones a la adopción inmediata del sistema norteamericano son sostenidas con sólidos fundamentos jurídicos, ya que la secuen- 
cia de un gen o un algoritmo no tendrían, en principio, ninguna utilidad industrial. Bercovitz agudamente señala que:

En el Convenio Europeo de Patentes de 1973 se mantiene esta exigencia, al exigir que las invenciones patentables sean susceptibles de aplicación industrial, lo cual equivale en la doctrina tradicional a exigir que las invenciones patentables sean invenciones técnicas, entendida la técnica como técnica industrial (2003, p. 18).

Bercovitz también subraya que el convenio AADPIC establece que "susceptibles de aplicación industrial" es sinónimo de "útiles", mas no distingue la diferencia:

Útiles, en el sentido que satisfacen necesidades humanas, son todas las invenciones, sean o no industriales. Y esta distinción entre utilidad y susceptibilidad de aplicación industrial tiene importancia porque en la legislación norteamericana no se contiene expresamente la exigencia de que las invenciones patentables sean industriales, aunque sí se exigen que sean útiles. Por ello los planteamientos sobre patentabilidad aplicados en los Estados Unidos no pueden ser trasladados pura y simplemente al Derecho europeo (Bercovitz, 2003, p. 18).

En el caso europeo, los países son más minuciosos en la definición de aquello que puede caer en el ámbito de lo patentable. En materia de patentes, en Europa se habla de "propiedad industrial", esto significa que solo pueden concederse a invenciones industriales, aunque la tendencia es cada vez más a acercarse al modelo norteamericano. Allí se hace cada vez menos rigurosa la demostración de la aplicación industrial de los resultados de la investigación y más borrosa la línea que divide lo que es un invento y un descubrimiento.

\section{Una nueva institucionalidad global y su impacto en América Latina}

De acuerdo a Saskia Sassen (2010), la entrada en vigencia el Acuerdo de Marrakech que fundaba la OMC en 1995 supuso el nacimiento de un nuevo derecho económico internacional, ya que regulaba el $97 \%$ del tráfico comercial internacional y obligaba a los países menos desarrollados a adoptar el AADPIC, que asigna una función permanente a la OMPI en actividades de 
cooperación. La OMPI es la institución creada por los Estados para aplicar los convenios multinacionales sobre propiedad intelectual, así como los Tratados de Internet y los convenios europeos sobre derechos de autor. Como las normas internacionales de la OMC deben incorporarse al derecho nacional, esto supone "nuevas formas de autoridad privada" como los sistemas de arbitraje, puesto que hay que "dejar de lado la solución de conflictos entre ordenamientos jurídicos nacionales y reenfocarse en los conflictos entre regímenes sectoriales, como ocurre cuando existen diferencias entre la OMPI, la OMC, la UE y los derechos nacionales" (Sassen, 2010, pp. 304-305).

La protección de la propiedad intelectual se constituye en la punta de lanza del cambio de régimen jurídico internacional que supone la des-nacionalización de los Estados nacionales (Sassen, 2007), o mejor aún, "de varios componentes institucionales especializados" de ellos. Pero esto no supone una disminución de las jerarquías ni la desaparición de la soberanía de los Estados:

Ciertos Estados, como el de Gran Bretaña y Estados Unidos, producen en efecto la formulación de esta nueva legalidad y la imponen a otros estados gracias a las interdependencias que caracterizan la etapa actual de la globalización. Incluso así, los estados participantes necesitan desarrollar sus propios instrumentos específicos en función de los ordenamientos político económicos que rigen en su interior (Sassen, 2010, pp. 290-291).

Estados Unidos condujo o forzó a otros Estados a adoptar esas obligaciones con el capital global, luego de una amplia experiencia en la ampliación de las operaciones transfronterizas para las empresas estadounidenses. Ya no se trata centralmente de respaldar a las industrias estratégicas, sino de crear las condiciones de competitividad para una economía global (Sassen, 2010 , p. 300). Estos cambios de la producción y la valorización basadas en el conocimiento obligan a discutir las relaciones entre la lógica "global" del capital y la dimensión "territorial" de las formas políticas asumidas por ella (Negri y Hardt, 2002, 2011; Míguez, 2015, 2017).

El problema con este esquema es que su difusión por todo el mundo a partir del Consenso de Washington y las normas de la OMC desde la Ronda Uruguay 1986-1994, impone condiciones muy desventajosas para los países en desarrollo. Para ingresar a la OMC los países deben cumplir acuerdos como el TRIPS (Trade Related Aspects of Intellectual Property Rights) de 1995, que buscaba reforzar la protección de la propiedad intelectual a partir de procedimientos y legislaciones a escala internacional, obligando a las naciones fir- 
mantes a crear mecanismos administrativos y penales respecto a derechos de propiedad intelectual y facultando al Sistema de Solución de Controversias de la OMC para actuar si surgen diferencias comerciales en torno a ellos, los cuales se comenzaron a aplicar en el año 2000 (Sádaba, 2008, p. 70).

En América Latina, estas disposiciones se vieron impulsadas en un primer momento por el NAFTA, creado en 1992, para que México se adapte a las normativas de Estados Unidos y Canadá. El NAFTA había sido el modelo para las normas de la OMC de 1994 y luego por el Proyecto ALCA, un proyecto de zona de libre comercio desde Alaska a Ushuaia que se impulsó desde 1998 hasta su rechazo en 2005. Ante el fallido intento por imponer el ALCA, Estados Unidos ha promovido numerosos tratados bilaterales de libre comercio (TLC) con varios países de América Latina. Es el caso de los tratados comerciales con Costa Rica, donde las leyes de propiedad intelectual de la OMPI se incluyen dentro de un paquete más general que incluye normas para el comercio internacional. Estados Unidos también impulsa en América Latina iniciativas multilaterales como la Alianza del Pacífico, que incluye a México, Colombia, Perú y Chile, y desde 2009 - a nivel globalel Acuerdo Transpacífico (conocido como TPP por sus siglas en inglés), creado entre Chile, Nueva Zelanda, Singapur y Brunei en 2005 y firmado luego por Estados Unidos, Canadá, México, Perú, Vietnam y Malasia, que solo entrarán en un impasse desde 2016 con el Gobierno de Donald Trump. Todavía está por verse si se trata de un efectivo revés a las normas del libre comercio o solo de medidas específicas para proteger a sectores industriales retrasados de Estados Unidos, que no son los beneficiarios principales de las normativas globales. El TPP se proponía organizar las nuevas reglas del derecho económico global del siglo XXI, en línea con la Asociación Transatlántica para el Comercio y la Inversión (conocido como Tratado Transatlántico o TTIP), una propuesta de libre comercio entre Estados Unidos y la Unión Europea sobre la base de la regulación del comercio, los servicios, la inversión y la propiedad intelectual (Merino, 2018, p. 23).

Los acuerdos regionales como el Mercosur o la CELAC intentaron avanzar en un bloque económico y político regional desde la caída del proyecto ALCA en 2005 y realizaron sustantivos avances en esta dirección, como la consolidación de un sistema de solución de controversias de carácter permanente, el Fondo de Convergencia Estructural del Mercosur (FOCEM) para resolver las asimetrías entre los países miembros y el Parlamento del Mercosur (Parlasur) para la representación directa de lo ciudadanos del bloque. En 
relación al conocimiento, como parte del intento de promover la integración productiva sobresale el Programa Marco de Ciencia y Tecnología y el Programa de Apoyo a la Biotecnología en la Plataforma Biotech, que se proponen promover innovaciones tecnológicas (dado el auge del agronegocio en la región). Esta segunda iniciativa es impulsada y a la vez condicionada por la Unión Europea, que es la fuente de financiamiento de estas actividades y que por ello pretende ser la propietaria de los derechos de propiedad derivados de estas iniciativas (Perrota y Porcelli, 2016).

Una de las excepciones notables a estos avances en el ámbito latinoamericano fue la iniciativa del Código Orgánico de la Economía Social de los Conocimientos, la Creatividad y la Innovación (conocido popularmente como el Código Ingenios) en Ecuador, donde se juntó en un solo cuerpo jurídico las normas sobre ciencia, tecnología e innovación, con los saberes ancestrales y la propiedad intelectual (Pazos, 2016, p. 553). El Código deroga la Ley de Propiedad Intelectual y aprovecha las flexibilidades de las normas internacionales promoviendo un equilibrio entre los derechos de los titulares y los usuarios, en procura de objetivos de desarrollo (Ramírez, 2014, pp. 49-54). Sin embargo, el cambio de signo de los Gobiernos de la región desde 2015 y la renovada preferencia por el "regionalismo abierto" de los años previos, llevan a priorizar la celebración de acuerdos de libre comercio como el MERCOSUR-Unión Europea, que en los hechos implican un renovado fortalecimiento de la propiedad intelectual.

\section{Nuevas mercancías "ficticias"}

El conocimiento - como los bienes de la naturaleza - debe ser considerado un bien común, y la forma de gestionarlo así como la propiedad de los bienes comunes es de hecho anterior a la basada en la distinción público/ privado. La privatización de las tierras comunes entre los siglos XV y XVI fue determinante en el proceso de desposesión de los productores, característico de la acumulación originaria, y fue condición necesaria para el desarrollo del capitalismo. Como señala Polanyi, la Tierra - en tanto producto de la naturaleza - no es producto del trabajo humano y es, por lo tanto "una mercancía ficticia". Es falso suponer que la mano de obra, la Tierra y el dinero sean mercancías, pero a partir de o con la ayuda de, esta ficción se organizan los "mercados", y lo más importante: se vuelven el principio organizador de la sociedad. 
El punto crucial es este: la mano de obra, la tierra y el dinero son elementos esenciales de la industria: también deben organizarse en mercados; en efecto, estos mercados forman una parte absolutamente vital del sistema económico. Pero es obvio que la mano de obra, la tierra y el dinero no son mercancías; en el caso de estos elementos, es enfáticamente falso que todo lo que se compra y se vende debe haber sido producido para su venta (Polanyi, 1992, p. 81).

Haciendo de la Tierra una mercancía se instala el principio de la propiedad privada y el principio de lo público-privado como los principios organizadores del orden económico y social, dejando al margen lo "común".

En la primera mitad del siglo XX la teoría económica convencional teorizó sobre los bienes públicos. A diferencia de los bienes privados, que son rivales (el aumento de la cantidad consumida por un individuo implica necesariamente la reducción de la cantidad consumida por otro) y excluyentes ( se puede excluir a un individuo del consumo de un bien mediante el sistema de precios), los bienes públicos son aquellos bienes donde el costo marginal de producir una unidad adicional es nulo. Asimismo, son bienes no excluyentes, no se puede excluir a ningún agente del consumo de dicho bien (por ejemplo, del alumbrado público), lo que justifica su provisión desde el Estado, ya que puede obtener el "precio" a través de los impuestos, a condición de que se reflejen las condiciones de equilibrio del mercado (precio positivo e igual al costo marginal). Adicionalmente, aparece el problema del free-rider, la posibilidad de un individuo de ocultar sus preferencias y acoplarse al consumo del bien sin pagar. Como vemos, lo que se muestra es un problema teórico y práctico, que el mercado no sirve para revelar las preferencias de los individuos, no se puede estimar la demanda y el oferente no sabe cuánto debe ofrecer del producto, alterando el funcionamiento fluido y equilibrador del mercado, justificando la provisión de dichos bienes por el Estado (seguridad y administración de justicia son ejemplos clásicos de bienes públicos).

El proceso político debe, entonces, reemplazar la ausencia de demanda, permitir revelar las preferencias de los consumidores/ciudadanos y determinar la oferta de bienes públicos. Sin embargo, que exista una "falla de mercado" no implica necesariamente la producción desde el Estado de dicho bien, pero sí al menos su financiamiento o la regulación de la actividad estableciendo una tarifa en el caso de las concesiones de servicios públicos o la creación de incentivos a la eficiencia mediante la creación o exención de impuestos o el otorgamiento de subsidios. 
En el período de auge del Estado keynesiano-benefactor, el hecho de que el Estado se encargara de la provisión de numerosos bienes públicos requería elaborar una justificación que permitiera congeniar dicha provisión con la subsistencia de los principios de la economía neoclásica. En ese contexto surge la idea de la Tragedia de los comunes (Hardin, 1968), donde se concluye que la acción racional e individual de explotación de bienes de la naturaleza, en tanto busca la maximización del bienestar individual, termina sobreexplotando el recurso natural y eliminando los beneficios comunes, de lo cual se deriva una justificación para la propiedad privada de los mismos. Con dichos argumentos también se pretende "proteger" en la actualidad a los productos del conocimiento, lo que deriva en un efecto contraproducente, denominado por Michel Heller, la Tragedia de los anticomunes (1998), esto es, la creación de un sistema que sub-utiliza el conocimiento a causa del patentamiento exagerado de bienes. Ello impide la libre utilización de los conocimientos porque se quiere estimular el crecimiento promoviendo la innovación, pero al mismo tiempo se bloquea la difusión de las innovaciones, lo que es una contradicción del capitalismo cognitivo que debería ser resuelta si se quiere construir una verdadera economía fundada en los conocimientos.

En el caso de los bienes de la naturaleza, subrayar el carácter común de estos bienes se propone como objetivo la conservación de recursos escasos y no renovables. Desde la economía neoclásica convencional, Elinor Ostrom (1990) - la investigadora de la escuela de Indiana que recibió el Premio Nobel de Economía en 2009- ha planteado una salida alternativa a la privatización, que consiste en alcanzar acuerdos adecuados entre los participantes basados en reglas claras, supervisiones recíprocas y compromisos mutuos, articulados para la búsqueda del bien común. En el caso del conocimiento, de forma alternativa a los principios individualistas de la economía neoclásica, el economista italiano Vercellone (2017) propone plantear lo común como "modo de producción", que tiene como punto de partida la transformación de la colaboración en el trabajo. Se trata justamente de un bien común que no es escaso, sino abundante, acumulable, "no rival" y "no excluible". Como no es susceptible de sobreexplotación y no justifica, por lo tanto, la propiedad privada de los mismos:

No sólo el capital, sino el mismo producto del trabajo es cada vez más inmaterial y se incorpora en bienes de innovación, de conocimiento, en servicios 
informáticos que constituyen mercancías ficticias. ¿Por que mercancías ficticias? Son mercancías ficticias porque escapan a los criterios que definen las mercancías tradicionales en razón de su carácter no competitivo, acumulativo y difícilmente excluible (Vercellone, 2009, p. 90).

Para algunos autores, los derechos de propiedad intelectual constituyen "nuevos cercamientos" o enclosures, de la misma forma que durante la llamada Acumulación Originaria las leyes de cercamientos de la tierra imponían las condiciones iniciales para el despliegue de la acumulación capitalista convencional. Esta vez estos cercamientos tendrían como objetivo imponer las bases de un capitalismo sustentado sobre nuevos pilares, un "capitalismo cognitivo" donde la producción de bienes inmateriales impone su hegemonía a la producción típica del período industrial clásico o fordista. En el capitalismo cognitivo, la propiedad intelectual es reforzada porque es el único mecanismo que permite la apropiación privada del conocimiento crecientemente social y su control es estratégico para la valorización del capital. Destaca Moulier Boutang que esta nueva "gran transformación" que significa el capitalismo cognitivo - tomando los términos de Karl Polanyi- hace necesaria la creación de nuevas "mercancías ficticias" como la introducción de mecanismos de escasez "artificiales", "para limitar temporalmente su difusión y para reglamentar el acceso" (Rullani, 2002). En ese sentido, Boutang señalaba en 2001 que:

El capitalismo cognitivo se encuentra en su fase de acumulación primitiva, en el sentido de que el conjunto de los derechos de propiedad instaurados entre los siglos XVII y XVIII, y a partir de los cuales ha razonado la economía política clásica - y que a su vez a contribuido a perfeccionar y legitimarconstituye un límite infranqueable para la inscripción del potencial de desarrollo de las fuerzas productivas de la actividad humana en una trayectoria de crecimiento regular y en el marco de un compromiso institucional con las fuerzas de la vieja economía (Moulier Boutang, 2004, p. 111).

Para Boutang, los viejos derechos de propiedad son un límite para el desarrollo de las fuerzas productivas en la medida que no permiten aprovechar los efectos productivos positivos y gratuitos ("externalidades positivas" en la jerga económica convencional) de las múltiples interacciones de una economía basada en el conocimiento, una actividad gratuita, incesante y continua. Si se obliga a recurrir al intercambio mercantil para la producción de bienes conocimiento-intensivos se estaría privando a la sociedad de una de 
las fuentes esenciales de la productividad de los agentes económicos (Moulier Boutang, 2004, p. 116).

En el mismo sentido se expresa el geógrafo David Harvey, para quien los mecanismos de la acumulación primitiva se perfeccionaron para dar origen a nuevos mecanismos de acumulación por desposesión:

La insistencia en los derechos de propiedad intelectual en las negociaciones de la OMC (El llamado acuerdo TRIPS) indica cómo se pueden emplear ahora la patentes y licencias de material genético, plasma de semillas y muchos otros productos contra poblaciones enteras cuyas prácticas han desempeñado un papel decisivo en el desarrollo de estos materiales (Harvey, 2003, p. 118).

Los juristas de la Universidad de Stanford, especializados en el estudio de la propiedad intelectual como James Boyle y Lawrence Lessig, coinciden con estas consideraciones ante la privatización de bienes comunes que a priori estaban excluidos del derecho de propiedad (Vercelli, 2004). Afirma James Boyle (2003) que aquello que se conoce como enclosure forma parte de un movimiento de privatización de los bienes comunes o bienes que estaban fuera del sistema propiedad. Lo que se conoce como la tragedia de los bienes comunes se dio primero en Inglaterra y luego en otras regiones europeas, durante el siglo XVIII. Yochai Benkler (2003) y Lawrence Lessig (2005), al discutir el alcance de la propiedad intelectual, propusieron actualizar el debate sobre los "bienes comunes", como son los recursos naturales y el propio conocimiento. Si a los bienes privados y a los bienes públicos corresponden la propiedad privada o la propiedad pública, a los bienes comunes les debería regir la no propiedad (Lessig, 2005). La posibilidad del capital de poner a trabajar al común surge de una nueva organización de la producción que necesita de la valorización del trabajo, pero bajo modalidades novedosas y sofisticadas.

\section{Conclusiones}

A lo largo de este trabajo hemos indagado en el origen y la evolución de los derechos de propiedad intelectual desde los primeros derechos de autor hasta las patentes, desde la protección otorgada a inventores individuales hasta su atribución contemporánea a las grandes corporaciones. Señalamos también el cambio en la materia que es objeto de derechos de propiedad in- 
telectual, su ampliación incesante e ilimitada más allá de los inventos hacia los descubrimientos y su extensión final hasta el patentamiento de la vida misma. Todo ello supone dar lugar a nuevas mercancías ficticias acompañadas de marcos jurídicos regulatorios de carácter nacional y global que son la condición de posibilidad del sostenimiento de dicho avance.

Procuramos establecer las claves para comprender el sentido del avance de la protección de la propiedad intelectual en los más diversos campos, incluso más allá del estrictamente vinculado a la economía propiamente dicha y en todos los niveles políticos: ya sean estatales, regionales o globales. Para ello establecimos la necesidad de pensar el conocimiento como un bien común, indispensable en una nueva lógica de la acumulación basada en la generación y apropiación de conocimientos donde estos se convierten en una mercancía fundamental que supone - parafraseando el título del célebre libro de Piero Sraffa (1975) - la "producción de conocimientos por medio de conocimientos".

Los principales beneficiarios - interesados e impulsores - de la proliferación de los derechos de propiedad intelectual son las grandes industrias y las grandes firmas de los sectores tecnológicos destacados durante el último cuarto de siglo, por ejemplo, la industria farmacéutica, las tecnológicas y las que sobresalen en el plano cultural y de entretenimiento, pues todas ellas se construyeron y se sostienen gracias a estos derechos. La industria de los medios está plagada de historias sobre copias de contenidos, pero hoy son los principales impulsores de la propiedad intelectual, en parte debido a que los ingresos por royalties y derechos constituyen actualmente el principal rubro de exportación de la industria norteamericana. Esto no debe sorprender, ya que la historia del ascenso en la economía mundial señala que los países que impulsaron deliberadamente el desarrollo siempre necesitaron de políticas industriales, comerciales y tecnológicas activas que incluyeran copiar desarrollos tecnológicos, de forma que cuando finalmente alcanzaron el status de países "desarrollados" no permitirían el mismo comportamiento de los países en vías de desarrollo... según la célebre expresión de Ha-Joon Chang, ellos dieron una "patada a la escalera" (Chang, 2002).

Los principales perjudicados de las leyes de propiedad intelectual son todos aquellos que pretenden disponer libremente de los conocimientos socialmente generados. La sociedad como un todo no percibe beneficios de estos "nuevos cercamientos". Tampoco los perciben los pueblos originarios que durante siglos se han dedicado a mejorar las semillas y que ven sus esfuerzos capturados por empresas multinacionales que luego les imponen sus 
lógicas rentistas. También se perjudican las empresas pequeñas y medianas que, para realizar una investigación - frente a la proliferación de las patentes más inverosímiles y ante la necesidad de desarrollar una innovación propia - probablemente infringirán alguna patente ya existente. Esta situación las colocaría en desventaja respecto a las grandes empresas, muchas de las cuales se dedican sobre todo a acumular patentes no necesariamente para utilizarlas, sino para evitar que otros las usen o como moneda de cambio frente a otras empresas grandes con las cuales concretan acuerdos de uso de patentes, perjudicando a las empresas pequeñas y favoreciendo la centralización del capital.

Probablemente las consecuencias derivadas de estos avances de la protección de la propiedad intelectual sigan teniendo lugar habida cuenta de la centralidad que adoptan como mecanismos de generación y apropiación privada de conocimientos comunes. Este recorrido deberá completarse en el futuro con estudios de caso que diferencien sectores, países y niveles de desarrollo relativo, para evaluar el impacto concreto de estas iniciativas que seguirán teniendo un lugar central en la governance del capital global. Esta gestión política de la acumulación a escala global no estará exenta de conflictos, en la medida que en este capitalismo cognitivo una de las contradicciones más evidentes radica en el hecho de procurar la difusión del conocimiento y de la información, y a la vez bloquear el desarrollo de los conocimientos con las regulaciones crecientes sobre la propiedad intelectual. Vercellone subraya muy claramente esta dimensión contradictoria del intento de captar lo común. Se trata entonces de pasar de un capitalismo cognitivo a una verdadera economía basada en el conocimiento, para lo que requerimos formas de propiedad públicas, comunes o mixtas, adecuadas a tales fines.

\section{Bibliografía}

Benkler, Y. (mayo/junio, 2003). La economía política del procomún. Novatica/Upgrade, 163, 6-9. Madrid: ATI.

Bercovitz, A. (mayo/junio, 2003). Sobre la patentabilidad de la invenciones referentes a programas de ordenador. Novatica/Upgrade, 163, 17-21. Madrid: ATI.

Boyle, J. (2003). The Second Enclosure Movement and the Construction of the Public Domain. Law and Contemporany Problems, 66(12), 33-74. Recuperado de https://bit.ly/2AHB23X/ 
Chang, H. J. (2002). Kicking Away the Ladder.Development Strategies in Historical Prespective. Londres: Anthem Press.

Coriat, B. (2008). El régimen de la propiedad intelectual y la innovación. Realidad Económica, 233(37), 49-65. Buenos Aires: IADE.

Dosi, G., Freeman, C., Nelson, R., Silverberg, G. y Soete, L. (eds.). (1988). Technical Change and Economic Theory. Londres: Pinter Publisher.

Forsyth, S. (2005). Hollywood recargado: el cine como una mercancía imperial. Socialist Register 2005: el imperio recargado, 145-164. Buenos Aires: CLACSO.

Hardin, G. (diciembre, 1968). The Tragedy of the Commons. Science, 162(3859), pp. 1243-1248. Recuperado de https://bit.ly/2q8FkZf/

Harvey, D. (2003). El nuevo imperialismo. Madrid: Akal.

Heller, M. (enero, 1998). The Tragedy of the Anticommons. Harvard Law Review, 111(3). Recuperado de https://bit.ly/2naQ3Sj/

Lebert, D. y Vercellone, C. (2006). Il ruolo della conoscenza nella dinamica di lungo periodo del capitalismo. En C. Vercellone (ed.), Capitalismo cognitivo. Conoscenza e finanza nell'epoca postfordista (pp. 19-37). Roma: Manifestolibri.

Lebert, D. y Vercellone, C. (2011). El rol del conocimiento en la dinámica de largo plazo del capitalismo. En C. Vercellone (2011): Capitalismo cognitivo. Renta, saber y valor en la época posfordista (pp.31-55). Buenos Aires: Prometeo.

Lessig, L. (2005). Por una cultura libre. Madrid: Traficantes de Sueños.

López, A. (1996). Las ideas evolucionistas en economía: una visión de conjunto. Buenos Aires: Pensamiento Económico, 1. Recuperado de https://bit. ly/2vqC $52 \mathrm{r} /$

Lundvall, B. A. (1992). National System of Innovation: Towards a Theory of Innovation and Interactive Learning. Londres: Pinter Publisher.

Merino, G. (2018). Los tratados comerciales y la era Trump. Realidad Económica, 313(47), 9-40. Buenos Aires: IADE. Recuperado de https://bit. ly/2KtWDMX/

Míguez, P. (2013). El Estado capitalista, la crisis financiera y el debate ImperioImperialismo. En J. Kan y R. Pascual (eds.) Integrados (?) las relaciones internacionales y la integración regional latinoamericana en debate (pp. 89-119). Buenos Aires: Imago Mundi.

Míguez, P. (2013-2014). Del General Intellect a las tesis del "Capitalismo Cognitivo": aportes para el estudio del capitalismo del siglo XXI. Bajo el 
Volcán, Revista de Sociología de la Benemérita Universidad Autónoma de Puebla, 13(21), 27-57, septiembre 2013/febrero 2014.

Míguez, P. (mayo-septiembre, 2017). Capital global, integración regional y Estados nacionales en el siglo XXI: más allá de las teorías del imperialismo y de las Relaciones internacionales. Revista Estado y Políticas Públicas, 8, 41-57.

Moulier Boutang, Y. (2004). Riqueza, propiedad, libertad y renta en el capitalismo cognitivo. En Y. Moulier Boutang, A. Corsanni, M. Lazzarato et al. (eds.), Capitalismo cognitivo, propiedad intelectual y creación colectiva (pp. 107-128). Madrid: Traficantes de Sueños.

Negri, A. y Hardt, M. (2002). Imperio. Buenos Aires: Paidós.

Negri, A. y Hardt, M. (2011). Commonwealth. Madrid: Akal.

Nelson, R. y Winter, S. (1982). An Evolutionary Theory f Economic Change. Cambridge, MA: Harvard University Press.

Noble, D. (1979). America by design. Nueva York: Alfred Knopf.

OMPI. (2000). Declaración Mundial sobre Propiedad Intelectual. Organización Mundial de la Propiedad Intelectual.

Pazos, R. (2016). El Código Ingenios y su construcción colaborativa. En R. Ramírez (ed.), Universidad urgente para una sociedad emancipada (pp. 541564). Quito: SENESCYT-IESALC.

Perrota, D. y Porcelli, E. (agosto, 2016). Mercosur 25 años: desafíos en su nueva etapa. Márgenes, Revista de Economía Política, 2. Los Polvorines: Universidad Nacional General Sarmiento-UNGS.

Polanyi, K. (1992). La gran transformación: los orígenes políticos y económicos de nuestro tiempo. México: FCE.

Ramírez, R. (2014). La virtud de los comunes: de los paraísos fiscales al paraíso de los conocimientos abiertos. Quito: Abya-Yala.

Rullani, E. (2004). El capitalismo cognitivo ¿Un deja-vú? En Y. Moulier Boutang et al. (eds.), Capitalismo cognitivo, propiedad intelectual y creación colectiva (pp. 99-106). Madrid: Traficantes de Sueños.

Rullani, E. (mayo, 2000). Le capitalisme cognitif: du déjà-vu. Multitudes, 2, 87-94.

Sádaba, I. (2008). Propiedad intelectual: ¿bienes públicos o mercancías privadas? Madrid: Los Libros de la Catarata.

Sassen, S. (2007). Sociología de la globalización. Buenos Aires: Katz.

Sassen, S. (2010). Territorio, autoridad y derechos: de los ensamblajes medievales a los ensamblajes globales. Buenos Aires: Katz.

Schumpeter, J. (1944). Teoría del desenvolvimiento económico. México DF: FCE. 
Schumpeter, J. (2002/1939). Ciclos económicos: análisis teórico, histórico y estadístico del proceso capitalista. Zaragoza: Prensas Universitarias de Zaragoza.

Sraffa, P. (1975). Producción de mercancías por medio de mercancías. Barcelona: Oikos-Tau.

Vercelli, A. (marzo, 2004). La conquista silenciosa del ciberespacio: creative commons y el diseño de entornos digitales en el nuevo arte regulativo de Internet. Buenos Aires. Recuperado de https://bit.ly/2naIGdx/

Vercellone, C. (2004). Las políticas de desarrollo en tiempos del capitalismo cognitivo. En Y. Moulier Boutang et al. (eds.), Capitalismo cognitivo, propiedad intelectual y creación colectiva (pp. 63-74). Madrid: Traficantes de Sueños.

Vercellone, C. (2009). Crisis de la ley del valor y devenir renta de la ganancia. Apuntes sobre la crisis sistémica del capitalismo cognitivo. En A. Fumagalli, S. Lucarelli, C. Marazzi, S. Mezzadra, A. Negri, C. Vercellone (eds.), La gran crisis de la economía global (pp. 63-98). Madrid: Traficantes de Sueños.

Vercellone, C., Giuliani, A., Brancaccio, F. y Vattimo, P. (2017). Il Comune come modo di produzione. Per una critica dell'economia politica dei beni comuni. Verona: Ombre Corte.

Fecha de recepción: 2018/04/15; Fecha de aceptación: 2018/07/24;

Fecha de publicación: 2018/09/01 



\title{
A cien años de Córdoba: entre imperativos tecno-económicos y la reelaboración de conocimientos
}

\section{A hundred years of Córdoba: between techno-economic imperatives and the re-elaboration of knowledge}

\author{
Alexis Mercado \\ Universidad Central de Venezuela \\ Centro de Estudios del Desarrollo (CENDES) \\ Área de Desarrollo Científico y Tecnológico \\ alexis.mercado@ucv.ve \\ Código Orcid: https://orcid.org/0000-0003-3984-8992
}

\begin{abstract}
Resumen
Un elemento renovador de la Reforma de Córdoba fue el fortalecimiento de la función social de la universidad, dando cabida al desarrollo de su tercera misión (la extensión). Partiendo de ello, se discuten problemas socioambientales globales apremiantes, la situación de la estructura productiva de América Latina y se analizan los elementos más remarcables del desarrollo de las tecnologías disruptivas y la emergencia de la 4i, elementos que tendrán serias implicaciones socioeconómicas para la región. El análisis de la información de diversas fuentes evidencia que a pesar de los avances tecnológicos, prevalecen formas de producción y consumo no sustentables. En América Latina, los problemas se agudizan a consecuencia del predominio de una estructura económica que aún depende de la explotación intensiva de recursos naturales. De no adoptarse acciones adecuadas esta situación empeorará con la irrupción de los nuevos sistemas tecnológicos que demandan los recursos que posee la región. Abordar los problemas socioambientales de manera efectiva requiere reelaborar formas de generación de conocimientos, asumiendo enfoques que trasciendan los modos tradicionales de investigación e incorporando diversos conocimientos y actores sociales. Se propone, entonces, que la extensión, aparte de la proyección cultural, sirva de correaje de intercambio entre las comunidades y los investigadores para generar nuevas agendas y contribuir a la creación de espacios que permitan implantar formas alternativas de realizar la actividad. En esta medida, se transforma también la segunda misión de la universidad.
\end{abstract}

\section{Palabras clave}

Reforma, Córdoba, crisis socio-ambiental, extensión, investigación.

Forma sugerida de citar: Mercado, Alexis (2018). A cien años de Córdoba: entre imperativos tecno-económicos y la reelaboración de conocimientos. Universitas, 29, pp. 67-87. 


\begin{abstract}
The Reform of Cordoba reinforced the social function of the university, allowing the development of its third mission (the Extension). In this article, urgent global socio-environmental problems and the situation of the productive structure of Latin America are discussed, and the most outstanding elements of the development of disruptive technologies and the emergence of the $4 i$ are analyzed. All of them will have serious socio-economic implications for the region. The analysis of information from different sources shows that despite technological advances, unsustainable forms of production and consumption prevail. In our region, these problems are exacerbated by the predominance of an economic structure that still depends on the intensive exploitation of natural resources, which, if appropriate measures are not adopted, will worsen with the irruption of the new technological systems. This because demand natural resources that abound in the region. An effective approach of socio-environmental problems requires the re-elaboration of forms of generation of knowledge, assuming approaches that overcome the traditional ways of research incorporating diverse knowledge and social actors. It is proposed that the extension works as a conveyor belt for exchange information between communities and researchers to generate new agendas and contribute to develop spaces that allow the implementation of alternative ways of carrying out the activity. To this extent, the second mission of the university is also transformed
\end{abstract}

Keywords

Córdoba reform, socio-environmental crisis, extension, research.

\title{
Introducción
}

La reforma de Córdoba, aparte de impulsar transformaciones en la universidad que apuntaban a la autonomía y la democratización de sus formas de gobierno, y desde el punto de vista académico a la libertad de cátedra y cambios en la organización y los métodos de enseñanza, supuso también la transformación de sus relaciones con la sociedad, proponiendo un fortalecimiento de su función social mediante la que, a la postre, se constituyó en su tercera misión (la extensión), y una mayor preocupación por los problemas nacionales (Tünnermann, 2008).

A cien años de este hito histórico de la educación superior latinoamericana, la universidad es blanco de cuestionamientos que en su mayoría se relacionan justamente con sus escasos aportes a la sociedad en temas que van desde su baja contribución al desarrollo económico-productivo al escaso abordaje de apremiantes problemas como la exclusión social y la degradación ambiental. 
Los reclamos en uno u otro sentido reflejan una controversia acerca de la naturaleza y función que debe tener la universidad en la que se confrontan, con diversos matices, dos posiciones antagónicas: la que le considera como bien público y social que debe contarse entre las prioridades del Estado (Hitner et al., 2017) y la que le concibe como un commodity privado (Williams, 2016) internacionalmente comercializable a un grado tal que ha llegado a discutirse en el seno del Acuerdo General Sobre Comercio y Servicios (AGCS) como un tema de su competencia.

Es evidente que las orientaciones que adopten las IES (Instituciones de Educación Superior) tendrán profundas implicaciones sobre la generación, transmisión y apropiabilidad de los conocimientos. Es incuestionable que las IES tienen la obligación de contribuir al desarrollo económico de sus países, más aún cuando se admite que avanzamos hacia una economía basada en el conocimiento. Pero esta constituye una entre varias prioridades y no - como se pretende evidenciar en el modelo de universidad emprendedora - la principal. Tan o más urgentes resulta el abordaje de la participación social y los impactos socioambientales derivados de las actividades antrópicas.

Se reconoce que transcurrido un siglo de la reforma de Córdoba, la universidad latinoamericana ha desempeñado un rol determinante en el desarrollo social y cultural de sus países. La ampliación del acceso a la educación superior ha contribuido a la inclusión social, a la vez que ha permitido la conformación de importantes comunidades profesionales en las diferentes áreas del conocimiento, en especial las tradicionales y - en menor medida - en las científicas y tecnológicas. Pero de manera general, no ha logrado acompañar los avances científicos y tecnológicos internacionales (Vessuri, 2004), contribuyendo muy poco tanto para la transformación de una estructura económica que presenta una matriz productiva fuertemente basada en actividades primarias y marcadas condiciones de dependencia como para proponer soluciones a importantes problemas socioambientales.

Tal situación presiona para una revisión de sus vínculos con la sociedad. Se le demanda que sus funciones sobrepasen los límites disciplinarios en los procesos de enseñanza- aprendizaje y la investigación, para lo que, imperativamente, debe trascender sus "muros" involucrándose activamente en el estudio y abordaje de problemas sociales. Sin embargo, a ello se interpone su lentitud para adaptarse, tanto estructural como funcionalmente, a los acelerados cambios que se experimentan en los diversos ámbitos de la sociedad (Peñalver en Hitner et al., 2017). Entre estos, destacan dos para las IES: la acelera- 
ción del desarrollo tecno-científico - manifestado en el auge de una serie de tecnologías disruptivas y la emergencia de la cuarta revolución industrial - y recientes movimientos de reelaboración de las formas de producción de conocimiento que promueven una mayor participación de las comunidades, la interculturalidad y el diálogo de saberes (Hitner et al., 2017). La ineludible incorporación de ambas en sus agendas dependerá, en gran medida, de la disposición para introducir cambios sustanciales en su naturaleza y funciones.

Este artículo destaca brevemente las orientaciones de la vinculación con la sociedad que planteó la Reforma de Córdoba, las cuales sirven de fondo para presentar una discusión sobre los problemas socioambientales globales más acuciantes y la situación de la estructura productiva de la región, que hacen imperativo su consideración por parte de las IES. Posteriormente, se analizan los elementos más resaltantes del desarrollo de las tecnologías disruptivas y la emergencia de la cuarta revolución industrial — que tendrán implicaciones socioeconómicas muy importantes - , y de la reelaboración de las formas de producción de conocimiento que presionan una revisión de los significados y alcances de las funciones de estas instituciones. Como colofón, se sugieren cambios en la orientación de las misiones de extensión e investigación para afrontar los ineludibles desafíos tecno-económicos y de nuevas formas de producción de conocimiento.

\section{La preocupación social en la Reforma}

La Reforma de Córdoba supuso, antes que todo, una transformación interna de la universidad. Partiendo del cuestionamiento al modelo universitario tradicional, planteó la obligación de llevar los conocimientos al pueblo. Contribuir al incipiente proceso de cambio social que comenzaba a experimentar la región fue el estímulo fundamental que estableció las pautas de la vinculación de la universidad con la sociedad (Anuies, 1979 en Serna Alcántara, 2007).

En términos de interacción e integración social, la influencia más trascendente de las ideas de la Reforma fue abrir las posibilidades de acceso a los jóvenes de estratos sociales menos favorecidos: "A los hijos de las capas sociales emergentes" (Tünnermann, 2008), ocurrida sobre todo durante la década de los sesenta, al compás de los hechos políticos vividos en la región. Pero este autor destaca que en el Manifiesto liminar de la Reforma se proclama la misión social de la universidad y la extensión universitaria, 
cuya función sería "la proyección al pueblo de la cultura universitaria y la preocupación por los problemas nacionales" (Tünnermann, 2008).

Esta perspectiva se arraigó fuertemente en estas instituciones. La extensión como medio de proyección (unidireccional) es la visión que ha prevalecido, concibiéndola como un mecanismo de socialización de la cultura que frecuentemente se limita a acciones de difusión cultural y actividades extra escolares, y la provisión de asistencia social (Fresan, 2004). Esta situación cuestionaría la validez del principio de indisociabilidad enseñanza-investigación-extensión (Baptista y Kuenzer en Fresán Orozco, 2004), creando obstáculos para una mayor inserción de la universidad en el tejido social.

En la actualidad, los problemas socioambientales y el imperativo de orientar las sociedades hacia trayectorias más sustentables, plantean un reenfoque de la vinculación y una renovación de la extensión que tendrán consecuencias sobre la formación y la investigación. La universidad debe superar las estrategias de socialización, promoviendo una participación ciudadana más activa que sirva de correaje para intercambiar información y conocimiento que ayude a enfocar estos problemas y contribuir conjuntamente a su resolución.

\section{Crisis socioambiental}

El trienio 2015-2017 registró las temperaturas más altas de la historia (WMO, 2018). Los escenarios del calentamiento global proyectados por el IPCC para 2100 prevén que aun disminuyendo el crecimiento de las emisiones de gases efecto invernadero (GEI) de acuerdo a los compromisos del acuerdo de París (2015), este no será inferior a $2{ }^{\circ} \mathrm{C}$. Los rangos probables de incremento lo ubican entre 2 y $4,9^{\circ} \mathrm{C}$, con una media de $3,2^{\circ} \mathrm{C}$ y con apenas $5 \%$ de probabilidad que sea menor de $2{ }^{\circ} \mathrm{C}$. El problema radica en el incremento de la cantidad de GEI en la atmósfera proveniente de actividades antrópicas (WMO, 2017). ${ }^{1}$

El aumento de la temperatura acrecienta los eventos ambientales extremos. Está ocasionando un aumento en el nivel de los océanos y su acidificación, lo cual afecta a la biodiversidad. El aumento de la frecuencia de fuertes precipitaciones, el incremento neto de la pluviosidad, así como de la

1 En 2016 la concentración de CO2 alcanzó records históricos, ubicándose en 403 partes por millón (ppm), 45\% por encima de los niveles preindustriales. En tanto que las de metano llegaron a 1853 ppm (157\% superiores a la concentración de la época preindustrial) y las de óxido nitroso a 329 ppm (22\% superiores) (WMO, 2017). 
frecuencia e intensidad de huracanes tropicales, son efectos constatables del cambio climático. También se evidencia una intensificación de las sequías y aumentos en la desertificación y desaparición de glaciares (IPCC, 2012). Tal situación coloca en extrema vulnerabilidad a centenares de millones de habitantes del planeta y la mayoría de los países de América Latina y el Caribe son sensiblemente vulnerables a estos eventos.

Por su parte, el crecimiento de la explotación de recursos naturales y el incremento de la producción industrial generan nuevas sustancias xenobióticas que agravan el problema de la contaminación y la afectación de la salud de los seres vivos. Por ejemplo, diariamente se descargan dos millones de toneladas de aguas residuales y desechos industriales y agrícolas en los cursos y reservorios de agua del mundo, afectando la disponibilidad de agua potable. Un porcentaje importante de los desechos sólidos presentan baja biodegradabilidad y en algunos casos alta toxicidad. En 2015 se generaron aproximadamente 6300 millones de toneladas de desperdicios plásticos, de los cuales $9 \%$ fueron reciclados, $12 \%$ incinerados y $79 \%$ arrojados en vertederos; de estos, alrededor de 13 millones de toneladas van a parar anualmente a los océanos, produciendo la creciente afectación de la biota marina (Salleh, 2015). Las proyecciones estiman que para 2050 la generación de desechos plásticos alcanzará los 12000 millones de toneladas. Su ubicuidad en el ambiente ha hecho que esta acumulación se sugiera como un indicador geológico de la era del Antropoceno (Geyer et al., 2017).

La principal causa de estos problemas radica en la sostenida expansión de sectores productivos tradicionales y la irrupción de nuevos sistemas tecnológicos ${ }^{2}$ bajo el paradigma del crecimiento continuo, debido a que mantienen -e incluso agravan - el impacto de la explotación y uso de recursos, y la consecuente degradación ambiental por la contaminación. Por ejemplo, la obtención de metales básicos, asociados al paradigma tecno-económico basado en el uso intensivo de materiales y energía, creció aceleradamente en este siglo, incluso por encima de la economía en general. La producción de hierro creció $180 \%$ entre 2002 y 2014 , en tanto que la de aluminio primario $108 \%$. Similarmente, la producción de combustibles fósiles, aunque atenuó su ritmo de crecimiento, se mantiene en escalas extraordinarias. La produc-

2 Se adopta la definición realizada por Hughes (1987) que establece que los sistemas tecnológicos están integrados por componentes técnicos (artefactos y procesos de producción) y organizacionales (empresas manufactureras, de asistencia técnica y financieras). Se integran, además, componentes científicos y de enseñanza, e incluso elementos de legislación como es el caso de normas regulatorias. 
ción de carbón creció $66 \%$, la de petróleo $28 \%$ y la de gas natural $41 \%$. Proporcionalmente, se registra el incremento de las emisiones de GEI, agravando, como se indicó, los problemas del calentamiento global.

A ello se suma que el desarrollo de tecnologías disruptivas estimula la producción de una constelación de nuevos dispositivos y nuevos servicios que ampliarán la demanda de nuevos materiales (los nuevos commodities), especialmente en los países desarrollados, exacerbando la explotación de recursos naturales. Tres elementos químicos (el litio, el niobio y el tántalo) destacan por su funcionalidad para la elaboración de los citados dispositivos, determinándose que la explotación de los materiales naturales que les contienen crece sostenidamente. Entre 2006 y 2014 (apenas ocho años), la producción de litio equivalente aumentó $86 \%$, muy superior al de la economía (52\%), en tanto que la de niobio fue de $76 \%$.

Estos resultados evidencian que lejos de una racionalización de la explotación de recursos inherentes al anterior paradigma tecno-económico, esta se acelera, adicionándose el crecimiento sostenido de la explotación de los nuevos commodities inherentes al nuevo paradigma. De esta manera, puede refutarse uno de los argumentos fundamentales de la tesis de estar avanzando hacia la "economía del conocimiento": el desacoplamiento entre el crecimiento económico y la explotación de recursos. Esto podrá estarse dando en muy contadas economías desarrolladas, pero un balance de masas impide confirmar que se esté llevando a cabo en el ámbito global.

Tanto más paradójico resulta que, a pesar del extraordinario incremento de la explotación de recursos naturales y del sostenido crecimiento de la economía financiera, el mantenimiento o aumento de la exclusión y la pobreza constituyan otros síntomas de la crisis socioambiental. En un reciente informe del Banco Mundial se estimó que la riqueza global - medida como la sumatoria del capital producido, el capital natural, el capital humano y los activos netos en el extranjero- creció 66\% entre 1995 y 2014. El informe señala que esto fue acompañado por una reducción importante de la concentración de la riqueza en los países de alto ingreso. Pero en los de bajo ingreso, que detentan apenas el $1 \%$ de la riqueza global (fundamentada en su patrimonio natural), salvo contadas excepciones, se observaron escasos avances, llegando a producirse una reducción de la riqueza per cápita en un importante número de ellos (WB, 2018).

Vale destacar que las cifras de la riqueza per cápita permiten dimensionar las diferencias globales de la desigualdad. En 2014, en los países de la 
OCDE, una persona al nacer, en promedio, poseía una riqueza equivalente de 708389 dólares, mientras que el promedio de una persona al nacer en un país de bajo ingreso era 13 629,52 veces menor (WB, 2018). Si a ello agregamos las diferencias internas que, como se indicó, son mayores en los países de bajo ingreso, estas brechas se vuelven inconmensurables. Así, resultan mucho más ilustrativos los datos acerca de la riqueza de las ocho personas más adineradas del planeta, riqueza que equivale a los bienes que poseen los 3600 millones más pobres del mundo (Hope, 2017).

\section{América Latina: ¿economía del conocimiento?}

Este panorama global de severa crisis socioambiental se manifiesta claramente en América Latina. Los persistentes niveles de pobreza y exclusión, así como importantes situaciones de deterioro ambiental medida debido a patrones económicos en los que predomina o se ha acentuado la explotación de recursos naturales, resaltan como los temas más acuciantes.

La integración de América Latina a la economía global se da de manera asimétrica, fundamentalmente como proveedor de materia prima, de ahí que los problemas descritos adquieran particular intensidad y el usufructo de los posibles beneficios sea sustancialmente menor. Así, ante la casi imposibilidad de sustraerse de las dinámicas globales de las transformaciones tecnológicas, es imperativa la contribución de sus estructuras científico-técnicas para superar los patrones primarios productivos, condición elemental para avanzar en la transición hacia formas de vida más sustentables.

\section{Perfil económico}

Después del estancamiento experimentado en las dos últimas décadas del siglo XX, América Latina registró índices positivos de crecimiento. Entre 2000 y 2014 la economía se incrementó en 110\% (CEPAL, 2014). ${ }^{3}$ Este período mostró una contracción en 2009 como consecuencia de la crisis global y en los años 2015 y 2016 (-0,4\% y -0,1\% respectivamente) asociada a lo que se ha denominado "el fin del súper ciclo de los commodities".

3 Estimado a precios constantes en U\$ de 2010 (CEPAL). 
El impacto de la caída de los precios de las commodities sobre las economías latinoamericanas refuerza el debate sobre el estancamiento estructural de la región, acentuando la controversia sobre su estructura económica, sostenida cada vez más en los servicios y en actividades primarias, que fundamentan su inserción asimétrica en la economía global. De hecho, la evolución del PIB por tipo de actividad de la región evidencia una alineación con la tendencia global de una creciente participación de los servicios en el PIB, la "dematerialización", pero en muchos casos asociados a la explotación y exportación de recursos naturales.

En el citado periodo, servicios básicos y comercio, transporte, comunicaciones y finanzas, fueron las actividades que registraron el mayor crecimiento. También hay correspondencia en la pérdida de importancia de la manufactura, el renglón que registra la mayor disminución en el crecimiento (tabla 1).

\section{Tabla 1}

\section{PIB anual por actividad económica a precios constantes en dólares*}

\begin{tabular}{|l|l|l|l|}
\hline \multicolumn{1}{|c|}{ Rubro } & \multicolumn{1}{c|}{$\mathbf{1 9 9 0}$} & \multicolumn{1}{c|}{$\mathbf{2 0 1 4}$} & \multicolumn{1}{c|}{ Variación } \\
\hline Agricultura, ganadería, caza, silvicultura y pesca & 136901 & 262613,3 & $91,8 \%$ \\
\hline Explotación de minas y canteras & 187546,8 & 324289,6 & $72,9 \%$ \\
\hline Industrias manufactureras & 437645,3 & 734586,9 & $67,8 \%$ \\
\hline Servicios básicos** & 54052,8 & 132284,6 & $144,7 \%$ \\
\hline Construcción & 178950,8 & 347050,6 & $93,9 \%$ \\
\hline Comercio, transporte, comunicaciones y finanzas & 860992,3 & 2061576,4 & $139,4 \%$ \\
\hline $\begin{array}{l}\text { * Millones de USD } \\
\text { ** Electricidad, gas y agua }\end{array}$ & & \\
\hline
\end{tabular}

Fuente: CEPAL

El PIB de la construcción casi se duplica en el período. Agricultura, ganadería, caza, silvicultura y pesca, actividades dependientes de la biodiversidad, muestran un crecimiento similar, apuntalado en el incremento del agronegocio, que consolidó a Brasil y Argentina, como grandes exportadores de cereales. Finalmente, minas y canteras registró un crecimiento algo inferior, muy ligado a la actividad exportadora.

La variación de la participación de estas actividades en el PIB permite apreciar mejor su peso dentro de la actividad económica. Aunque servicios 
básicos fue la que porcentualmente aumentó más en el período considerado, su participación en el PIB se mantiene marginal (pasa de 2\% a 2,4\%). A ello habría que agregar el extraordinario déficit que presentaban, cuya mejoría y ampliación de cobertura fueron colocadas por diversos organismos internacionales como condición para mejorar la calidad de vida. ${ }^{4}$

\section{Figura 1}

\section{Participación de diferentes actividades económicas en el PIB en América Latina (1990-2015)}

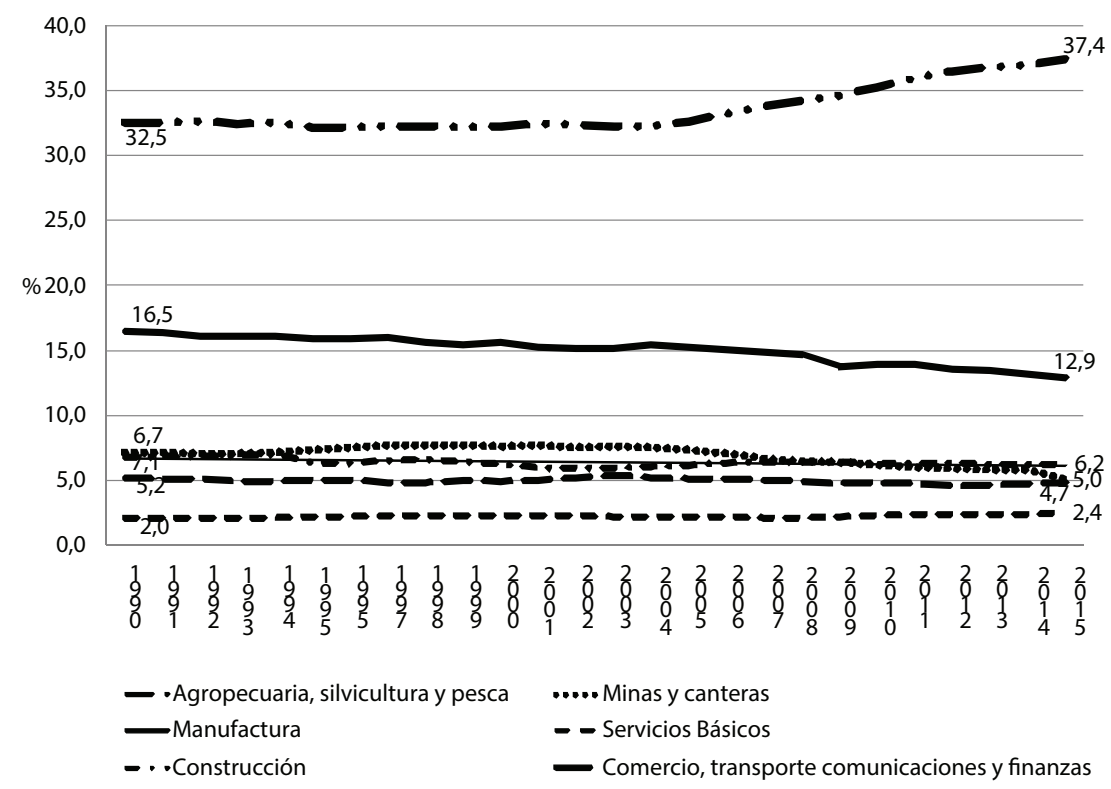

Fuente: CEPAL

Los servicios (comercio, transporte, comunicaciones y finanzas) se consolidan como el sector de más peso en la economía de la región, aumentando

4 A título de ejemplo, las Naciones Unidas establecieron en las Metas del Milenio la necesidad de aumentar la cobertura del acceso al agua mejorada y potable y el saneamiento: para 2015 se debía reducir a la mitad el porcentaje de personas sin acceso sostenible al agua potable y a servicios básicos de saneamiento. 
significativamente su participación de $32,5 \%$ a $37,4 \%$ (incremento de $15 \%$ ), mientras que en el otro extremo se ubica la manufactura cuya participación pasa de $16,5 \%$ a $12,9 \%$ (una disminución de su contribución de $22 \%$ ), inferior al $15 \%$ que presenta la Unión Europea que, consciente de la importancia que tiene esta actividad en el empleo y la generación de bienes, se ha propuesto revertir la tendencia y elevar su participación al 20\% en 2020 (Bussines Europe, 2014). El resto de las actividades, varían poco su participación: construcción (pasa de $6,7 \%$ a $6,2 \%$ ), agricultura $(5,2 \%$ a $4,7 \%)$ y minas y canteras (incluye explotación petrolera, de 7,1\% a 6,2\%) (Figura 1). Aun cuando esta última actividad haya visto ligeramente disminuida su participación en el PIB, el aumento en la explotación de recursos en el presente siglo es significativo. Los tres principales commodities minerales metálicos (hierro, cobre y aluminio-bauxita) muestran un crecimiento sostenido hasta 2008, registrando una caída al año siguiente producto de la crisis económica, pero retomándolo en la década siguiente a pesar de la caída de los precios (Tabla 2).

En 2001, la extracción de mineral de cobre fue de algo más de seis millones de toneladas. Esta creció lenta pero sostenidamente alcanzado 8433000 toneladas en 2015, lo que representa un incremento cercano al $40 \%$. En apenas seis años, la explotación de hierro experimentó un crecimiento de $64 \%$. Después del reflujo de la crisis de 2008, retomó el ritmo de crecimiento alcanzando un máximo de 521 millones de toneladas en 2011, un incremento de $110 \%$ respecto a 2001 . La bauxita también experimentó un alto ritmo de crecimiento entre 2001 y 2008 , cercano al $50 \%$, cayendo de manera importante en 2009 y a partir de 2010 retomó un lento pero sostenido crecimiento de su producción, aproximándose a 53 millones de toneladas en 2015.

\section{Los materiales estratégicos}

Aun cuando no se dispone de datos precisos sobre la explotación de los nuevos commodities y aunque su actual ritmo de explotación no es - todavíaimportante, es probable que se intensifique en los próximos años. Ello porque América Latina posee el 97\% de las reservas mundiales de niobio, 96\% de litio y 54\% de tántalo (Bruckmann, 2015). En otras palabras, detenta el patrimonio de los recursos clave para el desarrollo de los nuevos sistemas tecnológicos.

Es necesario señalar que los procesos de extracción y transformación de estos elementos se basarán, cada vez más, en las tecnologías convergentes 
(nanotecnología, biotecnología, tecnologías de la información y ciencias del conocimiento), áreas tecno-científicas en las que la región, en general, presenta capacidades de investigación exiguas, por lo que de no hacerse esfuerzos para superar esta situación, se agudizará el extractivismo.

Este incremento de la explotación de recursos agravará la degradación ambiental. Ya se comienzan a generar nuevos impactos, evidentes en la deforestación de selvas y bosques y la contaminación de cursos y reservorios de agua. Por ejemplo, la extracción del carbonato de litio requiere de gran cantidad de agua no salobre. Los salares que contienen las inmensa reservas del recurso se ubican en zonas desérticas, por lo que se está utilizando agua de acuíferos subterráneos prehistóricos, recurso que desde el punto de vista ecológico tiene un valor inestimable.

Se demuestra así que la estructura productiva de América Latina continúa anclada a las actividades inherentes al anterior paradigma tecno-económico. La consolidación global de los sistemas tecnológicos disruptivos colocará más presiones sobre sus recursos naturales, agudizando el fenómeno del "neoextractivismo". Si a ello se agrega una industria manufacturera que en la mayoría de los casos presenta limitadas capacidades tecnológicas (Westphal et al., 1985) y que pierde importancia en la composición del PIB, es casi inevitable el incremento de la brecha respecto a los países desarrollados y la agudización de las asimetrías. Por esta razón cabe preguntarse: ¿Compensan los costos, en términos de los impactos socioambientales y culturales negativos, de toda esta nueva fase del extractivismo? El mantenimiento del déficit social y la exclusión, los escasos avances tecnológicos y la degradación ambiental sugieren que no.

Es evidente que la crisis socioambiental y las profundas transformaciones tecnológicas colocan ingentes desafíos a la estructura tecnológica y científica de la región, y a su estructura productiva. En este escenario hay que revisar el papel que deben desempeñar las IES para abordar estos problemas y satisfacer sus requerimientos.

\section{Disrupciones tecnológicas y cuarta revolución industrial}

Gran parte de la investigación en tecno-ciencia que se realiza en las universidades en el ámbito global - especialmente en las áreas de química y ciencia de los materiales, matemáticas, ciencias de la computación e inge- 
niería - apuntan al desarrollo de tecnologías disruptivas (Thomsom Reuters, 2014a y b). De esta manera, estas instituciones se erigen en instancias clave para impulsar las transformaciones que actualmente experimentan diversos sistemas tecnológicos. Es tal el impacto de estas tecnologías que, aparte de modificar las concepciones mismas de producción, distribución y consumo, alterarán los hábitos cinestésicos de los seres humanos. ${ }^{5}$ La tabla 2 presenta las tecnologías que se considera tendrán mayores impactos socioeconómicos.

\section{Tabla 2 \\ Tecnologías disruptivas que impulsarán profundas transformaciones socio-técnicas}

\begin{tabular}{|l|l|}
\hline \multicolumn{1}{|c|}{ Área } & \multicolumn{1}{c|}{ Tecnología disruptiva } \\
\hline TIC & $\begin{array}{l}\text { Internet de las cosas } \\
\text { Cloud computing } \\
\text { Artefactos portátiles } \\
\text { Computación cuántica }\end{array}$ \\
\hline Nuevos materiales & $\begin{array}{l}\text { Nano materiales de grafeno } \\
\text { Nano materiales para electrodos de baterías }\end{array}$ \\
\hline Mecatrónica & Nueva generación de robots industriales \\
\hline Medicina & Próxima generación de secuenciación genómica \\
\hline Transporte & $\begin{array}{l}\text { Vehículos eléctricos } \\
\text { Vehículos auto-asistidos }\end{array}$ \\
\hline \multirow{2}{*}{ Almacenamiento avanzado de energía } & $\begin{array}{l}\text { Baterías de ion litio oxígeno } \\
\text { Baterías de ion sodio } \\
\text { Sistemas domésticos de almacenamiento }\end{array}$ \\
\hline
\end{tabular}

Fuente: el autor

Como puede apreciarse, inciden en los sistemas tecnológicos asociados prácticamente a todas las actividades socioeconómicas: producción industrial, energía y, prácticamente, en todos los servicios (transporte, finanzas, comunicaciones, etc.). Una característica importante de estas transformaciones es que no ocurren de manera independiente, sino mediante profundas in-

5 Sobre el uso de la tecnología, por ejemplo del automóvil, se avizoran modificaciones radicales: ¿Será necesario aprender a manejar un automóvil, entendiéndolo como el proceso de control del dispositivo y las reglamentaciones o se delegará estas habilidades a dispositivos autónomos? 
terrelaciones e interdependencias, lo que implica la emergencia de una revolución tecnológica (Pérez, 2002) o, probablemente, de varias revoluciones tecnológicas que están abriendo cauce a una cuarta revolución industrial.

Uno de los cambios más importantes en la estructura tecno-productiva se relaciona con la introducción de los sistemas "ciberfísicos" en la producción. Son redes de elementos interactivos que consideran sensores, máquinas, herramientas, sistemas de ensamblaje y partes, todas conectadas a través de redes de comunicación digitales (la nube), procesos que pueden ser controlados en forma remota. Algunos de sus componentes pueden actuar de manera independiente, estableciendo una diferencia fundamental con los tradicionales sistemas de control distribuido que, hasta ahora, constituyeron el núcleo de la automatización y control industrial (VDI, 2015). Pero surge una interrogante clave en la actual crisis socioambiental: ¿Incidirán todas estas transformaciones tecnológicas en el irracional consumo de recursos y la generación de contaminación? Algunas tecnologías disruptivas pueden contribuir a la disminución de GEI, atenuar la presión sobre los recursos naturales al posibilitar el diseño de procesos más eficientes y un aumento en el desarrollo de técnicas de reutilización y reciclaje. No obstante, la revisión de las tendencias en diversos sectores productivos y de servicios revela la consolidación de lo que se ha denominado gigantismo tecnológico (Mercado y Córdova, 2005), consustancial al paradigma económico del crecimiento continuo, que hace insignificantes los ahorros por mejoras en la eficiencia.

\section{Reelaboración de las formas de producir conocimientos}

La gravedad de los problemas socioambientales y la aparente imposibilidad de abordarlos desde el mainstream de la investigación y el desarrollo tecnológico, demandan una revisión de las formas de producir y usar el conocimiento. Así, paralelamente al imperativo desarrollo de la tecno-ciencia, está el papel que deben jugar otras formas de producción y transmisión de conocimientos (saberes ancestrales y/o tradicionales), capaces de impulsar formas alternativas de producción y consumo orientadas a satisfacer necesidades básicas de la población y, por lo tanto, más acordes con los postulados de la sustentabilidad. Además de sus posibilidades de ofrecer soluciones accesibles a los problemas y requerimientos de las comunidades. ¿Cuál debe ser el rol que deben desempeñar las universidades frente a estas formas 
alternativas de producción y uso del conocimiento? ¿Es posible el establecimiento de un diálogo de saberes que permita la conformación de espacios de co-creación de conocimientos?

Un caso concreto es el de las políticas de ciencia, tecnología y educación superior del Ecuador, que han establecido la necesidad de conjugar o al menos armonizar en la medida que sea posible, las tecnologías desarrolladas desde el mainstream de la tecno-ciencia con los saberes ancestrales, y entre ciencia y otros saberes. En el Plan de la Economía Social de los Conocimientos (PESC) (SENESCYT, 2017) se exploran posibles interrelaciones que apuntarían a lo que Vessuri (2004) destaca como la "hibridación de conocimientos".

Lo anterior abre cauces para una mayor interacción con la sociedad. El diálogo y el intercambio de saberes lleva a replantear los roles de la investigación en la educación superior. Del mismo modo, también exige redefinir algunos aspectos del papel de la universidad en desarrollo científico, tecnológico y económico, hasta retomar su lugar no solo como formadora individual, sino como ámbito de desarrollo de la cultura, la ciudadanía y la democracia (Zgaga, 2005). En otras palabras, se plantea una reelaboración de las formas de producir conocimientos.

\section{Ampliar prácticas de la investigación}

En la actualidad han surgido diversos movimientos de reelaboración de la producción de conocimiento. La "ciencia abierta" promueve una praxis científica que incluya el libre acceso a datos y publicaciones científicas, la posibilidad de compartir plataformas de investigación y desarrollar colaboraciones más amplias en proyectos científicos que pueden incluir la participación de profesionales (científicos) y practicantes no especializados (Barandiaran et al., 2015). Varios autores señalan que estas formas de organización y desarrollo de la investigación no implican la creación de un nuevo tipo de ciencia separada del sistema existente, sino la creación de una forma semi-institucionalizada que libere los resultados de la investigación. Aunque no se planteen explícitamente nuevos modos de generación de conocimiento, estas formas de organización pueden hacer más fluida su circulación, más allá de las comunidades de especialistas, posibilitando una mayor interacción entre estos y los practicantes no especializados. Indefec- 
tiblemente esto induce a una multidireccionalidad en el intercambio de información y conocimientos, por lo que dichos espacios pueden contribuir efectivamente a la hibridación de saberes (Hitner et al., 2017).

La "ciencia ciudadana" promueve el involucramiento activo de practicantes no profesionales en la investigación, considerando un amplio espectro de actividades que pueden ir desde proyectos realizados por pequeños grupos con intereses comunes, hasta proyectos internacionales que cuenten con la participación de instituciones de investigación sobre temas de interés de la sociedad (LERU, 2016). Los principales rasgos que configurarían esta praxis serían: la colaboración interdisciplinaria, la estructuración de redes de colaboración abierta ampliamente distribuidas y el estímulo a iniciativas que motiven a los ciudadanos a tener roles más activos en los proyectos (LERU, 2016).

Un tercer movimiento (la investigación participativa) va más allá, aportando métodos e instrumentos para una efectiva incorporación de las comunidades, basado en el establecimiento de relaciones mutuamente benéficas entre las universidades y los ciudadanos. Considera la co-creación y aplicación de conocimientos que incremente en ambos actores la capacidad para identificar temas y proponer soluciones. Se diferencia de la investigación tradicional en su propósito, procurando el beneficio de la comunidad, en una acepción amplia que puede considerar los ámbitos público, local, nacional y global (Stanton, 2012). También presenta diferencias importantes en los métodos, al prestar atención al carácter democrático que debe tener la colaboración, mediante la inclusión de todos los participantes en todas las fases de los proyectos: formulación, obtención y análisis de datos y aplicación de resultados. Esta última fase, aparte de suponer avances en el conocimiento, deberá también generar aportes que mejoren las condiciones de vida en las comunidades (Stanton, 2012).

$\mathrm{Al}$ adoptar estas prácticas no puede obviarse que la tecno-ciencia y otras formas de saber y conocer son incompatibles en su concepción y finalidades. Confrontar e integrar estas tendencias conlleva tensiones que es necesario considerar para una adecuada gestión de la producción del conocimiento. Por una parte, la imparable transformación socio-técnica global hace imperativo para la región el desarrollo de la tecno-ciencia, procurando orientarla hacia fines de mayor beneficio social y de soberanía. El fortalecimiento de la capacidad tecnológica de la industria, la agregación de valor a los recursos estratégicos aminorando los impactos socioambientales de su explotación, 
también son una prioridad. A la par, el desarrollo de vocaciones productivas locales que promuevan y rescaten conocimientos tradicionales y ancestrales que empoderen a las comunidades, constituyen espacios a construir mediante estas nuevas formas de organización y producción de conocimientos (por ejemplo: ciencia ciudadana, ciencia participativa).

Sin duda todos estos son grandes desafíos para las misiones de investigación y extensión. Pertinencia, vinculación con la sociedad e incremento de la participación, son temas pendientes en la agenda de la universidad latinoamericana.

\section{Redefinir la extensión}

El reposicionamiento de los temas de inclusión social y participación de los ciudadanos en la educación, ciencia y tecnología ha comenzado a recuperar la vigencia de la extensión universitaria, al ser esta misión la que permite el establecimiento de nexos entre las IES y otros actores de la sociedad con una mayor fluidez (Hitner et al., 2017).

Thiollent (1994), basado en experiencias en Brasil, propone que la extensión y la investigación se conciban como procesos de construcción social que cuenten con la participación de actores orientados al logro de objetivos concretos. En esta perspectiva, la metodología y los instrumentos de trabajo adquieren dimensiones participativas, críticas y reflexivas que favorecen propósitos de emancipación en los proyectos universitarios.

Se observa incluso el surgimiento de movimientos que hacen importantes cuestionamientos a la "renovada" tercera misión de la universidad (contribuir al desarrollo económico). Trencher (et al., 2014), basado en el análisis de experiencias en Norteamérica, Europa y Asia, apunta que la crisis socioambiental global está induciendo a muchas IES a desviar la atención del interés casi exclusivo hacia la generación de ingresos y el crecimiento económico, a constituirse en transformadoras sociales y co-creadoras. Esto desdibuja las fronteras entre los miembros de una comunidad (sociedad civil, gobiernos locales e industria) y los académicos, gracias a la instrumentación de mecanismos de colaboración orientados a la transformación física y sustentable de una localidad determinada para responder a requerimientos de algún grupo específico de la sociedad.

Aunque muchos de los métodos e instrumentos utilizados resultan ser prácticamente los mismos de los "paradigmas establecidos" — tales como 
la extensión agrícola, investigación y acción participativa, transferencia de tecnología y transdisciplinariedad - , lo novedoso radica en la emergencia de la función co-creativa, que consiste en la combinación de esos diversos modelos de acciones de compromiso social para responder a problemas socioambientales. Para ello es necesario internalizar los valores del desarrollo sustentable (Trencher et al., 2014).

Recientemente en EE.UU. un importante número de universidades ha realizado esfuerzos para revitalizar la participación cívica y comunitaria en sus localidades. En una tentativa que guarda similitud con las actividades de extensión latinoamericanas, subrayan la importancia de la participación de las comunidades en la orientación y desarrollo de sus funciones, haciendo uso de recursos institucionales para identificar y resolver los problemas que la comunidad afronta (Stanton, 2012). Considerando que el Modo 2 de generación de conocimiento plantea que su producción debe tomar en cuenta los contextos de aplicación, estas universidades proponen que parte del esfuerzo atienda a los problemas de las comunidades, lo que colocaría criterios que validarían el trabajo académico en sus espacios de localización (Stanton, 2012). Esto asigna importantes responsabilidades a las funciones de extensión, pues las universidades deberán constituir los puentes entre las comunidades y la segunda misión de las IES (la investigación), abriendo espacios a nuevas formas de desarrollar esta actividad (ciencia abierta, ciudadana o investigación participativa) bajo una perspectiva de pertinencia y relevancia.

El agravamiento de los problemas socioambientales y el imperativo de orientar las formas de vida por trayectorias más sustentables, parecen ser un punto de convergencia en el reenfoque de la extensión universitaria. Las IES, al ser factores claves en la participación ciudadana para enfocar estos problemas, proponer soluciones y participar en su resolución, tienen el gran desafío de repensar, en parte, sus otros grandes objetivos (formación e investigación) para renovar su contrato social y su vigencia.

\section{Conclusiones}

Un elemento renovador muy importante de la Reforma de Córdoba fue la valoración de las relaciones con la sociedad. Se planteó abrir la universidad mediante la proyección de la cultura y el asistencialismo, rasgos que conformaron y han caracterizado hasta hoy a su tercera misión: la extensión. 
La actual estructura tecno-económica global es, en gran medida, responsable de muchos de los graves problemas socioambientales que afronta el mundo y que colocan a un alto porcentaje de la población mundial en riesgo severo. Abordar temas como el calentamiento global, la contaminación y problemas sociales como la pobreza y la exclusión, es ineludible para las IES, pero para hacerlo de manera más efectiva deben asumir enfoques de investigación que trasciendan las formas tradicionales "intramuros", incorporando a través del diálogo a los saberes diversos y conocimientos de distintos actores sociales.

Simultáneamente, están ocurriendo grandes transformaciones tecnológicas que trastocan las concepciones establecidas de la producción y los servicios, con importantes consecuencias sobre la organización y división del trabajo, la estructura social e incluso sobre cada individuo, abriendo cauce a la cuarta revolución industrial. Pero al desarrollarse en la lógica del crecimiento continuo no plantean alternativas al actual patrón de desarrollo.

Esto coloca un doble desafío a las IES latinoamericanas. Responder, por una parte, al impuesto por las citadas transformaciones tecnológicas, partiendo de un rezago notable de su estructura productiva, basada en actividades primarias y de explotación de recursos naturales, con severas consecuencias ambientales. Ello mediante el desarrollo de una tecno-ciencia orientada hacia un mayor beneficio social y de soberanía. Por la otra, a las demandas de participación e inclusión que llevarían implícitas la reelaboración de las formas de producción de conocimiento.

Todo esto plantea redefinir la extensión, al constituir esta el espacio inmejorable de interacción con la sociedad. Aparte de la proyección cultural y las labores asistenciales, la universidad deberá desarrollar los mecanismos de correaje para la transmisión e intercambio de información y conocimientos entre las comunidades y los investigadores, con el fin de posibilitar nuevas agendas de proyectos y contribuir a crear los espacios que permitan la implantación de las formas alternativas para realizar la actividad (ciencia abierta, ciudadana o investigación participativa). En esta medida, se transforma también la segunda misión de la universidad.

\section{Bibliografía}

Barandiaran, X. Araya, D. y Vila-Viñas, D. (2015). Ciencia: investigación colaborativa, participativa y abierta. En Buen Conocer/FLOK Society: modelos 
sostenibles y políticas públicas para una economía social del conocimiento común y abierto en el Ecuador. Quito: IAEN.

Bruckmann, M. (2015). El litio y la geopolítica de integración de América Latina. En F. Nacif, y M. Lacabana (eds.), ABC del litio sudamericano soberanía, ambiente, tecnología e industria. Quilmes: Centro Cultural de la Cooperación Floreal Gorini/Universidad Nacional de Quilmes.

Bussines Europe. (2014). Revisión intermedia garantizar resultados. Recuperado de https://bit.ly/2OLz4lA/

Fresán Orozco, M. (2004). La extensión universitaria y la universidad pública. Reencuentro, 39, 47-54.

Geyer, R. Jambeck, J. y Lavender Law, K. (2017). Production, use, and fate of all plastics ever made. Science Advance. Recuperado de https://bit. ly/2Mw1RwL/

Hitner, V., Carlotto, M. y Mercado, A. (2017). Agenda 2035 para la educación superior en el Ecuador. Quito: SENESCYT.

Hope, K. (16 de enero de 2017). Eight billionaires “as rich as world's poorest half". BBC News. Davos: BBC. Recuperado de https://bbc.in/2vTiRDM/

Hughes, T. 1987 "The evolution of large technological systems" en Bijker, W.E.,Hughes, T.P. and Pinch, T.J. (eds) 1987 The Social Construction of Technological Systems (Cambridge: MIT Press).

LEAGUE OF EUROPEAN RESEARCH UNIVERSITIES (LERU) (2016). Citizen science at universities: Trends, guidelines and recommendations. en: http:// www.uib.cat/digitalAssets/409/409499_leru_ap20_citizen_science.pdf

Mercado, A. y Córdova, K. (2005). Desarrollo sustentable-industria: más controversias menos respuestas. Ambiente \& Sociedad, 8(1).

SENESCYT (2017). "Plan de Economía Social de los Conocimientos, la Creatividad, la Innovación y los Saberes Ancestrales”. En: http://observasur.org/ wp-content/uploads/2017/06/Diagrama-PESC-Revisado.pdf

Salleh, A. (13 de febrero de 2015). Plastic ocean: study names worst polluters. $A B C$ Science. Recuperado de https://ab.co/2Bwvryb/

Serna Alcántara, A. (2007). Misión social y modelos de extensión universitaria: del entusiasmo al desdén. Revista Iberoamericana de Educación, 43(3).

Stanton, T. (2012). New Times Demand New Scholarship II: Research Universities and Civic Engagement: Opportunities and Challenges. Journal of Higher Education Outreach and Engagement, 16(4), 27.

Thiollent, M. (1994). A inserção da pesquisa-ação no contexto da extensão universitária. Recuperado de https://bit.ly/2wcob4B/ 
Thomsom Reuters (2014b). Research Fronts 2014. Recuperado de https://bit. ly/2MSVFvH/

Thomsom Reuters. (2014a). Research Fronts 2014: 100 Top Ranked Specialties in the Sciences and Social Sciences. Recuperado de https://bit.ly/2MSbbrJ/

Trencher, G. Yarime, M. McCormick, K. Doll, C. Kraines, S (2014). Beyond the Third Mission: Exploring the Emerging University Function of Co-creation for Sustainability. Science and Public Policy, 41(2), 151-179.

Tünnermann, C. (ed.) (2008). Noventa años de la Reforma Universitaria de Córdoba: 1918-2008. Buenos Aires: CLACSO.

VDI. (2015). Industry 4.0 A Discussion of Qualifications and Skills in the Factory of the Future: A German and American Perspective. Recuperado de https:// bit.ly/2OK2PD5/

Vessuri, H. (2004). La hibridización del conocimiento: la tecnociencia y los conocimientos locales a la búsqueda del desarrollo sustentable. Convergencia, revista de ciencias sociales, 11(35), 171-191.

WB. (2018). The Changing Wealth of Nations 2018 Building a Sustainable Future. Recuperado de https://bit.ly/2FW7D7B/

Westphal, L., Kim, L. y Dahlman, C. (1985). Reflections on the republic of Korea's acquisition of technological capability. En N. Rosemberg y C. Frischtak (eds.), International Transfer of technology: Concepts, Measures, and Comparisons. NY: Praeger Press.

Williams, G. (2016). Higher education: Public good or private commodity? London Review of Education, 14(1).

WMO. (2017). Wmo Greenhouse Gas Bulletin. Recuperado de https://bit. ly/2A0py $7 \mathrm{~h} /$

WMO. (18 de enero de 2018). WMO confirms 2017 among the three warmest years on record. Recuperado de https://bit.ly/2mV8YRi/

Zgaga, P. (2005) Higher education for a democratic culture - The public responsibility. En: The public responsibility for higher education and research. Weber, L. Bergan, S (eds). Council of Europe Publishing. Disponible en: https://goo.gl/32nb7o 



\title{
Hacia una política pública del bioconocimiento: ciencia, tecnología e investigación
}

\author{
Towards a public policy of bio-knowledge: \\ science, technology and research
}

\author{
Pablo Samaniego Ponce \\ Pontifica Universidad Católica del Ecuador (PUCE) \\ psamaniego038@puce.edu.ec \\ Código Orcid: https://orcid.org/0000-0001-9792-2666
}

\begin{abstract}
Resumen
Este trabajo reflexiona sobre cuáles son las principales tendencias de la economía mundial y la forma cómo se articula el Ecuador a ellas, con el propósito de analizar de qué manera se puede delimitar la pertinencia de las actividades de la ciencia, tecnología e investigación, toda vez que se considera que en muchos aspectos el rumbo del desarrollo del país reproduce los principales defectos que ocurrieron y, en buena medida, siguen siendo los elementos no deseados en los países del norte desarrollado, en tanto que las bondades de las distintas vías hacia un mayor bienestar están ausentes. Para conseguir tal propósito se realizó una revisión de la discusión académica actual sobre el papel de la ciencia, la tecnología y la investigación como insumos para deliberar los principios generales que debería tener la política pública en el ámbito del bioconocimiento. De las múltiples carencias que tiene el país a este respecto, se precisa que debería ser prioritario volcar los esfuerzos de ciencia, tecnología e investigación hacia la satisfacción de las necesidades básicas de la población o el cumplimiento de los derechos consagrados en la Constitución, y, por otra parte, estructurar una estrategia doble para apoyar tanto a las actividades económicas más dinámicas como a las que utilizan métodos de producción tradicional.
\end{abstract}

\section{Palabras clave}

Economía mundial, ciencia y sociedad, tecnología, investigación, bioconocimiento, desarrollo económico y social, relaciones económicas, Ecuador.

Forma sugerida de citar: Samaniego Ponce, Pablo (2018). Hacia una política pública del bioconocimiento: ciencia, tecnología e investigación. Universitas, 29, pp. 89-108. 


\begin{abstract}
This paper reflects on world's economic trends and how Ecuador articulates to them. The purpose is to analyze how to delimit the relevance of science, technology and research activities given that in many aspects of the country's development the main defects reproduce and continue to be undesired in the countries of the developed north, whilst the benefits of the several paths towards greater welfare are absent. To achieve this, the current global discussion on the role of science, technology and research was reviewed as an input to discuss the general principles that public policy should have in the field of bioknowledge. It is necessary, given the unlimited deficiencies that the country has in this area, to prioritize, as appropriate, the efforts of science, technology and research towards the fulfillment of basic needs of the population or the rights enshrined in the Political Constitution, as well as, to structure a double strategy that consists on supporting the most dynamic economic activities and those that use traditional production methods.
\end{abstract}

Keywords

World economy, science and society, technology, research, bio-knowledge economic and social development, economic relations, Ecuador.

\title{
Introducción
}

El salto cualitativo y la posterior expansión de las tecnologías de la información y comunicación en los últimos años, junto con el desarrollo de distintas aplicaciones en los más diversos ámbitos de la actividad humana, está modificando significativamente la forma cómo se debe entender hoy y cómo se organizará en el futuro la sociedad y la economía (David y Foray, 2002). En este marco, también se está mostrando la manera en que se transformarán los actuales conceptos de desarrollo y bienestar, pero en el contexto de los límites que impone la explotación de los recursos naturales y la reproducción de la vida o, en otro sentido, los cotos que imponen las leyes que gobiernan a la biósfera (Martínez Alier y Roca Jusmet, 2016) y al planeta (Georgescu-Roegen, 1996). Dicho cambio en los conceptos se explica por la influencia que tienen el desarrollo y expansión de las TIC en la des- 
materialización ${ }^{1}$ de bienes y servicios; aunque limitado y concreto, el proceso conduce a repensar el concepto de modo de producción pues el trabajo se apropia de los beneficios de su propia creación. ${ }^{2}$ Este es el punto de partida o de entrada a la reflexión porque está íntimamente relacionado con la ciencia, la tecnología y la investigación, especialmente en lo concerniente a la manera cómo ellas se generan, gestionan, distribuyen y se apropian en el mundo.

De forma concomitante a ese proceso, existe un cambio en la estructura y distribución de la producción mundial que proviene de la emergencia de las economías que hoy se conocen como BRICS - a las que habría que añadir otros países menos "grandes", pero con procesos similares y anteriores como Corea del Sur o Malasia-, lo que ha significado que los centros de producción y la prestación de servicios se relocalicen a escala planetaria aprovechando las ventajas que exhiben algunas economías que tienen menores costos de producción, por lo general, en vista de que son países en los que los salarios son bajos, las condiciones del empleo precarias (Pérez, 2010) y la contratación de fuerza de trabajo está sujeta a menores controles y regulaciones en comparación con los países del norte industrializado. También, como contracara, estos países emergentes tienen segmentos de población con altos niveles académicos y de conocimientos, que son capaces de entender, compartir o proponer nuevos avances en los ámbitos de la ciencia, tecnología e investigación (UNESCO, 2010). Mientras el primer segmento de la población se internacionaliza a partir de mecanismos de explotación y en tanto consumidores, este otro segmento se globaliza porque tiene la ca-

1 Aquí no se emplea el concepto de “desmaterialización” utilizado por Malembaum (1978), que habla de "la reducción en la intensidad de uso de diferentes materias primas por unidad de PIB" (en Carpintero, 2005). El término hace referencia a que hay una porción importante de actividades que en la actualidad se realizan sin que se vuelvan corpóreas. Eso no significa, sin embargo, que para el funcionamiento de las TIC no se requiera de elementos materiales que se utilizan crecientemente (en general, el hardware) y del uso de energía.

2 Las TIC permiten que los trabajadores se apropien de los frutos de su creación en tanto son los mismos programadores, por ejemplo, dispersos por todo el mundo, quienes luego explotan los resultados de su trabajo sin que, necesariamente, deban depender de un capitalista pues lo desarrollado a partir de su conocimiento es una nueva forma de capital. Asimismo, se observan cambios en los mercados por la posibilidad de que individuos o pequeños y medianos productores se "conecten" directamente con los consumidores. El capital físico ha cedido el paso al capital intangible, que es un componente - a veces no valorado en cuanto a las dificultades que tiene hacerlo - que tiene el mayor peso en la inversión de muchas de las grandes empresas más dinámicas (Jaskel y Westlake, 2018). Estos rasgos son los que pueden hacer presumir que habrá cambios en la forma como se estructurará el modo de producción, sin que ello signifique que se modifiquen las grandes tendencias que lo conducen. 
pacidad de acceder y aportar a las redes mundiales de conocimientos, así como integrarse a empresas transnacionales y, en el extremo, migrar para incorporarse a los centros más dinámicos (Carrington y Detragiachi, 1998; Brandi, 2006).

Estas economías emergentes tienen como característica diferenciadora en relación al resto de países en desarrollo, la capacidad de ofertar productos de distinta complejidad tecnológica y calidad, de forma que ocupan el espectro productivo desde la elaboración de alimentos con poco contenido de valor agregado hasta bienes de alta tecnología que requieren especialmente la incorporación de investigación y conocimientos, aunque no todos estén en la frontera en comparación con los países desarrollados. Es decir, de los países en desarrollo antes señalados, algunos ofertan tecnología de última generación como robots para uso industrial o tecnologías para telecomunicaciones (es el caso de China), otros como India y Brasil ofertan aeronaves y otros como Rusia y Sudáfrica fabrican armas, aunque todos ellos producen energía nuclear con fines pacíficos o bélicos. Como señalan Naudé, Szirmai y Haraguchi (2015), mientras el crecimiento de China e India está siendo impulsado por la industria manufacturera, en Rusia, Brasil y Sudáfrica pese a los logros alcanzados en términos de producción industrial - el impulso proviene de los servicios.

En este escenario se encuentra un conjunto amplio de naciones que pugnan por establecer una estrategia de desarrollo en medio de la inmensa presión que significa el control de la tecnología de punta por parte de las empresas de los países industrializados del norte y la competencia a la que ha llevado la abundancia de producción de bienes y servicios de los BRICS. Estos países han establecido distintas opciones de articulación a fin de ser parte de esos procesos generales. La herramienta más utilizada para ello ha sido la suscripción de "tratados de libre comercio", unos mecanismos que logra internacionalizar la producción y los mercados de consumo con reglas que privilegian los intereses de las empresas de los países desarrollados (Acosta et al., 2006), especialmente en lo que atañe a las normas sobre propiedad intelectual y el control de los mercados de productos.

Esas naciones que pugnan por articularse globalmente, en lo que va del siglo XXI, se beneficiaron del incremento mundial de la demanda y de los precios de materias primas de origen mineral y vegetal (FAO, 2018). Eso ha determinado, en no pocos casos, la reprimarización de las economías y un deterioro sustancial de la balanza comercial física (Samaniego et al., 2017). 
Es decir, la adscripción a las corrientes mundiales de comercio se ha dado a costa de una explotación cada vez más intensa de recursos minerales y la ocupación de cada vez más amplias extensiones de territorio - terrestre y marino - para la provisión de biomasa al extranjero, lo que ha causado nuevos problemas para la reproducción de la vida, porque ha afectado a comunidades humanas y a ecosistemas específicos, y ha creado conflictos ambientales $^{3}$ (Pérez-Rincón, 2014).

Por otra parte, el aumento en los precios de los bienes primarios de exportación es uno de los elementos que explica una etapa de alto crecimiento económico en los países de Latinoamérica, expansión que tuvo como una de sus consecuencias un proceso de movilidad social con reducción de la pobreza y fortalecimiento del estrato medio. ${ }^{4}$ A este estrato se le atribuyen varios roles, desde estabilizar los sistemas democráticos (Bárcena y Serra, 2010) hasta llevar adelante procesos de innovación (Solimano, 2014). Tal vez lo singular de este segmento de la población es que en ocasiones ocupa posiciones de dirección y, por lo general, de control en el proceso productivo, o también son los obreros con alta calificación y en esa medida, puede estar en el lugar justo para aprovechar las oportunidades que brinda el mundo del conocimiento, a fin de volcarlo dentro del sistema productivo.

Finalmente, el agotamiento de la capacidad de carga del planeta (Hardin, 1968) y el cambio climático (IPCC, 2013) son los principales problemas que están condicionando la viabilidad de la vida y, por tanto, deben ser entendidos y enfrentados porque si es que no se encuentran soluciones, ninguna política nacional será viable. En otras palabras, tenemos un gran determinante que se origina en la forma que se ha organizado históricamente la sociedad y es una fuente de restricciones muy fuertes para el futuro: los procesos que rigen el funcionamiento del gran sistema, la biósfera, están siendo limitados por las convenciones (modo de producción, matriz institucional o

3 Algunas organizaciones y economistas ecológicos crearon el sitio web ejatlas.org que reúne los casos reportados de conflictos socio-ambientales. Actualmente (julio de 2018), se reportan 2508 casos alrededor del mundo. Gracias a esta iniciativa es posible determinar - por primera vez de manera sistemática - la forma cómo la sociedad civil aprovecha los sistemas modernos de comunicación e información para poner en alerta a la comunidad internacional sobre estos hechos y, así mismo, facilitar la investigación académica de estos fenómenos.

4 Se habla de "estrato medio" y no de "clase media" porque la metodología que emplean los estudios citados se basa en los ingresos percibidos por los hogares (Ravallion, 2009) y no en una clasificación de clases que es propia de la sociología (Giddens, 2000; Wright, 1985) y de los estudios sociales que proliferaron en América Latina entre las décadas de los 60 y 80 del siglo pasado (Sémbler, 2006). 
como se lo denomine) creadas por los humanos para construir, organizar y funcionar en sociedad.

Este es el escenario general sobre el que se debe constituir una política nacional del bioconocimiento, en el marco de las restricciones antes señaladas y con el propósito de superarlas. Sin embargo, es indudable que aisladamente no podremos avanzar porque los problemas que nos afectan son también generados por las políticas y acciones que ejecutan otros países.

Ahora bien, las transformaciones que vienen ocurriendo en el mundo y que hemos sintetizado, pueden abrir oportunidades si es que se logra articular al país teniendo como base las características y fortalezas propias, las condiciones particulares que provienen de su historia y, específicamente, de la pertinencia o concordancia con las características socioeconómicas, políticas, culturales y ambientales (Cuvi, 2013).

El Ecuador es un país pequeño, abierto, dolarizado y profundamente heterogéneo en varios sentidos. ${ }^{5}$ En este caso interesa poner de relieve la heterogeneidad productiva y dentro de ella el extremadamente alto grado de concentración en los mercados interno y de exportación, y de las ganancias. Tanto heterogeneidad como concentración económica definen y a la vez son resultado de relaciones sociales, políticas y culturales específicas. Por otra parte, la heterogeneidad cultural o de saberes es una fuente potencial de generación de conocimiento, siempre que esa diversidad se articule para la construcción del bioconocimiento.

Esta propuesta no puede estar libre del contexto político nacional. El Ecuador de los últimos diez años se distingue de las dos décadas anteriores por haber tenido un período amplio de estabilidad institucional y - lo que es de especial interés para esta investigación - por el "retorno del Estado" (Acosta, 2012). Por tanto, hemos asistido a un retorno de la capacidad y la decisión política para diseñar, estructurar y aplicar medidas que antes eran impensables en el neoliberalismo, el cual propugnaba que "la mejor políti-

5 Se usa el término heterogeneidad para designar la diversidad de poblaciones que ocupan el Ecuador, la mayor parte de ellas con proyectos de desarrollo específicos y diferenciados (Walsh, 2007), y una cosmovisión distinta del mundo o epistemes disímiles (de Sousa Santos, 2010). Geográficamente, implica la interacción de distintos pisos ecológicos que configuran un sistema natural megadiverso, cuya importancia radica en que de esa condición "depende la alimentación, la medicina, la provisión de bienes para la construcción, para la artesanía y para cubrir muchas necesidades de las poblaciones locales" (Bravo, 2013). Por último, el término heterogeneidad también recoge el funcionamiento e interrelación de estratos con grados diferenciados de desarrollo tecnológico, productividad y formas de producción (Cimoli et al., 2006). 
ca industrial es no tener política" (Becker, 1985). Sin embargo, ese retorno está y estará mediado, en el marco de la correlación de fuerzas políticas, por el grupo que conduzca el Gobierno. Incluso en esta fase de estabilidad institucional se observó cambios en la capacidad de injerencia de unos grupos sobre otros en la conducción de la política pública, siendo tal vez uno de los puntos de quiebre más importantes la decisión de explotar el bloque YasuníITT en 2010, antes incorporado a una novedosa propuesta de conservación del petróleo bajo tierra (Rival, 2010).

\section{El bioconocimiento como eje conceptual}

El bioconocimiento tradicionalmente ha estado asociado solamente a las ciencias de la vida, más específicamente a la biología y sus extensiones hacia la genética y demás especializaciones afines. El concepto de bioconocimiento que se emplea aquí es aquel que articula análisis, investigación y aprehensión del mundo a partir de la integración de todas las formas de vida y de los múltiples conocimientos generados por la humanidad. ${ }^{6}$ Además, reconoce que las relaciones sociales, políticas, económicas y culturales intervienen e inciden en el conocimiento.

Las necesidades en materia de ciencia, tecnología e investigación en el Ecuador son inmensas, porque el retraso con respecto a otros países clasificados como de desarrollo medio-alto y los países llamados desarrollados es abismal. Sin embargo, esa brecha debe ser analizada y resuelta a la luz de las necesidades propias y de los principios ético-normativos, que son la base de la organización del Estado ecuatoriano. Es decir, si es que no se establecen prioridades a partir de las necesidades nacionales, habría que atacar todos los frentes para intentar la superación de ese atraso de manera global, cosa que no es posible por la cantidad de recursos humanos y económicos que se requeriría, el tiempo necesario para que maduren las políticas aplicadas y la propia lógica de los procesos científicos, tecnológicos y de investigación, la cual demanda la formación de redes y sinergias que en el Ecuador están en fase de formación.

6 De Sousa Santos (2010) habla, en este sentido, del diálogo de saberes como una forma de evitar la supremacía de un conocimiento sobre los otros. Ese diálogo debería culminar con la constitución de una "epistemología del sur", basada en la comprensión de la epistemología que subyace a las distintas manifestaciones del conocimiento. 
Como señala Kranzberg (1986, p. 545) - y esto puede ser asimilado para el conocimiento-: "La tecnología no es buena ni mala; tampoco es neutra". Esto significa, entre otros aspectos, que debe estar articulada a unas necesidades particulares para que sea pertinente o explícitamente no neutra.

A fin de delimitar esta reflexión, se divide a la pertinencia en dos ámbitos. El primero, se refiere a que ciencia, tecnología e investigación, como elementos constitutivos del bioconocimiento, se vuelquen a examinar los medios para que la población tenga satisfechas sus necesidades básicas. Sin embargo, la definición de lo que son necesidades básicas depende del concepto de bienestar que se emplee y de lo que socialmente se determine como tal. Es por ello que, para especificarlas, se puede emplear alguna medida de pobreza o privación, pero además y principalmente debe existir correspondencia con la Constitución, ya que esta representa el pacto fundamental de la sociedad. Es decir, se propone que la Constitución, en tanto es un marco que define a los derechos de cumplimiento obligatorio en el Ecuador, sea la guía para acotar cuáles son las necesidades sobre las que se debe privilegiar las actividades del conocimiento en el campo de las necesidades de las personas.

El segundo ámbito, en términos de pertinencia, se refiere a dar solución a los problemas peculiares del aparato productivo doméstico. Como habíamos señalado, la estructura productiva en el Ecuador es extremadamente heterogénea y dispar, en tanto conviven sectores altamente tecnificados que utilizan tecnología importada de última generación, con otras formas de producción que ni siquiera alcanzan niveles de acumulación ampliada, es decir, que no generan ganancias para expandir los negocios. ${ }^{7}$ También hay grandes diferencias entre el ámbito urbano y el rural debido a sus propias lógicas de funcionamiento.

Interesa en este punto hacer hincapié en el área rural, pues además de las divergencias regionales (Costa, Sierra, Amazonía e Insular) debidas a las condiciones ecológicas propias de cada una, se puede encontrar producción de subsistencia que ha abandonado formas tradicionales de producción y por ello depende del mercado de agroquímicos, que convive con producción de subsistencia que continúa con las prácticas culturales ancestrales y tiene cultivos sustentables. Estos sectores, por otra parte, tienen la responsabilidad de garantizar la seguridad alimentaria porque ofertan su producción

7 Por ejemplo, mientras algunas de las empresas que fabrican vehículos utilizan robots en el ensamblaje de las partes y piezas, en otros sectores como el textil subsisten individuos o pequeñas empresas que desarrollan su actividad con tecnología que tiene por lo menos cien años de antigüedad. 
principalmente al mercado doméstico y debido a la dependencia que tiene esta población de su propia producción para cubrir sus necesidades básicas. Según Calero (2011, p. 33): "De las familias que para el 2006 estaban en estado de inseguridad alimentaria, el 76\% residía en el área rural y más de la mitad se localizaba en la región Sierra". Se especifica este aspecto porque da cuenta de la complejidad de los enfoques que deben tener la ciencia, la tecnología y la investigación.

Además, dentro de la estructura productiva están los segmentos exportadores, dominados por grandes plantaciones, que sostienen buena parte de las necesidades de importación. Estos sectores - con exclusión del petróleo que tiene características particulares - están concentrados en la producción primaria (agricultura, caza, silvicultura y pesca) y, en menor medida, en la industria alimenticia. ${ }^{8}$ Considerando que la economía al estar dolarizada depende de esta producción para tener un flujo adecuado de moneda circulante, entonces no se puede excluir a estos sectores del ámbito de la ciencia, la tecnología y la investigación.

En este contexto, el concepto de pertinencia en el campo de la estructura productiva puede ser complejo de definir, pues a más de los roles que tienen esos distintos modos de producción en la oferta de productos y como sostén económico, la pertinencia puede ser definida por el contenido de la política pública, es decir, respondiendo a las siguientes preguntas: ¿qué modelo de desarrollo se persigue? O ¿qué paradigma sociopolítico es la guía? La respuesta a esas preguntas dependerá de la forma cómo se define, en el marco de las políticas públicas, la disputa que existe actualmente - citando los dos extremos - entre un modelo de producción orgánica sustentable y el modelo basado en insumos industriales de alto rendimiento y modificaciones genéticas (Szirmai, 2005).

Por otra parte, en tanto se reconoce que el concepto de bioconocimiento es el resultado de la formación socioeconómica, política y cultural, requiere incorporar una postura ética fundamental que se refiere a la forma cómo se generan, gestionan, distribuyen y apropian la ciencia, tecnología e investigación.

En la gestación del conocimiento por lo general se desconoce su carácter social y colectivo, tanto en su generación como en las prioridades que se

8 Entre 2013 y 2017 el $61 \%$ de las exportaciones no petroleras fueron de productos primarios no industrializados, en tanto que la agroindustria contribuyó con el $21 \%$, en promedio, en ese período (datos obtenidos del Banco Central del Ecuador para junio de 2018). 
establecen, lo que va muy de la mano con la pertinencia, así como con sus consecuencias. Una hipótesis que guía esta reflexión es que existe una relación dinámica entre conocimiento y sociedad, pues los resultados del conocimiento llevan a modificaciones de la sociedad y esta, como receptora, alimenta y modifica los contenidos del conocimiento. Por tanto, no existe independencia entre ciencia, tecnología e investigación y sociedad. Algunos autores incluso proponen co-construcción y co-responsabilidad, proclamando una ciencia para la sociedad, con sociedad (Owen et al., 2012), es decir, conciben un sistema que pueda integrar a la sociedad a la construcción de la ciencia. Siendo ese el carácter que se busca en la gestación del bioconocimiento, puede convertirse en un espacio adicional de participación democrática y, de esa manera, ser pertinente a la solución de los problemas que enfrenta la sociedad, en cuyo caso la representación directa no tendría necesariamente que pasar por los planes de gobierno y las necesidades identificadas en ellos. A esta visión se contrapone la ficción individualista que pretende que el conocimiento es un acto aislado y personal, constituido fuera de la dinámica social y cultural; por tanto, al tener un origen estrictamente privado, se justifica el uso de derechos de propiedad intelectual para limitar, por una parte, y lucrar, por otra, de un bien público.

Desde otra perspectiva, este principio de co-construcción y co-responsabilidad debe también articularse en el marco del co-gobierno y la autonomía propuesta en el Manifiesto de Córdoba, entendiendo que esos dos principios llevan a responder o actuar en correspondencia con las necesidades de la sociedad de la que la universidad es una receptora no solo en términos de financiamiento, sino principalmente de la dinámica que ella engendra. Implica también que las universidades y sus centros de investigación sean espacios de excelencia académica que sirvan de puente para que el desarrollo científico que se requiere sea pertinente:

Los métodos docentes estaban viciados de un estrecho dogmatismo, contribuyendo a mantener a la Universidad apartada de la Ciencia y de las disciplinas modernas. Las lecciones, encerradas en la repetición interminable de viejos textos, amparaban el espíritu de rutina y de sumisión (Federación Universitaria de Córdoba, 1918).

En cuanto a la gestión, se reconoce la necesidad de superar la tragedia de los anti-comunes (Ouellette, 2010), es decir, los límites que se impone al acceso (David y Foray, 2002) y desarrollo del conocimiento, y el aumento de 
los costos que implica una gestión basada en el excesivo uso de patentes y derechos de propiedad intelectual (Ramírez, 2014), sin desconocer la necesidad de que quienes realizan descubrimientos o desarrollan nueva tecnología sean remunerados por su trabajo y la inversión que realizaron. Estas restricciones o el denominado "sobre-patentamiento" ocurren justamente cuando se dan las mejores condiciones, a través de las tecnologías de la información y comunicación, para la transmisión de los conocimientos, su intercambio y la formación de redes globales de pensamiento (Hagreaves, 2011).

El Código Orgánico de la Economía Social de los Conocimientos (Asamblea Nacional, 2016) contiene varios artículos cuyo propósito es evitar que esas formas de restricción en torno a ciencia, tecnología e innovación sean parte de la práctica de la gestión del conocimiento en el Ecuador. En el cuarto fin del tercer artículo, el Código establece que busca:

Incentivar la circulación y transferencia nacional y regional de los conocimientos y tecnologías disponibles, a través de la conformación de redes de innovación social, de investigación, académicas y en general, para acrecentarlos desde la práctica de la complementariedad y solidaridad (Asamblea Nacional, 2016, p. 4).

\section{Lineamientos para la construcción de una política pública del bioconocimiento}

La política más general del bioconocimiento debe enfocarse a entender la generación y permanencia de la vida humana y no humana en todas sus formas con el propósito de no interrumpir los sistemas de auto-reproducción (autopoiesis) (Maturana y Varela, 1984). Simplemente la continuidad de una de las especies animales, la humana, no tiene viabilidad si es que no se asegura la reproducción de cada sistema vivo en particular y la interacción de todos ellos; es decir, deben respetarse las leyes que gobiernan el funcionamiento de la propia biósfera (Martínez Alier y Roca Jusmet, 2016; Carpintero, 2005) como condición para que operen otros subsistemas como el económico o la organización social. Además, el potencial que tienen los sistemas ambientales para la vida humana se podría considerar como ilimitado, pues aún no se han descubierto todos los usos que pueden proveer plantas y animales (aunque tampoco podrá conocerse esto en toda su amplitud y en un 
momento determinado porque todas las especies estamos en un constante proceso de evolución).

Esta línea general y transversal debe ser incorporada en el marco de un análisis histórico y prospectivo, es decir, en la forma cómo el desarrollo de la humanidad ha hecho que lleguemos a un punto de saturación de las posibilidades de reproducción de la vida ya que debe informarse y analizar las restricciones que pesarán en el futuro, porque habitamos "un sistema [...] básicamente cerrado respecto a la entrada de materiales” (Martínez Alier y Roca Jusmet, 2016, p. 17).

Una de las principales paradojas y expresiones de la frivolidad del crecimiento de los países con menor grado de desarrollo relativo es que repiten el mismo patrón y camino que siguieron los países desarrollados. Son innumerables las similitudes de un nación clasificada en el rango de los que tienen ingreso medio y medio-alto por el PNUD (2014) con lo que ocurría en la década de 1970 en los países hoy desarrollados. Es especialmente asombrosa la incapacidad de evitar los problemas que ya presentaron esas sociedades hace treinta o cuarenta años: contaminación, extrema congestión vehicular, deficiencias en el transporte público, sobreexplotación de recursos naturales, inequidad social, sobreconsumo, aumento de la violencia, explotación indiscriminada de recursos de la biósfera, etc. En cambio, están ausentes las virtudes de ese proceso como la constitución de universidades de alto nivel académico, la alta inversión pública en investigación y desarrollo, el fortalecimiento de las expresiones culturales, la solidez de la democracia mediante la construcción del Estado de bienestar, la instalación de sistemas masivos de transporte de personas y bienes, etc.

Entonces, es indispensable conocer, estudiar y debatir sobre ese modelo de crecimiento, mas no de desarrollo, empleando la acepción de Sen (2000) o de Max-Neef (1993), al que se está arribando acríticamente y repitiendo los mismos errores. Por ello, una tarea indispensable en el marco del bioconocimiento es estructurar un pensamiento crítico en base a los aportes de la historia para construir modelos de organización social diferentes, a fin de superar esos escollos que implícitamente son vistos como "propios" o "connaturales" del "progreso". Y ello exige la formación de grupos multidisciplinarios que observen todas las dimensiones de esos procesos en el pasado, a fin de encontrar las formas de encarar el crecimiento y el aumento de la riqueza con paradigmas distintos o reformados. El conocimiento está permanentemente concibiendo y observando analíticamente este continuum de experimentos sociales que llamamos sociedad. 
Así mismo está la necesidad de elaborar estudios prospectivos, porque del análisis de las necesidades y opciones en el futuro se puede establecer las líneas que deben abordar la ciencia, la investigación y la tecnología. Se trata de conocer cuáles son los desafíos estratégicos que tiene el Ecuador como nación con el propósito de cumplir con una de las dimensiones del bioconocimiento, esto es, que sea pertinente. Como se mencionó antes, las prioridades deben referirse a cómo lograr satisfacer las necesidades básicas de la población para construir un ambiente adecuado para la reproducción humana y cómo resolver los problemas y desafíos que afronta la estructura productiva. Sin embargo, a más de los desafíos de la estructura productiva actual, es preciso prever cuáles serán las demandas en el contexto de los cambios que se producirían en los próximos años por efecto de la aplicación de políticas públicas y de las transformaciones en los ámbitos económico y político a nivel nacional y mundial, y de los propios avances en el conocimiento. Para nombrar algunos elementos clave, es necesario prever cuáles serán las trayectorias de la población, de producción y consumo de energía, de producción y demanda de agua, la forma cómo puede afectar y las previsiones que se debe tomar con respecto a los riesgos naturales, la manera cómo la movilidad social incidirá sobre el consumo y la sostenibilidad del sector externo y las características que asumirá la disputa política debido al fortalecimiento de la clase media.

A más de la incorporación del análisis histórico y prospectivo, el bioconocimiento se debe volcar también a la situación actual. En este sentido, parece adecuado recoger la propuesta de Carlota Pérez, quien presenta un modelo dual integrado que consiste en que:

La mitad de la estrategia de desarrollo a promover "desde arriba" apuntaría a lograr la competitividad en los mercados mundiales para llegar a la frontera tecnológica en ciertas áreas y procesos e incluso tomar la delantera, a veces mediante alianzas con empresas globales. Por su parte, la mitad de la estrategia "desde abajo" implicaría actuar directamente en cada porción del territorio, en los niveles municipal y local, identificando, promoviendo, facilitando y apoyando las actividades de creación de riqueza dirigidas al mercado más adecuado: local o regional, nacional o global. Estas tenderán a ser aglomeraciones productivas (clusters) especializadas dirigidas a mercados de nicho basados en las ventajas locales (Pérez, 2010, p. 124).

Esto implica que la preocupación del bioconocimiento no debe apuntar solamente a la creación de las condiciones para conocer, apropiarse y gene- 
rar investigación y conocimientos en los temas de punta o vanguardia en el mundo para que sean incorporados en los sectores locales más modernos en términos tecnológicos, sino también se requiere - como se había mencionado - resolver las problemáticas que se presentan en los sectores económicos que producen con tecnología y conocimientos ancestrales o en la industria pequeña y mediana que se enfrenta a desafíos evidentes de competitividad, pues:

El proceso de globalización ha traído consigo la hipersegmentación de tres áreas clave: las cadenas de valor, los mercados globales y las competencias tecnológicas. Cada una de estas áreas se convierte en una red compleja con componentes diferenciados [...]. Cuando la red de valor se ha segmentado hasta llegar a los subcomponentes más simples y los mercados se han fragmentado en innumerables nichos, las capacidades tecnológicas se pueden singularizar y la especialización innovativa profunda permite que unidades o empresas intensivas en conocimiento prosperen dentro o fuera de la corporación global. En el otro extremo, algunos métodos artesanales tradicionales pueden también ocupar nichos de alto valor (premium) ${ }^{9}$ (Pérez, 2010, p. 127).

Estos procesos, además, definen las prioridades de educación universitaria y de formación profesional y técnica. Por una parte, establecen la necesidad de elevar significativamente la calidad, métodos y contenidos de la formación, a fin de ganar con el tiempo mejoras en la producción y en la productividad con la incorporación paulatina de los conocimientos adquiridos en los procesos de elaboración de los productos, para incursionar en la elaboración de bienes y servicios con mayor incorporación de valor agregado, incluso y especialmente en aquellos sectores en los que el país ha tenido éxito como productor mundial y los que proveen con estándares adecuados al mercado local. Apunta, además, a establecer sinergias que permitan el desarrollo de nuevos productos a partir del conocimiento e investigación de la rica biodiversidad que se encuentra especialmente en la Amazonía, con el propósito de modificar paulatinamente una estructura productiva que ha permanecido sin mayores cambios en los últimos cuarenta años. ${ }^{10}$

9 Los mercados solidarios globales son un buen ejemplo de que es posible unir la producción orgánica de pequeña escala o de comunidades, asociaciones o cooperativas, con la demanda de nacional e internacional que busca consumir bienes producidos con características específicas.

10 Dentro de las múltiples formas para sustentar esa afirmación se puede citar al Índice de Complejidad Económica. En este se observa que solamente en el período del "boom petrolero" de la década de 1970 el índice mejora con una tendencia clara y sostenida, luego existe una alta volatilidad con una 
Por otra parte, la formación tanto universitaria como técnica debe servir de sustento y puntal al proceso de movilidad social experimentado en los últimos años. Si se concuerda en que dicha movilidad, vista desde una estratificación a partir de los ingresos, no ha sido acompañada por un proceso paralelo en términos de un aumento de los conocimientos y destrezas (Samaniego, 2015), entonces se concluye que existe la necesidad de aprovechar ese cambio a nivel social con una ampliación de las capacidades, a fin de eliminar posibles vulnerabilidades por ausencia de ellas, es decir, para evitar la pérdida de lo ganado en términos de movilidad. Tal vez la mayor urgencia en este ámbito estaría en la formación técnica, pues ella constituye la base para articular mejoras en el sector productivo con avances a nivel social.

$\mathrm{El}$ actor que debe llevar adelante una estrategia basada en el bioconocimiento es el Estado a través de las entidades del Gobierno y preferentemente de las universidades públicas. Es el actor principal porque puede poner a disposición los recursos humanos y materiales requeridos para superar las fallas de mercado que se producen en el campo del conocimiento (Stiglitz y Greenland, 2014), pero las prioridades que se establezcan deben provenir de la acción colectiva o de una amplia discusión que involucre a trabajadores y trabajadores; campesinos y campesinas; trabajadores y trabajadoras informales; empresarios y empresarias pequeñas, medianas y grandes; y académicos y académicas. Podría ser un gran desafío y hasta una utopía que en el proceso de definición de las líneas concretas en las que se debe concentrar el bioconocimiento se cree una pedagogía de la democracia participativa.

\section{Conclusiones}

El principal interés de esta exposición es incentivar la discusión y debate sobre el papel de la ciencia, la tecnología y la investigación en el Ecuador en un contexto marcado por importantes cambios globales que están reconfigurando las relaciones económicas, sociales, culturales y políticas planetarias, así como mostrando los límites de la reproducción de la vida y de los recursos de la Tierra.

Lo que se ha propuesto son las líneas generales para la construcción de un ecosistema de bioconocimiento pertinente con el país. Se ha particularizado

tendencia plana (MIT, 2018). 
en el Ecuador tratando de hacer un planteamiento lo más amplio posible con el propósito de que pueda servir, además, como reflexión para otros países.

En este sentido, se destacan tres ejes para dar contenido a la pertinencia. El primero es el sistema ambiental, pues es el principio sobre el cual se sostiene cualquier tipo de construcción humana. El segundo, se refiere a la atención a los derechos básicos de los que deben gozar las personas en el contexto de la movilidad social experimentada en los últimos diez años y, para acotar a ese conjunto, se ha propuesto que la pertinencia se sustente en el acuerdo nacional representado en la Constitución de 2008, pues allí están contenidos los principios ético-normativos básicos que ha asumido el Estado para fundamentar su existencia. El tercero es el desarrollo de las fuerzas productivas en una economía heterogénea, pequeña, abierta y dolarizada, que por esas características requiere pensar en distintos niveles, pues la estructura productiva está conformada por estratos tecnológicos diferenciados con problemas particulares y por momentos muy lejanos entre sí. Las necesidades en ciencia, tecnología e investigación de la economía de subsistencia son cualitativamente distintas de las que tienen los sectores económicos modernos.

Se propone que estos tres ejes sean el motivo y propósito para la construcción de la ciencia, tecnología e investigación porque el conocimiento es parte y está imbricado por las características del sistema ambiental y por la manera cómo se conforma la estructura socioeconómica, pero a la vez es la fuente para transformarla. En ese sentido, se recogen los planteamientos de co-construcción y co-responsabilidad social, de manera que el desarrollo del bioconocimiento se estructure a partir de un ejercicio democrático y participativo.

En tal sentido, y retomando las primeras líneas de este apartado, existe la esperanza de que el conocimiento elaborado en esta reflexión sea útil para provocar más conocimiento.

\section{Agradecimientos}

El autor agradece los comentarios y observaciones de los dos lectores ciegos que evaluaron el artículo. Así mismo, los exculpa de las posibles falencias que podría conservar. Esta reflexión fue originalmente presentada en el seminario "Bioconocimiento, una apuesta por la vida", organizado el 17 de septiembre de 2015 en FLACSO-Ecuador, por el Departamento de De- 
sarrollo Ambiente y Territorio en conjunto con la Agencia Catalana de Cooperación para el Desarrollo. El autor contó con financiamiento para su elaboración. El documento que se presenta aquí refleja una reflexión posterior a dicha presentación, que recoge los aspectos discutidos en el seminario.

\section{Bibliografía}

Acosta, A. (2012). El retorno del Estado: primeros pasos postneoliberales, mas no postcapitalistas. La Tendencia, Revista de Análisis Político, 63-72.

Acosta, A., Correa, R., Falconí, F., Jácome, H. y Ramírez, R. (2006). El rostro oculto del TLC. Quito: Abya-Yala.

Asamblea Nacional. (2016). Código orgánico de la economía social de los conocimeintos, creatividad e innovación. Quito: Boletín Oficial no 899.

Banco Central del Ecuador. (junio, 2018). Información estadística mensual. Quito: BCE. Bárcena, A. y Serra, N. (2010). Clases medias y desarrollo en América Latina. Santiago de Chile: CEPAL/CIDOB.

Becker, G. (25 de agosto de 1985). The Best Industrial Policy is None at All. Business Week. Volumen, número, páginas o dirección web.

Brandi, C. (2006). La historia del brain drain. Revista Iberoamericana de Ciencia, Tecnología y Sociedad, 65-85.

Bravo, E. (2013). Apuntes sobre la biodiversidad del Ecuador. Quito: Abya-Yala.

Calero, C. (2011). Seguridad alimentaria en Ecuador desde un enfoque de acceso a alimentos. Quito: Abya-Yala/FLACSO.

Carpintero, Ó. (2005). El desafío de la bioeconomía. Ecología Política, 41-58.

Carrington, W. y Detragiachi, E. (1998). How Big is the Brain Drain? FMI-Working Papers, 1-22.

Cimoli, M., Primi, A. y Pugno, M. (2006). Un modelo de bajo crecimiento: la informalidad como restricción estructural. Revista de la CEPAL, 88, 89-107.

Cuvi, N. (2013). Hegemonías culturales e impertinencias tecnológicas: reflexiones en torno a la potencial introducción de transgénicos en el agro ecuatoriano. Ecuador Debate, 131-146.

David, P. y Foray, D. (2002). Una introducción a la economía y a la sociedad del saber. Revista Internacional de Ciencias Sociales, 1-22.

De Sousa Santos, B. (2010). Descolonizar el saber, reinventar el poder. Montevideo: Trilce. 
FAO. (2018). Índice de precios de los alimentos de la FAO. Recuperado de https:// bit.ly/1cFXm6w/

Federación Universitaria de Córdoba. (21 de junio de 1918). La juventud argentina de Córdoba a los hombres libres de Sud América: manifiesto de la F. U. de Córdoba. La Gaceta Universitaria. Recuperado de https://bit. ly/1zTvyNj/

Georgescu-Roegen, N. (1996). La ley de la entropía y el proceso económico. España: Fundación Argentaria.

Giddens, A. (2000). Sociología. Madrid: Alianza.

Hagreaves, I. (2011). Digital Opportunity: A Review of Intellectual Property and Growth. London: UK Government.

Hardin, G. (1968). The Tragedy of Commons. Science, 1243-1248.

IPCC. (2013). Climate Change 2013: the Physical Science Basis. Geneve: Final Draft.

Jaskel, J. y Westlake, S. (2018). Capitalism without Capital. The Rise of Intangible Economy. Princeton, NJ: Princeton University Press.

Kranzberg, M. (1986). Technology and History: "Kranzberg's Laws". Technology and Culture, 544-560.

Martínez Alier, J. y Roca Jusmet, J. (2016). Economía ecológica y política ambiental. México DF: FCE.

Maturana, H. y Varela, F. (1984). El árbol del conocimiento: las bases biológicas del entendimiento humano. Buenos Aires: Lumen.

Max-Neef, M. (1993). Desarrollo a escala humana. Santiago de Chile: Comunidad Nordan-Icaria.

Meyer, J.-B. y Brown, M. (1999). Scientific Diasporas: A New Approach to the Brain Drain. UNESCO-Discussion Paper, 1-22.

MIT. (2018). The Observatory of Economic Complexity. Recuperado de https://bit. ly/1REpEoK/

Naudé, W., Szirmai, A. y Haraguchi, N. (2015). Structural Change and Industrial Development in the BRICS. New York: Oxford University Press.

Ouellette, L. L. (2010). Access to Bio-Knowledge: From Gene Patents to Biomedical Materials. Stanford Technology Law Review, 1-27.

Owen, R., Macnaghten, P. y Stilgoe, J. (2012). Responsible research and innovation: From science in society to science for society, with society. Science and Public Policy, 751-760.

Pérez, C. (2010). Dinamismo tecnológico e inclusión social en América Latina. Revista de la CEPAL, 123-145. 
Pérez-Rincón, M. A. (2014). Conflictos ambientales en Colombia: inventario, caracterización y análisis. En L. J. Garay Salamanca, Minería en Colombia. Control público, memoria y justicia socio-ecológica, movimientos sociales y posconflicto (pp. 256-326). Bogotá: Contraloría General de la República.

PNUD. (2014). Informe sobre desarrollo humano 2014. Sostener el progreso humano: reducir vulnerabilidades y construir resilencia. New York: PNUD.

Ramírez, R. (2014). La Virtud de los Comunes: de los paraísos fiscales al paraíso de los conocimientos abiertos. Quito: Abya-Yala.

Ravallion, M. (2009). The Developing World's Bulging (but Vulnerable) "Middle Class". Wolrd Bank-Policy Research Working Paper, 1-30.

Rival, L. (2010). Ecuador's Yasuni-ITT Initiative: The old and new values of petroleum. Ecological Economics, (70), 358-365.

Samaniego, P. (2015). La segunda ola de la clase media en el Ecuador: los cambios en la estratificación socioeconómica en el período 2003-13. Quito: Pontificia Universidad Católica del Ecuador.

Samaniego, P., Vallejo, M. C. y Martínez-Alier, J. (2015). Déficits comerciales y déficits físicos en Sudamérica. Aceptado en Revista Iberoamericana de Economía Ecológica, 1-26.

Samaniego, P., Vallejo, M. C. y Martínez-Alier, J. (2017). Commercial and biophysical deficits in South America, 1990-2013. Ecological Economics, 133, 62-73.

Sémbler, C. (2006). Estratificación social y clases sociales: una revisión analítica de los sectores medios. CEPAL-Serie Políticas Sociales, 125, 1-51.

Sen, A. (2000). Libertad y desarrollo. Barcelona: Planeta.

Solimano, A. (2014). Entrepreneurship, the Middle Class, and Social Mobiilty: an Overview of Literature. En E. Lora y F. Castellani (eds.), Entrepreneurship in Latin América: A Step Up The Social Ladder? (pp. 17-50). Washington: BID-Wold Bank.

Stiglitz, J. y Greenland, B. (2014). Creating a Learning Society: A New Approach to Growth, Development, and Social Progress. New York: Columbia University Press.

Szirmai, A. (2005). Agricultural development and rural development. En A. Szirmai, The Dynamics of Socio-Economic Development (pp. 354-425). Cambridge, MA: Cambridge Universtiy Press.

UNESCO. (2010). Informe de la UNESCO sobre la ciencia 2010. París: UNESCO. Walsh, C. (2007). Interculturalidad y colonialidad del poder: un pensamiento y posicioneamiento “otro" desde la diferencia colonial. En S. Castro-Gómez 
y R. Grosfoguel (eds.), El giro descolonial: reflexiones para una diversidad (pp. 47-62). Bogotá: Siglo del Hombre Editores.

Wright, E. O. (1985). Classes. Londres: Verso Editions.

Fecha de recepción: 2018/04/15; Fecha de aceptación: 2018/08/01;

Fecha de publicación: 2018/09/01 


\title{
Políticas públicas de retorno del talento humano calificado de Ecuador y su inserción internacional: el caso de los becarios de doctorado
}

\author{
Public policies for the return of qualified human talent \\ in Ecuador and its international insertion: the case of PhD scholars
}

\author{
Verena Hitner \\ Universidad de los Hemisferios \\ verena.hitner@gmail.com \\ Código Orcid: https://orcid.org/0000-0002-4151-2657 \\ Jesús Tapia López \\ Investigador del Centro Internacional de Estudios Superiores \\ para Latinoamérica-CIESPAL \\ Docente titular de la Universidad Central del Ecuador \\ jetapia@uce.edu.ec \\ Código Orcid: https://orcid.org/0000-0002-6801-851X
}

\begin{abstract}
Resumen
El objetivo de este trabajo es entender el proceso de regreso de científicos a Ecuador, con vistas a producir datos coherentes sobre los motivos de su regreso, sus redes sociales, políticas y disciplinarias en el país, lo que contribuye al esfuerzo de conocer las dinámicas de consolidación disciplinaria de los campos científicos, vinculadas con el exterior y, por lo tanto, el proceso de inserción del país en la nueva división internacional del trabajo. Para eso, el estudio utilizó las bases de datos de retornados ofrecida por la Secretaría de Educación Superior, Ciencia, Tecnología e Innovación (SENESCYT) de Ecuador, para elaboración de una encuesta. El marco muestral de referencia estaba conformada por algo más de 700 $\mathrm{PhD}$. En total, se realizó 126 encuestas, generando un error de estimación del 7,8\% y se recompuso la distribución de los casos levantados por sexo y área de conocimiento con el uso de factores de expansión para dar mayor consistencia a los resultados obtenidos. Con base en la muestra, hemos podido realizar inferencias por sexo y por una variable agrupada de años de finalización del doctorado. Se solicitó información demográfica, laboral y de actividades de investigación en forma muy general. Se concluye sobre la pertinencia de la política pública y sobre el perfil del retornado.
\end{abstract}

Palabras clave

Inserción internacional, talento humano calificado, política pública de educación superior.

Forma sugerida de citar: Hitner, Verena \& Tapia, Jesús (2018). Políticas públicas de retorno del talento humano calificado de Ecuador y su inserción internacional: el caso de los becarios de doctorado. Universitas, 29, pp. 109-132. 


\begin{abstract}
The paper aims to understand the process of return of scientists to Ecuador, with a view to producing coherent data on the reasons for the return of these scientists, their social, political and disciplinary networks in the country, which contributes to the effort of know the disciplinary consolidation dynamics of the scientific fields, its international links, and therefore the process of Ecuador's insertion in the new international division of labor. The study used the databases of returnees offered by the Secretariat of Higher Education, Science, Technology and Innovation (SENESCYT) of Ecuador for the preparation of a survey. The sample frame of reference was made up of a little more than $700 \mathrm{PhD}$. A total of 126 surveys were carried out generating an estimation error of $7.8 \%$ and the distribution of the cases raised by sex and area of knowledge was recomposed with the use of expansion factors to give greater consistency to the results obtained. Based on the sample, we were able to make inferences by sex and by a grouped variable of years of completion of the studies, demographic, labor information and research activities were requested in a very general way. The research concludes on the relevance of public policy and on the profile of returnees.
\end{abstract}

\title{
Keywords
}

International insertion, qualified human talent, public policy of higher education.

\section{Introducción}

El tema de la división internacional del trabajo en el contexto actual es motivo de discusión entre distintos autores (Carlotto y Guedes, 2015; Maniglio, 2017; Vercellone y Cardoso, 2016) y asume diferentes enfoques y perspectivas que muchas veces se complementan. El punto de encuentro de estos análisis es el argumento de que la nueva división internacional del trabajo está asentada sobre los principios cognitivos de un capitalismo posfordista y en el reforzamiento de los derechos de propiedad intelectual (Vercellone y Cardoso, 2016, p. 39). Según esa perspectiva, en los países capitalistas desarrollados la parte del capital llamado inmaterial e intelectual y las actividades de alta intensidad de conocimiento se consolidan como una variable clave para el crecimiento y la competitividad. Además, el sistema de formación e investigación, así como el tiempo libre - condición clave del desarrollo humano y de la experimentación de modelos cooperativos alternativos - "son al menos igual de importantes que el trabajo asalariado y que la esfera mercantil” (Vercellone y Cardoso, 2016, p. 44). 
Según estos mismos autores, una característica importante de ese nuevo sistema es que las actividades intensivas en conocimiento estarían ancladas territorialmente y la competitividad depende cada vez más de un stock de trabajo intelectual. De esa manera, gana relevancia la discusión de las migraciones calificadas y las interpretaciones sobre los flujos migratorios regionales. El fenómeno global de migración y la falta de datos o la producción de datos demasiado heterogéneos genera complejidad para el análisis. Los censos nacionales registran a los científicos extranjeros en forma diferente, contabilizando a todos los nacidos en otro país o bien solo a los que tienen estatuto de inmigrante o visas temporales de residencia. En consecuencia, los procesos de adquisición de la ciudadanía y los alcances de la noción de "extranjeros" obstaculizan de entrada cualquier esfuerzo para apreciar comparativamente la migración de científicos y tecnólogos.

En este sentido, el objetivo de este trabajo es entender el proceso de regreso de científicos al Ecuador, con vistas a producir datos coherentes sobre el los motivos del regreso de estos científicos y sus redes sociales, políticas y disciplinarias en el país; lo que contribuye al esfuerzo de conocer las dinámicas de consolidación disciplinaria de los campos científicos, vinculadas con el exterior y, por tanto, el proceso de inserción del país en la nueva división internacional del trabajo. La investigación busca responder a las preguntas: ¿Cómo se articula la fuga de cerebros en el proceso global de migraciones internacionales? ¿Cuál es su impacto en la brecha de desarrollo entre el norte y el sur? ¿Cuál es la repercusión en las políticas científicas y educativas nacionales del regreso de estos científicos a sus países de origen?

En su estado actual, los datos y conocimientos sobre la fuga de cerebros son insuficientes, pero bastan para evidenciar graves asimetrías en las capacidades de los países de la región para contrarrestarla y mostrar que, en algunos de ellos, se produce un drenaje de competencias más que una circulación. Hubo importantes programas de reinserción, retorno y retención en todos los países de América del Sur, cuyos resultados todavía no se conocen claramente.

\section{La nueva división internacional del trabajo y la fuga de cerebros}

Según la UNESCO, se entiende por "fuga de cerebros" a la parte de la migración calificada que corresponde al personal científico y a los titulares 
de un posgrado. Sobre ese tema se enfatizan esencialmente los efectos perversos acarreados por los intercambios desiguales de recursos humanos altamente calificados (los cuales afectan a un sur genérico), ya que impiden que los países de procedencia obtengan tasas de retorno de las inversiones públicas canalizadas a la educación superior y a la formación de investigadores (UNESCO, 2005, p. 28). En este sentido, la UNESCO ubica a la fuga de cerebros como "uno de los principales problemas que se deben resolver, si se quiere que en las sociedades del futuro el conocimiento sea un bien común compartido" (UNESCO, 2005, p. 30).

El tema da la relación entre la formación académica y el desarrollo es una de las principales consecuencias para los países del sur de la fuga de cerebros. Desde una perspectiva estructuralista, argumenta Sunkel que hay un desajuste entre la naturaleza de nuestro desarrollo industrial y la modernización por un lado y de ellos con el desarrollo del sistema universitario (Sunkel, 1972). En este sentido, la universidad sería un reflejo del carácter alienado del sistema económico nacional. Hay un traslado de los recursos humanos altamente calificados de los países relativamente más pobres, donde las universidades producen especialistas que una economía tecnológicamente dependiente no necesita, hacia las economías céntricas que exigen un número creciente de especialistas calificados que sus propios sistemas universitarios son incapaces de satisfacer.

Así, el desarrollo de la investigación científica y tecnológica en las universidades no puede ser una empresa divorciada de decisiones más fundamentales sobre la naturaleza misma del proceso de desarrollo y, particularmente, de la malla productiva nacional. El problema de desarrollo que se plantea desde la periferia del sistema es, por lo tanto, bastante básico: si nos quedamos en el modelo de desarrollo centro-periferia o si podemos lograr una vía de desarrollo más autónoma.

Más que enfatizar los efectos económicos de la fuga de cerebros en términos de la no recuperación de las inversiones, se subraya que esta fuga atrofia las capacidades instaladas para el desarrollo e inhibe las posibilidades de expansión de la base tecnológica, así como la producción de innovaciones en los países de envío, hipotecando su futuro, además de dificultar su presente. En ese sentido, la fuga de cerebros auspicia una espiral cada vez más desigual de concentración de conocimientos, situando a unos países como productores y a otros como consumidores, en nuevas relaciones de dependencia más que de codesarrollo. Este hecho queda más evidente en la 
coyuntura actual del capitalismo cognitivo, cuando el tema de la acumulación de saberes gana más relevancia.

En el ámbito de los estudios sobre el desarrollo económico y los patrones de inserción y cooperación internacional, el concepto de "sociedad del conocimiento" (Castells, 1999, 2002) ha sido ampliamente utilizado para describir el modelo predominante de organización del capitalismo global, en el que la generación y la aplicación sistemática de conocimiento y tecnología se toman como elementos esenciales de la dinámica económica actual. De hecho, el innegable dinamismo que los sectores intensivos en conocimiento vienen presentando en los últimos años, torna imposible ignorar el impacto que los procesos de innovación ejercen en la economía y, en consecuencia, en el proceso de producción de conocimiento. Reconocer la importancia de la investigación científica, del desarrollo técnico y de la innovación para la dinámica económica actual no significa, sin embargo, aplicar de modo acrítico el paradigma de la sociedad de conocimiento para la comprensión del actual momento del capitalismo, ni tampoco aceptar la inevitabilidad del modelo liberal de inserción internacional que este paradigma promueve (Hitner y Carlotto, 2015).

Es necesario reconocer, antes que nada y como dimensión esencial del problema, que el concepto "sociedad del conocimiento", oriundo de los centros de pensamiento del norte, desempeñó un papel político importante en América Latina durante los años 90 (Godin, 2004; Sharif, 2006), al tornarse el modo hegemónico de comprender el problema de la globalización en la región, contribuyendo para legitimar un patrón específico de inserción internacional basado en el establecimiento de acuerdos de libre comercio y en la a simple adhesión a la liberación económica (Arbix, 2002; Theis, 2013). El predominio del paradigma liberal en los años 90 significó el abandono de una visión estructural del desarrollo. El modelo de desarrollo desvinculaba la producción nacional de la producción académica. Por otra parte, las economías más desarrolladas, usuarias de la ciencia y la tecnología, operan como enormes imanes que atraen cuantiosos flujos de especialistas capaces de generar ideas o productos y de aplicar conocimiento en complejos procesos de producción e innovación.

Sobre el tema de la fuga de cerebros y su impacto sobre el desarrollo nacional de los países de la periferia, argumenta la OCDE en defensa del modelo:

Más recientemente, la literatura ha sugerido que la emigración de trabajadores calificados, como investigadores y científicos, puede estar asociada con 
efectos benéficos con relación a la creación del conocimiento y a su difusión en los países de envío. En particular, la posibilidad de la emigración puede fomentar la creación de habilidades en los países de envío, permitiendo incrementar potencialmente los niveles de capital humano y el crecimiento económico vía "una fuga de cerebros benéfica" [...]. La literatura reciente también señala los beneficios de la circulación de cerebros en lo tocante a transferencia de conocimientos en los países de envío. La circulación de cerebros puede ser referida al retorno de los migrantes calificados en su país de origen después de un periodo afuera o a un modelo de migración temporaria o circulación entre la casa y afuera. [...]. Considerados en conjunto, esos efectos sugieren que los flujos de conocimiento asociados con la emigración de investigadores y científicos pueden proveer beneficios a los países de origen. La literatura sostiene así la idea que la movilidad altamente calificada no es un simple juego de suma cero conforme al cual los países de destino ganan y los de partida pierden. La movilidad de recursos humanos altamente calificados puede ser ventajosa para todos (OCDE, 2008, p. 5).

El análisis de los datos totales de migración indican que en 25 años, la población mundial creció cerca de 40\% (Banco Mundial, 2018), mientras que el número de migrantes aumentó en 59\% (Organización Internacional para las Migraciones, 2018). Así, el 3,3\% de la población mundial es migrante.

\section{Figura 1 \\ Migración mundial (1990-2015)}

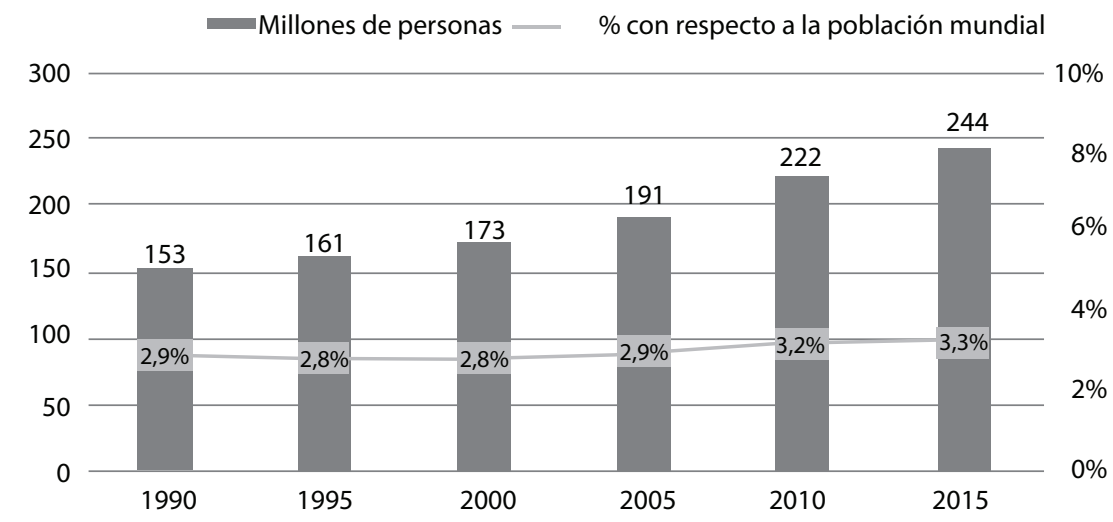

Fuente: el autor a partir de OIM, 2018 
Se estima que en los países de la OECD —-donde ocurre alrededor de $70 \%$ de los intercambios mundiales de bienes y servicios - el número de inmigrantes con una escolaridad de al menos 13 años aumentó en la década pasada de 12 a 20 millones de personas, provenientes en su mayoría de países en desarrollo, quienes se desplazaron en busca de salarios más elevados y de mejores oportunidades laborales o de desarrollo profesional. Aun así, las tasas de desempleo en los países de la OECD de los migrantes (no nativos) es mayor y en algunos casos mucho mayor que las tasas de desempleo de los nativos.

Figura 2

\section{Tasa de empleo 2016}

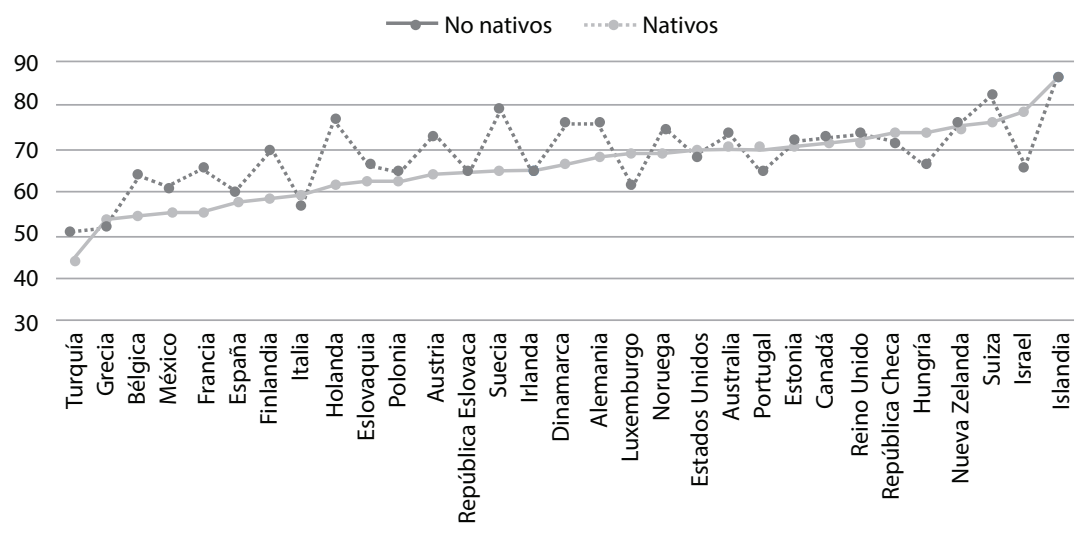

Fuente: el autor a partir de OIM, 2018

Para los migrantes latinoamericanos, EE.UU. sigue siendo el principal destino, seguido por España, con fuerte presencia de sudamericanos, principalmente mujeres con calificación relativamente elevada, y Canadá (Martínez, 2007, p. 41). Este cuantioso éxodo implica, para las naciones emisoras, la transferencia de un valioso recurso humano que los descapitaliza, merma sus capacidades para impulsar el desarrollo económico y social, erosiona su masa crítica y limita sus posibilidades de generar innovaciones. En consecuencia, en esos países, son muchas las voces que han subrayado la necesidad de contener la fuga de talentos y la emigración de personal calificado, así como de paliar sus efectos negativos. 
A pesar de la importancia de la discusión, las estadísticas sobre el fenómeno, en toda la región, siguen siendo imperfectas y no permiten rastrear, con un grado de certidumbre aceptable, cuáles profesionales salen de la región, qué grados tienen, hacia dónde van y qué hacen afuera. Y todavía menos permiten medir las proporciones de aquellos que regresan a su país de origen después de sus estudios en el extranjero. Así, la migración es paradójicamente un asunto cuya percepción social y cultural ha cambiado, en cuanto a escalas de valoración, a la vez que un fenómeno que sigue siendo mal conocido.

En este sentido, el problema de investigación que se plantea tiene que ver, por un lado, con la actual organización de la sociedad del conocimiento y la fuga de cerebros que genera dependencia y no codesarrollo, y por otro, con el regreso de los científicos de alto nivel a sus países de origen que tienen un impacto en la malla productiva nacional. Así, el significado de la sociedad del conocimiento para los países del sur desde el punto de vista de la producción del conocimiento y del impacto del conocimiento producido, se basa en el hecho de que el mundo está dividido en dos "civilizaciones cognitivas": una que produce conocimiento y otra que lo consume. Y el tema es geográfico, una vez que quienes producen el conocimiento en los países centrales no son necesariamente "nacionales", sino extranjeros buscando espacio en otros territorios para producir dicho conocimiento.

Así, por ejemplo, en el caso de los Estados Unidos, la composición de los graduados doctores $(\mathrm{PhD})$ tiene un perfil radicalmente diferente en la comparación de las diferentes áreas de conocimiento.

Si bien en áreas de las ciencias humanas, sociales y las artes el número de nacionales es mucho mayor que el número de graduados extranjeros, en el caso de las ciencias básicas, naturales, tecnologías e ingenierías, la composición se modifica. Los extranjeros tienen protagonismo, ocupando los $30 \%$ del total de graduados doctores, lo que podría tener impacto en la malla productiva nacional.

Es importante mencionar que no existen datos detallados con respeto a la nacionalidad de estos extranjeros o datos que permitan dar seguimiento al impacto real que eso genera en la malla productiva. Es decir, no se puede afirmar con seguridad qué les pasa a estos graduados: si regresan a sus países, si son empleados nacionalmente, si siguen o no en la carrera académica o de investigación. Por eso, estudiar a los retornados de cuarto nivel en Ecuador puede servir para el mapeo que nos permita responder a estar inquietudes. 
Figura 3

Composición graduados doctorado EE.UU. (2017)

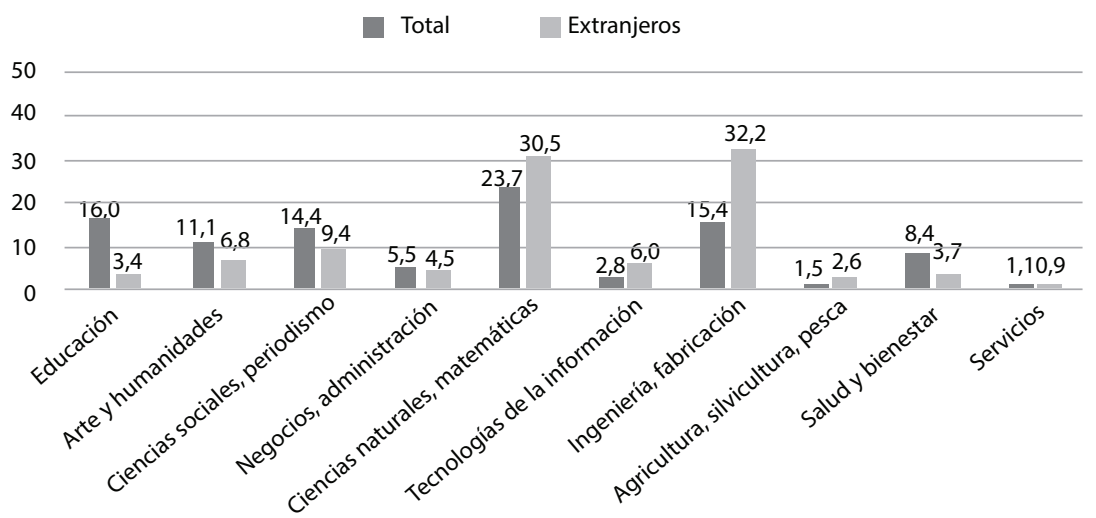

Fuente: el autor a partir de OECD, 2018

\section{Política pública en fortalecimiento del conocimiento y talento humano}

En términos institucionales, el punto de partida de construcción del nuevo sistema de educación superior fue la instauración de la Asamblea Constituyente y la expedición en 2008 de los mandatos sobre la evaluación de Instituciones de Educación Superior (IES), lo que llevó al cierre de varias universidades. El Mandato 14 fue responsable por el cierre de dos universidades de mala calidad en el país, mientras la Constitución determinó la creación de los nuevos entes rectores del sistema: el Consejo de Educación Superior (CES), el Consejo de Evaluación Acreditación y Aseguramiento de la Calidad de la Educación Superior (CEAACES), la Asamblea Universitaria y la SENESCYT, los cuales reemplazaron al Consejo de Educación Superior (CONESUP) y el CONEA (Consejo de Evaluación y Acreditación).

La política pública de fortalecimiento del talento humano en Ecuador, en el período 2010-2017, partía del presupuesto de que para transitar hacia un modelo de desarrollo basado en el conocimiento, se requiere generar procesos de acumulación sostenibles en el tiempo, reduciendo la dependencia del conocimiento científico y la tecnología foránea (SENESCYT, 2017). 
Así, la política de becas se articula, por un lado, hacia el cambio de la educación superior en el país y, por otro lado, al cambio en la matriz productiva. Desde esa perspectiva, uno de los más importantes principios de la educación superior, plasmado en la Ley Orgánica de Educación Superior (LOES), debía ser el de la "pertinencia". Más allá de los análisis normativistas de la política pública realizada en el país, al estudiar los datos concretos se puede notar que hubo un esfuerzo del Estado por garantizar la formación en el exterior de talento humano calificado en "áreas pertinentes" para el desarrollo nacional, que no había en la oferta nacional. De esa manera, la política de becas, formulada a partir de 2012, fue parte de este proceso de fortalecimiento del talento humano.

Fueron dos líneas de becas las ofrecidas por Ecuador desde la SENESCYT. Una de las líneas de becas tenía carácter social, de complemento a la gratuidad de la educación superior nacional; eran becas nacionales para sortear el costo de oportunidad de acceder a la educación de los miembros más pobres de la población. Se trató de una política importante de democratización del acceso a la educación superior, una vez que permitió el acceso de miles de jóvenes a ese nivel de formación. Según datos del Sistema Nacional de Nivelación y Acreditación (SNNA), 7 de cada 10 estudiantes que aceptan cupo en el sistema son primera generación en su hogar en realizar estudios universitarios. Igualmente, el porcentaje de personas de 18 a 24 años que no asisten por razones económicas cayó del 45\% en 2007 al 27\% en 2015.

\section{Figura 4}

Porcentaje de personas de 18 a 24 años que no asisten por razones económicas

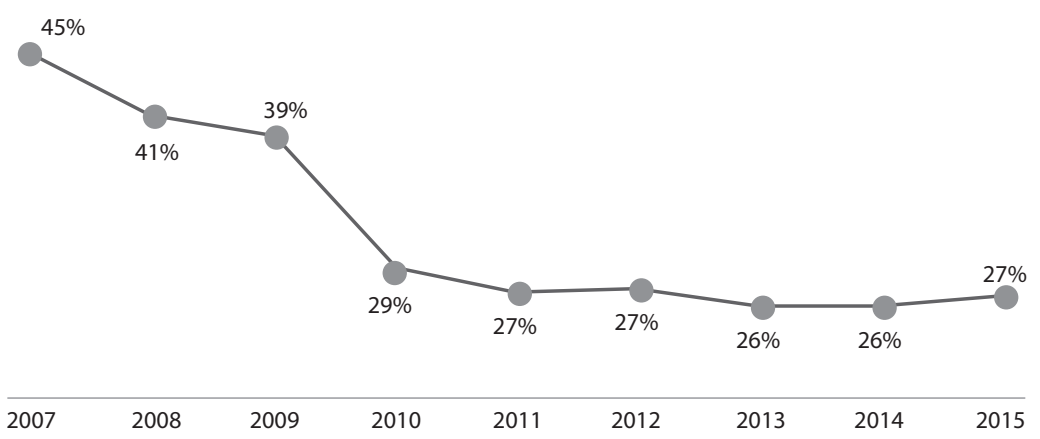


Si bien es necesario reconocer la importancia de esa política para la democratización de la educación superior en el país, ella no es objeto de análisis de este trabajo. En cambio, la política de la segunda línea se basa en la oferta de becas de grado y posgrado en el extranjero, y en estas últimas estará nuestra atención.

Según la SENESCYT, son cuatro los criterios para otorgar estas becas: excelencia individual, progresividad, excelencia institucional y pertinencia. La excelencia individual se refiere a procesos de selección basados en la valoración de las capacidades y cualidades individuales de los potenciales beneficiarios, buscando crear un sistema "meritocrático" que compense el esfuerzo, el conocimiento y la carrera académica. La progresividad implica la consideración de atención para grupos prioritarios, lo que permite incentivar el acceso a la educación de calidad, atención en zonas deprimidas o acciones afirmativas a grupos especiales. La excelencia institucional busca asegurar que los beneficiarios de la política pública ingresen a programas educativos de calidad, por lo que se requiere de herramientas como un listado de universidades de excelencia. Por fin, la pertinencia consiste en la focalización de los recursos públicos hacia áreas prioritarias para el desarrollo del Ecuador como: ciencias de la vida, ciencias de los recursos naturales, ciencias de la producción e innovación, entre otras.

\section{Arquitectura de los programas de becas}

\section{Programa de excelencia}

El programa de becas "Universidades de Excelencia" se ha diseñado para que los interesados puedan realizar estudios en instituciones de educación superior del más alto nivel mundial, para ello se definió una listado de universidades por medio del análisis por área del conocimiento de rankings académicos de reconocimiento mundial: Academic Ranking of World Universities (ARWU), Times Higher Education World University Ranking (THE), QS World University Ranking y SCImago Institutions Rankings. Las becas cubren los rubros de matrícula, colegiatura, manutención, traslado, bibliografía, tesis e investigación y seguro de salud y vida.

La concesión de la beca depende de exclusivamente de la admisión que los postulantes logren en alguna de las universidades involucradas en el programa. El tiempo de compensación (trabajo en territorio ecuatoriano en una 
institución pública o privada) es el doble de la duración total de los estudios de posgrado financiados por el Estado.

\section{Convocatoria abierta}

Es un programa de estudios de cuarto nivel en universidades de excelencia académica en el extranjero, para la posterior transferencia de conocimiento, que posibilite la consecución de los grandes objetivos nacionales, financiados por la SENESCYT. Las becas cubren rubros de matrícula, colegiatura, manutención, traslado, bibliografía, tesis e investigación y seguro de salud y vida. Existe una división por áreas de priorización para su adjudicación. Tal política utiliza una lista modificada de la división de saberes hecha por la UNESCO y se enfoca en las siguientes áreas: educación; artes; ciencias naturales, matemáticas y estadística; tecnologías de la información y de la comunicación; ingenierías, industria y construcción; agricultura, silvicultura, pesca y veterinaria; salud y bienestar. Las áreas de ciencias sociales, psicología, administración y demás quedaron descartadas desde 2014. ${ }^{1}$ Anteriormente, había una ponderación del número de becarios para este tipo de estudios, del $10 \%$ del total de becas asignadas, pero esta posibilidad se ha eliminado.

El proceso de concesión de la beca incluye la aprobación de una evaluación de aptitudes y conocimientos y una entrevista. Por eso, para obtener la beca, después de la postulación, quienes hayan sido preseleccionados, se someten al Examen de Ingreso a Posgrado (EXAIP), el mismo que mide capacidad verbal, capacidad lógico-matemática, conocimientos en desarrollo de proyectos y conocimientos en inglés. Se aprueba con un $75 \%$ de aciertos en la parte general y $60 \%$ en la sección de inglés.

Después de realizar sus estudios, los becarios vuelven al país para la etapa de compensación, por el doble de tiempo de la duración total de los estudios de posgrado. Después de esta etapa, el becario ya no está vinculado de ninguna manera con el Estado por concepto de la beca y queda en situación de libre movilidad laboral.

1 En este punto es importante mencionar que, para el cuarto nivel, hubo una política de fortalecimiento de los programas nacionales en áreas de ciencias humanas y sociales. 


\section{Programa Globo Común}

A través del Programa Globo Común, el Gobierno en conjunto con instituciones y Gobiernos de países amigos, otorgan becas para cursar estudios de educación superior con altos estándares de calidad académica a nivel internacional, con el objetivo de fortalecer el talento humano ecuatoriano en diversas áreas del conocimiento. Se cuenta con dos tipos de convocatorias: becas financiadas completamente por otros países y becas cofinanciadas entre el Ecuador y otros países. En este tipo de becas las directrices no dependen, al menos en forma exclusiva, de las políticas de la SENESCYT.

\section{Reconstruyendo el perfil de los programas}

Los programas de becas de estudios en el extranjero han otorgado un total de 19586 becas al exterior desde 2007, constituyendo en el programa de financiamiento de estudios más importante de la historia del Ecuador que algún Gobierno haya emprendido, superando 82 veces lo otorgado en los once años anteriores. Además, constituye en uno de los programas de especialización más ambiciosos de la región.

\section{Figura 5}

Becas de pregrado y posgrado internacionales adjudicadas (total acumulado 2007-2016)

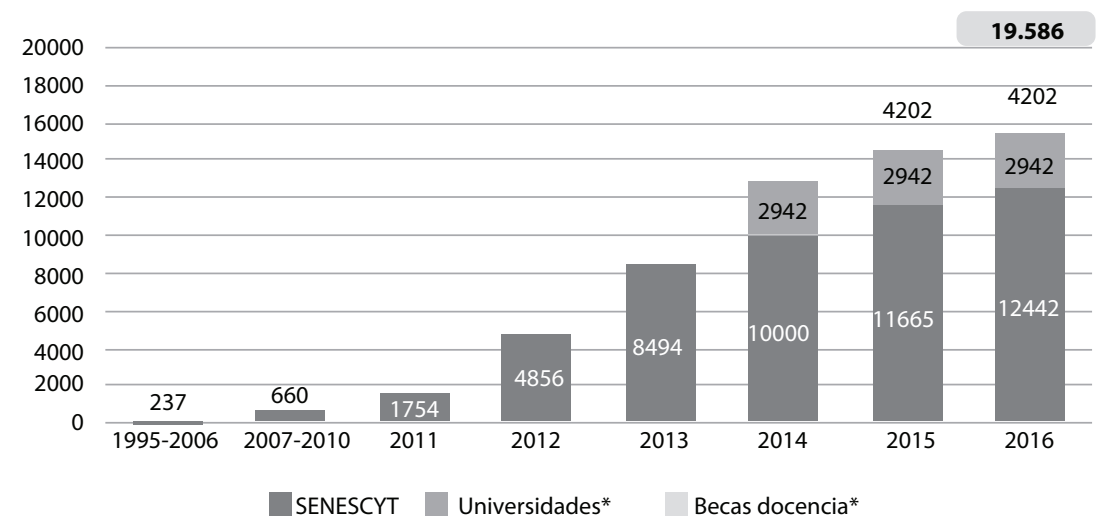

Fuente: SENESCYT, diciembre 2016 
Hasta el mes de diciembre del año 2016 se reportaron 4818 becarios que realizaron sus estudios de educación superior y han retornado al país, de los cuales el 97,6\% se encuentra en etapa de compensación: el 2\% se encuentra en periodo de gracia de acuerdo a lo establecido en las bases de los programas (tiempo en el cual realizan su vinculación al sector laboral) y solamente el 0,4\% solicitó diferimiento de compensación.

\section{Figura 6 \\ Porcentaje de becas según nivel de estudios}

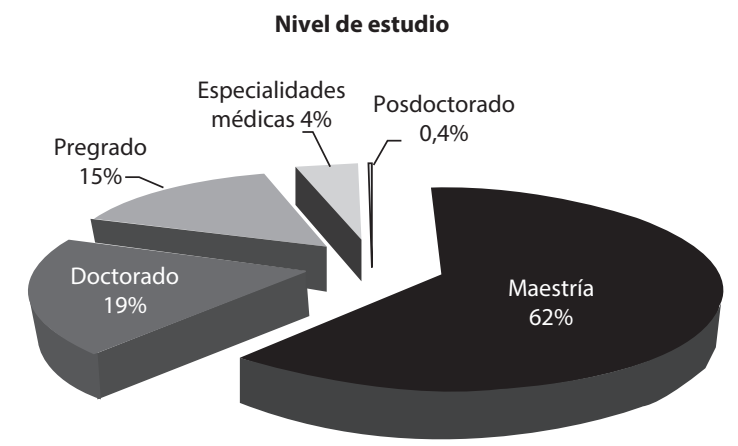

Fuente: Subsecretaría de Fortalecimiento del Conocimiento y Talento Humano

Según la Subsecretaría de Fortalecimiento del Conocimiento y Talento Humano, de todas las becas ofrecidas para cuarto nivel, $62 \%$ corresponden a becas de maestría, $19 \%$ a becas de doctorado y $0,4 \%$ a becas de posdoctorado. Se constata que las becas de pregrado corresponden solo a un $15 \%$, lo que indica que el énfasis de la política es hacia la formación de cuarto nivel. Todos estos programas de formación en el exterior presuponían un período de compensación nacional, es decir, los estudiantes que salían al exterior estaban obligados a retornar al país después de cumplido el período de la beca.

A pesar de que el flujo internacional de migración para estudios de cuarto nivel está dirigido sobre todo a EE.UU. e Inglaterra (Maniglio, 2017), ${ }^{2}$

2 Según los datos de la OCDE presentados por el autor, Estados Unidos captura el mayor número de estudiantes internacionales a nivel de maestría y doctorado (26\% del total), seguido por el Reino Unido (15\%), Francia (10\%), Alemania (10\%) y Australia (8\%) (Maniglio, 2017, p. 35). 
ese fenómeno no ocurre entre los estudiantes ecuatorianos. Para ellos, a pesar del Programa Enseñanza de Inglés, que otorga becas con objetivo de perfeccionar el nivel de esta lengua de los docentes y desarrollar sus técnicas de enseñanza mediante una inmersión total en países de habla inglesa, la opción de los estudiantes de cuarto nivel del país sigue siendo mayoritariamente a países de habla hispánica. Los principales destinos son España y los países de América Latina. En el caso de los países latinoamericanos, el porcentaje de estudiantes que decide ir a Brasil es muy bajo.

Para estudios de doctorado la participación de EE.UU. e Inglaterra es aún menor, correspondiendo a $11,3 \%$ en el caso de EE.UU. y solo $4,5 \%$ de los estudiantes tienen a Inglaterra como destino para sus estudios de doctorado. Para estudios de maestría, llama la atención la participación de Australia, país que recibe el 13,8\% de nuestros estudiantes de cuarto nivel.

Figura 7

\section{País de estudios becarios de cuarto nivel retornados (2017)}
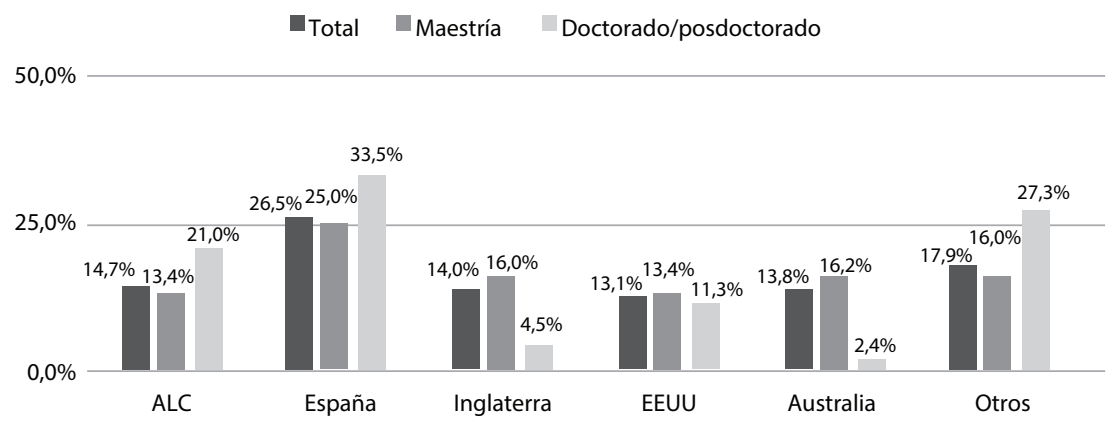

Fuente: Subsecretaría de Fortalecimiento del Conocimiento y Talento Humano

Si bien la lengua puede ser una barrera importante para los estudiantes de cuarto nivel que han retornado al país, es interesante notar que desde el punto de vista de las carreras que escogen para estudiar afuera, la opción para maestría y doctorado sigue la tendencia de los extranjeros graduados en doctorado en las universidades de EE.UU. Son también carreras pertinentes, con impacto en la malla productiva nacional. La principal opción para estudios de cuarto nivel es en las áreas de ingenierías, seguida por ciencias natu- 
rales, matemáticas y estadísticas. De los que salen a esas últimas, la mayoría va hacer su doctorado, correspondiendo a un $30 \%$.

Tabla 1

Distribución de los becarios retornados de cuarto nivel por área de conocimiento y nivel de formación (2017)

\begin{tabular}{|l|l|l|l|}
\hline & \multirow{2}{*}{ Total } & \multicolumn{2}{c|}{ Nivel de formación } \\
\cline { 3 - 4 } & & Maestría & \multicolumn{1}{c|}{$\begin{array}{c}\text { Doctorado/ } \\
\text { Posdoctorado }\end{array}$} \\
\hline Educación & $3,3 \%$ & $3,6 \%$ & $1,5 \%$ \\
\hline Artes y humanidades & $6,8 \%$ & $6,9 \%$ & $6,6 \%$ \\
\hline Ciencias sociales, periodismo e información & $16,1 \%$ & $16,9 \%$ & $12,4 \%$ \\
\hline Administración de empresas y derecho & $5 \%$ & $5,8 \%$ & $1,2 \%$ \\
\hline Ciencias naturales, matemáticas y estadística & $19,9 \%$ & $17,8 \%$ & $30 \%$ \\
\hline TIC & $10,3 \%$ & $10,1 \%$ & $11,3 \%$ \\
\hline Ingeniería, industria y construcción & $29,7 \%$ & $30,9 \%$ & $23,8 \%$ \\
\hline Agricultura, silvicultura, pesca y veterinaria & $3,9 \%$ & $2,8 \%$ & $8,9 \%$ \\
\hline Salud y bienestar & $5 \%$ & $5,1 \%$ & $4,3 \%$ \\
\hline Total & $100 \%$ & $100 \%$ & $100 \%$ \\
\hline
\end{tabular}

Fuente: Subsecretaría de Fortalecimiento del Conocimiento y Talento Humano

Otro análisis importante es la relación entre género y pertinencia de los estudios. Los becarios retornados de cuarto nivel son, en la mayoría hombres. Del total de retornados, $57,9 \%$ son hombres, mientras que $42,1 \%$ son mujeres. La brecha se amplía en los estudios de doctorado y de posdoctorado, donde el $65,1 \%$ son hombres.

A pesar de la brecha de género existente, un dato importante sobre el perfil de los retornados de cuarto nivel es que de las mujeres que salen para sus estudios de doctorado, salen para áreas de alta pertinencia para el país. Indicando que la política de pertinencia propuesta por el estado ha funcionado. 


\section{Figura 8 \\ Becarios retornados por género (2017)}

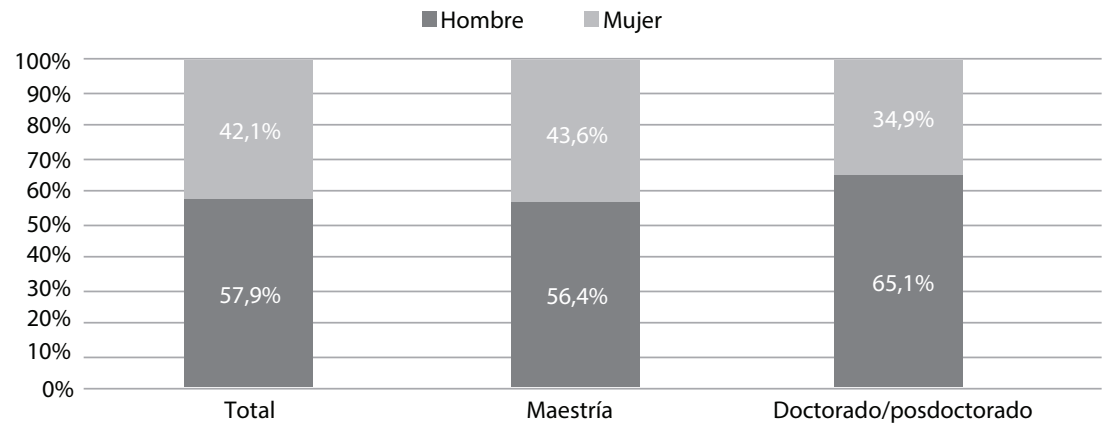

Fuente: Subsecretaría de Fortalecimiento del Conocimiento y Talento Humano

\section{Tabla 2}

Distribución de los becarios retornados de cuarto nivel por área del conocimiento, género y nivel de formación (2017)

\begin{tabular}{|c|c|c|c|c|c|}
\hline & \multirow{3}{*}{ Total } & \multicolumn{4}{|c|}{ Nivel de formación } \\
\hline & & \multicolumn{2}{|c|}{ Maestría } & \multicolumn{2}{|c|}{$\begin{array}{c}\text { Doctorado/ } \\
\text { Posdoctorado }\end{array}$} \\
\hline & & Hombre & Mujer & Hombre & Mujer \\
\hline Educación & $3,3 \%$ & $2,2 \%$ & $5,5 \%$ & $1,4 \%$ & $1,7 \%$ \\
\hline Artes y humanidades & $6,8 \%$ & $5,9 \%$ & $8,2 \%$ & $7,3 \%$ & $5,1 \%$ \\
\hline Ciencias sociales, periodismo e información & $16,1 \%$ & $13,5 \%$ & $21,3 \%$ & $8,7 \%$ & $19,2 \%$ \\
\hline Administración de empresas y derecho & $5 \%$ & $5,8 \%$ & $5,9 \%$ & $1,1 \%$ & $1,3 \%$ \\
\hline Ciencias naturales, matemáticas y estadística & $19,9 \%$ & $17,4 \%$ & $18,2 \%$ & $28,6 \%$ & $32,5 \%$ \\
\hline TIC & $10,3 \%$ & $12,3 \%$ & $7,4 \%$ & $12,6 \%$ & $9 \%$ \\
\hline Ingeniería, industria y construcción & $29,7 \%$ & $37,5 \%$ & $22,5 \%$ & $27,9 \%$ & $16,2 \%$ \\
\hline Agricultura, silvicultura, pesca y veterinaria & $3,9 \%$ & $2,4 \%$ & $3,5 \%$ & $9,6 \%$ & $7,7 \%$ \\
\hline Salud y bienestar & $5 \%$ & $3,1 \%$ & $7,7 \%$ & $2,7 \%$ & $7,3 \%$ \\
\hline Total & $100 \%$ & $100 \%$ & $100 \%$ & $100 \%$ & $100 \%$ \\
\hline
\end{tabular}

Fuente: Subsecretaría de Fortalecimiento del Conocimiento y Talento Humano 
De las mujeres que salen del país para estudios de doctorado y posdoctorado, $32,5 \%$ se decide por estudios en ciencias naturales, matemáticas y estadística. De las que salen para estudiar la maestría, 37,5\% van a áreas de ingenierías. Eso no se reproduce en la distribución nacional, sea a nivel de posgrado o pregrado. Nacionalmente, la opción de las mujeres sigue siendo por las humanidades, salud y bienestar.

\section{Percepción de beneficiarios del programa de becas internacionales}

Además del trabajo de análisis de los datos agregados realizado anteriormente, una contribución importante de esta investigación fue la realización de encuestas con los doctores retornados al país. El conjunto de individuos objeto de la encuesta está conformado por aquellos beneficiaros que ya culminaron sus estudios de doctorado hasta mediados del año 2017,3 el marco muestral de referencia que estaba conformado por algo más de $700 \mathrm{PhD}$.

Inicialmente se estableció una muestra con un error del 5\%, considerando la composición por área de conocimiento, pero la acogida de 126 personas no permitía un análisis representativo con respeto a las áreas de conocimiento, generando un error de estimación del 7,8\%. Se recompuso la distribución de los casos levantados por sexo y área de conocimiento con el uso de factores de expansión para dar mayor consistencia a los resultados obtenidos. En todos los casos se realizaron inferencias por sexo y por una variable agrupada de años de finalización del doctorado, ${ }^{4}$ se solicitó también información demográfica, laboral y de actividades de investigación en forma muy general.

Como resultado de la encuesta se pude determinar que, a nivel demográfico, siete de cada diez doctores están casados o unidos, las mujeres en menor medida que los hombres (cerca de 15 puntos menos y algo más de dieciséis puntos si consideramos la tenencia de hijos). Es decir, entre los retornados, $71,7 \%$ de los hombres tienen hijos y solo $54,9 \%$ de las mujeres.

3 Se tuvo acceso a la información de contacto de becarios retornados hasta esa fecha.

4 Se consideraron dos grupos: quienes culminaron su programa hasta $2015(55 \%)$ y quienes terminaron entre 2016 y 2017 (45\%), con la finalidad de verificar si existen diferencias en el tiempo transcurrido luego de terminar sus estudios. 
Otro dato importante que demuestra la diferencia de género es que, de los retornados, existen más mujeres que hombres que no trabajan al regresar, a pesar que las que trabajan no tardan más tiempo que los hombres en conseguir el empleo. Es decir, el 95\% de los beneficiarios del programa se encuentran trabajando, pero la proporción de mujeres que declaran estar desempleadas $(10,5 \%)$ es cuatro veces mayor a la de los hombres. Quienes han retornado en los años 2016 y 2017 tienen tres veces más posibilidades de encontrarse desempleados $(7,7 \%)$. Apenas un $6 \%$ se encuentran empleados en empresas privadas, cerca del $90 \%$ trabajan en universidades y ni el $1 \%$ declara estar vinculado a un instituto de investigación.

\section{Tabla 3}

\section{Ocupación de los retornados: distribución por sexo y año de retorno}

\begin{tabular}{|l|c|c|c|c|c|}
\hline \multirow{2}{*}{} & \multirow{2}{*}{ Total } & \multicolumn{2}{|c|}{ Sexo } & \multicolumn{2}{c|}{ Año de retorno } \\
\cline { 3 - 6 } & & Hombre & Mujer & Antes de 2016 & $\mathbf{2 0 1 6}$ y 2017 \\
\hline No trabaja & $5,1 \%$ & $2,5 \%$ & $10,5 \%$ & $2,7 \%$ & $7,7 \%$ \\
\hline Sector privado & $32 \%$ & $32 \%$ & $31,9 \%$ & $35,5 \%$ & $28 \%$ \\
\hline Sector público & $62,9 \%$ & $65,5 \%$ & $57,7 \%$ & $61,8 \%$ & $64,2 \%$ \\
\hline & $100 \%$ & $100 \%$ & $100 \%$ & $100 \%$ & $100 \%$ \\
\hline Casos muestrales & 126 & 80 & 46 & 65 & 61 \\
\hline
\end{tabular}

Fuente: el autor

\section{Tabla 4}

Lugar donde trabajan los retornados: distribución por sexo y año de retorno

\begin{tabular}{|l|c|c|c|c|c|}
\hline \multirow{2}{*}{} & \multirow{2}{*}{ Total } & \multicolumn{2}{|c|}{ Sexo } & \multicolumn{2}{c|}{ Año de retorno } \\
\cline { 3 - 6 } & & Hombre & Mujer & Antes del 2016 & El 2016 y 2017 \\
\hline Universidad & $86,7 \%$ & $82,6 \%$ & $95,9 \%$ & $89,5 \%$ & $83,6 \%$ \\
\hline Instituto de investigación & $0,8 \%$ & $1,1 \%$ & & & $1,7 \%$ \\
\hline Institución pública & $6,3 \%$ & $8,2 \%$ & $2 \%$ & $5,7 \%$ & $7 \%$ \\
\hline Institución privada & $5,5 \%$ & $7,0 \%$ & $2,1 \%$ & $3,5 \%$ & $7,8 \%$ \\
\hline NR & $0,7 \%$ & $1,1 \%$ & & $1,4 \%$ & \\
\hline & $100 \%$ & $100 \%$ & $100 \%$ & $100 \%$ & $100 \%$ \\
\hline Casos muestrales & 119 & 78 & 41 & 63 & 56 \\
\hline
\end{tabular}

Fuente: el autor 
Entre quienes declaran ser docentes a nivel general, el 28\% son ocasionales y el $36 \%$ en el caso de los que retornaron ente el 2016 y 2017, esto último podría sugerir que existen dificultades para obtener la titularidad en una universidad, pero en general, se vinculan inmediatamente al campo laboral, en promedio obtuvieron un empleo un mes luego de retornar. Los retornados no necesariamente ocupan todo su tiempo de dedicación a actividades de investigación, en el caso de quienes declaran ser docentes, una quinta parte de los $\mathrm{PhD}$ no realiza investigación y cerca de la cuarta parte a nivel general. Las mujeres se encuentran más satisfechas que los hombres con su salario, esta diferencia es estadísticamente significativa. Uno de cada cinco doctores recibe incentivos económicos adicionales por sus logros u objetivos alcanzados, pero en menor medida mujeres y retornados en los años 2016 y 2017.

En relación a las diferencias salariales que pueden existir entre hombres y mujeres, el $80 \%$ de hombres y el $73 \%$ de mujeres consideran que la remuneración salarial para mujeres es similar a la de sus pares masculinos por la realización de las mismas actividades profesionales, sin embargo, no existen diferencias significativas al $1 \%$ en estas proporciones. Asimismo, no existen diferencias en las proporciones de tiempo que los hombres y mujeres dedican a labores domésticas.

Como se mencionó, la política implementada por la SENESCYT busca que el capital humano retorne al país. De acuerdo a los entrevistados, el $60 \%$ de beneficiados hubiese retornado aún si la política de compensación del país no hubiera restringido su posibilidad de quedarse en el exterior y entre quienes no hubiese regresado principalmente no lo hubiesen hecho por oportunidades laborales y de profesionalización. Es importante destacar que la mitad de becarios retornados entre el 2016 y 2017 declara tener la intención de una vez concluido el periodo de compensación de su beca trabajar dentro del país y un 62\% entre quienes retornaron antes del 2016.

El número de publicaciones y de participaciones en eventos científicos por año se triplica luego de obtener su doctorado y dentro de las principales dificultades, según la percepción de los entrevistados, están la falta de financiamiento e infraestructura: 
Tabla 5

En su opinión ¿cuáles son las barreras más importantes que enfrenta la investigación en su área de conocimiento? (múltiple)

\begin{tabular}{|c|c|c|c|c|c|}
\hline & \multirow[b]{2}{*}{ Total } & \multicolumn{2}{|c|}{ Sexo } & \multicolumn{2}{|c|}{ Año de retorno } \\
\hline & & Hombre & Mujer & $\begin{array}{l}\text { Antes } \\
\text { de } 2016\end{array}$ & $\begin{array}{r}2016 \\
\text { y } 2017\end{array}$ \\
\hline Financiamiento & $61 \%$ & $65 \%$ & $53,1 \%$ & $62,4 \%$ & $59,5 \%$ \\
\hline Infraestructura & $21,2 \%$ & $23 \%$ & $17,6 \%$ & $18,9 \%$ & $23,8 \%$ \\
\hline Tiempo & $15,7 \%$ & $14,3 \%$ & $18,6 \%$ & $16,8 \%$ & $14,4 \%$ \\
\hline $\begin{array}{l}\text { Falta de insumos para investigación (bases } \\
\text { de datos, bibliografía, acceso a literatura de } \\
\text { relevancia científica) }\end{array}$ & $11,5 \%$ & $10,3 \%$ & $13,9 \%$ & $8,1 \%$ & $15,2 \%$ \\
\hline Burocracia y trámites administrativos & $10,7 \%$ & $10,1 \%$ & $12 \%$ & $15 \%$ & $5,9 \%$ \\
\hline Falta de apoyo institucional & $10,6 \%$ & $13,3 \%$ & $5,3 \%$ & $11,3 \%$ & $9,9 \%$ \\
\hline Falta de apoyo gubernamental & $10 \%$ & $9,5 \%$ & $10,9 \%$ & $11,6 \%$ & $8,1 \%$ \\
\hline $\begin{array}{l}\text { Sobre carga laboral en docencia y actividades } \\
\text { administrativas }\end{array}$ & $8,2 \%$ & $7,0 \%$ & $10,5 \%$ & $8,2 \%$ & $8,2 \%$ \\
\hline Escasez de investigadores y de personal técnico & $8 \%$ & $7,7 \%$ & $8,7 \%$ & $6,7 \%$ & $9,5 \%$ \\
\hline $\begin{array}{l}\text { Conciencia de la importancia de la investigación } \\
\text { para el país. }\end{array}$ & $7,2 \%$ & $8,1 \%$ & $5,4 \%$ & $9,2 \%$ & $5 \%$ \\
\hline Falta de incentivos para la investigación & $6,9 \%$ & $8,1 \%$ & $4,4 \%$ & $8,2 \%$ & $5,4 \%$ \\
\hline $\begin{array}{l}\text { Falta de asociaciones/grupos/redes de } \\
\text { investigadores en el país. }\end{array}$ & $5,1 \%$ & $5,7 \%$ & $4,0 \%$ & $3,8 \%$ & $6,6 \%$ \\
\hline $\mathrm{N} / \mathrm{R}$ & $5 \%$ & $2,3 \%$ & $10,4 \%$ & $4,9 \%$ & $5 \%$ \\
\hline Procesos de evaluación ineficientes/mediocres & $4,4 \%$ & $4,8 \%$ & $3,7 \%$ & $5,6 \%$ & $3,1 \%$ \\
\hline $\begin{array}{l}\text { Falta de plazas de empleo bien remuneradas para } \\
\text { investigadores. }\end{array}$ & $3,9 \%$ & $4,9 \%$ & $1,8 \%$ & $4,3 \%$ & $3,4 \%$ \\
\hline Falta de cultura de investigación & $3,6 \%$ & $4,7 \%$ & $1,5 \%$ & $5,6 \%$ & $1,5 \%$ \\
\hline Idioma & $3,5 \%$ & $2,5 \%$ & $5,6 \%$ & $3,5 \%$ & $3,5 \%$ \\
\hline Medios de publicación & $2,8 \%$ & $4,3 \%$ & & $2,2 \%$ & $3,6 \%$ \\
\hline Inestabilidad laboral & $2,4 \%$ & $2,4 \%$ & $2,5 \%$ & $1,6 \%$ & $3,4 \%$ \\
\hline Cooperación interinstitucional & $2,2 \%$ & $2,4 \%$ & $1,8 \%$ & $3 \%$ & $1,3 \%$ \\
\hline Legislación/normativa & $2,2 \%$ & $2,3 \%$ & $1,8 \%$ & $1,2 \%$ & $3,3 \%$ \\
\hline Compras públicas & $1,5 \%$ & $2,3 \%$ & & $1,5 \%$ & $1,6 \%$ \\
\hline Visión & $1,5 \%$ & $1,1 \%$ & $2,5 \%$ & $2,9 \%$ & \\
\hline Competencia desleal & $0,8 \%$ & $1,2 \%$ & & $1,6 \%$ & \\
\hline Casos muestrales & 126 & 80 & 46 & 65 & 61 \\
\hline
\end{tabular}

Fuente: el autor 


\section{Conclusiones}

A lo largo del texto quisimos demostrar que hubo pertinencia en la política pública de becas de cuarto nivel para estudios en el exterior y que el retorno de los becarios tiene impacto en la malla productiva nacional, una vez que el $95 \%$ de los retornados están empleados y trabajando. Ese proceso puede tener, en el largo plazo, impacto en el tipo de inserción internacional periférica del país.

Se pudo demostrar que la institucionalización del sistema se refleja en un mejor ambiente para plantear relación investigación-docencia-innovación, ya que hubo un claro cambio en la estructura de la pertinencia de los estudios de los becarios. La encuesta, a pesar del margen de error, nos permitió cerrar una brecha con respeto al conocimiento adquirido en el país para analizar, con datos científicos, qué hacen los retornados, dónde se ubican en términos laborales, las razones por las que han regresado y su impacto en la malla productiva nacional.

Históricamente los flujos migratorios han consolidado la geografía de la dependencia entre países que se denominaron desarrollados y subdesarrollados. Una dependencia que sigue creciendo y produciendo otras estructuras de desigualdad como la gobernanza corporativa (Bebchuck y Roe, 2014) y la gobernanza cognitiva (Maniglio, 2016). En ese sentido, la política pública de formación en el exterior pertinente y de retorno de cerebros buscó enfrentar la dimensión cognitiva de vuestra dependencia histórica y del colonialismo estructurante del sistema mundial.

Si bien estas acciones creativas han sido viables gracias a la peculiar composición de fuerzas políticas alternativas en los Estados de la región, tienen orígenes que corresponden a disputas sociales que precedieron a la llegada de esos Gobiernos al poder. Si bien sea verdad que esas son políticas que buscan una mejor y más soberana inserción en el sistema, si no se mantienen en la estructura del Estado, pueden estar amenazadas por la llegada de grupos de poder que encuentran su sentido en la dependencia, por lo cual buscan revertir procesos de autonomía cognitiva que se han empezado a gestar en el país. La disputa por la soberanía cognitiva debe ser encarada como una de las principales disputas de un país. 


\section{Bibliografía}

Arbix, G. (2002). Da liberalização ceda dos anos 90 à construção estratégica do desenvolvimento. Tempo Social, 14(1).

Bebchuck, L. y Roe, M. (2014). Una teoría sobre dependencia de caminos en propiedad y gobierno corporativo, TH-MIS-Revista de Derecho, 46, 47-75.

Carlotto, M. C. y Guedes Pinto, J. P. (2015). A divisão internacional do trabalho no século XXI: um estudo sobre o peso da propriedade intelectual na relação EUA-América Latina. Carta Internacional USP, 10, 94.

Castells, M. (1999). A sociedade em rede. São Paulo: Paz e Terra.

Castells, M. (2002). O novo paradigma do desenvolvimento e suas instituições. En A. C. Castro (ed.), Desenvolvimento em debate (pp. 397-416). Rio de Janeiro: BNDES.

Estadísticas OECD. Recuperado de https://bit.ly/1tMGu9F/

Godin, B. (2004). The new economy: what the concept owes to the OECD. Research Policy, 33, 679-90.

Hitner, V. y Carlotto, M. (2015) Padrões de cooperação, padrões de inserção: a cooperação técnica agrícola entre Brasil e Venezuela para além da inserção na “sociedade do conhecimento". Revista Oikos, 13(2). Río de Janeiro: UFRJ.

International Organization for Migration. (2018). Worl Migration Report 2018. Recuperado de https://bit.ly/2OGhnnp/

Maniglio, F. (2016). Trabajo y plustrabajo en la sociedad del conocimiento. Algunas evidencias desde los procesos de financiarización de la economía. En Francisco Sierra Caballero; Francesco Maniglio (comps.), Capitalismo financiero y comunicación (pp. 51-79). Quito, Ecuador: Ediciones Ciespal.

Maniglio, F. (diciembre, 2017). La injusticia cognitiva en la división internacional del conocimiento: el caso de la migración altamente cualificada. Revista Crítica de Ciências Sociais, 114, 27-46.

Martínez, J. (2007). Tendencias y rasgos salientes de la migración internacional en América Latina y el Caribe. En P. Leite, S. Zamora y L. Acevedo (eds.), Migración internacional y desarrollo en América Latina y el Caribe. México DF: Consejo Nacional de Población.

OCDE. (2008). Adjusting to the global competition for talent . París: OCDE-Directorate for Science, Technology and industry, DSTI/STP.

SENESCYT. (2017). Informe de fin de gestión. Subsecretaría de Ciencia, Tecnología e Innovación. Mimeografiado. 
Sharif, N. (2006). Emergence and development of the national innovation systems concept. Research Policy, 35, 745-66.

Sunkel, O. (2011/1972). La universidad latinoamericana ante el avance científico y técnico; algunas reflexiones. En: J. Sabato, El pensamiento latinoamericano en la problemática ciencia-tecnología-dependencia. Buenos Aires: Ediciones Biblioteca Nacional/PLACTED.

Theis, I. M. (2013). A sociedade do conhecimento realmente existente da perspectiva do desenvolvimento desigual. Urbe, Revista Brasileira de Gestão Urbana, 5(1), 133-148.

UNESCO. (2005). Hacia las sociedades del conocimiento. París: Ediciones UNESCO. Recuperado de https://bit.ly/1nlFjcZ/

Vercellone, C. y Cardoso, P. (2016-2017). Nueva división internacional del trabajo, capitalismo cognitivo y desarrollo en América Latina. Chasqui, 133(diciembre-marzo), 38-59.

Fecha de recepción: 2018/04/14; Fecha de aceptación: 2018/07/24;

Fecha de publicación: 2018/09/01 


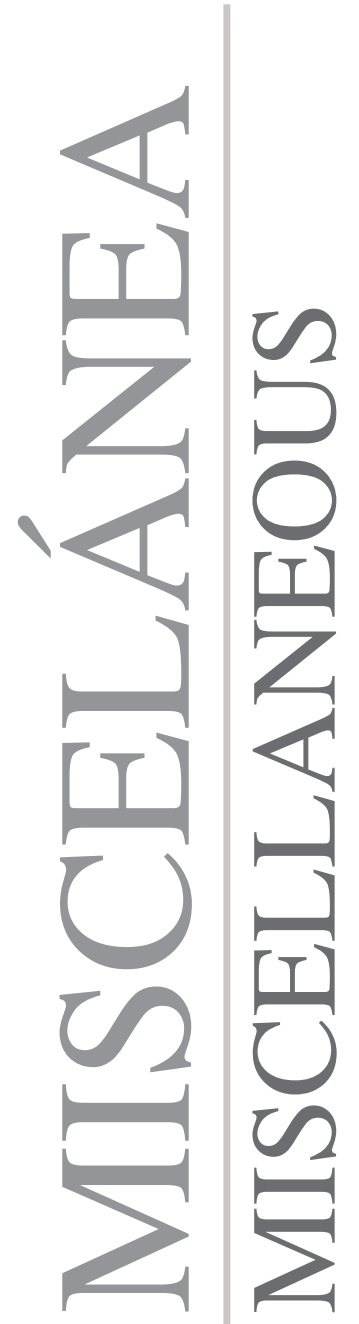





\title{
Análisis comparativo del framing mediático en agencias internacionales de noticias Oriente-Occidente. Estudio de caso: Atentado al aeropuerto de Estambul
}

\section{Comparative analysis of media framing in international news agencies east-west. Case Study: Attack at Istanbul airport}

\author{
Sabina Civila de Dios \\ Investigadora de la Universidad de Cádiz, España \\ sabicivila@gmail.com \\ Código Orcid: https://orcid.org/0000-0001-6059-9893 \\ Luis M. Romero-Rodríguez \\ Profesor e investigador de la Universidad Internacional de La Rioja, España \\ luismiguel.romero@unir.net \\ Código Orcid: https://orcid.org/0000-0003-3924-1517
}

\begin{abstract}
Resumen
Las realidades sociales son constructos discursivos, por lo que las actitudes y representaciones son el reflejo de un enfoque informativo. En este sentido, las brechas culturales y lingüísticas entre distintas civilizaciones, aunado a una construcción discursiva de naturaleza bélica, pudieren estar creando el caldo de cultivo para un enfrentamiento continuo entre Oriente y Occidente. La presente investigación analiza los diferentes encuadres retóricos de las agencias internacionales de noticias Reuters, Al Arabiya, Al Jazeera y Associated Press sobre el atentado terrorista al aeropuerto de Estambul (Turquía) el 28 de julio de 2016. Se realiza un estudio cualitativo de las figuras retóricas y los tópicos más repetidos en una muestra de 144 titulares relacionados con el atentado. El poder de los medios de comunicación en la opinión pública y construcción de la realidad generan un debate sobre cómo se redactan estas noticias y sus efectos. El objetivo es comparar los encuadres entre las agencias de ambas civilizaciones e identificar los estereotipos proyectados y si se contribuye a la espectacularización del conflicto. Se obtiene como resultado principal que no hay diferencias discursivas significativas, lo que lleva a concluir que tanto en los medios y agencias internacionales de Oriente medio como de Occidente se utilizan figuras retóricas para producir cierto efecto en la población, entre las que resaltan los eufemismos, disfemismos, la demonización y la polarización discursiva, recursos que sirven para enfatizar el miedo y crear aún mayores brechas de significación social.
\end{abstract}

Forma sugerida de citar: Civila de Dios, Sabina, \& Romero-Rodríguez, Luis M. (2018). Análisis comparativo del framing mediático en agencias internacionales de noticias Oriente-Occidente. Estudio de caso: Atentado al aeropuerto de Estambul. Universitas, 29, pp. 135-156. 


\title{
Palabras clave
}

Encuadre informativo, agencias de noticias, estereotipos, discurso bélico, demonización, encuadres retóricos.

\begin{abstract}
Social realities are discursive constructs, so that attitudes and representations are the reflection of an informative approach. In this sense, the cultural and linguistic gaps between different civilizations, together with a discursive construction of a war nature, could be creating the breeding ground for a continuous confrontation between East and West. The present study analyzes the different rhetorical frames of the international news agencies Reuters, Al Arabiya, Al Jazeera and Associated Press about the terrorist attack at the Istanbul (Turkey) airport on July 28, 2016. A quantitative study of the figures speech and the most repeated topics in the headlines of the attack is carried out. The power of the media in public opinion and the construction of reality generate a discussion about how these news are spread and their effects. The objective is to compare the different rhetorical frames in both civilizations and to identify if stereotypes are projected and if this framing contributes to the spectacularization of the confict. The main result is that there are no significant discursive differences, which leads to the conclusion that east-west rhetorical figures are used to produce a certain effect in the population, among those that highlight the euphemisms, disfemisms, demonization and discursive polarization, resources that serve to emphasize fear and create even larger gaps of social significance.
\end{abstract}

\section{Keywords}

Framing, news agencies, stereotypes, war discourse, demonization, rhetorical frames.

\section{Introducción}

El 28 de junio de 2016, veintiún días más tarde de los atentados del 7 de junio, tiene lugar un atentado en el Aeropuerto Internacional Atatürk de Estambul (Turquía). Las explosiones ocurrieron en diferentes partes de la infraestructura aeroportuaria, mientras paralelamente se llevó a cabo un tiroteo en el aparcamiento y dos explosiones en la terminal de llegadas internacionales. Estos actos dejaron un total de 44 fallecidos y 239 heridos. La cobertura mediática de este hecho fue amplia y los medios de comunicación del mundo se hacían eco de las informaciones, emitiendo noticias en directo y mostrando vídeos alive del momento de los atentados. 
En las noticias sobre atentados terroristas, las cuales disponen de un contexto social e histórico que se da en un conflicto que perdura a lo largo de los años, predominan los clichés, las simplificaciones y la falta de profundidad (Hernández, 2016; Casteleiro, 2015). El discurso de los medios de comunicación construye formas concretas de entender la realidad y condiciona nuestro conocimiento compartido del mundo (Rodrigo-Alsina, 1989 y 1997). La actual presentación del Islam incluye crispaciones xenófobas y cristalizaciones identitarias, tanto en Occidente como en Oriente (Bensalah, 2006), utilizándose para ello encuadres que contienen dispositivos retóricos los cuales permiten condensar los significados (Montoya-Londoño \& MejiaVallejo, 2015). La mayoría de estos encuadres convergen en un mismo objetivo: equiparar el islam a la barbarie y mostrar aquellos que practican esta religión como seres retrasados, violentos y sanguinarios (Bensalah, 2006).

Por su parte la relación entre los medios de comunicación y el terrorismo es compleja debido a que la difusión de las acciones terroristas pueden ser propagandísticas y a su vez puede deberse a la presión que los grupos violentos ejercen sobre los medios (Torres, 2006). Por lo tanto, es imperante la necesidad de abordar los encuadres retóricos de los ataques terroristas llevados a cabo en nombre del islam para así comprender la información transmitida, identificar si se proyectan estereotipos y si se contribuye a la espectacularización a través del tratamiento informativo.

La presente investigación analizará el tratamiento informativo que las agencias internacionales de noticias, en sus plataformas de prensa digital, tuvieron con respecto al del 28 de junio de 2016 en el aeropuerto de Estambul (Turquía), a través de un análisis de contenido de base interpretativa sobre los encuadres retóricos de las principales agencias internacionales de noticias, tomando como ejes muéstrales comparativos tanto empresas informativas del mundo occidental (Reuters y AP) como del Medio Oriente (Al Jazeera y Al Arabiya). Este estudio parte de la importancia de estudiar las agencias internacionales de noticias, en el sentido que son fuentes de información replicadas -incluso a veces sin contrastar- por medios de comunicación de todo el mundo, fenómeno conocido como el "efecto ventrílocuo", en el que un solo medio se convierte en múltiples voces (Arráez, 1998). 


\section{Los medios y la creación de realidades: Estado de la cuestión}

\section{Cobertura mediática del terrorismo, framing y encuadres retóricos}

El incremento de actos terroristas alrededor del mundo se ha convertido en un problema de preocupación (Shoshani \& Slone, 2008). Entre los mecanismos primarios por los cuales esta extensión y magnificación ocurre está la guerra psicológica, que constituye el uso planificado de las comunicaciones para influir en las opiniones, emociones, actitudes y comportamientos de los grupos destinatarios (Weimann, 1983).

Las señales enviadas por los medios de comunicación a través de una cuidadosa construcción del evento terrorista está diseñada para crear y mantener la ilusión de poder más allá del ataque mismo (Hoffman \& McCormick, 2004). La cobertura de los medios de comunicación sobre las noticias de terrorismo pueden jugar un papel importante en el cambio de actitudes, tales como la percepción del enemigo y los estereotipos (Shoshani \& Slone, 2008).

Uno de los componentes más importantes de estas actitudes son, los ya nombrados anteriormente, estereotipos que describen la tendencia humana a recurrir a una imagen simplificada de un determinado grupo social frente a una compleja realidad social (Mackie \& Hamilton, 1993).

De acuerdo con Torres-Toukoumidis et al. (2017), las agencias internacionales de noticias son las que se encargan de configurar la agenda informativa, el enfoque y sus versiones, generando matrices de opinión publicas globalizadas, coincidiendo así también con el "efecto ventrílocuo" explicado por Arráez (1998), en el que pocas agencias potentes fijan el encuadre de muchos medios de comunicación.

Cualquier texto comunicativo requiere de estrategias narrativas que organicen el discurso. En el caso de los medios de comunicación, los acontecimientos noticiosos se presentan de manera sistematizada, basados en convenciones narrativas que ofrecen una explicación acerca de quién está haciendo qué, y con qué propósito -framing- (Ardèvol-Abreu, 2015). Así, el framing consiste en seleccionar algunos aspectos de la realidad y hacerlos más destacables en la comunicación (Valera, 2016). Entman (2005) explica que este "encuadre de agenda informativa" se aplica a una teoría de cascada que consta de los siguientes niveles: 
- El gobierno: se encuentra en primer lugar porque este posee más control sobre el discurso y más poder e independencia para decidir.

- Otras élites: aquellas cercanas a los gobiernos y que tienen cierta influencia en ellos.

- Medios de comunicación: se trata de un nivel complejo puesto que no todos tienen los mismos intereses ni la misma influencias, crean su propia cascada.

- Encuadres, se trata de la forma que se tiene de enviar el mensaje.

- Público, a pesar de parecer que tiene un poder mínimo, Entman (2005) no considera al público como un sujeto pasivo que acepta sin cuestionar las interpretaciones de los medios.

El abordaje del discurso a través del concepto frame pone de manifiesto la importancia de los aspectos cognitivos más allá del análisis de los elementos puramente lingüísticos que constituyen al texto (Palma \& Manrique, 2010). Desde la perspectiva de la teoría de los frames planteada por Fillmore (2006), estas estructuras conceptuales desempeñan una función protagónica como mecanismos que facilitan la organización del conocimiento del mundo y proporcionan las bases para lograr la coherencia discursiva. Lakoff (2008) considera que los frames tienen un gran poder de persuasión o manipulación puesto que mantienen un vínculo muy estrecho con el mundo emocional del receptor, cuestión que es utilizada cuando se quiere movilizar al lector (Lakoff, 2008, p. 33).

El framing $o$ encuadre contiene dispositivos retóricos que se apoyan en la organización jerárquica de los textos, así como en sus estructuras narrativas. Para el encuadre se utilizan símbolos como las figuras retóricas que permiten condensar los significados (Díaz, 2009). Como analizan Rodríguez y Castro (2012, p. 443), la mayoría de los asuntos públicos derivan en una lucha de frames, los actores buscan consolidar su poder mediante una estrategia que consiste en planificar deliberadamente la activación de determinadas asociaciones mentales, contando con un saber cultural compartido (congruencia), entonces también estamos hablando de una activación retórica.

\section{Estrategias retóricas del conflicto: Demonización, estereotipos y espectacularización}

Cada vez es más común encontrar en los medios de comunicación elementos retóricos dispuestos para la manipulación del mensaje que son emi- 
tidos por autoridades o miembros del establishment con acceso al podio discursivo social (Grijelmo, 2001). Entre estos elementos se encuentra la demonización, entendida como una técnica retorica que fija los cimientos de un enfrentamiento real o imaginario para causar temor social, buscando desinformar o alterar las percepciones y realidades sobre un acontecimiento, descripción o una persona a partir de presentarlas como nocivas para la sociedad, generalmente como pocos argumentos válidos pero con gran carga emocional (Romero-Rodríguez, Aguaded \& Gadea, 2015; Romero-Rodríguez \& Römer-Pieretti, 2016).

Por su parte, la demonización parte necesariamente de la división social -real o imaginaria- a través de la polarización, entendida como un fenómeno social que aparece cuando los individuos alinean sus creencias en posiciones extremas y en conflicto, mientras otros mantienen opiniones más moderadas o neutrales (Isenberg, 1986; Sunsteins, 2002). De acuerdo con Cañizalez (2004), la polarización implica un desconocimiento del otro y ha tenido un correlato mediático, pues también los medios y los periodistas se han atrincherado en posiciones que excluyen la posibilidad de entender al otro. La estrategia de polarización en el plano discursivo trata de minimizar los logros del oponente y de maximizar los propios, así como de minimizar los errores propios y maximizar los del otro (van Dijk, 2003, 2009).

Otra de las estrategias retóricas más comúnmente encontradas en el discurso del conflicto es el eufemismo, que etimológicamente significa "buen habla" o "habla favorable". Según Allan y Burridge (1991) un eufemismo es utilizado como alternativa a una expresión negativa, con el fin de desprestigiar u ofender a las audiencias. El eufemismo intenta aminorar los efectos de la construcción de una realidad que colisiona con los intereses o creencias de la audiencia para no afectar o reducir el daño de la percepción del emisor frente a terceros (Romero-Rodríguez, 2014).

Mientras tanto el disfemismo -que también emerge continuamente en la retórica informativa- es una forma que consiste en nombrar una realidad con una expresión peyorativa o con intención de bajarla de categoría. Este recurso suele aparecer en el discurso hegemónico no ya como instrumento de transmisión de un contenido proposicional, sino como medio de persuasión, pues se suele utilizar para ejercer control ideológico, por lo que el contenido connotativo o valorativo de las palabras elegidas suele primar sobre el valor puramente denotativo (Crespo, 2010). 
El lenguaje es un método no instintivo de comunicar ideas, emociones y deseos por medio de un sistema de símbolos producidos de manera deliberada (Sapir, 1980). El lenguaje y las diferentes formas lingüísticas son muy importantes a la hora de elaborar y construir discursivamente los hechos. Algunos pensamientos dependen del lenguaje utilizado a la hora de expresar ciertas ideas (Searle, 1997). A través del lenguaje, ocurre la espectacularización de las noticias, que de acuerdo con Cimaturibus (2011) hace referencia a la explotación exhaustiva de un acontecimiento utilizando recursos estilísticos como exageraciones o descontextualizaciones de una frase, a fin de que ésta sea más impactante a pesar que el contenido de la noticia sea superficial. Este fenómeno tiene una clara vinculación con la tendencia creciente en los medios de comunicación hacia el infoentretenimiento, es decir, a la combinación y fusión de la información con el entretenimiento y sus propias fórmulas discursivas (Lozano, 2000; Radunski, 1999).

Los medios de comunicación son los encargados de reflejar la realidad generando modelos que influyen en la creación de la identidad social (Gila \& Guil, 1999; Marín, 2012), por lo que los estereotipos surgen de los medios sociales y se aprenden a través de procesos de socialización. Los estereotipos se convierten en el instrumento de salida más cómodo a la hora de informar-pues permiten la simplificación conceptual-y establecer pautas de conductas sociales frente a las imágenes que el espectador está consumiendo, provocando la confusión de la realidad (Vega \& Martín, 1999).

\section{Materiales y método}

La presente investigación tiene como objetivo comparar el discurso periodístico de las agencias internacionales de noticias (Reuters, AP, Al Jazeera y Al Arabiya), a través de las unidades informativas relacionadas con el atentado terrorista de Atatürk de Estambul (Turquía) del 28 de junio de 2016. Se entiende como unidades informativas el compendio de contenido que integra una noticia, gracias a los cuales se logra armar el esqueleto visual de las publicaciones (Hernández, 2017). Para su consecución, se plantean como objetivos específicos: i) Comparar los encuadres retóricos (framing) entre las agencias occidentales (Reuters y Associated Press) y las agencias del mundo árabe (Al Jazeera y $\mathrm{Al}$ Arabiya); ii) Identificar si de las unidades informativas se extraen tópicos y/o estereotipos sobre una u otra civilización y; iii) Revisar 
si los medios de comunicación y en especial las agencias internacionales de noticias contribuyen a la espectacularización del conflicto a través de la polarización y demonización del mundo árabe o del mundo occidental. Como teleología, se busca demostrar si la difusión de las informaciones sobre el atentado genera tópicos e ideas relacionadas con atribuciones negativas como el miedo o estereotipos nocivos sobre una civilización en concreto.

Para dar respuesta a estas cuestiones, el estudio se abordará con diseño cualitativo y alcance exploratorio-correlacional desde un análisis de contenido de base interpretativa de los encuadres retóricos de los titulares, lo que ayudará a examinar la forma en que se elaboran los significados (Saini y Schlonsky, 2012), mediante las figuras del discurso y cómo expresan favorabilidad u oposición hacia el mundo árabe/ islam en ambas civilizaciones, así como la espectacularización. Además, se ofrece información respecto a la relación actual entre dos o más variables (correlacional), en este caso entre las agencias de comunicación occidentales (Reuters y Associated Press) y las de Medio Oriente (Al Jazeera y Al-Arabiya). Para ello se utilizará el sistema de análisis de datos cualitativos (QDA) Atlas.ti v. 8.03 para la catalogación hermenéutica de distintas muestras de titulares sobre el atentado terrorista en el Aeropuerto Internacional Atartürk de Estambul. La selección de las agencias, además de representar paridad "n-n" entre ambas civilizaciones, se justifica porque coinciden en que son las que mantuvieron más tráfico durante 2016-2017 (ver tabla 1), de acuerdo con Alexa®.

\section{Tabla 1}

Tráfico web de las agencias internacionales de noticias

\begin{tabular}{|l|l|l|l|}
\hline \multicolumn{1}{|c|}{ Agencia } & \multicolumn{1}{c|}{$\begin{array}{c}\text { Posición } \\
\text { en el ranking }\end{array}$} & \multicolumn{1}{c|}{ Web } & \multicolumn{1}{c|}{ Tráfico } \\
\hline Al Arabiya & 1985 & https://goo.gl/63dPtU & $48,80 \%$ \\
\hline Al Jazeera & 1974 & https://goo.gl/TBDnJL & $64,90 \%$ \\
\hline Reuters & 348 & https://goo.gl/NiY8cw & $63,70 \%$ \\
\hline Associated Press & 4613 & https://goo.gl/Lm9wsn & $62,00 \%$ \\
\hline
\end{tabular}

Fuente: elaboración propia a partir del ranking Alexa®

A continuación se realizó una búsqueda a través de las páginas web principales de cada una de las agencias señaladas, utilizándose como elemen- 
tos de búsqueda: Istambul/Estambul, Terrorism/Terrorismo, Attack/Ataque, Muslism/Musulman, Daesh/Isis, Jihad/ Yijadismo. Airport/ Aeropuerto, utilizando además en los algoritmos booleanos AND y OR. Posteriormente se han seleccionado todos los titulares publicados en cada una de las agencias desde el momento del atentado hasta una semana natural más tarde (del 28 de junio de 2016 al 5 de julio de 2016), obteniéndose una muestra total de 144 titulares en total (ver tabla 2 y figura 1 ).

\section{Tabla 2}

$\mathrm{N}$ de unidades informativas por agencia de noticia (del 28/06/15 al 05/07/16)

\begin{tabular}{|l|c|l|}
\hline \multicolumn{1}{|c|}{ Agencia } & Nro. unidades & \multicolumn{1}{c|}{ Página Web } \\
\hline Al Arabiya & 23 & https://goo.gl/pogvCx \\
\hline Al Jazeera & 11 & https://goo.gl/VYHP23 \\
\hline Associated Press (AP) & 36 & https://goo.gl/ceVmJ3 \\
\hline Reuters & 74 & https://goo.gl/Q23oKS \\
\hline
\end{tabular}

Fuente: elaboración propia

Figura 1

\section{Evolutivo de unidades informativas/tratamiento por día de análisis}

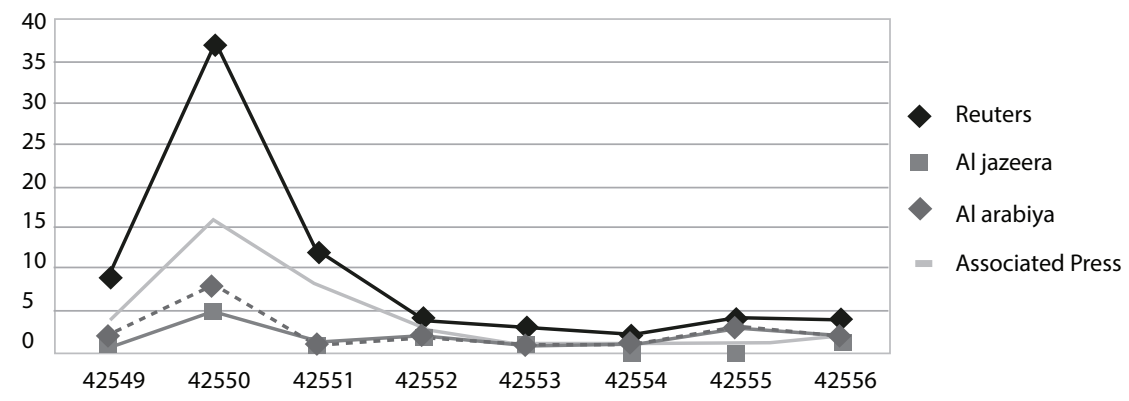

Fuente: elaboración propia

Como instrumento de análisis se utiliza la construcción de las familias discursivas emergentes utilizadas y validadas por Torres-Toukoumidis et al. (2017), que nos permitirá correlacionar y diferenciar las posiciones discur- 
sivas de las informaciones presentadas por estas agencias. Por ende, el análisis del discurso de nuestra investigación también está basado en los tres principios básicos comprendidos por van Dijk (1983): funcionalidad, significación y direccionalidad de la meta. La funcionalidad explica que el significado de las expresiones del discurso es una función de las expresiones que la componen, enfocándose en las opciones léxicas y en el estilo de las oraciones para los posibles actos que deben realizarse con la enunciación del discurso. Entonces, de acuerdo con Meersohn (2005) el significado de una oración debe ser calculado sobre la base del significado de sus palabras componentes. La significación, por su parte, se refiere al establecimiento de estructuras de coherencia en las oraciones hacia una temática general. Por último, la direccionalidad de la meta se orienta a los actos potenciales imbuidos en el discurso.

Asimismo, las familias emergentes de la ronda hermenéutica utilizadas por Torres-Toukoumidis, et al. (2017), fueron seleccionadas para el presente trabajo en virtud de la similaridad material del estudio, así como por la vinculación de las mismas con los principios comunicativos de van Dijk (1983). Estos códigos emergieron por la validación en el precitado estudio, siendo los siguientes:

\section{a. Atribución ideológica del islam}

a.1 Demonización del islam

a.2 Exaltación del islam

\section{B. Atribución ideológica del mundo árabe}

b.1 Demonización del mundo árabe

b.2 Exaltación del mundo árabe

\section{Política exterior Occidente- Medio Oriente}

c.1 Polarización Occidente-Medio Oriente

c. 2 Convivencia Occidente-Medio Oriente

D. Estado emocional deseado en la población civil

d.1 Enfatización del miedo/ pánico en la población

d.2 Enfatización de la tranquilidad/ paz de la población

E. Expresión retórica del discurso

e.1 Utilización de disfemismos

e.2 Utilización de eufemismo/ simplificación conceptual 
Los resultados obtenidos corresponden al resultado inductivo de la revisión previa de la muestra que se utiliza en su análisis, identificando la reiteración de dichos códigos de manera asistida mediante la plataforma de QDA. Para conocer los porcentajes, se realiza una regla de los resultados obtenidos en cada una de las familias emergentes.

\section{Análisis de resultados}

En el periodo analizado, correspondiente al intervalo entre el 28 de junio y el 5 de julio, las cuatro agencias presentaron un total de 144 unidades informativas. Éstas representan la muestra efectiva definitiva, ya que estaban relacionadas a los hechos y sus efectos. Reuters y AP contienen el mayor número de noticias con 74 y 36 unidades, respectivamente; mientras que $\mathrm{Al}$ Arabiya y Al Jazeera contaron con un total de 23 y 11 unidades informativas (tal como se extrae en la tabla 2). El día siguiente al atentado (29 de junio) se emitió el mayor número de unidades informativas por día (figura 1).

Del total de la muestra seleccionada se extraen un total de 286 códigos emergentes, siendo más reiterados los pertenecientes a la familia "enfatización del miedo de la población civil" con 90 codificaciones. Los "eufemismos" se sitúan en el segundo puesto más alto con un total de 75 reiteraciones. Cabe destacar que la "demonización del Islam y del mundo Árabe" cuenta con un total de 33 códigos. La "enfatización de la paz" aparece con 38 códigos emergentes, mientras que la "atribución ideológica del Islam" y la "exaltación del Islam" se sitúan en el último lugar con 13 y dos códigos.

\section{Diferencias discursivas y framing}

$\mathrm{Al}$ adaptar los criterios expuestos por el estudio semántico del discurso mediático (van Dijk, 1983) a las familias emergentes validadas y extraídas del estudio hermenéutico de las agencias internacionales de noticias realizado por Torres-Toukoumidis et al. (2017), se evidencia la siguiente vinculación:

a) Funcionalidad: La sustitución léxica es la propiedad asumida como principal indicador en este contexto específico. Si se valora la existencia de otros componentes, se observa que la reiteración de eufemismos y disfemismos acuciada por la sensibilidad del mensaje contrasta en la superficie de los discursos emitidos por las cuatro agencias internacionales (ver tabla 3 ). 


\section{Tabla 3}

\section{Sustitución léxica de las agencias internacionales en la expresión retórica del discurso}

\begin{tabular}{|l|c|c|c|c|c|}
\hline & Al Arabiya & $\begin{array}{c}\text { Al } \\
\text { Jazeera }\end{array}$ & $\begin{array}{c}\text { Associated } \\
\text { Press }\end{array}$ & Reuters & Total \\
\hline $\mathrm{N}^{\mathrm{a}}$ Eufemismos & 13 & 8 & 20 & 34 & 75 \\
\hline $\mathrm{N}^{\mathrm{a}}$ Disfemismos & 5 & 2 & 4 & 11 & 22 \\
\hline Expresión Retórica del discurso & 18 & 10 & 24 & 45 & 97 \\
\hline
\end{tabular}

Fuente: elaboración propia

Se tiene en cuenta que de los 23 titulares analizados de Al Arabiya se obtienen 13 códigos de eufemismo, por lo que se deduce que para igualarlo hipotéticamente Al Jazeera contendría 6, Reuters 42 y Associated Press 20. Por tanto se observa que las agencias internacionales de noticias que pertenecen al mundo árabe presentan un número más alto de eufemismos, aunque Associated Press lo iguala y Reuters se aproxima. Esto evidencia que se utilizan patrones reiterados basados en una manipulación del lenguaje con efectos desinformativos, por ejemplo:

\section{Eufemismo}

Turkey's Erdogan vows unity after deadly airport blasts (Al Jazeera, 29 de junio).

\section{Disfemismo}

ISIL turns 'shock and awe' doctrine against Islam (Al Jazeera, 5 de julio).

b) Significación: La figuración de la unidad del discurso sobre los atentados del 28 de junio de 2016 está representada por la coherencia local y la coherencia global manifestada en la información suscrita por las cuatro agencias internacionales. De acuerdo con Torres-Toukoumidis et al. (2017) en primer lugar la coherencia local está simbolizada por la atribución ideológica del islam y del mundo árabe, referenciando la implicación semántica del texto que derivan de los hechos, mientras que la coherencia global no es 
más que la temática general de la información expuesta en la coherencia local (ver tabla 4).

\section{Tabla 4}

Significación semántica de las codificaciones extraídas de las agencias internacionales

\begin{tabular}{|l|c|}
\hline \multicolumn{1}{|c|}{ Significación semántica } & N codificaciones \\
\hline Atribución ideológica del islam ( coherencia local) & 13 \\
\hline Atribución ideológica del mundo árabe ( coherencia local) & 31 \\
\hline Política exterior Occidente-Medio Oriente (coherencia global) & 44 \\
\hline
\end{tabular}

Fuente: elaboración propia.

Cuando se especifican las agencias internacionales y los subcódigos emergentes de la coherencia local, también existe sincronización de los datos con los subcódigos emergentes de la coherencia global. Es decir, la demonización del islam y del mundo árabe corresponde a la familia expuesta por la polarización Occidente-Medio Oriente, entretanto que la exaltación del islam y del mundo árabe corresponde a la convivencia Occidente-Medio Oriente (ver tabla 5 y 6 ).

\section{Tabla 5}

\section{Relación de códigos de connotación negativa clasificados por agencia}

\begin{tabular}{|l|l|l|l|l|l|}
\hline & $\begin{array}{c}\text { Al } \\
\text { Arabiya }\end{array}$ & $\begin{array}{c}\text { Al } \\
\text { Jazeera }\end{array}$ & $\begin{array}{c}\text { Associated } \\
\text { Press }\end{array}$ & Reuters & Total \\
\hline Demonización del islam & 2 & 2 & 3 & 4 & 11 \\
\hline Demonización del mundo árabe & 5 & 2 & 4 & 11 & 22 \\
\hline Polarización Occidente-Medio Oriente & 7 & 4 & 7 & 15 & 33 \\
\hline
\end{tabular}

Fuente: elaboración propia 


\section{Tabla 6}

\section{Relación de códigos de connotación positiva} clasificados por agencia

\begin{tabular}{|l|c|c|c|c|c|}
\hline & $\begin{array}{c}\text { Al } \\
\text { Arabiya }\end{array}$ & $\begin{array}{c}\text { Al } \\
\text { Jazeera }\end{array}$ & $\begin{array}{c}\text { Associated } \\
\text { Press }\end{array}$ & Reuters & Total \\
\hline Exaltación del islam & 1 & 1 & 0 & 0 & 2 \\
\hline Exaltación del mundo árabe & 0 & 0 & 2 & 7 & 9 \\
\hline Convivencia Occidente-Medio Oriente & 1 & 1 & 2 & 7 & 11 \\
\hline
\end{tabular}

Fuente: elaboración propia

Se evidencia en las tablas anteriores que las cuatro agencias de noticias analizadas utilizan la retórica de descrédito sobre la de reconocimiento, mientras que la demonización del mundo árabe es la atribución ideológica que mayor carga de significación semántica tiene. Asimismo se puede evidenciar con meridiana claridad que se construye un discurso inclinado hacia la polarización de Occidente-Medio Oriente, tal como se extrae de los siguientes titulares:

France temporarily closes missions in Turkey over threat (Associated Press, 5 de julio).

New York airport security increased after Istanbul attack (Associated Press, 28 de junio).

White House condemns attack on Istanbul airport (Reuters, 29 de junio).

Mientras tanto algunas noticias, mediante la polarización del mundo árabe -que tiene el mayor número de codificaciones en los aspectos positivos- equilibran la polarización con la convivencia Occidente-Medio Oriente. Este fenómeno se puede observar en los siguientes titulares:

Tunisian father who went to Turkey to bring back militant son killed (Al Arabiya, 29 de junio).

Obama: U.S. stands with Turkey after Istanbul airport attack (Reuters, 29 de junio). 
c) Direccionalidad de la meta: $\mathrm{Al}$ tomar en cuenta las familias emergentes del estudio de Torres-Toukoumidis et al. (2017), expuestas en la funcionalidad y en la significación, la finalidad comunicativa resultó asociada con las situaciones sociales proyectadas en un contexto específico (ver tabla 7).

\section{Tabla 7}

\section{Finalidad comunicativa en el estado emocional deseado a la población civil}

\begin{tabular}{|l|c|c|c|c|c|}
\hline & $\begin{array}{c}\text { Al } \\
\text { Arabiya }\end{array}$ & $\begin{array}{c}\text { Al } \\
\text { Jazeera }\end{array}$ & $\begin{array}{c}\text { Associated } \\
\text { Press }\end{array}$ & Reuters & Total \\
\hline Enfatización del miedo & 14 & 5 & 23 & 48 & 90 \\
\hline Enfatización de la tranquilidad & 8 & 5 & 8 & 17 & 38 \\
\hline $\begin{array}{l}\text { Estado emocional deseado en la } \\
\text { población civil }\end{array}$ & 22 & 10 & 31 & 65 & 128 \\
\hline
\end{tabular}

Fuente: elaboración propia

Las codificaciones extraídas demuestran cómo se expone la acentuación del miedo sobre la información dirigida a la tranquilidad y la paz en la población civil. Teniendo conocimiento de estos resultados, se observa la forma en que los medios -como replicadores del discurso de las agencias de noticias - tanto del mundo occidental como del mundo árabe recurren a la enfatización del miedo como estrategia discursiva provocando pánico. De esta forma la población acepta decisiones que no aceptaría con otros sentimientos. El uso de esta retórica se puede observar en los siguientes titulares:

German spy chief can't rule out Istanbul-style attacks at home (4 de julio en todas las agencias).

Ghostly quiet as tourists stay away from Turkey's magical Istanbul (Al Jazeera, 4 de julio).

Tips for staying safe while traveling overseas this summer (Associated Press, 29 de julio). 


\section{Estereotipos y tópicos}

Se utilizan estereotipos que acercan a Occidente el concepto de terrorismo de forma equívoca, demonizando colectivos y marginándolos al ostracismo perceptivo. En algunos titulares se estereotipa el tipo de atentado que ejerce el Estado Islámico (EI), lo que provoca que se les atribuya siempre a este grupo terrorista. Esto maximiza los rumores sobre el mundo árabe y la demonización del Islam, lo que provoca que las noticias sobre terrorismo activen el estereotipo del árabe-terrorista. Con el uso de palabras como terrorismo islámico, yihadista o extremista y resaltando las nacionalidades de los terroristas se estereotipa al mundo árabe, afiliándolo perceptivamente de forma automática al terrorismo. Se puede observar en los siguientes titulares:

CIA says Istanbul airport attack bears hallmarks of Islamic State (Reuters, 29 de junio).

US congressman: Chechen extremist behind Istanbul airport attack (Associated Press, 29 de junio).

Once again, Saudi Arabia is on the terrorism frontline (Al Arabiya, 5 de julio).

\section{Espectacularización del conflicto}

Tras la realización del análisis se ha podido observar una nueva forma de transmisión y espectacularización de los conflictos. Un atentado terrorista, como hecho noticiable, tiene todos los componentes para la espectacularización: emoción, suspenso, violencia e incertidumbre. La forma en que los medios de comunicación toman ventajas de esas características se han podido observar en los diferentes titulares en los que se encuentran:

a) Elementos multimedia, los cuales ayudan al espectador a crear una percepción de los hechos, como si de una película de ciencia ficción se tratara. Se puede observar en los siguientes titulares:

New terrifying scenes of Ataturk Airport attack (Al Arabiya, 29 de junio).

Ataturk Airport attack: Scenes of carnage in Istanbul (Al Jazeera, 29 de junio).

b) Fragmentación del contenido, lo que conlleva a que el espectador esté pendiente constantemente a las actualizaciones de los medios y a man- 
tener el interés y la incertidumbre en el conflicto. Se puede observar en los siguientes titulares:

Last hour: Obama hints at ISIS responsibilty for the Istanbul attack (Al Arabiya, 29 de junio).

ISIL 'key suspect' in Istanbul's Ataturk airport attack (Al Jazeera, 29 de junio).

c) Storytelling. Para la creación de este tipo de contenidos, de acuerdo a los titulares, se observan acciones tales como visitar familias de las víctimas y compartir historias de los testigos, lo que conecta al público de forma emocional. La forma en la que se ha utilizado el storytelling en la muestra puede ser observada en las siguientes unidades:

Tunisian father who went to Turkey to bring back militant son killed (Al Arabiya, 29 de junio).

Al Arabiya visits the family of a Saudi man killed in Istanbul attack (Al Arabiya, 30 de junio).

d) Descontextualización. El atentado de Turquía y en general, otros atentados, se han mostrado aislados de su contexto histórico y espacial, de manera que se convierten en hechos incompresibles y emocionales, lo que provoca una sensación de confusión entre la audiencia. La desinformación retiene información y la espectaculariza, haciendo noticiable aquello que vende. Se puede observar en los siguientes titulares:

Istanbul airport attack killed 2, injured 25 Saudis: envoy (Al Arabiya, 29 de junio).

Vast majority' of dead in Istanbul airport attack were Turkish, official says (Reuters, 29 de junio).

Thirty-one killed, 147 wounded in Istanbul airport attack (Reuters, 29 de junio).

41 dead in Istanbul airport attack (Associated Press, 29 de junio).

e) Titulares de intriga. Al fragmentar la información, se envían un gran número de noticias al día. Esto provoca que estemos saturados de información y que muchas no sean abiertas a la reflexión. Para que el lector abra aquellas noticias que de acuerdo al medio son relevantes, se utiliza vocabu- 
lario que deja intrigada a la audiencia como "Last hour", "special cover", "the latest". Este vocabulario capta la atención del espectador, ya que crea sensación de proporcionar actualidad y formar parte de la trama principal de la serie.

Last hour: Special coverage of Istanbul Ataturk airport attack (Al Arabiya, 29 de junio).

The Latest: Video in Turkey shows man being shot at airport (Associated Press, 30 de junio).

\section{Conclusiones y discusión}

Para alcanzar el primer objetivo específico "comparar los enfoques (framing) discursivos entre las agencias occidentales (Reuters y Associated Press) y las agencias del mundo árabe (Al Jazeera y Al Arabiya)", tras realizar el análisis, se llega a la conclusión de que no hay diferencias discursivas significativas. Todas las noticias, independientemente de la agencia a las que pertenecen, utilizan eufemismos y disfemismos, polarizan, demonizan y enfatizan el miedo. En ambos casos se utilizan figuras retóricas con el fin de producir un efecto en la población y alterar las percepciones a través del lenguaje. Llama la atención que se contabilizan un mayor número de unidades discursivas de demonización del Islam en las agencias de propiedad árabe (7 unidades), situación que puede deberse a que incluso las noticias del mundo árabe o los temas pertenecientes al mundo islámico se tratan bajo la presión de los ideales occidentales (eurocentrismo), de las relaciones con Occidente y en la medida en que Oriente se ve afectado por ellos.

También se puede observar con meridiana claridad cómo la "enfatización del miedo" es una constante en las informaciones de las cuatro agencias de noticias analizadas. Se utiliza la desinformación y descontextualización de los hechos para evitar un pensamiento crítico, omitiendo informaciones sobre la historia del conflicto y las relaciones políticas y sociales (Romero, 2012).

Asimismo y alcanzando nuestro segundo objetivo, se observa tendencia a generar estereotipos, sobre todo en las noticias del mundo occidental, lo cual no ayuda a la sensibilización de la opinión pública con el mundo árabe y produce un incremento de los prejuicios que provocan problemas en nuestro entorno social y en la posibilidad de convivencia. 
En el mismo orden de ideas y alcanzando nuestro tercer objetivo, se entrevé en los resultados que las agencias internacionales contribuyen a la espectacularización del conflicto. Esto provoca que no se garantice la profesionalidad en todas las comunicaciones, pues la calidad es menos importante que utilizar las características que imponen los canales digitales en la nueva era de la comunicación. Así también se utilizan estrategias emocionales difundiendo imágenes sensacionalistas que pueden herir la dignidad de las personas y ofreciendo representaciones distorsionadas de la realidad. En algunos casos estas estrategias se pueden considerar espectacularización positiva ya que ayudan a ampliar nuestro espacio moral, logrando sensibilizar o conmover a la audiencia frente al sufrimiento, aunque sin situar los hechos desde una mirada crítica y reflexiva.

Se afirma así que en las cuatro agencias de noticias analizadas se utilizan figuras retóricas con el fin de producir un efecto en la población y construir una realidad a través del lenguaje. En este sentido se evidencia que los medios de comunicación no dicen la manera cómo pensar pero sí en qué pensar (agenda setting) y desde qué punto abordarlo (framing). Esto se relaciona con lo referido por Tuchman (1978), que describe la noticia como una ventana cuyo marco delimita la realidad a la que se tiene acceso, limitando la percepción de otra realidad diferente y centrando la atención en ese fragmento especifico, afirmándose incluso como resultado de esta investigación que las noticias de las agencias del Medio-Oriente se tratan bajo la presión de los ideales occidentales, considerándolos como discurso predominante.

En relación a la tendencia a generar estereotipos, se observa que las agencias occidentales de noticias crean una visión negativa del Islam presentándolo como amenaza y contribuyendo a lo que se conoce como "racismo contemporáneo", el cual se basa en la autodefensa más que en las diferencias raciales. Esto confirma lo dicho por Torres-Toukoumidis et al.(2017) que afirman que los estereotipos están cobrando mayor fuerza en el plano emocional del discurso y obligan al consumidor de información a adherirse a los esquemas elaborados por los medios en base de repeticiones constantes, cuyo fin es conseguir que el espejismo se convierta en una realidad indiscutible.

Por último se observa que las noticias sobre terrorismo se han convertido en un discurso enfocado al entretenimiento de masas en ambas sociedades. Al ser noticiable y estar en la opinión pública puede crear lo que se ha denominado "espectacularización positiva", término el cual no es apoyado por Hacker (1976) que afirma que la espectacularización es innecesaria creando barreras entre el espectador de la noticia y quien lo sufre. 


\section{Referencias}

Allan, K., \& Burridge, K. (1991). Euphemism and dysphemism: language used as shield and weapon. Oxford: Oxford University Press.

Ardèvol-Abreu, E. (2015). Framing o teoría del encuadre en comunicación. Orígenes, desarrollo y panorama actual en España. Revista Latina de Comunicación Social, 70, 423-450. https://doi.org/10.4185/RLCS-2015-1053

Arráez Betancort, R. M. (1998). La comunicación para el desarrollo. Su aplicación desde el medio radio / Revisión preliminar del estado de la cuestión. Revista Latina de Comunicación Social, 9.

Bensalah, M. (2006). Islam y representaciones mediáticas. Revista CIDOB d'afers internationals, (73/74), 69-83.

Casteleiro Ruiz de Azcarate, J. (2015). Islam, terrorismo y medios de comunicación. Documento de opinión. Instituto español de estudios estratégicos, 83. Recuperado el 15 de abril de 2017 de: https://goo.gl/uDSbPu

Cañizalez, A. (2004). Apuntes sobre medios y periodistas en una sociedad polarizada. Estudios venezolanos de Comunicación, (127), 14-19.

Cimatoribus, F. (2011). La espectacularización mediática, un crecimiento desmedido. Máximo Tell. Recuperado de https://maxitell.wordpress.com/2011/12/12/ la-espectacularizacion-mediatica-un-crecimiento-desmedido/

Crespo, E. (2010). Eufemismo y disfemismo léxico en la designación del inmigrante 'sin papeles'. Bulletin of Hispanic Studies, 87(3), 273.

Entman, R. (2005). Projections of power, framing news, public opinion and U.S. Foreign Policy. Chicago: University of Chicago Press

Fillmore, C. (2006). Frame semantics. En Dirk Geerearts (Ed.), Cognitive linguistics: Basic Readings (pp. 373-401). Berlín: Mouton de Gruyter.

Gila, J., \& Guil, A. (1999). La mujer actual en los medios. Estereotipos cinematográficos. Comunicar, 12, 89-93.

Grijelmo, A. (2001). El estilo del periodista. Madrid: Taurus.

Hernández Valls, F. (2016). Terrorismo y propaganda en los medios de comunicación. El final de ETA a través de la prensa. Madrid: Universidad Complutense.

Hernández, R. (2017). Unidades informativas. Venezuela: Universidad Católica Andrés Bello.

Hoffman, B, \& McCormick, G. (2004). Terrorism, Signalling, and Suicide Attack. Studies in Conflict \& Terrorism, 27, 243-281.

Isenberg, D. (1986). Group polarization: A critical review and meta-analysis. Journal of personality social psychology, 50(6), 114. 
Lakoff, G. (2008). The political mind. New York: Penguin Group.

Lozano, J.C. (2000). Espectacularización de la información en noticieros televisivos de Canadá, Estados Unidos y México. Revista diálogo político, 12, 103-116.

Mackie, D, \& Hamilton, D. (1993). Affect, Cognition, and Stereotyping interactive Processes in Group Perception. San Diego: Academic Press.

Marín, A. L. (2012). La nueva comunicación. Madrid: Editorial Trotta, S.A

Meersohn, C. (2005). Introducción a Teun Van Dijk: Análisis de Discurso. Cinta Moebio 24, 288-302.

Montoya Londoño, C., \& Vallejo Mejías, M. (2015). Encuadres retóricos-políticos en la ley de víctimas y restitución de tierras en Colombia. Análisis político, 28(84), 23-83.

Palma, J. \& Manrique, B. (2010). La teoría de los frames en el análisis del discurso. Lingua americana, 26(14), 129 - 142.

Radunski, P. (1999). Management de la comunicación política. En J. Thesing y F. Priess (Eds.), Globalización, democracia y medios de comunicación (pp. 179-198). Buenos Aires: Centro Interdisciplinario de Estudios sobre el Desarrollo Latinoamericano (CIEDLA).

Romero, L.M. (2012). La desinformación en la nueva aldea global. Comunicación. Estudios venezolanos de la Comunicación, (159), 52-55.

Romero-Rodríguez, L. M. (2014). Pragmática de la desinformación. Estratagemas $e$ incidencia de la calidad informativa de los medios. Tesis Doctoral. Huelva: Repositorio Institucional Arias Montano. Disponible en línea en: http://rabida.uhu.es/dspace/handle/10272/9605

Romero-Rodríguez, L.M., Aguaded, I., \& Gadea, W. (2015). De la demonización a la polarización: un análisis desde el discurso digital del gobierno y la oposición venezolana. Argos, 32(62), 97-117.

Romero-Rodríguez, L. M., \& Römer Pieretti, M. (2016). Proceso de demonización de la oposición política en los hitos discursivos de Hugo Chávez según la prensa digital. Temas de Comunicación, (32).

Rodrigo Alsina, M. (1989). La construcción de la noticia. Barcelona: Paidós.

Rodrigo Alsina, M. (1997). Por un uso crítico de la prensa. Revista SIGNOS, 21.

Saini, M., \& Shlonsky, A. (2012). Systematic synthesis of qualitative research: A pocket guide for social work research methods. New York, NY: Oxford University Press.

Sapir, E. (1980). El lenguaje: introducción al estudio del habla. México: Fondo de Cultura Económico. 
Searle, J. (1997). La construcción de la realidad social. Barcelona: Universidad de Barcelona.

Shoshani, A, \& Slone, M. (2008). The Drama of Media Coverage of Terrorism: Emotional and Attitudinal Impact on the Audience. Studies in Conflict \& Terrorism, 31(7), 627-640.

Torres-Toukoumidis A., Romero-Rodríguez, L. M., Casas-Moreno, P., \& Aguaded, I. (2017). Construcción del discurso bélico desde las agencias internacionales de noticias: Estudio de caso atentados del 13 de noviembre de 2015. Revista mediterránea de comunicación, 8(1), 121-135.

Torres Romay, E. (2006). El tratamiento de la imagen en los atentados del 11-M. Terrorismo y violencia en la prensa. Tenerife: Revista Latina de Comunicación Social, 61.

Van Dijk, T. (1983). Discourse analysis: Its development and application to the structure of news. Journal of communication, 33(2), 20-43.

Van Dijk, T. (2003). Ideología y discurso. Barcelona: Ariel Gedisa.

Van Dijk, T. (2009). Discurso y poder. Barcelona: Ariel Gedisa.

Valera, L. (2016). El sesgo medio céntrico del framing en España: Una revisión crítica de la aplicación de la teoría del encuadre en los estudios de comunicación. Revista de estudios de comunicación, 41(21).

Vega, A., \& Martín, R. (1999). Los medios ante la discapacidad. Más allá de los estereotipos. Comunicar, 12, 111-116.

Fecha de recepción: 2018/04/22; Fecha de aceptación: 2018/08/10;

Fecha de publicación: 2018/09/01 


\title{
Acceso a la educación superior: Uruguay y Ecuador Estudio de derecho comparado
}

\author{
Access to higher education: Uruguay and Ecuador \\ Comparative Law study
}

\author{
Rina Pazos \\ Universidad Tecnológica Equinoccial (UTE) \\ Universidade do Minho \\ rinapazos986@hotmail.com \\ Código Orcid: https://orcid.org/0000-0002-2522-8138
}

\begin{abstract}
Resumen
En el mundo contemporáneo la educación superior se ha tornado un elemento de gran importancia no solo desde la perspectiva de los derechos individuales, sino también como parte de la estrategia de desarrollo de los Estados. El Pacto Internacional de Derechos Económicos, Sociales y Culturales (PIDESC, 1966) reconoce a la educación como un derecho de las personas y establece que el acceso igualitario y la implantación progresiva de la gratuidad en la educación superior son necesarios para lograr el pleno ejercicio de ese derecho. En ese marco, los ordenamientos jurídicos de la materia dan importantes insumos para conocer los modelos sobre acceso a la educación superior de cada país. El presente trabajo tiene por objetivo aproximarse a los modelos de dos países de América Latina: Uruguay y Ecuador, a través de sus ordenamientos jurídicos en la materia; para ello se ha adoptado el "método del derecho comparado" que permite realizar un análisis de las diferentes fuentes del Derecho de los Estados a comparar, para alcanzar una síntesis que brinde evidencia de las semejanzas y diferencias sobre el contenido jurídico, valores y modelos políticos sobre los que se asientan. Ambos Estados, a través de sus normas, consideran a la educación superior como un bien público y un derecho, las diferencias se reflejan en los mecanismos de implementación del acceso a ese derecho.
\end{abstract}

\section{Palabras clave}

Derecho comparado, derecho a la educación, democratización de la educación, enseñanza superior, enseñanza gratuita, oportunidades educacionales.

Forma sugerida de citar: Pazos, Rina (2018). Acceso a la educación superior: Uruguay y Ecuador, estudio de derecho comparado. Universitas, 29, pp. 157-176. 


\begin{abstract}
Nowadays, higher education has become an important element not only from the individual rights perspective but also as part of the development strategy of many countries. The International Covenant on Economic, Social and Cultural Rights (ICESCR, 1966) recognizes education as an individual's right and establishes that equal access and progressive free education in higher education is necessary to achieve the full exercise of that right. In this framework, the legal norms in the field give important inputs to understand the access patterns to higher education in each country. The aim of this paper is to approach to the models in two Latin American countries: Uruguay and Ecuador, through the scrutiny of their regulations on this matter; the Comparative Law method has been adopted, which allows an analysis of the different sources of Law to be compared to achieve a synthesis that provides evidence of the similarities and differences on their legal content, values and political models. Both legal systems consider higher education as a public good and a right, the differences are reflected in the mechanisms for implementing access to that right.
\end{abstract}

\title{
Keywords
}

Comparative Law, right to education, democratization of education, higher education, free education, educational opportunities.

\section{Introducción}

En el mundo contemporáneo la formación del talento humano - también llamado capital humano - tiene relevancia no solamente en el plano del derecho individual de las personas, sino también como una estrategia de desarrollo de los Estados, tanto desde las perspectivas liberales como desde las socialistas/comunistas.

El Pacto Internacional de Derechos Económicos, Sociales y Culturales (PIDESC, 1966) reconoce a la educación como un derecho de las personas y establece que el acceso igualitario y la implantación progresiva de la gratuidad en la educación superior, son necesarias para lograr el pleno ejercicio de ese derecho. Para los países de América Latina, la educación superior implica un reto y un tema ineludible en el mundo actual. Uno de los desafíos de la región es la masificación con equidad para la promoción y movilidad social (UNESCO, 2015, p. 90). 
Los ordenamientos jurídicos seleccionados para realizar la comparación son el ecuatoriano y el uruguayo. Esta elección se realizó considerando:

- Que los ordenamientos jurídicos de ambos países están insertados en la misma tradición jurídica, es decir, en la tradición civilística, lo cual hace más viable la comparación de las instituciones al estar asentadas sobre los mismos fundamentos jurídicos.

- Ambos países reconocen y garantizan la gratuidad de la educación superior pública, una semejanza inusual sobre la cual resulta interesante indagar con mayor profundidad.

- Ambos países se encuentran en la misma región geográfica, lo cual puede sugerir que existen factores históricos y sociales coincidentes.

- El tamaño de los sistemas de educación superior a comparar es similar en relación al de otros países de la región que mantienen las características detalladas en los numerales anteriores.

Si bien existen otros países en América Latina que mantienen sistemas públicos de educación superior gratuitos, como el caso de Argentina y Brasil (UNESCO, 2018), sus dimensiones son mucho mayores que los sistemas de educación superior ecuatoriano y uruguayo (UNESCO, 2018), una variable que exigiría otro tipo de abordaje para sus problemas propios de su tamaño y, más aún, si se considera sus modelos federales de gobierno.

El método que se utiliza en esta investigación es el descrito por De Almeida Ferreira y Carvalho Morais (2017, pp. 26-36), en el que se sugiere realizar la micromparación a través de la idea gráfica de una parrilla comparativa con un eje sintagmático (en el que se incluyen las dimensiones histórica, metajurídica y jurídica del tema a comparar) y un eje paradigmático (en el que se desarrollarán las variaciones de las dimensiones sintagmáticas). El proceso incluye una fase analítica y una integrativa, para finalizar con una síntesis comparativa. Siguiendo lo propuesto por Moura Vicente (2012, p. 39), se intenta identificar las semejanzas y diferencias entre los dos sistemas $\mathrm{y}$ encontrar algunas causas.

Como ya se anticipó, el presente trabajo plantea el abordaje del objeto de estudio a través del "método del derecho comparado", que implica la comparación sistemática de derechos u ordenamientos jurídicos para identificar semejanzas y diferencias (De Almeida y Carvalho, 2017, p. 11). Específicamente, se realizará un ejercicio microcomparativo que consiste en la 
comparación de temas o instituciones jurídicas afines en ordenamientos jurídicos distintos, considerando a una institución jurídica como el conjunto de normas, principios y organizaciones de naturaleza jurídica que forman parte de un determinado ordenamiento jurídico y constituyen una unidad basada en aspectos sociales, jurídicos o doctrinarios (De Almeida y Carvalho, 2017, p. 13). La aproximación de la microcomparación será funcional, es decir, se selecciona y compara una institución jurídica que en diferentes sistemas jurídicos da soluciones jurídicas a necesidades similares (De Almeida y Carvalho, 2017, p. 27).

El objeto de la comparación es el acceso a la educación superior desde su dimensión jurídica, en dos ordenamientos jurídicos distintos con un criterio temporal actual y sincrónico, pero incorporando una perspectiva histórica y considerando los aspectos que sean susceptibles de ser comparados.

\section{Dimensión histórica}

\section{Evolución histórica de la educación superior en Uruguay}

La fundación de la universidad en Uruguay inicia con la creación de la Casa de Estudios Generales en 1833, transformada en Universidad de la República de Uruguay en 1838. Los siguientes treinta años la universidad se caracterizó, según Contera (2008, p. 535), por la corriente filosófica del espiritualismo ecléctico que sirvió para mantener una línea anticlerical y liberal.

En el último tercio del siglo XIX inició el periodo positivista con la creación de la Facultad de Medicina y Matemáticas, modelo que fue impulsado por José Pedro Varela, cuyo proyecto se caracterizaba por lograr que la educación fuese obligatoria, gratuita y laica (Consejo de Educación Primaria, 2018). En la primera mitad del siglo XX se avanzó hacia una universidad profesionalista y en la Constitución de 1934 se declaró de utilidad social la gratuidad de la enseñanza oficial (art. 62); además, en la Constitución de 1952 se estableció la forma de designación del Consejo Directivo de la Universidad de la República en la que participarían estudiantes, docentes y egresados (art. 205) y se declaró la autonomía de las instituciones de enseñanza pública (art. 204). La segunda mitad del siglo XX inició con la consagración de la autonomía académica y política en Ley Orgánica de la Universidad de la República (1958), impulsada por las movilizaciones 
estudiantiles influenciadas por el Movimiento Autonomista de Córdoba en Argentina (1918). En la Constitución de 1967 se garantizó la libertad de enseñanza. En 1973, la dictadura militar silenció a la institución y destituyó a varios profesores; en ese periodo también empezó un proceso de masificación de la matrícula, pasando de 16 mil alumnos en los años 70 a 63 mil en 1988. En 1980, terminada la dictadura, la Universidad de la República de Uruguay pudo volver a repensarse y a decidir por sí misma, a través de la recuperación del sentido y hábito de la crítica (Martínez, 2003, pp. 3-12).

Sobre la historia más reciente, Contera $(2008$, p. 535) señala que el proceso de privatización de la educación superior en Uruguay inició en 1984, con la creación de la Universidad Católica de Uruguay, y continuó en la década de los 90 con algunas más, sin embargo, la mayor parte de la matrícula universitaria se concentra en la Universidad de la República.

\section{La evolución histórica de la educación superior en el Ecuador}

La educación superior en el Ecuador tiene sus orígenes en la Real Audiencia de Quito, durante la Colonia española. Desde 1620 funcionaban en el territorio de lo que hoy es el Ecuador tres universidades y en 1779 todas las universidades de Quito se unificaron con el nombre de Universidad de Santo Tomás, por iniciativa del obispo José Domingo Pérez Calama (Pacheco, 2015, pp. 175-178). Luego de la Independencia, el modelo napoleónico profesionalizante es el que se importó para la educación superior.

A esta etapa le siguieron tres reformas importantes. La primera reforma fue la del liberalismo y la secularidad, que inició en 1907, cuando el Estado adoptó un rol de financiamiento y se avanzó hacia la inclusión de los mestizos (Guijarro, 2016, pp. 220-221). La segunda, fue de reflexividad y crítica, desde mediados del siglo XX, en la que cobró una mayor relevancia la dimensión social de la universidad, marcada por la organización estudiantil influida por el Movimiento Autonomista de Córdoba en Argentina (1918), la Revolución Cubana (1958), la Revolución Cultural China (1966) y los eventos de Mayo del 68 en Francia. Este periodo estuvo marcado por la búsqueda de una mayor democratización del acceso a las aulas universitarias, una mayor autonomía institucional frente al Estado y una verdadera función social (Guijarro, 2016, pp. 224-226). Finalmente, La tercera reforma se gestó a fines de la primera década del siglo XXI, en el escenario de la globalización 
y el neoliberalismo, cuyos efectos más notorios se observaron entre 1980 y mediados de la primera década del siglo XXI, periodo durante el cual la universidad sufrió empobrecimiento y privatización (Ramírez, 2013, p. 17). De tal forma que entre 1998 y 2000 se crearon quince universidades, de las cuales trece eran particulares autofinanciadas y dos públicas (Minteguiaga y Ramírez, 2010,p. 138). Esta reforma llegó de la mano con la ola de Gobiernos progresistas en América Latina, que en Ecuador inició en 2007, lo cual implicó un nuevo proceso constituyente y una agenda política y programática de recuperación del Estado, la inversión pública y los derechos, bajo el paradigma del Buen Vivir. En ese marco, la actual Constitución expedida en 2008 declaró la gratuidad de la educación superior hasta el tercer nivel y el establecimiento de un sistema de nivelación y admisión para el sistema público de educación superior.

\section{Dimensión metajurídica}

\section{Características socioeconómicas de Uruguay}

Uruguay es una república democrática con una extensión territorial continental de $176215 \mathrm{~km}^{2}$ y está ubicada en la costa este de América Latina. Cuenta con una población de 3440157 habitantes (INE, 2014, pp. 17, 22), donde más del $90 \%$ de su población se considera blanca (INE, 2018). En general, es considerada como la sociedad con mayores avances en temas de igualdad en América Latina: la brecha entre ricos y pobres visibilizada a través del coeficiente de Gini por ingreso ${ }^{1}$ ha bajado desde 0,47 en 2006 a 0,41 en 2015 (BM, 2018); es decir, hay una importante reducción de la desigualdad en ese periodo, aunque no alcanza el nivel de los países de la OCDE, cuyo promedio en 2014 fue 0,318 (OCDE, 2018). Sin embargo, tiene el ingreso per cápita más alto de América Latina y una clase media del $60 \%$ de su población (BM, 2018). Su PIB pasó de 19,5 mil millones a 52,4 mil millones de dólares entre 2006 y 2016 (BM, 2018) y sus exportaciones se con-

1 Según el Sistema Integrado de Indicadores Sociales del Ecuador, el coeficiente de Gini del ingreso es una medida estadística de la desigualdad en la distribución del ingreso de los perceptores individuales, que varía entre 0 y 1 . Muestra mayor desigualdad mientras se aproxima a 1 y corresponde a 0 en el caso hipotético de una distribución totalmente equitativa. 
centran en productos como carne, cereales, leche y lácteos, madera y manufacturas (Instituto Uruguay XXI, 2011).

La inversión pública de Uruguay en educación superior fue del 1,2\% sobre el PIB en el año 2011 (Ballas, 2016,p. 90) y su tasa bruta de matrícula en la educación superior ${ }^{2}$ tuvo un importante crecimiento entre 2006 y 2010 , pasando de 46,03 a 63,13 (BM, 2018).

\section{Características socioeconómicas de Ecuador}

En cuanto a los indicadores sociales, el Ecuador cuenta con un territorio de $256370 \mathrm{~km}^{2}$ y tiene una población de 14483499 habitantes según el censo poblacional de 2010 (INEC, 2018). El 21,6\% se considera montubio, afroecuatoriano o indígena, el 71,9\% mestizo y el 6,1\% blanco. En general, es una sociedad desigual, sin embargo, han existido esfuerzos para reducir la brecha entre ricos y pobres. Así, el coeficiente de Gini por ingreso pasó de 0,54 en 2006 a 0,47 en 2015 (SIISE, 2018), es decir, hubo una importante reducción de la desigualdad en ese periodo, aunque no se alcanzó el nivel de los países de la OCDE, cuyo promedio en 2014 fue 0,318 (OCDE, 2018).

La economía del país es eminentemente primario-exportadora y secundario-importadora. Su principal recurso es el petróleo con lo cual depende en gran medida de su precio en el mercado internacional. A pesar de los esfuerzos realizados durante los últimos años, en que el PIB pasó de 51 millones de dólares a 98 millones de dólares 3 (BCE, 2018), las exportaciones no petroleras solo crecieron un $14 \%$ entre 2012 y 2016, y esto debido a la caída de los precios del petróleo en los últimos años (BCE, 2018); sin embargo, en la época de la bonanza por los altos precios del petróleo, tales ingresos fueron invertidos en la reducción de la pobreza (Ramírez, 2017, p. 84) para que la crisis no afectara a los estratos más pobres (Ramírez, 2017).

En lo que respecta al acceso a la educación superior, la matrícula creció en 136 mil estudiantes, entre 2006 y 2014, lo que implicó el incremento de 4,1 puntos porcentuales del total y corresponde al doble del crecimiento

2 Tasa bruta de matrícula, educación superior (niveles 5 y 6 de la CINE), total. Corresponde al número total de estudiantes matriculados en educación superior (niveles 5 y 6 de la CINE), independientemente de su edad, expresado como porcentaje de la población total del grupo etario cinco años después de finalizar la enseñanza secundaria (BM, 2018).

3 Años comparados: 2007 y 2016. 
anual poblacional. La probabilidad de ingresar a la universidad siendo pobre en 2006 era del 33\% y en 2014 esa probabilidad aumentó al 67\% (Ramírez, 2016, p. 26).

\section{Dimensión jurídica}

\section{Fuentes del derecho sobre la educación superior}

Las fuentes de derecho que tratan sobre los aspectos de la educación terciaria en Uruguay son las siguientes normas en vigor (enumeradas jerárquicamente): la Constitución de la República del Uruguay (CRU), el PIDESC, la Ley General de Educación (LGE), las leyes de creación de las universidades públicas (Universidad de la República de Uruguay y la Universidad Tecnológica de Uruguay), la ley de presupuesto para el periodo 2016-2021, el Decreto Ley $\mathrm{N}^{\mathrm{o}} 15661$ del 20 de noviembre de 1984 referido a las universidades privadas y el Decreto Ley No 104/014 aprobado el 28 de abril de 2014 que trata sobre las autorizaciones de funcionamiento y registro de carreras de las instituciones de educación terciaria universitaria y no universitaria privadas.

La costumbre no es fuente del derecho en el sistema jurídico uruguayo excepto en los casos que la ley se remite a ella (González et al., 2017, p. 25). No se ha identificado la existencia de litigios que hayan dado lugar a sentencias relacionadas con el ámbito de la enseñanza terciaria. La jurisprudencia no constituye fuente de derecho en el sistema jurídico uruguayo conforme el artículo 12 de su Código Civil, el cual señala: "Solo toca al legislador explicar o interpretar la ley, de un modo generalmente obligatorio. Las sentencias judiciales no tienen fuerza obligatoria sino respecto de las causas en que actualmente se pronunciaren" (en González et al., 2017, p. 26).

En el caso de Ecuador, las fuentes normativas de la educación superior son: la Constitución de la República del Ecuador (CRE), el PIDESC, la Ley Orgánica de Educación Superior (LOES), el Reglamento General a la Ley Orgánica de Educación Superior (RGLOES), la Ley del Fondo de Desarrollo Universitario y Politécnico (FOPEDEUPO), los reglamentos expedidos por el Consejo de Educación Superior (CES) y los reglamentos expedidos por el Consejo de Evaluación, Acreditación y Aseguramiento de la Calidad de la Educación Superior (CEAACES). 
La costumbre no es fuente del derecho en el sistema jurídico ecuatoriano excepto en los casos que la ley se remite a ella tal como lo establece el Código Civil ecuatoriano en su artículo 2. La jurisprudencia constituye fuente de derecho en el sistema jurídico ecuatoriano cuando proviene de parámetros interpretativos de la CRE fijados por la Corte Constitucional. El artículo 2 de la Ley de Garantías Jurisdiccionales y Control Constitucional señala la obligatoriedad del precedente constitucional de interpretación de la CRE; sin embargo, no se ha identificado la existencia de jurisprudencia relacionada con la educación superior.

\section{Categoría de la educación superior en el ordenamiento jurídico de Uruguay y Ecuador}

\section{Uruguay: bien público y derecho fundamental en la ley}

En Uruguay, la educación en general, incluyendo la educación superior - denominada como educación terciaria - es considerada por la LGE como un bien público y un derecho fundamental (arts. 1 y 2 ). Además, se comprende como "el conjunto de propuestas educativas integradas y articuladas para todos los habitantes a lo largo de la vida" (art. 20). Dentro de este sistema se sitúa la educación terciaria como un nivel de formación (art. 22). Sus principios son: universalidad (art. 6), obligatoriedad (art. 7), diversidad e inclusión educativa (art. 8), participación (art. 9), libertad de enseñanza (art. 10), libertad de cátedra (art. 11), autonomía (art. 46), coordinación (art. 47). Por su lado, la CRU garantiza la libertad de enseñanza (art. 68) y declara de utilidad social la gratuidad de la enseñanza superior (art. 71).

\section{Ecuador: bien público y derecho constitucional}

En el Ecuador la educación superior es considerada como un bien público, además de un derecho. La CRE establece que "la educación es un derecho de las personas a lo largo de su vida y un deber ineludible e inexcusable del Estado" (art. 26); además, determina claramente que esta constituye la garantía de la igualdad e inclusión social. El artículo 28 de la CRE señala que "la educación pública será universal y laica en todos sus niveles, y gratuita hasta el tercer nivel de educación superior". A nivel legal, el artículo 2 de la LOES determina que la educación superior es un derecho de 
las personas y un bien público y social. Nuevamente, la misma CRE señala la existencia del sistema de educación superior, conformado por las universidades, escuelas politécnicas, institutos superiores técnicos, tecnológicos y pedagógicos, y conservatorios de música y artes (art. 350). Los principios por los que se rige el sistema que son: autonomía responsable, cogobierno, igualdad de oportunidades, calidad, pertinencia, integralidad, autodeterminación para la producción del pensamiento y conocimiento, en el marco del diálogo de saberes, pensamiento universal y producción científica tecnológica global (art. 351).

\section{Sintesis comparativa}

La educación superior, tanto en Uruguay como en el Ecuador, es considerada como un bien público y un derecho de las personas. En este sentido, ambos países mantienen una visión similar, sin embargo, existen algunas diferencias en cuanto a la relevancia concedida según la fuente normativa. Mientras que en Uruguay la CRU solamente menciona la declaración de utilidad pública de la gratuidad de la enseñanza superior y la garantía de la libertad de enseñanza, la CRE concibe a la educación en general como un derecho y un deber ineludible e inexcusable del Estado. Esa declaración en el caso uruguayo ocurre en la LGE, como parte de la educación en general.

La incorporación como un derecho de carácter constitucional en el Ecuador hace que pueda ser tutelado a través de la justicia constitucional. En el caso de Uruguay, a pesar de no estar expresamente determinado a ese nivel, la CRU establece que "la enumeración de derechos, deberes y garantías hecha por la Constitución, no excluye los otros que son inherentes a la personalidad humana o se deriven de la forma republicana de gobierno" (art. 72). En tal sentido, al ser la educación un derecho reconocido en el PIDESC ratificado por Uruguay, sí sería posible su tutela a través de la acción de amparo establecida en la Ley $\mathrm{N}^{\circ} 16011$ del 19 de diciembre de 1988. Por lo que, en definitiva, la educación superior mantiene el mismo estatus de derecho y bien público en ambos ordenamientos jurídicos.

La consideración de bien público trae consigo, entre otros, el reto de la democratización en su acceso y una mayor atención desde la política pública para evitar una orientación hacia los intereses privados y mercantiles. Sin embargo, las estrategias adoptadas en ambos países guardan diferencias, por ejemplo, la consagración de la autonomía en Uruguay es bastante amplia, mostrando resultados positivos en su entorno, mientras que en el Ecuador a 
la autonomía se la ha caracterizado como "responsable", desde la perspectiva de una nueva ética de las IES (Instituciones de Educación Superior) del Ecuador para actuar con miras a la vinculación y diálogo con la sociedad, y que implica una mayor presencia estatal a través de órganos de control y coordinación de las IES.

\section{Acceso a la educación superior en el ordenamiento jurídico de Uruguay y Ecuador}

Tanto Uruguay como Ecuador han suscrito y ratificado el PIDESC (1966), que al formar parte de los derechos internos de ambos países, implica el reconocimiento dado por estos al "derecho a toda persona a la educación" (art.13, $\left.\mathrm{n}^{\mathrm{o}} 1\right)$. Para alcanzar el pleno ejercicio de ese derecho "la enseñanza superior debe hacerse igualmente accesible a todos, sobre la base de la capacidad de cada uno, por cuantos medios sean apropiados, y en particular por la implantación progresiva de la enseñanza gratuita" (art. 13, $\mathrm{n}^{\circ} 2$-c).

El Comité de Derechos Económicos, Sociales y Culturales (CDESC) determina que para que el derecho a la educación superior se ejerza plenamente, deben existir los elementos de disponibilidad, accesibilidad, aceptabilidad y adaptabilidad. El elemento de disponibilidad se enfoca en la existencia de IES y programas en funcionamiento para responder a la demanda en base a las capacidades de los ciudadanos. El elemento de accesibilidad implica la garantía de no discriminación para el ingreso a la educación superior, asegurando las facilidades físicas y ubicación geográfica, y la eliminación de barreras económicas. El elemento de aceptabilidad tiene que ver con el cumplimiento de estándares mínimos de calidad. Finalmente, el elemento de adaptabilidad está relacionado con la flexibilidad de acoplarse, en el tiempo, a las necesidades y cambios en las sociedades (CDESC, 2013, p. 9, 10, 14).

En tal contexto el siguiente análisis se realizará considerando la accesibilidad a partir de la gratuidad y los sistemas de ingreso como eliminación de las barreras económicas.

\section{La gratuidad como eliminación de barreras económicas}

Uruguay y la gratuidad absoluta. El acceso a la educación superior se caracteriza por ser gratuito y al respecto la CRU señala: 
Declárase de utilidad social la gratuidad de la enseñanza oficial primaria, media, superior, industrial y artística y de la educación física, la creación de becas de perfeccionamiento y especialización cultural, científica y obrera, y el establecimiento de bibliotecas populares. En todas las instituciones docentes se atenderá especialmente la formación del carácter moral y cívico de los alumnos (art. 71).

Al respecto, Justino Jiménez Aréchaga (en Biasco, 2001, p. 13) señala que tal norma es una mera proclamación de aspiraciones, puesto que la gratuidad de la enseñanza en el Uruguay ha existido desde siempre. El autor mencionado considera a la declaratoria de utilidad social una norma de carácter programático, en el sentido de recomendación para que el legislador la considere al momento de expedir las leyes. De forma que la LGE señala que la educación pública estatal se rige por el principio de gratuidad (art. 15).

La Ley de la Universidad de la República es más expresa en su redacción, al afirmar que la enseñanza oficial es gratuita y los estudiantes no deben pagar ningún tipo de derecho o matrícula (art. 66).

La condición de norma programática mas no prescriptiva del artículo 71 de la CRU, se ratifica al observar la excepción establecida en la Ley $\mathrm{N}^{\circ}$ 16.226 del 29 octubre de 1991 (sobre rendición de cuentas y balance de ejecución presupuestal, correspondiente al ejercicio 1990) en donde se faculta a la Universidad de la República a cobrar una matrícula a los estudiantes que tengan las condiciones económicas para pagarla (art. 407).

Ecuador y la gratuidad con responsabilidad académica. La CRE establece que la educación superior pública será gratuita hasta el tercer nivel y que se vinculará a la responsabilidad académica de los estudiantes (art. 356). Esa norma contiene una prescripción condicionada. Por un lado, al disponer la gratuidad existe una prohibición de cobro a los estudiantes en las instituciones de educación superior públicas, pero en el marco de la responsabilidad académica. Es en este punto que la CRE da margen al legislador para que desarrolle el contenido de dicho criterio y así lo hace la LOES, que fija los parámetros a observarse para gozar de la gratuidad. Entre los más relevantes están: a) estudiantes que se matriculen en al menos el 60\% de las materias en cada periodo académico, b) solo se cubre las primeras matrículas ordinarias, c) se financia una sola carrera, d) solo se cubre los rubros obligatorios e indispensables para cursar y obtener la titulación, y e) se pierde la gratuidad de manera definitiva si el estudiante reprueba el 30\% de las materias cursadas (art. 80). 


\section{Sintesis comparativa}

Ambos ordenamientos establecen el acceso gratuito a la educación superior en el sistema público, una característica relevante, tomando en cuenta que la gratuidad es considerada por el PIDESC como una forma de alcanzar el pleno ejercicio del derecho a la educación. No obstante, existen algunas diferencias. La gratuidad de la educación superior pública en Uruguay no se encuentra prescrita a nivel constitucional, pero ha sido una realidad que acompaña a la universidad uruguaya desde su nacimiento, por lo que, aunque puede considerarse jurídicamente más frágil, el consenso social sobre el tema parece garantizar su permanencia. En contraste, en el Ecuador la gratuidad existe hace apenas diez años, tanto a nivel normativo-constitucional como en los hechos. En términos jurídicos, tiene mayor fortaleza que en el caso uruguayo y constituye una reivindicación lograda por los movimientos estudiantiles en un escenario político favorable para una agenda pro derechos.

Por otra parte, mientras la gratuidad en Uruguay es absoluta, en Ecuador está condicionada al criterio de responsabilidad académica. Este punto puede estar influenciado por las diferencias económicas y poblacionales de ambos Estados. Uruguay tiene una población estudiantil ${ }^{4}$ significativamente menor a la que existe en Ecuador, con un PIB per cápita significativamente mayor al de Ecuador, ${ }^{5}$ en tal sentido, le resulta posible disponer de los recursos en términos absolutos para garantizar la gratuidad de manera incondicionada. En Ecuador, a pesar de los esfuerzos para la inversión en educación superior - que incluso ha superado el porcentaje promedio de los países de la OCDE (Ballas, 2016, p. 90) - , los recursos deben ser cuidadosamente administrados. Por otro lado, se considera que si bien las personas tienen derecho a la educación pública gratuita, también es necesaria una retribución al esfuerzo social encaminado a través del Estado para su formación, y que esa retribución se traduzca principalmente en el esfuerzo y cumplimiento de las responsabilidades académicas. Es decir, el aspecto de la responsabilidad académica implica una nueva ética social que busca la superación de la mirada individual liberal a través de la integración de esfuerzos para alcanzar objetivos colectivos.

4 La matrícula de educación superior en Uruguay a 2014 fue de 165 mil personas (Presidencia de Uruguay, 2016).

5 PIB per cápita: Ecuador USD 5 968,98 (BM, 2016), Uruguay USD 15 220,57 (BM, 2016). 


\section{Sistema de ingreso en el ordenamiento jurídico}

Uruguay y el libre ingreso sin discriminación. En Uruguay generalmente la educación superior pública tiene libre ingreso, esto es, la inexistencia de un examen nacional o institucional o cualquier otro mecanismo de selección para ser aceptado en una institución pública. No se ha encontrado ninguna norma que lo prescriba de esa manera, sin embargo, en la noción de máxima autonomía, la Universidad de la República no aplica exámenes para el ingreso, en consecuencia, todos los aspirantes que deseen estudiar pueden hacerlo; así lo manifiesta Martínez (2003, p. 38), señalando, además, que otras instituciones de educación terciaria pública sí realizan algún proceso de selección por falta de cupos.

Ecuador y el sistema de nivelación y admisión para garantizar meritocracia y eficiencia. En el Ecuador el ingreso a la educación superior pública no es libre. La LOES determina un sistema unificado de acceso a la educación superior a través de un examen nacional y un periodo de nivelación de conocimientos debido a la heterogeneidad de los resultados de aprendizaje de la educación media. Este sistema es administrado por la Secretaría de Educación Superior, Ciencia, Tecnología e Innovación (SENESCYT). Los cupos son asignados en base a: el puntaje obtenido, la selección por parte del futuro estudiante de un número de posibles opciones de IES y el número de plazas disponibles dentro de esa selección (art. 81). ${ }^{6}$

Las IES privadas que reciben recursos del Estado deben poner a disposición de este sistema de acceso un número determinado de plazas (art. 74) y respecto a los demás cupos, al igual que el resto de las IES privadas, pueden aplicar sus propias reglas de ingreso, siempre que estas no sean de carácter discriminatorio conforme lo determina el RGLOES (art. 4), además de conceder un número de becas equivalente al $10 \%$ del total de su matrícula para personas con alto rendimiento académico, deportivo o pertenecientes a grupos históricamente excluidos (art. 77).

\section{Sintesis comparativa}

En lo que respecta al sistema de ingreso, a nivel de ordenamiento jurídico no es posible efectuar una comparación puesto que Uruguay no cuenta

6 Actualmente, en la Asamblea Nacional se encuentra en tratamiento un proyecto de reforma a la Ley Orgánica de Educación Superior del Ecuador, que podría modificar el sistema de ingreso a las IES en este país. 
con reglas relacionadas al tema. Podría señalarse que la ausencia de un sistema de ingreso implica una mayor democratización en el acceso, puesto que elimina cualquier discriminación del origen y la educación previa de los aspirantes a la educación superior; esto sumado a la gratuidad, se traduce en la ausencia de barreras para acceder a la formación superior. En contraste con esta idea, Germán Rama señala que:

El hecho de que la universidad no tenga un proceso de selección no quiere decir que este no exista. Existe y es el más duro, es el fracaso. Es también el más caro desde el punto de vista humano y material (en Martínez, 2003, p. 38).

No obstante, desde el punto de vista del derecho a la educación superior, en relación a las condiciones para el acceso — gratuidad y libre ingreso-, el esquema uruguayo garantiza un alto grado de igualdad de oportunidades para el acceso. Esto no quiere decir que por ello no sea necesario considerar otros aspectos que no son materia de este trabajo, como la homogeneidad de los resultados de aprendizaje de la educación media y los costos de oportunidad entre los estudios y el trabajo para los jóvenes de los estratos más pobres de la sociedad.

Por otro lado, el sistema de Ecuador intenta alcanzar un equilibrio entre la eficiencia económica, la igualdad de oportunidades, la meritocracia y la calidad. En los esfuerzos por construir una sociedad más justa e igualitaria, la educación superior tiene un lugar privilegiado, pero no es el único ámbito que requiere atención del Estado. Así, los recursos públicos para este sector se han duplicado en diez años (Ballas, 2016, p. 92), pero lograr una armonía entre la demanda y oferta de cupos en las IES es una tarea compleja, pues la primera supera a la segunda. En tales condiciones, el libre ingreso podría implicar el detrimento de la calidad (Ramírez, 2017, p. 25). Frente a recursos escasos, a aumentar la capacidad física del sistema y a incrementar la calidad, resulta necesario un mecanismo que procure equilibrio, viabilidad y la mayor justicia posible. Así, el examen busca identificar a los ciudadanos con mayores aptitudes para la formación superior y la nivelación pretende igualar los conocimientos de partida que pueden tener diferencias por la heterogeneidad de la educación media (Araujo, 2016, pp. 139-147). No obstante, existen posiciones contrarias que cuestionan el examen, entre otros aspectos, por considerar que es un mecanismo discriminador puesto que no se evalúa solo aptitudes, sino también conocimientos, por tanto, aquellos 
que no tuvieron la oportunidad de aprehender esos conocimientos estarían siendo discriminados (Zambrano, 2016, p. 11).

En todo caso, a pesar de que este sistema no tiene el mismo grado de democratización de Uruguay, significa un avance autorreferencial en la materia, considerando que existe desde el año 2010; previo a eso, cada IES definía sus propios procesos de selección bajo diferentes perspectivas y objetivos que dieron como resultado una discriminación negativa por origen socioeconómica. De tal suerte, Ramírez (2016) señala que "la posibilidad de entrar a la educación superior siendo parte del 20\% más pobre en el 2014 es del 67\% en tanto que en el 2006 era del 33\%" (p. 20). En este sentido, desde una perspectiva del derecho a la educación superior en el Ecuador, este sistema representa un importante avance en la eliminación de barreras económicas y por tanto en mejorar las condiciones para el pleno ejercicio de ese derecho.

\section{Conclusiones}

\section{Educación como bien público y derecho de las personas}

Si bien los ordenamientos jurídicos uruguayo y ecuatoriano se asemejan al considerar a la educación superior como un bien público y un derecho de las personas, se diferencian en la jerarquía de la norma jurídica en la que se efectúa este reconocimiento. Mientras en el Ecuador el carácter de bien público y derecho se encuentra a nivel constitucional, en Uruguay halla su basamento en la LGE como una declaración aplicable a todos los niveles de educación; no obstante, esta distinción no limita la posibilidad de que el derecho sea tutelado jurisdiccionalmente, puesto que la CRU extiende su protección a los derechos inherentes a la personalidad humana.

\section{Acceso gratuito a la educación superior pública}

Los ordenamientos jurídicos uruguayo y ecuatoriano guardan similitud en cuanto al establecimiento de la gratuidad de la educación superior en el sistema público y se diferencian, una vez más, en la jerarquía normativa del instrumento que la contempla. La Constitución del Ecuador es expresa al 
consagrar la gratuidad de la educación superior, mientras que en Uruguay existe la declaración de utilidad pública de la gratuidad a nivel constitucional y a nivel legal el principio de gratuidad.

Otra diferencia relevante es que la gratuidad en Uruguay es incondicional en todos los niveles, mientras que en Ecuador depende de la responsabilidad académica del estudiante y se aplica a una sola carrera de tercer nivel.

\section{Sistema de ingreso a la educación superior}

En lo que se atiene a los sistemas de ingreso a la educación superior, pese a que Uruguay no contempla normas al respecto en su legislación, en la práctica, lo que acontece es que se evidencia un acceso es libre e incondicionado, mientras tanto en Ecuador se ha desarrollado un sistema reglado que procura eficiencia económica, igualdad de oportunidades, meritocracia y calidad.

\section{Bibliografía}

Araujo, L. (2016). El Sistema Nacional de Nivelación y Admisión en Ecuador. En R. Ramírez (ed.), Universidad urgente para una sociedad emancipada (pp. 127-162). Quito: IESALC.

BCE. Estadísticas. Recuperado de https://goo.gl/doFWco/

BM. Datos Banco Mundial. Recuperado de https://goo.gl/34gGqn/

Ballas, C. (2016). Financiamiento de la educación superior en Ecuador. En R. Ramírez (ed.), Universidad urgente para una sociedad emancipada (pp. 84-106). Quito: IESALC.

Biasco, E. (s/f). La gratuidad de la enseñanza pública superior en el Uruguay. Recuperado de https://goo.gl/8FbRYw/

CEAACES. Lista de institutos técnicos y tecnológicos. Recuperado de www.ceaaces.gob.ec

Consejo de Educación Primaria. (8 de enero de 2018). Fundamentos generales para un programa de educación común. Recuperado de https://goo.gl/tbyLaL/

CES. Universidades y Escuelas Politécnicas. Recuperado de www.ces.gob.ec

De Almeida, C. y Carvalho, J. (2017). Introdução ao Direito Comparado. Coimbra: Almedina.

CDESC. (2013). Right to Education: Scope and Implementation. UNESCO. Recuperado de https://bit.ly/2KrTRYs/ 
Contera, C. (2008). La educación superior en Uruguay. Avaliaçao, 13(2), 533-554. González, M., Howard, W., Vidal, K. y Bellin, C. (2017). Manual de derecho civil. Montevideo: Universidad de la República de Uruguay.

Guijarro, J. (2016). Autonomía universitaria: política no metafísica. En R. Ramírez (ed.), Universidad urgente para una sociedad emancipada (pp. 241262). Quito: IESALC.

INE. (s/f). Uruguay en cifras. Montevideo: INE. Recuperado de https://goo.gl/jfQVtk/ INE. (s/f). Estadísticas Uruguay. Recuperado de https://goo.gl/U47fHo/ INEC. (s/f). Resultados del Censo 2010. Recuperado de https://goo.gl/yJ1rw4/ Instituto Uruguay XXI. (2011). Concentración de las exportaciones de Uruguay y las de sus competidores. Recuperado de https://goo.gl/byDhjE/

Martínez, E. (2003). La educación superior de Uruguay en transición: inercias y horizontes de cambio. Montevideo: IESALC/UNESCO.

Minteguiaga, A. y Ramírez, R. (2010). Transformaciones en la educación superior ecuatoriana: antecedentes y perspectivas futuras como consecuencia de la nueva Constitución política. Las transformaciones de la educación superior en América: Identidades en construcción. Educación Superior y Sociedad, 1, 129-154. Recuperado de https://goo.gl/Tvr4wG/

Moura Vicente, D. (2012). Direito Comparado. Coimbra: Almedina.

OCDE. (8 de enero de 2018). Distribución del ingreso por pobreza. Recuperado de https://goo.gl/cEfnGe/

Pacheco, L. (2015). La primera evaluación de la universidad ecuatoriana (19801988). Quito: CES.

Ramírez, R. (2013). Tercera ola de transformación de la educación superior en el Ecuador: hacia la constitucionalización de la sociedad del buen vivir. Quito: SENESCYT.

Ramírez, R. (ed.). (2016). Universidad Urgente para una Sociedad emancipada. Quito: IESALC.

Ramírez, R. (2017). La gran transición: en busca de nuevos sentidos comunes. Quito: CIESPAL.

Ramírez, R. (28 de enero de 2017). Rompiendo con la ley de la gravedad económica: primero los pobres, las grandes mayorías y "ajuste a la inversa”. Recuperado de reneramirez.ec.

SIISE. Distribución del consumo: coeficiente de Gini. Recuperado de https://goo. $\mathrm{gl} / 3 \mathrm{bZWmx} /$

QS Universities. (s/f). QS World University Rankings Latin America. Recuperado de https://goo.gl/cL2CKj/ 
UNESCO. (2015). Revisión regional 2015 de la educación para todos: América Latina y el Caribe. Recuperado de https://goo.gl/hrXnv7/

UNESCO. (2018). Enrolment by level of education and type of institution. Recuperado de https://goo.gl/jvyCsw/

Zambrano, J. (2016). Una mirada crítica al examen nacional para la educación superior en Ecuador. EduSol, 16(56), 37-51.

\section{Fuentes normativas de Uruguay}

Código Civil de Uruguay No 16603 (1994).

Constitución de la República Oriental de Uruguay (1830).

Constitución de la República Oriental de Uruguay (1918).

Constitución de la República Oriental de Uruguay (1934).

Constitución de la República Oriental de Uruguay (1952).

Constitución de la República Oriental de Uruguay (1967).

Decreto de Uruguay No 308/995 (1995).

Decreto de Uruguay No 104/014 (2014).

Ley de Creación de la Universidad Tecnológica de Uruguay No 19043 (2013).

Ley General de Educación de Uruguay N 18437 (2009).

Ley de Instrucción Pública de Uruguay No 1350 (1877).

Ley de Presupuesto Nacional de Uruguay 2016-2020 No 19355 (s/f).

Ley de Rendición de Cuentas y Balance de Ejecución Presupuestal del Ejercicio $1990 \mathrm{~N}^{\mathrm{o}} 16226$ (1991).

Ley Orgánica de la Universidad de la República de Uruguay (1958).

Ley sobre disposiciones para los títulos profesionales que otorguen las universidades privadas de Uruguay $\mathrm{N}^{\circ} 15661$ (1984).

Pacto Internacional de Derechos Económicos, Sociales y Culturales (1966).

\section{Fuentes normativas del Ecuador}

Código Civil de Ecuador (2005).

Constitución Política del Ecuador (1835).

Constitución Política del Ecuador (1861).

Constitución Política del Ecuador (1897).

Constitución Política del Ecuador (1929).

Constitución Política del Ecuador (1945).

Constitución Política del Ecuador (1967).

Constitución Política del Ecuador (1979).

Constitución Política del Ecuador (1998).

Constitución Política del Ecuador (2008). 
Ley del Fondo Permanente de Desarrollo Universitario y Politécnico de Ecuador (1996).

Ley de Universidades y Escuelas Politécnicas de Ecuador (1982).

Ley Orgánica de Educación Superior de Ecuador (2000).

PIDESC Pacto Internacional de Derechos Económicos, Sociales y Culturales (1966).

Reglamento General a la Ley Orgánica de Educación Superior de Ecuador (2011).

Fecha de recepción: 2018/04/01; Fecha de aceptación: 2018/07/24;

Fecha de publicación: 2018/09/01 


\title{
Club de periodismo como incidente comunicacional en el proceso educativo
}

\author{
Journalism club as a communicational incident \\ in the educational process
}

\author{
Jefferson J. Sandoval G. \\ Universidad de Guayaquil \\ jefferson.sandovalg@ug.edu.ec \\ Código Orcid: https://orcid.org/0000-0002-3732-2041 \\ Tomás H. Rodríguez C. \\ Universidad de Guayaquil \\ tomas.rodriguezc@ug.edu.ec \\ Código Orcid: https://orcid.org/0000-0002-4673-9295
}

\begin{abstract}
Resumen
Este trabajo analiza la recepción de los géneros periodísticos interpretativos en la Academia Naval Guayaquil, a partir de la incidencia comunicacional del Club de Periodismo del diario El Telégrafo. Se buscó identificar los procesos de recepción de los géneros interpretativos y su incidencia comunicacional en los estudiantes. El tipo de investigación fue descriptiva, con una metodología hermenéutica y nueve técnicas de investigación (entre cuantitativas y cualitativas). La población para la investigación fue de 357 estudiantes, usando una técnica probabilística con ecuaciones matemáticas para cuantificar la muestra, la misma que correspondió a 145 alumnos. A través de esto, se logró observar la necesidad de implementar los géneros interpretativos como tema de estudio, para generar y desarrollar las habilidades cognitivas y diseñar estrategias de comunicación efectivas dentro de la institución, todo esto enfocado a mejorar el proceso de aprendizaje.
\end{abstract}

\section{Palabras clave}

Comunicación, educación, recepción, incidencia, géneros interpretativos.

Forma sugerida de citar: Sandoval, Jefferson y Rodríguez, Tomás (2018). Club de periodismo como incidente comunicacional en el proceso educativo. Universitas, 29, pp. 177-199. 


\begin{abstract}
In this work it was analyzed the reception of interpretive genres in Guayaquil Naval Academy based on the communicational impact of the Journalism Club from the newspaper El Telégrafo. It was sought to identify the processes of reception of the interpretive genres and their communicational incidence on students. The type of research is descriptive, the methodology is hermeneutical. In this investigation it was used nine research techniques, between quantitative and qualitative. Population is 357 students, it was used the probabilistic technique with mathematical equations to quantify the sample, which corresponds to 145 students. It was found out that there is a need to implement interpretive genres in the study area, to generate and develop cognitive skills, and design effective communication strategies in the institution. All these techniques will help to improve the learning process.
\end{abstract}

\title{
Keywords
}

Communication, education, reception, incidence, interpretive genres.

\section{Introducción}

El conocimiento de los géneros interpretativos desde el colegio, comprende un desenvolvimiento en las áreas de educación, comunicación, información y redacción de datos. Los clubes de periodismo en los centros educativos son ideados para ejercer el desarrollo de las habilidades cognitivas a temprana edad. El pensar e investigar de una manera enfática sobre problemas recurrentes de la sociedad, los invita a manifestar esas habilidades que no son desarrolladas durante la etapa de bachillerato, sino mucho tiempo después, cuando entran a una carrera universitaria; por tal motivo su implementación a escala progresiva dará forma y guía a estas destrezas.

Esta investigación promueve el análisis de recepción e incidencia que producen estos géneros en los estudiantes de la Academia Naval Guayaquil, que ha sido sede del Club de Periodismo del diario público El Telégrafo.

Esta indagación presenta un problema frecuente dentro de las unidades educativas, como por ejemplo, la no utilización de planes estratégicos que vinculen el periodismo con las demás asignaturas, lo que ocasiona futuros jóvenes sin la habilidad de conocer el panorama que los rodea o la poca es- 
timulación de sus sentidos para actuar en pro de una sociedad ávida de información como la actual.

Por tal motivo se ha formulado la siguiente pregunta: ¿Cómo se analiza la recepción de los géneros interpretativos en los alumnos de Bachillerato de la Academia Naval Guayaquil a partir de la incidencia comunicacional del Club de Periodismo de El Telégrafo?, la misma que será contestada más adelante.

Dentro del proyecto se conocen nuevos referentes teóricos que avalan este proceso, la utilización de métodos y técnicas para encontrar resultados válidos y fehacientes del progreso, asimismo, se visualiza el campo de los clubes en la actualidad y el desempeño que estos ejercen en los alumnos. No obstante, se plantea una propuesta de inserción de estos géneros a través de un plan de revista mensual realizado por los propios docentes y jóvenes.

De esta forma se expone el objetivo general, que concluye en identificar los procesos en cuanto al análisis de recepción de los géneros interpretativos y su incidencia comunicacional en los alumnos de bachillerato de la Academia Naval Guayaquil, los mismos que fueron impartidos por el Club de Periodismo de El Telégrafo en el año 2017. Se deja claro que los objetivos específicos - como el investigar las teorías, métodos y técnicas de la incidencia y recepción comunicacional, variables que se presentan a lo largo del proceso - son los mismos que ayudan a conseguir los resultados, el desarrollo del objetivo general y el planteamiento de la propuesta mencionada.

En el transcurso de este artículo se desglosa a la comunicación como una de las ciencias que permite al ser humano dar significado a su lenguaje y a la forma que transmite un mensaje. No está de más comprender que a través de un club de periodismo esta área se refuerza y se visualiza como el campo de partida que toma esta investigación. De la misma forma, se refuerza a la educación como una disciplina en la cual intervienen métodos y técnicas que facilitan la enseñanza y el aprendizaje de nuevos conocimientos. Además, se determina la predisposición de los estudiantes en cuanto a la inserción del periodismo con las demás asignaturas.

Cabe destacar que la comunicación y la educación, son fundamentales en el proceso investigativo, los mismos que al cohesionarse forman vertientes de estudio, por lo que al avanzar con el proyecto comunicativo se destaca al mismo tiempo el eje educativo la segunda:

La educación ha de ser pensada, practicada y valorada desde diferentes perspectivas. Hay que sumar las aportaciones de los diversos sectores y actores a 
la tarea educativa. La educación es un fenómeno social y cultural, y no solo un proceso instructivo y cognitivo que se lleva a cabo en las escuelas (Freinet y Saint-Luc en González, 2013, p. 16).

La fehaciente realidad de las instituciones nos demuestra que ellas proponen las mismas actividades de aprendizaje sin ningún cambio, lo que provoca desinterés por parte del estudiantado y motiva la conducta "repetitoria" que ha marcado la educación por años. Sin embargo, la inserción de dinámicas extracurriculares o la integración de estas a la malla curricular, promueven una salida de este círculo interminable de frustraciones educativas.

Este mismo proceso revela a la enseñanza como un factor imprescindible, pero que sin una comunicación efectiva se vuelve una pequeña versión de una estructura gigante, tal como puede inferirse de las opiniones de Mario Kaplún:

El profesor uruguayo Mario Kaplún (1997) usaba expresiones como: “se aprende al comunicar", "conocer es comunicar" o "del educando oyente al educando hablante", y afirmaba: "educarse es involucrarse y participar en un proceso de múltiples interacciones comunicativas” (Pérez y Valdés, 2018, p. 59).

No existe razón para no involucrarse en los procesos educativos de las instituciones, puesto que ellos necesitan una mejora en cuanto a sus estrategias comunicativas y el mismo Kaplún lo menciona: se debe participar conjuntamente y más aún con jóvenes en etapa de formación de sus habilidades. Pero la educación y los medios deben aparecer unidos desde temprana edad:

El ámbito escolar es uno de los espacios apropiados para iniciar la educación en medios. El desarrollo del pensamiento crítico y creativo y la capacidad de análisis constituyen dos grandes oportunidades de aprendizaje a partir del uso de las tecnologías de información y comunicación en el ámbito educativo, destinado a crear un periódico digital donde la escuela y sus protagonistas son generadores de noticias (Fischietto, 2014, p. 58).

Por esta razón, la educación que se imparta será vital en el desarrollo de las habilidades y construcción de los conocimientos vinculados a la relación que tiene la comunicación con esta área. Porque a través de ella se crean hábitos, valores, creencias, y no solo se aprende en un aula de clase, sino que al buscar información de internet, de personas y de algún otro sitio - lo que se conoce como educación autodidacta - , se incentiva al estudian- 
tado a permanecer en los clubes con la aportación de nuevas ideas. Por eso, un proceso de aprendizaje a temprana edad sobre la comunicación y el periodismo, sería la solución a los errores que se cometen a la hora de redactar o manifestar ideas.

Al destacar el periodismo dentro de las actividades extracurriculares, los jóvenes interactúan dentro del área comunicativa, sin embargo, desconocen la profesión y por ende asumen que la misma solo es una carga de trabajo. Es así que en el trabajo de titulación de Castro y Ortiz se puede leer lo siguiente:

Cuando se ejerce periodismo educativo, se requiere que los estudiantes desarrollen habilidades básicas para escribir, organizar los pensamientos, hacer un primer borrador y expresar ideas (editar, pulir y presentar un producto final). Esta forma de utilizar el periodismo, demanda que los estudiantes produzcan mensajes en forma de escritos (artículos de opinión, noticias, etc.); avisos publicitarios persuasivos (texto e imagen); y permite la aplicación práctica de los conceptos teóricos (Castro y Ortiz, 2011, p. 6).

El periodismo educativo o la educación periodística (a temprana edad), organizan y desarrollan el pensamiento de los jóvenes, promoviendo la creación de mensajes inéditos, el mejoramiento de las técnicas de investigación y la ampliación de conocimientos y las destrezas de escritura. El periodismo motiva a que los jóvenes se involucren en actividades que no conocían, ya no solo en la malla curricular, sino que visualicen los problemas comunes y desatendidos de la sociedad, donde ellos puedan tomar parte de los inconvenientes y a través de la redacción aprendan a contar o expresar las situaciones que los rodean. Se trata de un conocimiento indispensable para el desarrollo de cualquier otra asignatura, como se puede ver a continuación:

Con esta concepción nace el modelo "aprender haciendo", configurando el carácter activo-participativo de la formación periodística, el mismo que involucra el planteamiento de problemas auténticos para estimular el pensamiento, las observaciones, las situaciones analíticas y las oportunidades para descubrir soluciones. De esta manera nace el Club de Periodismo de Diario El Telégrafo, una iniciativa que consolida la redacción como el eje principal del aprendizaje periodístico y la mejor manera de aprender a escribir es promoviendo la práctica constante como medio de conocer, analizar, valorar y criticar (Correa, 2016, p. 17). 
Fue así como el club de periodismo surgió desde los estudiantes para los estudiantes. Cabe recalcar que todos los jóvenes fueron guiados por profesionales de la comunicación, pero con el objetivo no de enseñar la profesión, sino de generar un pensamiento crítico. En un principio, solo se lo analizó como una ayuda a los estudiantes universitarios para la expansión de sus prácticas o una ampliación de su vida laboral, sin embargo, la aceptación fue tal, que se lo transmitió a los colegios con el afán de mejorar el método de aprendizaje utilizado en el pensum académico.

El porqué de los géneros interpretativos se explica por el proceso cognitivo del estudiante: a través de la redacción de los textos incrementa o perfecciona su creatividad, su formación y despliegue de ideas, así como su desenvolvimiento en las escenas periodísticas, sobre todo al utilizar el conocimiento aprendido en las demás asignaturas.

Dentro de este análisis se tuvieron en cuenta dos variables que permitieron medir la opinión y el desempeño de los estudiantes. La primera se basó en la recepción de los géneros interpretativos como un sistema de enseñanza y de mejoramiento en el desempeño estudiantil. La segunda fue la incidencia que provoca recoger esta información, adoptarla, transformarla y utilizarla en los diferentes campos de estudio en los que se desenvuelven los jóvenes. Porque esto repercute tanto en su vida social como escolar.

\section{Recepción comunicacional}

Como primer punto del análisis, se trabaja la estructura de la recepción que se origina dentro de la comunicación. Asimismo, se contempla que esta permite acoger información, interpretarla y sacar de ella un estímulo capaz de generar una retroalimentación del investigador y de los estudiantes. Un proceso científico valedero de analizar en el documento Estudio de recepción del periódico comunitario El Chulla Quiteño, deja claro que:

El análisis de la recepción es una corriente teórica de las ciencias de la comunicación que ofrece interesantes posibilidades para la investigación; como marco teórico y fuente de conceptos útiles para comprender la relación que establecen las audiencias con los medios y como una fértil matriz de recursos metodológicos y técnicas para producir información sobre dicha relación (Flores en Tapia, 2016, p. 17). 
En este sentido, se propone un campo de investigación que va en relación hacia el aprendizaje de los jóvenes, de cómo captan las imágenes, las ideas y sobre todo el conocimiento, fundamental en su proceso de formación, progreso y construcción de habilidades. Por eso la recepción abarca un proceso fundamental en este planteamiento, ayuda a cuantificar y medir el desarrollo de cada uno de los temas propuestos en el club de periodismo. Además, se estimulan los sentidos, la proyección de los escritos, el trabajo continuo de los estudiantes y el carácter periodístico que se necesita para trabajar en un medio.

Así, es necesario reconocer las diferentes formas en que los estudiantes aprenden, para lo cual es de utilidad la siguiente tabla de La "Flipped Classroom" como recurso metodológico aplicado a la docencia:

\section{Tabla 1}

\section{Dimensiones del aprendizaje}

\begin{tabular}{|l|l|l|l|}
\hline $\begin{array}{c}\text { Aprendizaje } \\
\text { Significativo }\end{array}$ & $\begin{array}{c}\text { Clasificación de las } \\
\text { relaciones entre los } \\
\text { conceptos }\end{array}$ & $\begin{array}{c}\text { Enseñanza } \\
\text { audiotutelar bien } \\
\text { diseñada }\end{array}$ & $\begin{array}{l}\text { Investigación científica } \\
\text { o de creación (música o } \\
\text { arquitecturas nuevas) }\end{array}$ \\
\hline & $\begin{array}{l}\text { Conferencias, o } \\
\text { presentaciones de la mayor } \\
\text { parte de los libros de texto }\end{array}$ & $\begin{array}{l}\text { Trabajo escolar en el } \\
\text { laboratorio }\end{array}$ & $\begin{array}{l}\text { "Investigación" más } \\
\text { rutinaria o producción } \\
\text { intelectual }\end{array}$ \\
\hline $\begin{array}{l}\text { Aprendizaje } \\
\text { por repetición }\end{array}$ & Tablas de multiplicar & $\begin{array}{l}\text { Aplicación de } \\
\text { fórmulas para } \\
\text { resolver problemas }\end{array}$ & $\begin{array}{l}\text { Soluciones a } \\
\text { rompecabezas por } \\
\text { ensayo y error }\end{array}$ \\
\hline & $\begin{array}{l}\text { Aprendizaje por } \\
\text { recepción }\end{array}$ & Guiado & Autónomo \\
\cline { 2 - 4 } & Aprendizaje por descubrimiento \\
\hline
\end{tabular}

Fuente: Ausubel et al., en Balbas, 2014,p. 11

En esta tabla se hace énfasis a los distintos métodos de aprendizaje entre los cuales están el significativo, por repetición, por descubrimiento y por recepción - que engloban los procesos y técnicas utilizadas por docentes para el sistema educativo, no obstante, se plantea un estudio comunicacional donde el estudiante a más de recibir la clase, formule ideas relevantes de lo que ha captado durante todo el tiempo.

No hay que olvidar que cada metodología aplica un sinnúmero de factores entre los estudiantes, las mismas que desarrollan habilidades, entre ellas, 
las que benefician el perfeccionamiento de la comunicación, como muestra se refleja la participación continua de los asistentes, es decir, una retroalimentación entre ambos bandos.

\section{Incidencia del proceso comunicacional}

Por otro lado, la incidencia se posiciona desde el punto de vista que logra influenciar o repercute en la vida social de un joven. Dentro del aula de clase, los jóvenes son expuestos a decenas de conocimientos, sin embargo, no todos ellos pueden ser adquiridos. En el club de periodismo de El Telégrafo se propone la construcción y exposición de los géneros interpretativos, y la repercusión en el aprendizaje de los estudiantes; además, dentro de la investigación intervienen otros factores como la motivación y la participación, que también pueden ser valorados.

Es importante mencionar que la Incidencia de la Metodología en el Rendimiento Académico de la Matemática los alumnos utilizan desde los primeros niveles educativos la memoria y la ejercitación repetitiva para estudiar. A esto se suma que la mayoría de los estudiantes llegan con grandes falencias, entre ellas, falta de conocimientos básicos mínimos en las diferentes disciplinas, carencia de hábitos de lectura y de perseverancia y esfuerzo en la búsqueda de resultados (Mena et al., en Toledo y Balseca, 2013, p. 11).

Así como en las matemáticas, que es una ciencia exacta, el lenguaje o la comunicación debe darse de una forma clara, concisa y precisa. Esto permite que el receptor, en este caso el estudiante, reciba un mensaje sin intervenciones ni modificaciones, lo que a su vez representa un proceso comunicacional superior.

Los estudiantes manejan un lenguaje básico, en ellos se refleja una carencia de conocimientos en cuanto a la redacción de una noticia, así como en la locución de pequeños textos y la realización de preguntas simples, por lo tanto, observar su determinación en las charlas propone el tema a investigar y plantear la evolución que tendrán en el transcurso del club.

Por ello, es prometedora esta investigación, como se aborda el siguiente gráfico: 
Figura 1

Categorías fundamentales
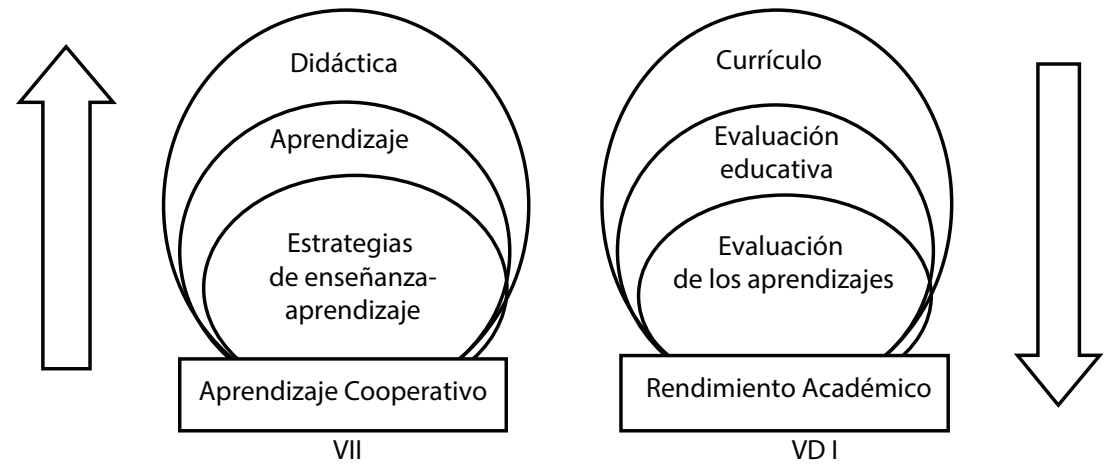

Fuente: Cotallat y DT-Núñez, 2012, p. 18

En la figura se observan dos perspectivas, la primera que apunta al aprendizaje cooperativo y cómo es transmitido a los estudiantes; por consiguiente, se plantea el uso de estrategias en la enseñanza y el método didáctico por el cual son transferidos. La segunda, producto de un procedimiento más elaborado, analiza la incidencia que tienen los conocimientos impartidos, resolviendo a través de una evaluación que mide el entusiasmo, la motivación, etc., así como cuantifica el conocimiento adquirido a través de otra valoración.

Cada área de la comunicación representa una estructura organizada y sistematizada desde el punto de vista de un periodista, por esta razón, conocer los diferentes esquemas y bases teóricas sobre la recepción e incidencia que marcan esta investigación, será relevante para ponerlos en práctica con los estudiantes.

\section{Habilidades cognitivas}

En el transcurso de esta investigación vimos que el aprendizaje periodístico genera en los estudiantes habilidades cognitivas, pues abarca el estudio del pensamiento, del lenguaje y del conocimiento. Además, apreciamos que 
la recolección de información - que en este caso son los géneros interpretativos - ayuda al proceso de creación e imaginación. Entre las habilidades a relucir se encuentra: la atención, la comprensión, la elaboración y la memorización, que son técnicas de estudio, cada una de ellas inmersas en el ser humano, pero no formadas ni desarrolladas en el proceso educativo, lo que a través del club de periodismo como una actividad extracurricular se intenta motivar. Por eso es ilustrativa la siguiente tabla del trabajo "La enseñanza de estrategias de aprendizaje en educación infantil":

Tabla 2

Habilidades de procesamiento

\begin{tabular}{|l|l|}
\hline \multicolumn{1}{|c|}{ Habilidades } & \multicolumn{1}{c|}{ Sub-habilidades } \\
\hline Observar & Auto-observación, observación directa \\
\hline Comparar & Análisis comparativo, búsqueda eficaz de información \\
\hline Ordenar, clasificar & Orden: serial, temporal, espacial \\
\hline Representar & Representación: gráfica, icónica, verbal, gestual \\
\hline Memorizar & Codificación cognitiva, evocación, reconocimiento, reconstrucción \\
\hline Evaluar & Toma de decisiones, demostración \\
\hline Transferir & Inferir, transferir, interpretar \\
\hline
\end{tabular}

Fuente: Nisbet et al., en Jiménez et al., 2007, p. 9

Es seguro precisar múltiples habilidades y sub habilidades necesarias para aprender y pensar, puesto que todas ellas están relacionadas dentro de la comunicación. Conocer las estrategias que demanda un trabajo periodístico no solo ayuda a su desarrollo intelectual, sino también a su parte locuaz. Un comunicador debe poder observar los hechos de una manera diferente a los demás, excavar lo profundo de un tema al punto de revelar nueva información que en el futuro pueda utilizar; sin embargo, estas habilidades se construyen desde la escuela y ya en el colegio su perfeccionamiento debe acelerarse. Si bien esta es una tarea muy complicada, se la puede llevar a cabo mediante técnicas de estudio como las que se expresan a continuación: 
Dentro de la Taxonomía de Bloom las habilidades cognitivas son las destrezas que permiten al individuo adquirir y desarrollar pensamiento y conocimientos nuevos. Las habilidades cognitivas se pueden clasificar en dos órdenes: las básicas y las superiores, entendiéndose con ello que las primeras facilitan la adquisición del conocimiento y las segundas la calidad y la aplicación del mismo (Mendoza et al., 2013, p. 31).

Bloom hace énfasis en la clasificación de las habilidades. Primero la persona debe adquirir conocimiento, debe poder comprenderlo y a la vez tener almacenado todos esos datos, pero nada de ello es posible si tiempo después no son utilizados, no obstante, en este análisis, las habilidades no solo mejoran, sino que muchas veces se crean.

\section{Material y métodos}

Esta investigación presenta un diseño no experimental transeccional, puesto que el análisis que se plantea dentro de la Academia Naval Guayaquil sirve para ahondar en la problemática, así como en la recolección de datos y el perfeccionamiento de las habilidades periodísticas. Igualmente, se acogió el tipo de investigación descriptiva porque la recepción e incidencia se manifiestan como las variables dentro del análisis y repercuten en sus habilidades cognitivas y el lenguaje periodístico que adquieren a través del tiempo. Se deja claro que la indagación atravesó un estudio exploratorio, que conservó las variables y dimensiones antes escritas, para concluir en una investigación descriptiva, analizando la comprensión lectora de los estudiantes, así como su construcción periodística en las aulas.

En consecuencia, se planteó la siguiente hipótesis: el desinterés en temas de periodismo por parte de los alumnos de bachillerato de la Academia Naval Guayaquil, se ve afectado por el desempeño de sus docentes en temas de noticias y el no planteamiento de proyectos periodísticos eficaces dentro de la institución. Y luego de ello, se concretó que las variables dentro del proyecto son la recepción e incidencia del proceso comunicacional, y a través de la ya mencionada hipótesis, se detalla a continuación el cuadro de la definición operacional de las variables que se utilizó por completo dentro del trabajo (en el presente artículo solo se toman las principales): 
Tabla 3

Definición operacional de las variables

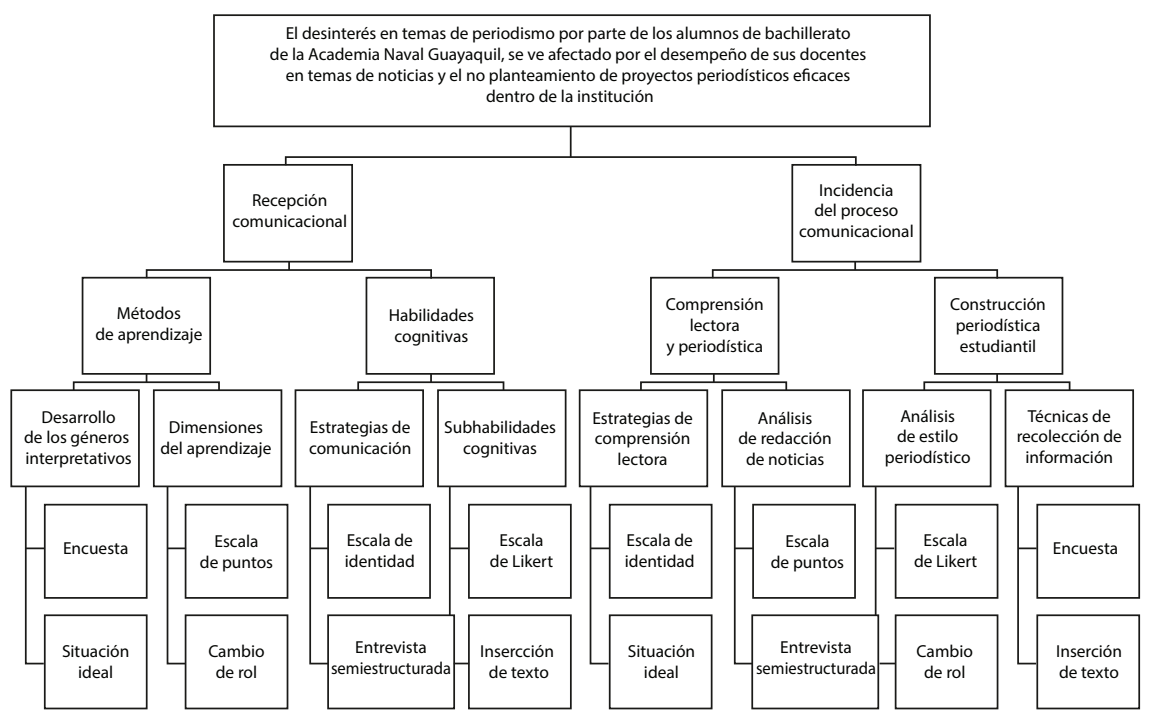

Fuente: los autores

La investigación se hizo con una metodología hermenéutica porque la relación del investigador con los alumnos se concentró en los procesos históricos de la institución y los proyectos básicos de periodismo generados a través del tiempo. Por tanto, se estructuró nueve diferentes técnicas de investigación, para observar el grado de profundidad con el que se abordó a los estudiantes de bachillerato de la Academia Naval Guayaquil. Entre ellas, cuatro fueron cuantitativas - la encuesta, escala de Likert, escala de intensidad y escala de puntos - y cinco cualitativas - investigación bibliográfica, entrevista semi estructurada, inserción de texto, cambio de rol y situación ideal-.

La población de esta indagación fue de 357 estudiantes fragmentados en doce bachilleratos unificados (primero, segundo y tercero), de la Academia Naval Guayaquil sección matutina. Por esto se debió utilizar una técnica probabilística para cuantificar la muestra de trabajo, donde las ecuaciones matemáticas complementaron el desarrollo y se estableció el número de 
estudiantes a encuestar. Así, después de la fórmula $n=(Z)^{2}(P)(Q)(n) /(E)^{2}$ $(\mathrm{N}-1)+(\mathrm{Z})^{2}(\mathrm{P})(\mathrm{Q})$, y con la tipología estratificada, se obtuvo una muestra de 145 estudiantes que se dividieron en 54 hombres y 91 mujeres.

\section{Análisis y resultados}

Las preguntas y resultados que se detallan a continuación son una recopilación de las mejores derivaciones que se manifestaron en el trabajo de campo en la Academia Naval Guayaquil. Las preguntas reflejan el estudio de las variables, dimensiones, indicadores y técnicas planteadas en el trayecto, lo que reveló resultados fehacientes y contundentes de la hipótesis. Cabe recalcar que cada pregunta fue pensada y creada desde el trabajo de investigación a través de expresiones de autores y pensamientos detallados en artículos.

\section{Figura 2}

\section{La enseñanza de los géneros interpretativos}

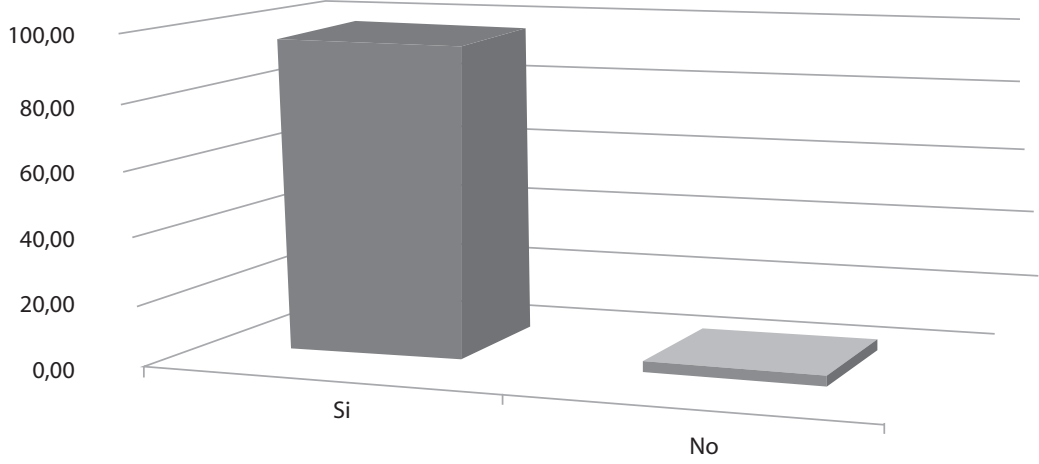

Fuente: los autores

Variable: recepción comunicacional

Dimensión: métodos de aprendizaje.

Indicador: desarrollo de los géneros interpretativos

Técnica cuantitativa: encuesta 
Pregunta 1: ¿Cree que es necesario la enseñanza de los géneros interpretativos en las aulas?

Se presta atención a la rotunda afirmación en la integración de los géneros interpretativos en el aula de clase, con un resultado del 97\%, es decir, 140 estudiantes del total de encuestados mantienen una total disposición a la inserción de un capítulo diferente en sus enseñanzas.

\section{Figura 3 \\ Manejo las dimensiones del aprendizaje}

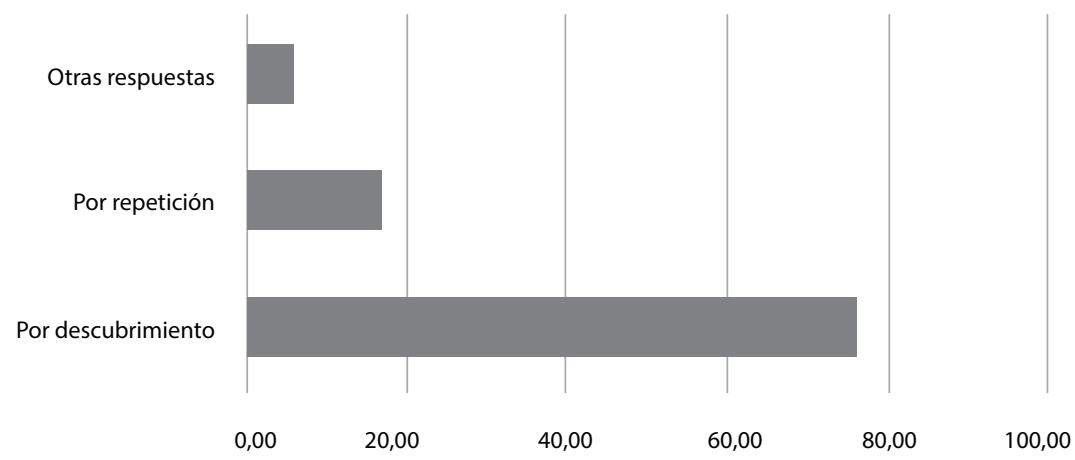

Fuente: los autores

Variable: recepción comunicacional

Dimensión: métodos de aprendizaje

Indicador: dimensiones del aprendizaje

Técnica cualitativa: cambio de rol

Pregunta 2: Si usted manejara las dimensiones del aprendizaje, ¿utilizaría el aprendizaje por descubrimiento o por repetición?

Los estudiantes reflejaron su compromiso al aprendizaje por descubrimiento con un $77 \%$ a favor, mientras que el $17 \%$ decidieron optar por la repetición. Aunque las dos dimensiones son esenciales para la enseñanza, no cabe duda que cuando se descubre una información el cerebro la guarda por mucho más tiempo y es lo que en el periodismo funciona mejor. 
Figura 4

Dimensiones del aprendizaje que impulsan el club

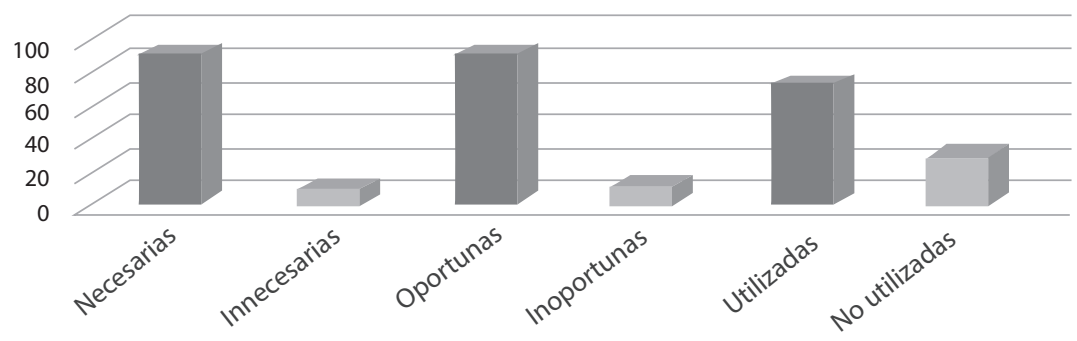

Fuente: los autores

Variable: recepción comunicacional

Dimensión: métodos de aprendizaje

Indicador: dimensiones del aprendizaje

Técnica cuantitativa: escala de puntos

Pregunta 3: Las dimensiones del aprendizaje para impulsar el club de periodismo dentro de la institución son...

Con respuestas más allá del $70 \%$ sobre impulsar un club de periodismo en la institución, los jóvenes insistieron en que su implementación es necesaria y oportuna, sin embargo, con la existencia de un club de periodismo en la institución, un $28 \%$ cree que no es utilizado correctamente, de ahí la razón de ser de esta investigación.

Figura 5

\section{Desarrollar habilidades cognitivas}

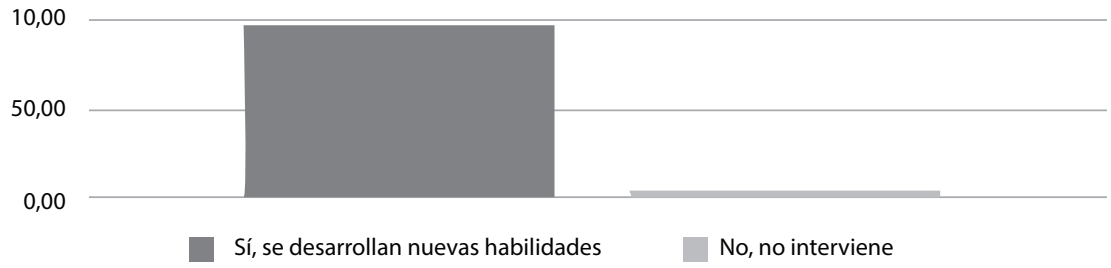

Fuente: los autores 
Variable: recepción comunicacional Dimensión: habilidades cognitivas Indicador: sub-habilidades cognitivas Técnica cualitativa: inserción de texto

Pregunta 4: Después de leer la cita, ¿cree usted que mediante un club de periodismo se puedan desarrollar habilidades cognitivas?

La cognición es una serie de procesos interrelacionados mediante los cuales obtenemos y utilizamos conocimientos relacionados con el mundo. Abarca el pensamiento, el aprendizaje, la percepción, el recuerdo y la comprensión. Por lo tanto llamaremos desarrollo cognoscitivo al crecimiento y perfeccionamiento de estos procesos y habilidades (Allueva et al., 2015, p. 2).

Una cita es el pensamiento de un autor, los estudiantes observaron y analizaron dichas palabras y el 95,86\% aseguraron que la implementación de un club de periodismo es necesario, porque a través de este se incrementan sus habilidades, lo cual no es visto por otras materias y desencadena un sinnúmero de respuestas favorables hacia la iniciativa.

\section{Figura 6 \\ Comunicación y los temas periodísticos}

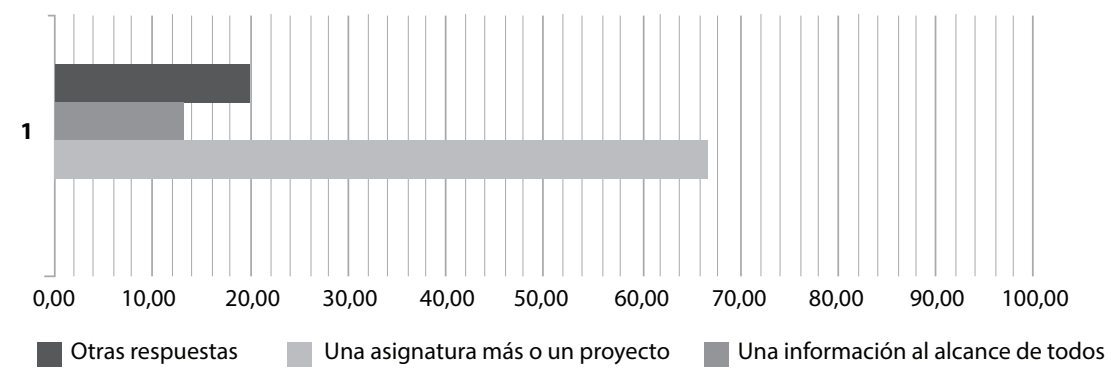

Fuente: los autores

Variable: incidencia del proceso comunicacional

Dimensión: comprensión lectora y periodística

Indicador: estrategias de comprensión lectora

Técnica cualitativa: situación ideal 
Pregunta 5: Para que la comunicación y los temas periodísticos sean enseñados de manera correcta en la institución, la comprensión de la lectura debe proponerse como...

El pilar fundamental de un buen periodista se basa en la lectura, su comprensión y el análisis que ejercen los valores fundamentales en la profesión. De esta manera, el 66,9\% expresó que si se convierte en una materia o un proyecto, se originaría un mayor desenvolvimiento en otras áreas de trabajo y no solo en el periodismo. Asimismo, se visualizó que el 13,1\% lo preferiría por estar al alcance de todos con nueva información.

Figura 7

\section{Enseñanza de redactar noticias}

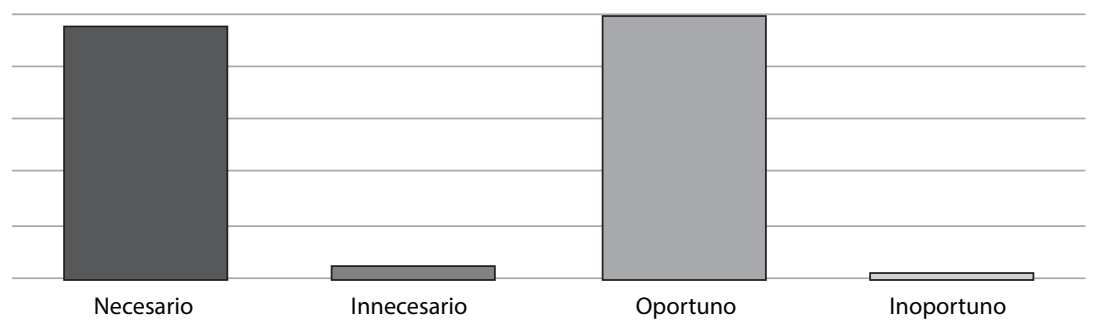

Fuente: los autores

Variable: incidencia del proceso comunicacional

Dimensión: comprensión lectora y periodística

Indicador: análisis de redacción de noticias

Técnica cuantitativa: escala de puntos

Pregunta 6: la enseñanza de redactar noticias es...

Es fácil comprender que una enseñanza pronta de los géneros periodísticos en los estudiantes es necesaria en un $95,17 \%$ y oportuna en un $98,62 \%$. De aquí su lenguaje aumenta y su pensamiento los hace ser más críticos, sin embargo, es fundamental que se lo ejerza con un poco más de rigurosidad en la institución, debido a la poca intención de fomentar esta disciplina en el aula de clase. 
Figura 8

Técnicas para el aprendizaje periodístico

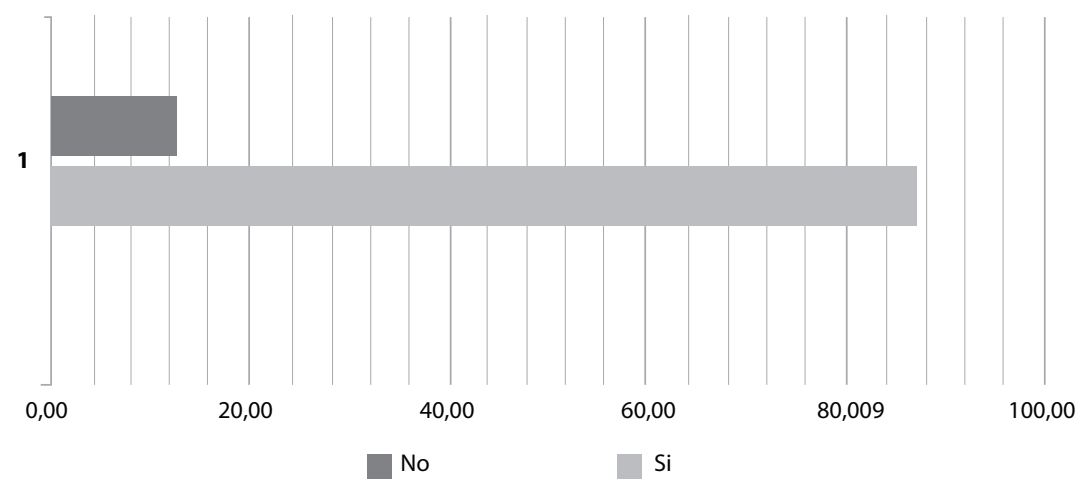

Fuente: los autores

Variable: incidencia del proceso comunicacional

Dimensión: construcción periodísticas estudiantil Indicador: técnicas de recolección de información Técnica cuantitativa: encuesta

Pregunta 7: ¿Cree usted que conocer las técnicas de recolección de información son vitales para el aprendizaje periodístico?

Como se sabe, el periodismo implica investigación, por ende, las técnicas de recolección de información abarcan un eje fundamental en este proceso. Un $87 \%$ de los estudiantes manifiestan que aprender las técnicas de recolección de información son la clave para el periodismo, pero el fin no es solo trabajar para ese cargo, sino que vaya más allá de ello, por ejemplo, con las otras asignaturas cuando son enviados a investigar y solo se concentran en una fuente, ignorando que existe un sinfín de voces que pueden ser tomadas en cuenta. De ahí la práctica e inserción de estas técnicas. 
Figura 9

Implementación de las técnicas de recolección de información

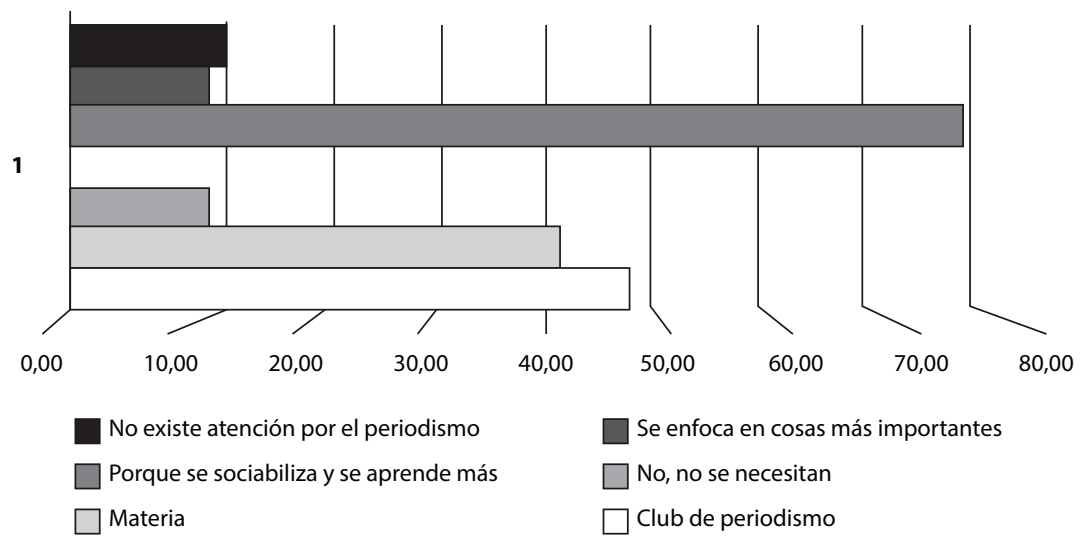

Fuente: los autores

Variable: incidencia del proceso comunicacional Dimensión: construcción periodísticas estudiantil Indicador: técnicas de recolección de información Técnica cualitativa: inserción de texto

Pregunta 8: después de leer la cita, ¿cree usted que las técnicas de recolección de información, deben ser implementadas en las aulas a través de las materias, o a partir de un club de periodismo? ¿Por qué?

Las técnicas de recolección de datos se refieren a los procedimientos para obtener datos o información. De acuerdo con Arias (2006) “...la aplicación de una técnica conduce a la obtención de información que debe ser registrada en un medio de manera que los datos puedan ser recuperados, procesados, analizados e interpretados posteriormente" (Marcano et al., 2013, p. 55).

Tras una contemplación de las palabras de un autor, se reflejó una división en cuanto a dónde enseñar las técnicas de recolección de información, se da en la inserción del periodismo como una materia en un 41,38\%, así como dentro del club de periodismo con un 46,9\%. Pero cuando se les pre- 
gunta por qué debería ser en alguna de ellas, se inclinan hacia el club con un $75,17 \%$ porque se sociabiliza y se obtiene información más específica; además, implica menos estrés como manifiesta uno de ellos y así cultivan una profunda guía hacia la carrera, pues varios alumnos se encuentran indecisos en la elección de la misma cuando salen de la unidad educativa.

\section{Conclusiones}

El presente trabajo de investigación denotó la predisposición de los estudiantes en el proceso de las técnicas de investigación y la inserción de los géneros interpretativos como una opción de integración a su malla curricular. Se concluye que la indagación formó parte de un modelo de reestructuración y construcción de conocimiento sobre el periodismo en los jóvenes de la Academia Naval Guayaquil.

Las teorías de recepción y de incidencia comunicacional son viables y desempeñan parte fundamental de los procesos efectuados en el transcurso de la investigación y recolección de datos. Con un 96,55\% del total de la muestra, se observó que la implementación de los géneros interpretativos, correspondientes a una enseñanza periodística, son viables para su inserción, así como aplicar estas dimensiones en el aprendizaje para desarrollar la comunicación y el interés hacia estos temas $(97,24 \%)$.

Al seguir con el análisis, se observa que los métodos de aprendizaje son fundamentales para la inserción de temas periodísticos y el desarrollo crítico de los estudiantes, así como un desempeño óptimo en las demás materias. Además, se plantea que la institución y los docentes manejan las estrategias de comunicación en ciertas áreas y no se toma la debida importancia de este tema, esto se ve en un 67,59\%. Mientras que los clubes de periodismo como idea formadora de las capacidades y habilidades cognitivas en los estudiantes tienen un apoyo del 95,86\%. Por eso se concluye que las habilidades cognitivas permiten al investigador conocer el proceso en el que está el estudiantado, para así promover el uso de estrategias que mejoren la comunicación dentro de las aulas.

Asimismo, la formación periodística estudiantil puede incidir en el desempeño y desenvolvimiento de las capacidades académicas, para generar un estilo dentro de esta área y consecutivamente orientar a los alumnos a una carrera universitaria. Sin embargo, el no planteamiento de proyectos dentro 
de la institución también es cuestionado por el 95,17\%. En cuanto a la redacción de noticias, los estudiantes apostaron a la necesidad de que exista esta oportunidad, pero su decisión está basada en ciertas respuestas, como en la integración a través de una asignatura o un proyecto, con un 67,5\% a favor, lo que significaría para ellos algo novedoso e interesante.

La investigación dentro del periodismo es fundamental, sin embargo, también lo es para cualquier materia. Un gran porcentaje de estudiantes no conoce las técnicas de investigación, no obstante, el 87,59\% asegura que es imperativo para el aprendizaje periodístico. Es decir, no existe una implementación en el área de la comunicación dada por los docentes. Por esto, al increparles a los jóvenes cómo deberían ser transmitidas, más de la mitad objetó que se llevara a cabo mediante un club de periodismo, porque el $75,17 \%$ cree que se enfocaría más al asunto y se aprendería a sociabilizar, aunque en la institución existe un precedente de club, el mismo debe ser mejorado y actualizado para el estudio de temas más importantes y relevantes, además de una integración colectiva entre ellos mismos.

Por último, se deja clara la integración de la comunicación y el proceso educativo. Los clubes de periodismo son esenciales tanto en las escuelas como en los colegios. Los estudiantes precisan una nueva forma de conseguir información de tal manera que más adelante se tengan jóvenes con capacidades críticas e investigativas, las cuales no son enseñadas ni clarificadas en las materias. Por eso la implementación a temprana edad de estos clubes es imprescindible.

\section{Bibliografía}

Allueva, S., Pueyo, M. y Altemir, I. (2015). Habilidades cognitivas visuales en niños con antecedentes de prematuridad (Tesis de pregrado). Universidad Zaragoza, España. Recuperado de https://goo.gl/p2bab5/

Balbas, F. (2014). La "Flipped Classroom" como recurso metodológico aplicado a la docencia de Expresión Gráfica de $4^{\circ}$ de ESO (Tesis de maestría). Universidad de Valladolid, España. Recuperado de https://goo.gl/irr5Y1/

Castro, M. y Ortiz, A. (2011). Importancia del periodismo educativo en la formación de los niños y niñas de la escuela fiscal mixta Dr. Carlos Moreno Arias del cantón Milagro (Tesis de pregrado). Universidad Estatal de Milagro, Ecuador. Recuperado de https://goo.gl/y4X6Bk/ 
Correa, D. (2016). Club de periodismo, modelo de práctica educativa para fortalecer la escritura periodística. INNOVA Research Journal, 1(6), 14-26. Recuperado de https://goo.gl/tEYR4W/

Cotallat, J. y DT-Núñez, M. (2012). Aprendizaje cooperativo y su incidencia en el rendimiento académico de los estudiantes de segundo año de Bachillerato especialidad Ciencias del Instituto Tecnológico Pelileo (Tesis de maestría). Universidad Técnica de Ambato, Ecuador. Recuperado de https:/goo.gl/sPFdnK/

Fischietto, A. (2014). Desarrollo de Periódicos Escolares en Ambiente Virtual. Revista Científica EduWeb, 8(1), 57-70. Recuperado de https://bit. 1y/2L4KVJ3/

González, J. (2013). Célestin Freinet, la escritura en libertad y el periódico escolar. Un modelo de innovación educativa en la primera mitad del siglo 20. História da Educação, 17(40), 11-26. Recuperado de https://bit. ly/2nGVHMn/

Jiménez, L., Pérez, H. y Fernández, S. (2007). La enseñanza de estrategias de aprendizaje en educación infantil. Profesorado, Revista de currículum y formación de profesorado, 11(2). Recuperado de https://goo.gl/mBbvSZ/

Marcano, M., Quintero, A. y Rodríguez, N. (2013). Plan de formación en tecnologías de información y comunicación para el profesorado de educación media del instituto escuela. Píxel-Bit, revista de medios y educación, (42), 51-64. Recuperado de https://goo.gl/f8jm93/

Mendoza, L., Zermeño, M. y Zermeño, R. (2013). Desarrollo de habilidades cognitivas y tecnológicas con aprendizaje móvil. Revista de Investigación Educativa de la Escuela de Graduados en Educación, 3(6), 30-39. Recuperado de https://goo.gl/KWLoEf/

Pérez, Z. y Valdés, A. (2018). Estrategias para la formación profesional en periodismo radiofónico: experiencias y propuestas/Strategies for professional training in radio journalism: experiences and proposals. Revista de Comunicación de la SEECI, (46), 53-63. Recuperado de https://bit. ly/2L3uBbw/

Tapia, L. (2016). Estudio de recepción del periódico comunitario El Chulla Quiteño (Tesis de pregrado). Universidad Politécnica Salesiana, Ecuador. Recuperado de https://goo.gl/TK3joo/

Toledo, D. y Balseca, C. (2013). El uso de las aulas virtuales y su incidencia en el Rendimiento Académico Estudiantil en Matemática de la Facultad de Fi- 
losofía, Letras y Ciencias de la Educación de la Universidad Central del Ecuador (Tesis de maestría). Universidad Técnica de Ambato, Ecuador. Recuperado de https://goo.gl/gscgBa/

Fecha de recepción: 2018/02/20; Fecha de aceptación: 2018/08/15;

Fecha de publicación: 2018/09/01 



\title{
Aprendizaje ubicuo, interfaces de comunicación y las competencias mediáticas
}

\section{Ubiquitous learning, communication interfaces and media skills}

\author{
Soraya María Ferreira Vieira \\ Universidad Federal de Juiz de Fora. Facultad de Comunicación Social (UFJF) \\ sovferreira@gmail.com \\ Código Orcid: https://orcid.org/0000-00021147-4987
}

Luana Castilho

Universidad Federal de Juiz de Fora. Facultad de Comunicación Social (UFJF)

luanacastilho@gmail.com

Código Orcid: https://orcid.org/0000-0001-6049-4688

\begin{abstract}
Resumen
El presente trabajo trata de la hipermovilidad que genera nuevas posibilidades de aprendizaje que proponen nuevos desafíos a los productores de contenido y a los educadores. El aprendizaje ubicuo deriva de estos nuevos ambientes hiperconectados y, aunque incorpore características del m-learning, no constituye un plan educacional, es totalmente informal, es "espontánea, contingente, caótica y fragmentaria". Este trabajo se propone destacar, en este contexto, una experiencia brasileña: la aplicación Geekie Games, que tiene el objetivo de ayudar a los candidatos en la preparación para el ENEM (Examen Nacional de la Enseñanza Media) y está disponible en las tiendas online de dispositivos móviles con el sistema operativo Android. El usuario puede acceder a los simuladores, vídeo-clases expositivas animadas y tutoriales, imágenes y ejercicios específicos de cada disciplina, desarrollados por la Fundación Lemann en asociación con otras instituciones del sector privado y con el apoyo del Ministerio de la Educación. Aquí haremos una primera reflexión respecto a cómo este nuevo dispositivo está relacionado con las competencias mediáticas y sus dimensiones, como las conceptuadas por Ferrés. Los flujos de comunicación se vuelven intensos en la era de la hipermovilidad y la ubicuidad. Los dispositivos móviles han sido grandes protagonistas en esta ecología comunicacional que se diseña y cambia el aprendizaje.
\end{abstract}

\section{Palabras clave}

Aprendizaje ubicuo, juego, dispositivos móviles, competencia mediática, tactibilidad, hipermobilidad.

Forma sugerida de citar: Ferreira, Soraya y Castilho, Luana (2018). Aprendizaje ubicuo, interfaces de comunicación y las competencias mediáticas. Universitas, 29, pp. 201-215. 


\begin{abstract}
The present work deals with the hypermobility that generates new possibilities of learning that propose new challenges to the producers of content and the educators. Ubiquitous learning derives from these new hyperconnected environments and, although it incorporates m-learning characteristics, it does not constitute an educational plan, it is totally informal, it is "spontaneous, contingent, chaotic and fragmented". In this context, a Brazilian experience: the Geekie Games application, which aims to assist candidates in preparing for the ENEM (National Examination of Secondary Education) and is available in the online stores of mobile devices with the Android operating system. The user can access the simulated, animated video-lectures and tutorials, images and exercises specific to each discipline, developed by the Lemann Foundation, in partnership with other institutions of the private sector and with the support of the Ministry of Education. A first reflection on how this new device is related to media skills and its dimensions, as conceptualized by Ferrés. Communication flows become intense in the era of hypermobility and ubiquity. Mobile devices have been a great protagonist in this communicational ecology that is designed and changing learning.
\end{abstract}

\title{
Keywords
}

Ubiquitous learning, game, mobiles device, media competence, tactility, hypermobility.

\section{Introducción}

El surgimiento y la popularidad de los dispositivos móviles digitales cambiaron la relación entre hombre, tecnología y ambiente. Con la convergencia mediática, los artefactos técnicos pasaron a desempeñar diferentes funciones, muchas incluso, que extrapolan el objetivo central de la comunicación interpersonal. Hoy, con un solo aparato, es posible organizar la agenda, monitorear latidos cardíacos, reservar el alojamiento en un hotel, verificar la ubicación del autobús en tiempo real, ver vídeos, administrar perfiles en las redes sociales, además de enviar y recibir e-mails, enviar mensajes y hablar por teléfono. Además de la facilitación de concentrar numerosas funciones en un único dispositivo, el avance tecnológico permitió que se sumara a ello la movilidad informacional. Con el advenimiento de los celulares, notebooks, paginadores, palmtops, etc. se dio inicio a ese movimiento, pero la estructura técnica restringía las potencialidades de estos aparatos, 
en la medida en que las conexiones todavía necesitaban soporte técnico y la movilidad informacional era reducida. A partir de la creación de las redes $3 \mathrm{G}$ y $4 \mathrm{G}$, la tecnología Wi-Fi y la conexión Bluetooth, los dispositivos georreferenciales garantizaron que las conexiones también pudieran ser móviles, propiciando la hipermobilidad (Santaella, 2013), que amplía y refina los modos de presencia que se expanden a medida que las tecnologías están más disponibles y móviles, propiciando mayores flujos de información y conectividad. Lo que se plantea con fuerza en este ambiente convergente es justamente el modo de distribución de la información.

El usuario, a su vez, tiene en su cotidiano cada vez más la presencia de esos dispositivos, que pasan a mediar parte significativa de sus interacciones, ya sea interpersonal, con el ambiente, con sus tareas diarias, con su ocio, con sus emociones. Cada vez los sentimientos también pasan a figurar y configurar la intimidad que también habita en el ambiente convergente. La revolución digital trae consigo una transformación en el comportamiento del, hasta entonces, receptor. La cultura participativa (Jenkins, 2009) es el gran fenómeno que viene alterando todos los procesos que envuelve la comunicación. La producción ahora pasa a ser pensada, o debería ser, en las posibilidades de interacción y retroalimentación.

$\mathrm{Si}$ antes el medio, el mensaje y quien la transmitía concentraban mayoritariamente los esfuerzos del pensamiento científico, hoy, aunque no se excluyan esos elementos anteriores, es el receptor $-\mathrm{o}$ el nuevo usuario, prosumidor - quien guía los estudios que buscan comprender las nuevas prácticas de comunicación. Jenkins (2009) señala esta tendencia al abordar la cultura participativa, colocando al proceso colectivo como elemento central de las prácticas de consumo informacional.

El público, por otra parte, desarrolla otros estímulos con el contenido que interactúa. Antes, el medio definía el sentido afectado en la recepción como vista, oído, olfato. Ahora, la relación ocurre en esferas multisensoriales, incluso táctiles, con las interfaces hápticas de los teléfonos inteligentes y tabletas (Haywards et al., 2004 en Palacios y Cunha, 2012, p. 2). Santaella argumenta que esos aparatos "se relacionan con usuarios de modos nuevos, engranan nuestros sentidos y nuestro cuerpo de maneras diferentes" (2010, p. 69). Defiende que todo y casi toda la gente son mediados por la tecnología digital, incluso las prácticas educacionales.

En el ambiente hiperconectado dado por el contexto de la convergencia mediática, como mencionamos arriba y las modalidades de aprendiza- 
je que de ahí derivan, traen la necesidad de repensar los estudios de "midaeducación". Los flujos de comunicación se vuelven intensos en la era de la hipermobilidad y la ubicuidad. Los dispositivos móviles han sido un gran protagonista en esta ecología comunicacional que se diseña, así como los usuarios que se insertan en esta nueva cartografía social, sin embargo, ¿estamos hábiles para hacer frente a estas nuevas formas de comunicación y dispositivos?, ¿cómo es nuestra implicación con las interfaces utilizadas en el ambiente hiperconectado que estimula la autonomía, la colaboración, la organización y operacionalización de múltiples tareas? Se busca entender este fenómeno a la luz de las competencias mediáticas.

\section{Nuevos modelos de aprendizaje y el aprendizaje ubicuo}

Desde la interacción con las nuevas tecnologías comunicacionales, surgen nuevos modelos de enseñanza-aprendizaje. Santaella (2011) destaca el surgimiento del e-learning, m-learning y el aprendizaje ubicuo. En esos paradigmas, el soporte posibilitó un desplazamiento de los procesos educacionales a los ambientes domésticos, de trabajo y las calles, todos ellos en movimiento. El consumo y la fruición de las informaciones se volvieron más individualizados y personalizados, al mismo tiempo, esas modalidades estimularon prácticas más colaborativas y participativas, que favorecieron modalidades de aprendizaje autodidactas.

El uso intensivo de las TIC con el objeto de realizar búsquedas online, acceder a diversos contenidos e incluso para construir el repertorio intelectual de los individuos y establecer las relaciones de sentido, ha reconfigurado la relación de los usuarios con los contenidos informacionales, generando formas espontáneas de educación.

En la perspectiva educacional, Belloni y Gomes defienden que las TIC proporcionan un ambiente eficaz para las prácticas educacionales. Los aprendientes se relacionan con colegas, con adultos más experimentados, comparten y debaten opiniones, construyendo un conocimiento colaborativo y participativo. Las autoras también argumentan que la autonomía es una competencia esencial para el proceso de aprendizaje y muy estimulada en la absorción de contenidos a través de las TIC. A la hora de decidir cuáles herramientas y funciones de los dispositivos usar, la ruta de navegación y cómo elaborar un texto, el usuario participa de un medio de aprendizaje 
más favorable, principalmente en los casos de niños y jóvenes que se dan cuenta que pueden aprender sin intervención de los adultos (Belloni, 2009; Gomes, 2008).

El aprendizaje sin un enseñante en los ambientes virtuales (autodidaxia no ciberespacio) solo es una de las formas que vienen de las TIC y constituye un proceso que debe ser complementario a las prácticas de enseñanza más tradicionales. Sin dispensar otras modalidades, este aprendizaje actúa como potenciador del desarrollo de las competencias necesarias para el proceso de cognición, en la medida en que estimula la autonomía, la colaboración, la organización y la realización de múltiples tareas. En el aprendizaje ubicuo, la autodidaxia es el elemento central, pues da las bases para la constitución de las competencias asociadas a este nuevo modo de aprendizaje.

El e-learning o aprendizaje electrónico, por otra parte, es un modelo que sustituye la antigua educación a distancia. En la era de la hipermovilidad y todas sus transformaciones, las prácticas ubicuas cambiaron en los individuos las nociones de presencia, ausencia y distancia. Las herramientas de educación online se han sofisticado en la medida en que nuevas tecnologías emergen, y a través de plataformas de contenidos estáticos, los nuevos ambientes de e-learning permiten la realización de conferencias, hospedaje de contenido audiovisual e interactivo, y también el uso de herramientas de administración del tiempo y planeamiento de estudios.

La convergencia mediática y el surgimiento de los ordenadores móviles crearon nuevas posibilidades de e-learning, resultando un nuevo paradigma de aprendizaje virtual: el m-learning o aprendizaje móvil. Este añade la movilidad a las prácticas de educación online: el estudiante es quien decide, más allá de la hora y el tiempo de estudios, la ubicación dónde va a acceder el contenido. A pesar de utilizarse en las nuevas herramientas computacionales, estos paradigmas pertenecen al campo de la educación formal, en la medida en que tienen por objetivo principal un proceso de aprendizaje de sistema pre-definido.

La revolución tecnológica y la popularización de los dispositivos móviles digitales promovieron un cambio en el comportamiento de consumo informacional. Los aparatos multimedia y multitareas invadieron el cotidiano de los usuarios y los nuevos hábitos de interacción pasaron a reflejarse en la dinámica de las prácticas sociales. La comunicación híbrida, instantánea, descentralizada y fragmentaria - característica del ciberespacio - con la hipermovilidad pasó a invadir las ciudades, inaugurando nuevas formas de re- 
lación y dinámicas sociales. En este contexto, la deficiencia de la enseñanza tradicional se ve acentuada y enfatiza la necesidad de una reformulación de las prácticas educativas.

En el ámbito de los medios de comunicación, hace algunos años los investigadores sostienen que las TIC deben incorporarse a la enseñanza, en la medida en que presentan funcionalidades que pueden potenciar los procesos de aprendizaje, así como están más alineadas al nuevo perfil cognitivo, principalmente de los niños y jóvenes. María Luiza Belloni, una de las precursoras en el estudio de la integración de las TIC al ambiente escolar, argumenta que ese movimiento es necesario para una mejora en la calidad y sobre todo para una democratización de la enseñanza. La autora defiende que la agregación de estas tecnologías puede promover una educación para la ciudadanía:

La escuela debe integrar las tecnologías de información y comunicación porque ellas ya están presentes e influyentes en todas las esferas de la vida social, cabiendo a la escuela, especialmente a la escuela pública, actuar para compensar las terribles desigualdades sociales y regionales que el acceso desigual a estas máquinas están generando (Belloni, 2009, p. 10).

En la práctica, las cuestiones estructurales completan el proceso de integración de las TIC. Las dificultades económicas, la falta de políticas públicas que capaciten a los educadores, así como la necesidad de reformulación de las metodologías y dinámicas de enseñanza, parecen hacer un poco utópicas previsiones abreviadas de un cambio completo en ese sistema. Aún más si se considera el sistema público de educación donde la incipiente inclusión digital retrasa las fases importantes requeridas por la dinámica de la cultura digital. Porque la cultura de la convergencia es una vía de mano doble, requiere el sujeto conectado tecnológica y mentalmente.

El dominio de las competencias mediáticas, en lo que se refiere al lenguaje, permite al ciudadano analizar de forma crítica los mensajes que recibe y también realizar su comunicación de forma efectiva. En el ambiente hiperconectado y fluido, el lenguaje es la instancia que propicia la correlación con los modos de producción de lo que se ve en la interfaz del producto, como por ejemplo: una red social, un sitio, una aplicación. También es a través del lenguaje que la competencia estética del individuo y la sensibilidad para reconocer la calidad estética de una producción son accionadas. Así, el lenguaje potencia el proceso de cognición, en la medida en que estimula la conexión con las demás competencias. 
En contra de las dificultades de la enseñanza colectiva, las modalidades de aprendizaje más personalizadas e individualizadas crecen a medida que aplicaciones y plataformas de enseñanza digital se popularizan en los ambientes virtuales. Los modelos e-learning, m-learning, la autodidaxia y el aprendizaje ubicuo se derivan de las nuevas prácticas en la hipermobilidad y plantean nuevos desafíos a los productores de contenido y a los educadores. A continuación, presentaremos más detalladamente estas tipologías.

El aprendizaje ubicuo deriva de este nuevo ambiente hiperconectado y aunque incorpore características del m-learning - no es constituyente de un plan educativo, es totalmente informal, "espontaneo, contingente, caótico y fragmentario" (Santaella, 2013, p. 303). Desde el surgimiento de la radio y la televisión, con los reportajes y programas informacionales, los medios de comunicación se convirtieron en fuentes de educación informal. Con los ordenadores, ese tipo de educación pasó a ocupar el día a día de los usuarios, que pueden fácilmente acceder a noticias, literatura, tutoriales y vídeos. Con los dispositivos móviles, el acceso a los contenidos digitales ha quedado más disponible, cualquier persona que porte uno de esos aparatos puede acceder a acervos virtuales, hacer búsquedas y obtener todo o tipo de información. Sin embargo, Santaella argumenta que ese modelo no sustituye a los otros tipos de aprendizaje y que debe actuar en conjunto con los modelos anteriores. Así como los medios que forman una red denominada de "ecología mediática" — en que nuevos medios y los tradicionales se integran-, este potencial híbrido de las ecologías se muestra también en las nuevas prácticas de educación que derivan de los medios.

\section{Geekie Games: las nuevas modalidades de aprendizaje}

Con la popularización de los dispositivos móviles, principalmente los Smartphone, ha empezado uno de los más promisores segmentos de la industria tecnológica: el desarrollo de aplicaciones. ${ }^{1}$ Sin embargo, pocas iniciativas, sobre todo gratuitas, exploran las potencialidades de estos programas en prácticas de enseñanza. Muchos juegos, quizzes y pasatiempos usan, informal y espontáneamente, procesos de aprendizaje, es decir, estimulando

1 A pesar de la situación económica, Brasil ha generado, en 2015, aproximadamente 25 mil millones de dólares en el sector. El Ministerio de Ciencia, Tecnología e Innovación prevé superar en 2017 la marca de 70 mil millones. Con todo el potencial de consumo, centenares de apps están disponibles diariamente en las plataformas de distribución para los más distintos fines. 
prácticas del aprendizaje ubicuo, pero la mayoría aún está relacionada con las producciones de entretenimiento.

En Brasil podemos destacar Geekie Games, una aplicación desarrollada por la Fundación Lemann en asociación con otras instituciones del sector privado y con el apoyo del Ministerio de Educación. La aplicación tiene como objetivo auxiliar a los candidatos en los estudios para el ENEM (Exame Nacional do Ensino Médio) y está disponible en tiendas online de dispositivos móviles con el sistema Android. El usuario puede acceder a los simuladores, vídeo-clases expositivas animadas, tutoriales, imágenes y ejercicios específicos de cada disciplina. Al descargar el software, el usuario realiza su catastro y selecciona el curso que pretender seguir (Figura 1a). En nuestro acceso contamos 607 opciones, entre cursos técnicos, bachilleratos y licenciaturas. Después de elegir el curso y el tiempo semanal de dedicación, un plan de estudios es elaborado de acuerdo con las necesidades del candidato (Figura 1b y 1c). Para cada temática propuesta hay un análisis del repertorio sobre el tema, el Rayo X Inicial, la clase y el Check Final (un ejercicio para evaluar y revisar el contenido).

\section{Figura 1}

\section{Interfaces iniciales de Geekie Games}

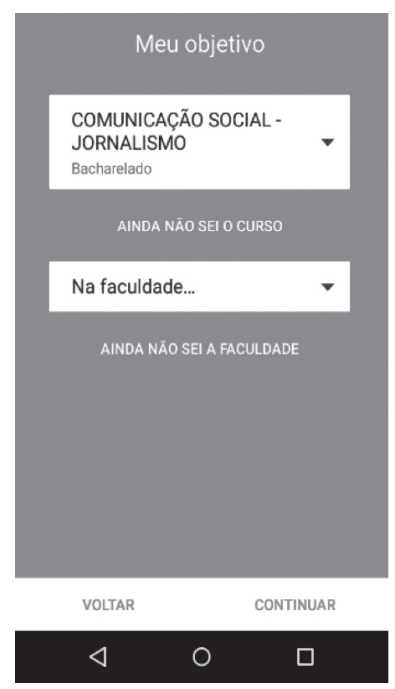

(a)

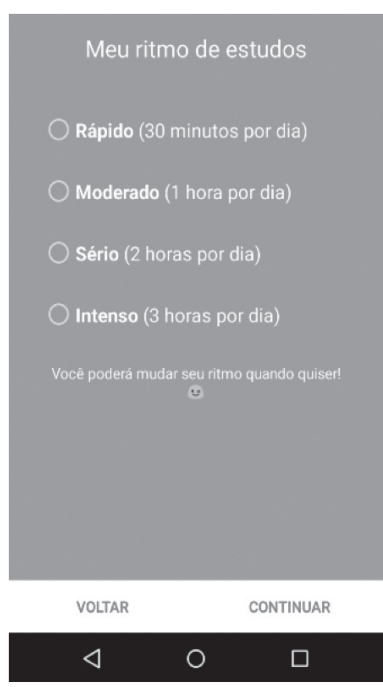

(b)

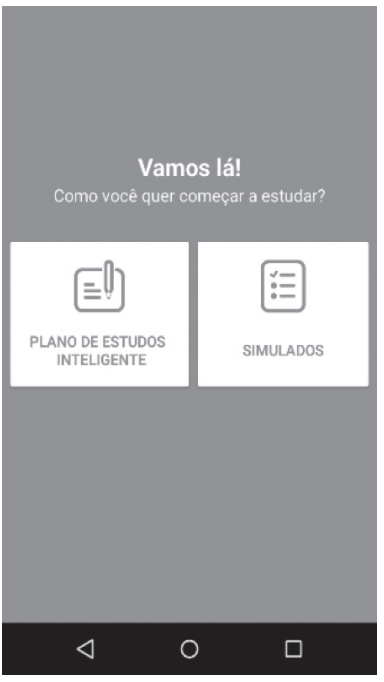

(c)

Fuente: las autoras 
Es posible notar el carácter individualizador de la herramienta, pues se ofrece al usuario la posibilidad de seleccionar un contenido más personalizado, alineado a sus demandas. Cada clase tiene aproximadamente 20 diapositivas. Ellas son divididas en las cuatro grandes áreas del conocimiento exigidas en el ENEM: matemáticas y sus tecnologías; ciencias humanas y sus tecnologías; lenguajes y códigos; ciencias de la naturaleza y sus tecnologías. Normalmente, las video-clases tienen el audio del profesor seguido de la ilustración de una pizarra que se va cambiando mientras ocurre la explicación. También se muestran textos e imágenes digitalizados. En los ejercicios integrados a las clases, al seleccionar la respuesta, correcta o no, el programa marca y justifica la respuesta adecuada.

Se nota que distintos sentidos son estimulados mientras se da la navegación: más allá de la vista, tradicionalmente utilizada en lecturas, los aprendientes movilizan oído y tacto. Los diferentes elementos que componen la interfaz de la aplicación activan en un alto nivel la percepción de los usuarios.

Con la "tactibilidad" - función característica de los dispositivos con pantallas táctiles - la relación física entre tecnología e individuo es estrechada. De la misma forma, la ruta de navegación o el modo de fruición del mensaje son individualizados. En la interacción, la sensorialidad del tacto y la experiencia del manejo material traen una nueva forma de procesamiento cognitivo que extrapola las operaciones mentales. El usuario, por ejemplo, a fin de identificar algún elemento de una imagen puede aumentarla o disminuirla, pausar el vídeo, arrastrar y pasar la diapositiva y, respecto a los ejercicios, puede efectivamente modificar aquel contenido.

Dialogando con las ideas de McLuhan - que comprendía los medios como extensiones del hombre y fue uno de los precursores del estudio de la tactibilidad-, Palacios y Cunha (2012) argumentan que la tactibilidad genera un alto involucramiento sensorial, contrariando la anestesia de sentidos promovida por siglos de vivir en la "Galaxia de Gutenberg" (McLuhan, 1972).

El retorno del involucramiento físico con los medios, propiciado por las nuevas tecnologías en las interfaces hápticas, tiene su auge en las transformaciones cognitivas, así como en la cognición distribuida ${ }^{2}$ (proceso que tiene en cuenta la relación con el ambiente, las interacciones sociales y con

2 Teoría desarrollada por Edwin Hutchins, que entiende la cognición como un fenómeno contextualizado, que tiene en cuenta el ambiente, enfatizando el carácter social y cultural del procesamiento de los mensajes. 
los sistemas computacionales). Los estímulos neurales se materializan en el toque. En la navegación en las pantallas táctiles, muchas decisiones son tomadas intuitiva e instantáneamente al toque de nuestros dedos. Esa funcionalidad, así como muchas otras al largo de la evolución humana, ha sido naturalizada por nuestros cuerpos y mentes con una eficacia comunicativa.

Más que sustituir la función del cursor y del ratón, la tactibilidad simula la manera cómo manejamos objetos físicos en nuestro día a día. Es establecida una relación de más intimidad e involucramiento con el contenido, aproximando al usuario, que cambia su manera de interacción. Delante de la dificultad de comprender una información específica, por ejemplo, el individuo, través del toque, busca conocer más sobre el contenido y, por tanto, su envolvimiento táctil se vuelve más amplio, sea manipulando imagen, texto, vídeo etc.

Esos múltiples estímulos demandan nuevas competencias de los usuarios. Ellos necesitan organizar las informaciones que reciben y distribuir la atención para las diversas tareas que realizan al mismo tiempo. Esas competencias son estimuladas, principalmente, fuera de los ambientes de aprendizaje. Al gestionar un perfil en Facebook, crear un foro, enviar un correo electrónico, acceder a documentos online, enviar informaciones de tráfico a Waze, etc., los usuarios adquieren más habilidades operacionales y mentales que los hacen cada vez más hábiles para interactuar con los nuevos medios y, concomitantemente, de forma espontánea aumentan sus repertorios culturales.

Para Ferrés (2012), la competencia que el individuo posee para comprender los mensajes en su complejidad de códigos y las multimodalidades del ambiente digital, están involucradas en algunas dimensiones como la tecnológica, la del lenguaje, de la ideología y los valores, los procesos de interacción, de producción y difusión, y también en la dimensión estética. Sin duda la competencia tecnológica (Ferrés 2012), es decir, la comprensión del funcionamiento de las herramientas de comunicación a fin de entender cómo los mensajes son elaborados y la capacidad de usarlos, se potencia cuando la tactilidad tiene la función de pasar de un flujo a otro de informaciones través la pantalla.

Como ya dijimos, el dominio de las competencias mediáticas en la dimensión del lenguaje, permite analizar de forma crítica los mensajes y comunicarlos efectivamente a través de los distintos tipos de tecnología disponibles, ya que es el lenguaje el que proporciona la correlación entre todos los elementos que se ven en la interfaz de un producto (una red social, un sitio web, una aplicación como Geekie Games, etc.). 
Creemos que es también en la dimensión del lenguaje donde la competencia del individuo para la dimensión estética se expresa, ya que se entiende que la habilidad accionada tiene que ver con la sensibilidad que, desde nuestro punto de vista, reconoce la calidad en las formas, los colores, en la distribución espacial de los elementos, en la composición de la escena y dependiendo del lenguaje de producción - también en la unión de las escenas para la creación de un producto. Así, es posible decir que el lenguaje potencia el proceso de cognición sensible y también emocional, reconfigurado ahora por la tactibilidad, en la medida en que estimula la conexión con las demás competencias. El lenguaje estimula la sensibilidad que guía el proceso de producción de sentido y la competencia de los procesos de interacción con una postura activa delante de las pantallas, para interactuar con los contenidos y evaluar críticamente los elementos emocionales, racionales y contextuales de un mensaje.

Creemos también que cuanto más grande es la habilidad del individuo (competencia) en el universo digital, más grande es la comprensión de las ideologías, valores y polifonías que el nuevo ecosistema social propicia (nos referimos al ambiente hiperconectado donde los procesos de producción y difusión son los grandes gestores que articulan el conocimiento y permiten la cognición diferenciada). Entender las diferentes funciones de los procesos de producción y difusión por las cuales pasa un producto de comunicación, significa estar atento a las posibilidades de ser un "prosumidor".

La convergencia reconfigura los procesos de distribución y difusión de la cultura y del conocimiento. Eso pasa en la propia vida cotidiana, en el presente de los acontecimientos, en el momento en que podemos acceder - en cualquier sitio y tiempo - a bancos de datos, archivos en nubes, múltiples pantallas que traen informaciones, interacciones y conexiones para el conocimiento con varias finalidades. Aunque de manera tímida, no hay cómo negar que sea la competencia tecnológica la fuente motriz de los cambios.

En el caso de Geekie Games, el estímulo es para un consumo colectivo y participativo que ocurre en las herramientas de interacción con el usuario. Ya en el primer acceso son sincronizados los contactos de Facebook del usuario, se muestran los amigos que usan la aplicación y se ofrece la posibilidad de invitar nuevos amigos (Figura $2 \mathrm{a}$ y b). 
Figura 2

El consumo colectivo de Geekie Games

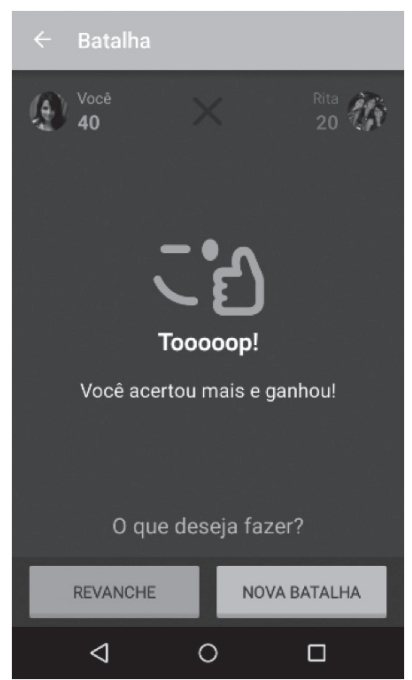

(a)

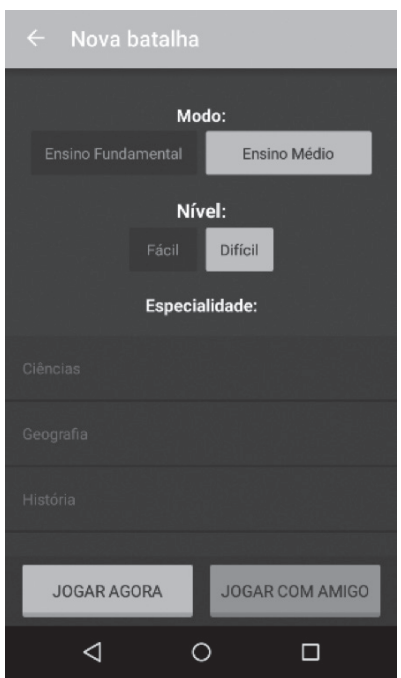

(b)

Fuente: lwas autoras

\section{Conclusiones}

Vimos que la aprehensión de contenidos compuestos por signos de distintas naturalezas exige habilidades de utilizar múltiples estímulos sensoriales, potenciando la comprensión del mensaje y accionando competencias para fluir en diferentes dimensiones con el lenguaje y los estímulos recibidos. Si hay falta de dominio de un código, por ejemplo, el usuario puede utilizar otros recursos.

En las actuales sociedades hipercomplejas, hibridadas y ubicuas, de cultura participativa y colaborativa, la comunicación mediada por dispositivos móviles es más adecuada a la realidad y al nuevo perfil de consumo de mensajes. El gran cambio proporcionado por la comunicación ubicua es la relación de los ambientes virtuales con los físicos, con el propio cuerpo y el potencial personalizante, lúdico y espontáneo de las prácticas ubicuas. La aplicación Geekie Games, por ejemplo, utiliza recursos propios de los jue- 
gos y redes sociales para que el contenido sea atractivo y para identificar el consumo del contenido educacional y de los medios de entretenimiento.

Creemos que el carácter más espontáneo, emergente de las nuevas modalidades de enseñanza-aprendizaje, no debe ser despreciado. Es más, los nuevos estudios que se propongan evaluar la capacidad comunicacional de los usuarios deben tener en cuenta el impacto de los estímulos multisensoriales con los que interactúan esos individuos, ya que gran parte de las decisiones y del procesamiento cognitivo derivan, hoy, de estímulos menos racionales que intuitivos.

Todos estos cambios, la nueva ecología mediática, el cambio del perfil cognitivo de los usuarios y las nuevas teorías que surgen en ese panorama, implican una reformulación del sistema educacional: una enseñanza más descentralizada y horizontal, que amenaza el sistema cartesiano tradicional. Se necesitan nuevas políticas públicas que capaciten a los educadores, garanticen estructura para que los ambientes escolares puedan volverse ubicuos y que se desarrollen estrategias para que, en esas ecologías, cohabiten las potencialidades de cada medio y sean creadas metodologías que incluyan ese panorama cada vez más híbrido.

En la era de la conectividad y en un ambiente conectivo tenemos un sujeto que experimenta el lenguaje y que desempeña muchas tareas, donde las TIC pasan a ser también TAC (tecnologías de aprendizaje y conocimiento) que hacen surgir un nuevo ambiente prácticas comunicativas distintas de acuerdo con los objetivos deseados. Las tecnologías de aprendizaje y conocimiento, al configurar un nuevo ambiente educativo, moldean también de manera profunda las experiencias culturales de las personas que participan de manera activa de las plataformas de los medios educativos y sociales. Entonces, de ese ambiente hiperconectado deben emerger sujetos críticos con prácticas educomunicativas diferentes a las de sus padres.

Ciertamente, existen tensiones entre los diferentes tipos de aprendizajes formales e informales dentro y fuera de las escuelas, porque el aprendizaje ubicuo transforma también la noción de tiempo y espacio, y porque las plataformas digitales unidas con los dispositivos móviles proyectan la educación a otro nivel cualitativo, a través de la comunicación integrativa, participativa y colaborativa. La conectividad es un entorno en desarrollo, con nuevas estructuras de enseñanza, con derecho a interlocución a través de la tecnología y con diversidad de prácticas educativas, donde los medios de 
comunicación están en el orden del día así como las competencias para disfrutar de sus beneficios.

\section{Bibliografía}

Araujo, R. (2003). Computação Ubíqua, Princípios, Tecnologias e Desafios. Simpósio Brasileiro de Redes de Computadores, 21, 45-115.

Belloni, M. (2009). O que é mídia-educação. São Paulo: Campinas.

Gomes, N. (octubre, 2008). Infância, mídias e aprendizagem: autodidaxia e colaboração. Educação \& Sociedade Educação \& Sociedade, 29(104), 717746. Campinas, Brasil: Centro de Estudos Educação e Sociedade.

Bottentuit Junior, J. (2012). Do Computador ao Tablet: Vantagens Pedagógicas na Utilização de Dispositivos Móveis na Educação. LATEC/UFRJ, 6(1), 125-149. Laboratório de Pesquisa em Tecnologias da informação e da Comunicação da Universidade Federal do Rio de Janeiro. Disponible en https://bit.ly/2wmQc9n/

Fantin, M. (2012). Cultura Digital e Escola: pesquisa e formação de professores. São Paulo: Papirus.

Ferrés y Prats, J. (2014). Las pantallas y el cerebro emocional. Barcelona: Romanya Valls.

Piscitelli, A. (2012). La competencia mediática: propuesta articulada de dimensiones e indicadores. Comunicar, revista iberoamericana de comunicación y educación, 19(38), 75-82. Andalucía, España. Disponible en https://bit. 1y/2P3WQJI/

Fígaro, R. (2010). Estudos de recepção para entender os usos da mídia na escola. Comunicação \& Educação, 15(3), 17-28. Disponible en https://bit. $1 \mathrm{y} / 2 \mathrm{w} 4 \mathrm{D} 35 \mathrm{~J} /$

Jenkins, H. (2009). Cultura da Convergência. São Paulo: Aleph.

Lemos, A. (julio-diciembre, 2013). Cultura da Mobilidade. Revsita Famecos, 12(2). Porto Alegra, Brasil.

Lévy, P. (2007). Cibercultura. São Paulo: Editora 34.

Lévy, P. (1999). A inteligência coletiva: por uma antropologia do ciberespaço. São Paulo: Loyola.

Magnoni, A., Affini, L. y Américo, D. (2007). Da Mobilidade a Ubiqüidade da Comunicação. II Colóquios Multitemáticos em Comunicação. Santos: Intecom. Disponible en https://bit.ly/2MKJ3tW/ 
Mcluhan, M. (1964). Os meios de comunicação como extensões do homem. São Paulo: Cultrix.

Mcluhan, M. (1972). A galáxia de Gutenberg: a formação do homem tipográfico. São Paulo: Edusp.

Ortiz, A., Affonso, L. y Timponi, R. (eds.) (2012). Tecnologias de comunicação e cognição. Porto Alegre: Salinas.

Santaella, L. (2010). A ecologia pluralista da comunicação. São Paulo: Paulus.

Santaella, L. (2013). Comunicação ubíqua. Repercussões na cultura e na educação. São Paulo: Paulus.

Santaella, L. (2005). Semiótica Aplicada. São Paulo: Pioneira Thomson Learning.

Santaella, L. (2008). Mídias locativas: a internet móvel de lugares e coisas. Revista Famecos, 1(35). Recuperado de https://bit.ly/2o943wu/

Palacios, M. S. y Cunha, R. (2012). A tactilidade em dispositivos móveis: primeiras reflexões e ensaio de tipologias. Contemporânea, revista de comunicação e cultura, 10(3), 658- 685. Universidad Federal de Bahía. Recuperado de https://bit.ly/2BIJj8v/

Fecha de recepción: 2018/03/22; Fecha de aceptación: 2018/08/19;

Fecha de publicación: 2018/09/01 



\title{
Tendencias globales que marcan el desarrollo de la educación superior en el Ecuador: pertinencia, regionalización y expansión de la oferta académica
}

\author{
Global trends marking the development of Ecuador's \\ higher education: relevance, regionalization and expansion \\ of the academic market
}

\author{
José A. Flores \\ FLACSO-Ecuador \\ pepejos66@gmail.com \\ Código Orcid: https://orcid.org/0000-0002-3640-9129 \\ Endel D. Pernía \\ UNEARTE-Caracas \\ endelperniaecuador@gmail.com \\ Código Orcid: https://orcid.org/0000-0002-0238-4584
}

\begin{abstract}
Resumen
Ecuador ha logrado grandes avances en relación a la calidad, la inclusión y la pertinencia de la educación superior, sin embargo, el sistema de educación superior aún conserva profundas brechas que reproducen las características estructurales de la asimetría económica y poblacional del país. El presente estudio explora la concepción de la educación como "derecho humano" y "bien público", y desde esa perspectiva explora los retos que el sistema de educación superior debe enfrentar. El análisis parte de los datos presentados por los organismos rectores del nivel de educación en mención, para someterlos a una lectura crítica y presentar formas de regionalizar los impactos de las instituciones de educación superior. Los datos son contrastados con los principales discursos presentes en los diversos marcos sociales del Ecuador (legal, planificación y desarrollo) y del contexto internacional (documentos de la UNESCO, la ONU, entre otros).
\end{abstract}

\section{Palabras clave}

Educación superior, Ecuador, brechas, regionalización, bien público, derecho humano.

Forma sugerida de citar: Flores, José y Pernía, Endel (2018). Tendencias globales que marcan el desarrollo de la educación superior en el Ecuador: pertinencia, regionalización y expansión de la oferta. Universitas, 29, pp. 217-239. 


\begin{abstract}
Ecuador has achieved great progress in terms of quality, inclusion and relevance of Higher Education. However, the higher education system still shows deep gaps which reproduce the structural characteristics of the economic and demographic asymmetry of the country. This study explores the conception of education as a human right and public assets. From this perspective, the study explores the challenges that the higher education system faces. The analysis starts from the data presented by the entities in charge of higher education, and subjects it to a critical reading while presenting ways to regionalize the impacts of the higher education institutions in Ecuador. The data is contrasted with the different social, legal, planning, and development the Ecuadorian framework as well as the international framework (UNESCO and the UN documents among others).
\end{abstract}

\title{
Keywords
}

Higher Education, Ecuador, gaps, regionalism, public assets, human right.

\section{Introducción}

Desde 2008, el Gobierno del Ecuador inició el rescate de la educación superior como "derecho humano" y "bien público", enfatizando en su discurso la democratización del acceso y la calidad como vías para implementar el nuevo modelo de desarrollo y alcanzar el pacto social plasmado en la Constitución de 2008. Existen varios modelos para el desarrollo regional de la educación superior, los cuales serán explorados en el presente documento, en aras de que se propicie la discusión para continuar la construcción de un modelo que se adapte a las necesidades y características del Ecuador y que permita que el derecho a la educación superior sea ejercido con criterios de expansión potencial de la oferta, calidad, inclusión y pertinencia.

El país ha logrado grandes avances en relación a la calidad, la inclusión y la pertinencia de la educación superior, sin embargo, el sistema de educación superior aún conserva profundas brechas que reproducen las características estructurales de la asimetría económica y poblacional del país. En este sentido, la mayor cobertura en relación al acceso y localización de universidades, escuelas politécnicas e institutos superiores se encuentra en los centros más poblados, pero hay grandes retos en términos de movilidad interna de estudiantes, docentes e investigadores; a pesar del importante incremento 
de la matrícula, persiste una buena parte de la población que no tiene acceso a educación superior.

En este escenario, la tensión fundamental que explora el presente artículo es la referente a las maneras más adecuadas para regionalizar la educación superior como "derecho humano" y "bien público". Para resolver esta tensión se presentará un análisis del contexto internacional en relación a la tasa bruta de matrícula de los países de América y Europa, pasando a la localización de los discursos más importantes que la normativa de educación superior ecuatoriana ha introducido para su configuración, para finalmente localizar el análisis social del contexto ecuatoriano.

\section{El contexto internacional de la educación superior en América y Europa}

En el Compendio mundial de educación (UNESCO, 2012) se puede observar que en América los países con más alta tasa de matrícula bruta son: ${ }^{1}$ Cuba (95\%), EE.UU. (95\%), Argentina (71\%) y Uruguay (63\%). Mientras que en Europa están Finlandia (94\%), Dinamarca (74\%), Suecia (74\%) y España $(73 \%)$. Dentro de estos países, la relación entre esfera pública y privada en la oferta de educación superior es la siguiente:

Tabla 1

Oferta de educación superior pública y particular

\begin{tabular}{|l|c|c|c|}
\hline \multicolumn{1}{|c|}{ País } & $\begin{array}{c}\text { Oferta académica en } \\
\text { instituciones públicas }\end{array}$ & $\begin{array}{c}\text { Oferta académica } \\
\text { en instituciones } \\
\text { subsidiadas }\end{array}$ & $\begin{array}{c}\text { Oferta académica en } \\
\text { instituciones privadas }\end{array}$ \\
\hline Cuba & $100 \%$ & $0 \%$ & $0 \%$ \\
\hline EE.UU. & $72,5 \%$ & $0 \%$ & $27,5 \%$ \\
\hline Argentina & $72,7 \%$ & $5,5 \%$ & $21,9 \%$ \\
\hline Uruguay & $87 \%$ & $0 \%$ & $13 \%$ \\
\hline
\end{tabular}

1 La SENESCYT utiliza este indicador como "la relación entre número de alumnos/as que están matriculados en establecimientos de enseñanza de Educación Superior independiente de su edad en relación al total de la población en edades entre los 18 a 24 años" (2015). Este enfoque es asumido en el presente análisis y se centra en el cálculo, a nivel de provincia, como complemento al análisis presentado por la Secretaría en mención. 


\begin{tabular}{|l|c|c|c|}
\hline Dinamarca & $98,3 \%$ & $1,6 \%$ & $0,1 \%$ \\
\hline Finlandia & $81,2 \%$ & $18,8 \%$ & $0 \%$ \\
\hline España & $69 \%$ & $27,9 \%$ & $3,2 \%$ \\
\hline Suecia & $93,4 \%$ & $6,6 \%$ & $0 \%$ \\
\hline
\end{tabular}

Fuente: UNESCO, 2012

Para lograr la mayor cantidad de matrícula, algunos países utilizan la expansión territorial de sus sistemas de educación superior, pero con diferentes estrategias. EE.UU., Cuba, Argentina y España apuestan por una "territorialización intensiva". Así, en EE.UU. se intenta cubrir casi todos los condados del país, en Cuba todos los municipios, en Argentina todas las provincias y municipios, y en España todos los territorios con poblaciones mayores a 50 000 habitantes. ${ }^{2}$ Por otro lado, los casos de Dinamarca, Finlandia, Suecia y Uruguay, aunque también tienen una cobertura territorial importante de la oferta en educación superior, poseen un marcado rasgo de "movilidad estudiantil" interna, donde los estudiantes se desplazan de su lugar de origen hasta los centros de estudios, normalmente ubicados fuera de su localidad (Arnesen y Lundahl, 2006; Fägerlind y Strömqvist, 2004; Andersen, 2017). ${ }^{3}$

Se debe mencionar que en el caso de Dinamarca, Finlandia y Suecia el sistema de educación superior tiene como rasgo fundamental, un sistema de bienestar estudiantil bien desarrollado para la atención integral que incluye, entre otras cosas, el otorgamiento de becas para todos los estudiantes de educación superior, la posibilidad de acceder a viviendas con subsidio destinadas únicamente a estudiantes y el acceso a créditos con fines educativos a una tasa de interés mínima.

Por lo tanto, más allá de la estrategia de expansión, la cobertura elevada de la matrícula tiene una correlación directa con la prestación pública de la oferta de educación superior. Los modelos de incremento de matrícula pueden estar basados en una territorialización intensiva - como el caso de los países ex-

2 Para mayor información sobre la expansión territorial intensiva en estos países puede consultar las siguientes páginas por país: EE.UU. (https://goo.gl/Tx5xXQ), Cuba (https://goo.gl/fdCet1), Argentina (https://bit.ly/2MRNyiW) y España (https://goo.gl/1spf6N).

3 Para mayor información sobre la expansión territorial por movilidad en estos países puede consultar las siguientes páginas por país: Dinamarca (https://goo.gl/GW52LT) (https://goo.gl/FZR9De), Finlandia (https://goo.gl/ZgT7zV), Suecia (https://goo.gl/ebhwc1) y (https://goo.gl/jRWtqT) y Uruguay (https://goo.gl/TxzKhV). 
puestos en primer lugar - o una movilidad intensiva hacia polos de desarrollo universitario - como es el caso de los países expuestos en segundo lugar - .

En relación a la movilidad interna estudiantil, docente y de investigadores, en cada país pudieron identificarse dos modelos básicos. Por una parte, sistemas con elevado nivel de integración para permitir la movilidad interna, tal como el sistema europeo producido por el proceso de Bolonia y la creación del Espacio Europeo de Educación Superior, que favorece los intercambios estudiantiles a nivel interno y externo de los países miembros, mediante el desarrollo de una estructura común de titulaciones y mecanismos de acreditación del conocimiento (Pereyra, 2006). Por otra parte, se identificaron sistemas de educación superior con poco nivel de integración para permitir la movilidad estudiantil, profesoral y de investigadores, donde a los estudiantes se les dificulta cambiarse de una universidad a otra o cursar un semestre en una universidad distinta en su mismo país o región; a pesar de que en América Latina se han realizado esfuerzos importantes para la integración sistémica de la educación superior, los resultados aún están por debajo de las necesidades (Aupetit, 2006).

\section{Marco normativo de la educación superior ecuatoriana y sus perspectivas de desarrollo}

En el ámbito internacional, plantear el desarrollo regional del sistema de educación superior del Ecuador se relaciona directamente con cuatro de los 17 Objetivos de Desarrollo Sostenible, promulgados por la Asamblea General de la ONU (2015) - e indirectamente con todos los demás - , que son:

- Objetivo 4. Garantizar una educación inclusiva y equitativa de calidad y promover oportunidades de aprendizaje permanente para todos.

- Objetivo 8. Promover el crecimiento económico sostenido, inclusivo y sostenible, el empleo pleno y productivo y el trabajo decente para todos.

- Objetivo 10. Reducción de las desigualdades: reducir las desigualdades entre países y dentro de ellos.

- Objetivo 12. Garantizar modalidades de consumo y producción sostenibles.

En el ámbito nacional, el desarrollo regional del sistema tiene su base legal en la Constitución de la República del Ecuador, en el art. 3, que men- 
ciona el deber del Estado de garantizar el derecho a la educación y a promover el desarrollo equilibrado de la nación; se define a la educación como derecho, estableciendo los parámetros para su cumplimiento. ${ }^{4}$ Por otro lado, en el Título VII del Régimen del Buen Vivir, se establecen diversos elementos fundamentales de la educación como derecho. ${ }^{5}$ Así mismo, en relación a la Ley Orgánica de Educación Superior (LOES) ${ }^{6}$ se definen los fines de la educación superior y los derechos de la "comunidad educativa" dentro del sistema, entre los cuales se puede observar claramente la generación de conocimientos para el bienestar y el desarrollo de la nación, así como la garantía del derecho al estudio y a la investigación. El art. 107 define el principio de pertinencia de la educación superior y recoge la importancia de que esta debe contener para desarrollar procesos formativos que respondan a las expectativas y necesidades de la sociedad y del territorio.

En relación al Plan Nacional del Buen Vivir (2013-2017), el desarrollo regional del sistema de educación superior se relaciona directamente con cinco de los objetivos nacionales - e indirectamente con los siete restantes - :

- Objetivo 2. Auspiciar la igualdad, la cohesión, la inclusión y la equidad social y territorial, en la diversidad.

- Objetivo 8. Consolidar el sistema económico social y solidario, de forma sostenible.

- Objetivo 10. Impulsar la transformación de la matriz productiva.

- Objetivo 11. Asegurar la soberanía y eficiencia de los sectores estratégicos para la transformación industrial y tecnológica.

- Objetivo 12. Garantizar la soberanía y la paz, profundizar la inserción estratégica en el mundo y la integración latinoamericana.

Estos objetivos se complementan con la actual planificación del Estado (Plan Nacional de Desarrollo 2017-2021). De esta forma, ya que la transformación social se articula como un proceso a largo plazo, en el presente texto se consideran los objetivos planteados en la última década, donde la planificación estratégica vuelve al Estado. En la última propuesta - en consonancia con la planificación 2013-2017- se plantea:

4 Artículos 26, 27, 28 y 29.

5 Artículos 343, 350, 351 y 352.

6 Artículos: $3,4,5,6,7$ y 9 . 
- Objetivo 1. Garantizar una vida digna con iguales oportunidades para todas las personas.

- Objetivo 5. Impulsar la productividad y competitividad para el crecimiento económico sostenible de manera redistributiva y solidaria.

- Objetivo 6. Desarrollar las capacidades productivas y del entorno para lograr la soberanía alimentaria y el Buen Vivir rural.

- Objetivo 7. Incentivar una sociedad participativa con un Estado cercano al servicio de la ciudadanía.

En el período en el que se centra este análisis, Ecuador experimentó un proceso de reformas normativas que lo conectaron con el ámbito internacional. De esta forma, se incorporó en la planificación nacional conceptos de desarrollo que apuestan a la centralidad de los procesos educativos para impulsar cambio estructurales integrales. Se apostó por la equidad de procesos de distribución de riquezas como condición para la expansión de la oferta educativa de calidad. En este sentido, se rompió con el prejuicio de la democratización de la educación sin calidad, pues — como se visualiza en sistemas internacionales - ampliar la cobertura de educación con criterios de pertinencia en el marco de un concepto en disputa como el Buen Vivir supone mejorar los niveles de pobreza e impulsa el progreso equitativo de los territorios.

\section{Desigualdad territorial, oferta y pertinencia de la educación superior ecuatoriana}

Ecuador tiene una asimetría territorial y económica, fomentada por la relación de dos polos regionales de poder económico y político denominados Sierra-Costa (Quito-Guayaquil), donde se aglutinan los principales centros poblados, servicios básicos y empresas generadoras de riqueza social (SENPLADES, 2009). Este fenómeno se reproduce también en la distribución de la oferta de educación superior. Al respecto, "una distribución inequitativa de la educación genera un impacto negativo en el ingreso per cápita en la mayoría de los países" (Muñoz, 2004, p. 28). Para contribuir a romper la asimetría económica se debe romper la asimetría de la oferta educativa universitaria: la distribución regional actual de las posibilidades de estudiar es un freno a las potencialidades de desarrollo económico del Ecuador ( $c f$. Bourdieu, 1981) y de su capacidad de inserción en la economía del conocimiento. 
Sobre este tema, la planificación estatal realizada en el año 2013 mencionaba que "auspiciar la igualdad y erradicar la pobreza requiere eliminar las brechas, territoriales mediante el fomento del desarrollo rural y la promoción de una estructura nacional policéntrica, que permita el equilibrio urbano-rural" (SENPLADES, 2013, p. 120).

En este marco, la necesidad de profundizar el desarrollo regional de la educación superior viene dada al menos por dos factores fundamentales. El primero consiste en las dificultades que tiene parte importante de la población para trasladarse a las ciudades en las que se encuentran las instituciones de educación superior. De esta forma, al no haber oferta en su región, se limita la posibilidad de acceder a la educación de tercer nivel. El segundo factor tiene que ver con el desarrollo local y regional, donde la oferta académica debería estar relacionada con las potencialidades y las necesidades del territorio (Díaz, 2000). Una visión como la planteada permitiría realizar investigación, generar enclaves y clúster productivos, solucionar problemas a nivel tanto de las comunidades más cercanas como de la región en general. Sería una oferta académica pertinente que se relaciona con el sector productivo aledaño, potenciando sus capacidades y escalando la producción nacional. Sobre esto, podemos mencionar que:

Las relaciones de interdependencia, junto con las relaciones asimétricas de poder entre el campo y la ciudad, han contribuido a organizar las dinámicas sociales y productivas de los territorios, incluyendo la estructuración de brechas de desigualdad, frecuentemente arraigadas en patrones de discriminación racial y en dinámicas sociales que han provocado fuertes presiones sobre los recursos naturales. Esto hace evidente serios conflictos de uso y de aprovechamiento sustentable del potencial local. En este contexto, es necesario consolidar la especialización de los diversos asentamientos humanos presentes en el sistema territorial nacional, basándose en la capacidad de acogida de los territorios (SENPLADES, 2013, p. 121).

Asimismo, vale la pena mencionar cuál es la noción de "pertinencia" que la LOES presenta:

El principio de pertinencia consiste en que la educación superior responda a las expectativas y necesidades de la sociedad, a la planificación nacional, y al régimen de desarrollo, a la prospectiva de desarrollo científico, humanístico y tecnológico mundial, y a la diversidad cultural. Para ello, las instituciones de educación superior articularán su oferta docente, de investigación 
y actividades de vinculación con la sociedad a la demanda académica, a las necesidades de desarrollo local, regional y nacional, a la innovación y diversificación de profesiones y grados académicos, a las tendencias del mercado ocupacional local, regional y nacional, a las tendencias demográficas locales, provinciales y regionales; a la vinculación con la estructura productiva actual y potencial de la provincia y la región, y a las políticas nacionales de ciencia y tecnología (LOES, 2010).

El desarrollo regional del sistema de educación superior es una pieza fundamental para afianzar este importante derecho humano, contra la problemática referente al acceso a la educación superior (Cedeño y Machado, 2012). Ahora bien, es necesario reflexionar críticamente alrededor de uno de los temas más álgidos en la territorialización: ¿cómo lograrla sin detrimento de la calidad de la educación? En este sentido, la educación de calidad se constituye como uno de los elementos centrales de la democratización de derechos, como primer paso para construir una sociedad más productiva: "El supuesto para tal apuesta es que una educación de calidad para todos y todas es el principal medio para construir una democracia radical de calidad, y es un mecanismo eficaz para transformar la matriz productiva primariaexportadora y secundaria-importadora" (Ramírez, 2016, p. 6).

La regionalización de la oferta educativa debe tener en cuenta los criterios de expansión de la educación como un bien público (aun cuando esté administrado por una institución particular) y la pertinencia del conocimiento para la comunidad, los sectores productivos y las potencialidades naturales del Ecuador.

El derecho a la educación desde los territorios, desde la pertinencia, significa en el mundo actual reivindicar la necesidad del derecho a conocimientos alternativos, que sean creados por una nueva "epistemología desde el Sur" (De Sousa, 2010). De no romperse esta estructura se hará mucho más difícil la consecución de la democracia cognitiva de la población, el cambio de la matriz productiva, el logro de los objetivos plasmados en la Constitución y el desarrollo integral del Ecuador.

Boaventura De Sousa (2010) propone que el bien público de la universidad pase a ser producido en red, que se unan los recursos, se busquen las sinergias y se potencie el desempeño del sistema. Así, la construcción de la red pública implicará compartir recursos y equipamientos, la movilidad de docentes y estudiantes, y una estandarización mínima de planes y carreras, organización del año escolar y de los sistemas de evaluación. Nada de esto debe eliminar las especificidades con que cada institución de educación superior pretende res- 
ponder al contexto local o regional en el que está inserta. Por el contrario, esa especificidad, al mantenerse, puede valorarse mucho más al interior de la red.

Para la producción de esta red debemos desarrollar el sistema regional de educación superior, propiciar su interacción, su movilidad, su sinergia para la búsqueda de soluciones y transformación de la realidad existente en una realidad construida por la mayor cantidad de actores posibles, desde nuestras intersubjetividades, nuestras potencialidades de desarrollo, para lograr la construcción del buen vivir.

\section{Avances y retos en el plano de la regionalización del sistema de educación superior ecuatoriano}

Ecuador atravesó en esta última década un proceso de reorganización y aumento de la calidad de sus instituciones de educación superior. El denominado "Mandato 14" del proceso constituyente trajo consigo la evaluación de todas las instituciones, dando como resultado el cierre por falta de calidad de 14 universidades, 40 extensiones y 125 instituciones técnicas (Ramírez, 2016). Asimismo, se revirtió la tendencia a la mercantilización del sistema, se transformaron los modelos institucionales de conocimiento, aprendizaje y organización académica para la creación de ambientes de aprendizaje e investigación que conduzcan a nuestro país a la sociedad del conocimiento, particularmente a través de la generación de bioconocimiento (De Sousa, 2010; Ramírez, 2016).

En el período 2006-2014, en términos absolutos, la matrícula ha crecido en 136 mil estudiantes. En este sentido, la matrícula de los dos quintiles más pobres se ha duplicado pasando del $33 \%$ al $67 \%$. Hoy en día, uno de cada dos ecuatorianos que accede a la educación superior proviene de familias en que ni el padre, ni la madre asistieron a este nivel educativo (aproximadamente cien mil estudiantes) (Ramírez, 2016). En este sentido, la tasa bruta de matrícula universitaria ha crecido y ha pasado de 28,8\% en 2006 a 33,3\% en 2014. Este crecimiento se refleja más al detalle entre áreas rurales y urbanas, pasando de $38 \%$ a $42,1 \%$ en las ciudades y de $10,9 \%$ a $14 \%$ en las periferias entre 2006 y 2014 (INEC, 2016).

No obstante los avances del sistema de educación superior en estos últimos años, las condiciones estructurales en torno al desequilibrio regional de la matrícula no se han podido trasformar en su totalidad, ya que este a su vez es producto de la condición de desequilibro estructural del desarrollo 
territorial ecuatoriano y la tensión histórica que ha favorecido, en términos de servicios, a los centros de poder económico, político y más poblados del país en detrimento de las regiones más alejadas.

En este sentido, se puede observar el desequilibrio existente en la tasa bruta de matriculación por provincia:

Tabla 2

Tasa bruta de matrícula por provincia (2014)

\begin{tabular}{|l|c|}
\hline \multicolumn{1}{|c|}{ Provincias } & Tasa bruta \\
\hline Morona Santiago & $10,2 \%$ \\
\hline Sucumbíos & $12,2 \%$ \\
\hline Napo & $14,3 \%$ \\
\hline Orellana & $14,5 \%$ \\
\hline Zamora Chinchipe & $15,5 \%$ \\
\hline Pastaza & $18 \%$ \\
\hline Carchi & $20,3 \%$ \\
\hline Santa Elena & $21 \%$ \\
\hline Cotopaxi & $22,6 \%$ \\
\hline Los Ríos & $22,7 \%$ \\
\hline Santo Domingo de los Tsáchilas & $23 \%$ \\
\hline Esmeraldas & $23,7 \%$ \\
\hline Cañar & $24,8 \%$ \\
\hline El Oro & $27,1 \%$ \\
\hline Chimborazo & $29,7 \%$ \\
\hline Manabí & $30 \%$ \\
\hline Guayas & $34,5 \%$ \\
\hline Imbabura & $34,7 \%$ \\
\hline Tungurahua & $34,7 \%$ \\
\hline Azuay & $34,9 \%$ \\
\hline Bolívar & $36,7 \%$ \\
\hline Loja & $44,1 \%$ \\
\hline Pichincha & $49,1 \%$ \\
\hline
\end{tabular}

Fuente: INEC, 2016

Las provincias con más baja matrícula bruta en educación superior son Napo (14,3\%), Morona Santiago (10,2\%) y Sucumbíos (12,2\%). Las provincias que se encuentran por encima de la media nacional son Pichincha $(49,1 \%)$, Loja (44,1\%), Bolívar (36,7\%), Imbabura (34,7\%), Azuay (34,9\%), Tungurahua $(34,7 \%)$ y Guayas $(34,5 \%)$. En este sentido, en siete provincias 
las instituciones de educación superior (IES) no tienen oferta de formación en cuarto nivel (posgrado): El Oro, Zamora Chinchipe, Morona Santiago, Orellana, Napo, Sucumbíos y Carchi.

La formación que tiene mayor ocupación territorial es la técnica y tecnológica superior, como se puede corroborar en la siguiente tabla $3:^{7}$

Tabla 3

IES por provincia

\begin{tabular}{|c|c|c|}
\hline Provincia & $\begin{array}{c}\text { Universidad o } \\
\text { escuela politécnica }\end{array}$ & $\begin{array}{c}\text { Instituto técnico o tecnológico } \\
\text { y conservatorio }\end{array}$ \\
\hline Orellana & 0 & 1 \\
\hline Sucumbíos & 0 & 2 \\
\hline Morona Santiago & 0 & 4 \\
\hline Santo Domingo de los Tsáchilas & 0 & 6 \\
\hline Zamora Chinchipe & 0 & 7 \\
\hline Santa Elena & 1 & 0 \\
\hline Galápagos & 1 & 0 \\
\hline Pastaza & 1 & 3 \\
\hline Napo & 1 & 4 \\
\hline Carchi & 1 & 5 \\
\hline Esmeraldas & 1 & 5 \\
\hline Bolívar & 1 & 7 \\
\hline Cañar & 1 & 10 \\
\hline Cotopaxi & 1 & 10 \\
\hline El Oro & 1 & 10 \\
\hline Los Ríos & 2 & 6 \\
\hline Loja & 2 & 17 \\
\hline Chimborazo & 2 & 23 \\
\hline Imbabura & 3 & 12 \\
\hline Tungurahua & 3 & 21 \\
\hline Azuay & 4 & 9 \\
\hline Manabí & 5 & 8 \\
\hline Guayas & 13 & 38 \\
\hline Pichincha & 16 & 78 \\
\hline
\end{tabular}

Fuente: SNIESE, 2016

7 Para ampliar esta información se puede revisar: https://goo.gl/zB4wfg/ 
Considerando lo anteriormente señalado, la relación entre el número de IES por provincia y la tasa bruta de matriculación es la siguiente:

Tabla 4

Tasa bruta de matriculación y total de IES por provincia

\begin{tabular}{|l|c|c|}
\hline \multicolumn{1}{|c|}{ Provincias } & Tasa bruta & $\begin{array}{c}\text { Total } \\
\text { IES }\end{array}$ \\
\hline Morona Santiago & $10,2 \%$ & 4 \\
\hline Sucumbíos & $12,2 \%$ & 2 \\
\hline Napo & $14,3 \%$ & 5 \\
\hline Orellana & $14,5 \%$ & 1 \\
\hline Zamora Chinchipe & $15,5 \%$ & 7 \\
\hline Pastaza & $18 \%$ & 4 \\
\hline Carchi & $20,3 \%$ & 6 \\
\hline Santa Elena & $21 \%$ & 1 \\
\hline Cotopaxi & $22,6 \%$ & 11 \\
\hline Los Ríos & $22,7 \%$ & 8 \\
\hline Santo Domingo de los Tsáchilas & $23 \%$ & 6 \\
\hline Esmeraldas & $23,7 \%$ & 6 \\
\hline Cañar & $24,8 \%$ & 11 \\
\hline El Oro & $27,1 \%$ & 11 \\
\hline Chimborazo & $29,7 \%$ & 25 \\
\hline Manabí & $30 \%$ & 13 \\
\hline Guayas & $34,5 \%$ & 51 \\
\hline Imbabura & $34,7 \%$ & 15 \\
\hline Tungurahua & $34,7 \%$ & 24 \\
\hline Azuay & $34,9 \%$ & 13 \\
\hline Bolívar & $36,7 \%$ & 8 \\
\hline Loja & $44,1 \%$ & 17 \\
\hline Pichincha & $49,1 \%$ & 94 \\
\hline
\end{tabular}

Fuente: los autores

Se debe destacar que la mayor tasa bruta de matriculación se corresponde con un número elevado de IES por provincia. La brecha del número de 
instituciones de una provincia a otra es muestra del desarrollo históricamente desigual del sistema de educación superior ecuatoriano.

Para comenzar a corregir el desequilibrio estructural de este sistema, tres de las cuatro universidades creadas recientemente se encuentran en el interior del país: la Universidad Nacional de Educación (UNAE) en Cañar, la Universidad Regional Amazónica Ikiam en Napo y la Universidad de Investigación en Tecnología Experimental Yachay en Imbabura.

Considerando las pequeñas dimensiones territoriales del país en comparación con otros de la región, como parte de la corrección de estos desequilibrios, se ha apostado a un modelo de movilidad académica interregional, que permite la asignación de los estudiantes en centros universitarios alejados de la comunidad de origen y el desarrollo de un sistema de becas y atención a la comunidad universitaria para que puedan cursar los estudios superiores (Ramírez, 2016). Sin embargo, de acuerdo al Sistema Nacional de Nivelación y Admisión, para marzo de 2015, del total de participantes en el examen ENES, el porcentaje que aceptó cupo fuera de su provincia fue del $27,3 \%$, mientras que los que no aceptaron fue del 73,7\%, lo cual se puede tomar como un indicador del volumen de la movilidad de los nuevos ingresos en el sistema (SNNA, 2015).

\section{Figura 1}

Porcentaje de aspirantes que aceptan cupo que se movilizaron según su provincia de residencia y provincia de campus (marzo 2015)

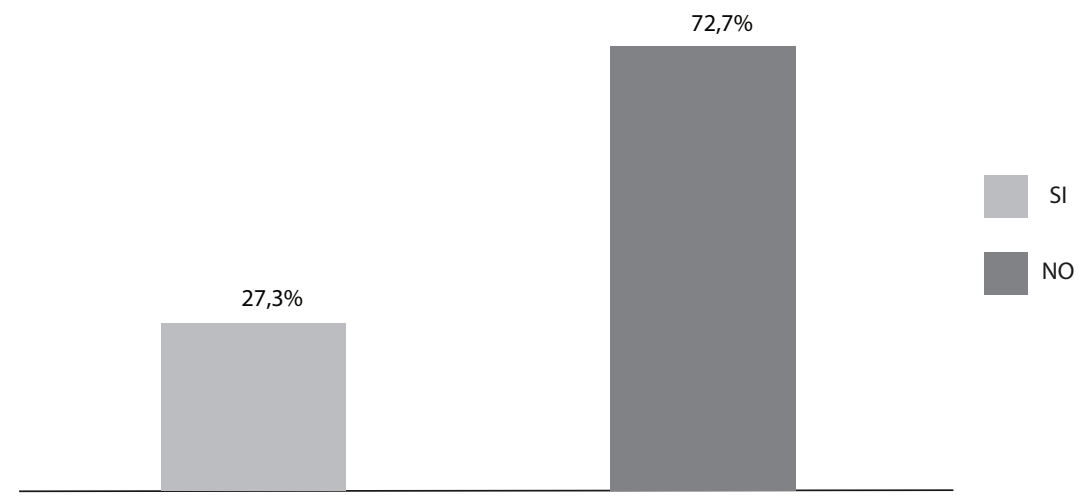


En relación a la movilidad, se debe mencionar que al optar por dicha alternativa como fórmula de desarrollo inclusivo del sistema de educación superior, también se debe considerar la pertinencia de las carreras estudiadas respecto al desarrollo de la comunidad de origen del estudiante y las dificultades que se presentan para el retorno una vez graduado.

Desde la formulación de la LOES, los proyectos de nuevas carreras deben contener el componente de pertinencia y vinculación con la sociedad, para que el Consejo de Educación Superior (CES) pueda considerar su aprobación, lo que motivó que todas las carreras creadas desde 2010 hasta hoy consideren su contribución al desarrollo del país.

Entre otras medidas, se fijaron cuatro premisas para avanzar hacia la proliferación de carreras pertinentes: servicios para alcanzar el buen vivir, carreras con demandas menos saturadas o inexistentes, articulación con la estructura productiva (sectores estratégicos, industrias básicas, empresas públicas, ciencias de frontera) y pertinencia territorial. Se establecieron 67 carreras pertinentes en las universidades, la mayor parte de ellas concentradas en ingeniería, industria y construcción, ciencias naturales, matemática y estadística. Aunque los resultados esperados de estas carreras dependen de un proceso a largo plazo, en los últimos años se ha conseguido aumentar en un $14 \%$ la oferta nacional de carreras pertinentes. No obstante los esfuerzos por la pertinencia académica, se debe mencionar que más del $90 \%$ de las carreras ofertadas en los institutos técnicos y tecnológicos - sobre todo del área privada - corresponden a la educación comercial (Samaniego, 2016).

Sobre la educación técnica y tecnológica pública, se debe decir que se ha hecho un esfuerzo para revalorizarla en el discurso oficial y en el rediseño de su oferta académica, para que tenga pertinencia social y productiva. Para 2017 se crearon 48 nuevas carreras técnicas y tecnológicas de modalidad dual, focalizadas en la industria y la producción, y se aumentó el número de cupos disponibles para estas formaciones a nivel nacional de 7406 en 2012 a 16771 para 2015 (SENESCYT, 2015). 


\section{Figura 2}

Oferta académica: cupos reales y aceptación total (2012-2015)

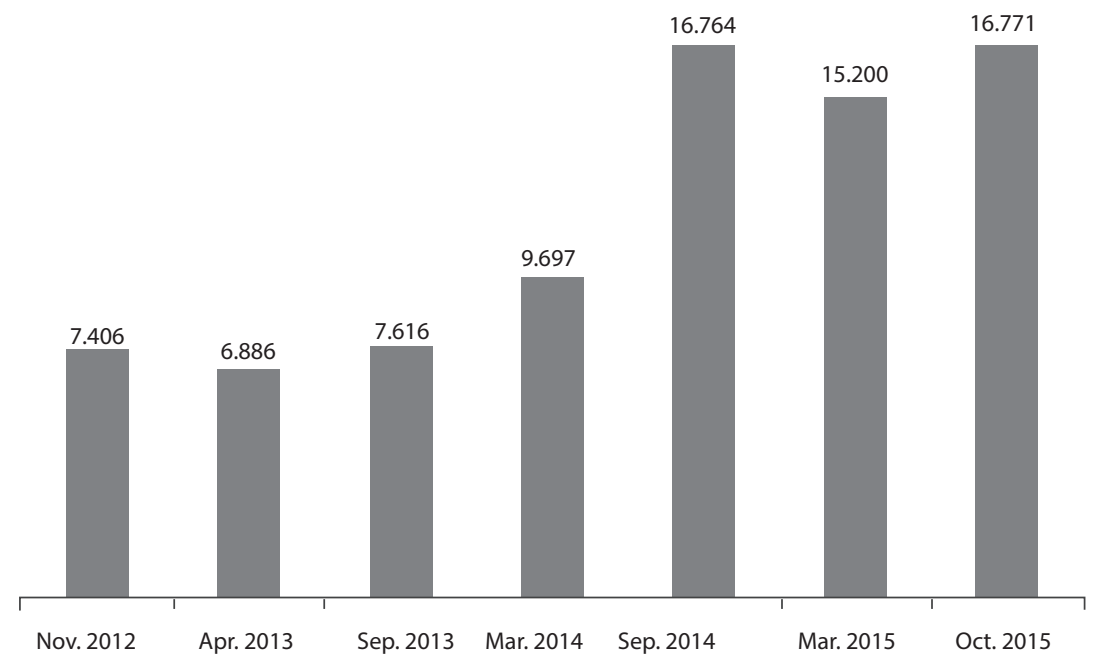

Fuente: SNNA, 2015

Otro aspecto importante sobre el desarrollo regional del sistema es la pertinencia multicultural ${ }^{8}$ y su capacidad de absorber a los grupos históricamente marginados en los territorios. Sobre esto, en 2015 la Secretaría de Educación Superior, Ciencia, Tecnología e Innovación (SENESCYT) emitió un decreto ministerial donde hace vinculante que las universidades públicas reserven el 10\% y las universidades particulares el 5\% de su matrícula para poblaciones históricamente excluidas (indígenas, afroecuatorianos, montubios, ciudadanos con discapacidad y personas privadas de libertad, entre otros). A su vez, las universidades particulares deben adjudicar un 5\% como mínimo de sus becas o ayudas económicas a estudiantes excluidos por razones sociales. Además, un lineamiento donde todas las carreras tienen

8 Se utiliza el concepto "multicultural" y no intercultural. Lo multicultural remite al reconocimiento del "otro", mientras la interculturalidad remite a las condiciones de tal reconocimiento. Ecuador ha dado pasos importantes para democratizar el acceso. El sistema intercultural sigue siendo un reto en el plano epistemológico y material en el Ecuador. 
que repensarse desde una perspectiva intercultural y todos los estudiantes, antes de titularse, deben hacer prácticas atendiendo problemáticas sociales en lugares rurales y urbanos marginales (Ramírez, 2016). Sin embargo, los retos en materia intercultural aún son superiores a las capacidades desarrolladas en el sistema para su abordaje.

El sistema de educación superior, a nivel regional, aún tiene limitaciones en el plano del acceso equitativo de todas las poblaciones y en cuanto a la movilidad de profesores, investigadores y estudiantes. No hay sinergias cotidianas para realizar procesos de investigaciones conjuntas entre las universidades o institutos superiores, intercambio estudiantil, la posibilidad de prosecución de estudios sin perder los créditos obtenidos en otra institución y estructuras para posibilitar el tránsito de un estudiante de instituciones técnicas superiores a instituciones de educación terciaria (esto último es consecuencia del proceso de depuración del sistema para asegurar la calidad académica de las universidades).

A pesar de lo mencionado, se han dado pasos importantes para propiciar la movilidad interna y externa de docentes, investigadores y estudiantes como elemento de desarrollo del sistema. En estos momentos, Ecuador posee un avance notable en términos jurídicos para propiciar la movilidad, el instrumento más relevante en este aspecto es el Reglamento de Régimen Académico del Sistema Nacional de Educación Superior, dictado por el CES en 2013, el cual señala: "Favorecer la movilidad nacional e internacional de profesores, investigadores, profesionales y estudiantes con miras a la integración de la comunidad académica ecuatoriana en la dinámica del conocimiento a nivel regional y mundial" (CES, 2013, art. 2-E). Además, ordena que el período académico de las instituciones debe, obligatoriamente, desarrollar dos períodos ordinarios al año, con un mínimo de 16 semanas efectivas "a efectos de facilitar la movilidad académica en el sistema de educación superior” (CES, 2013, art. 13). Específicamente, en relación a la movilidad interna de los estudiantes se establece que las horas de un curso o asignaturas aprobadas:

Serán susceptibles de transferencia entre carreras y programas de un mismo o de distinto nivel de formación, en la misma o diferente IES, conforme a este Reglamento. El CES podrá supervisar este proceso y promoverá la movilidad académica en los ámbitos regional, nacional e internacional (CES, 2013, art. 63). 
En el mismo espíritu, pero con respecto a los profesores, se menciona que:

A fin de garantizar la movilidad del personal académico, las instituciones de educación superior públicas podrán conceder licencias o comisiones de servicio, así como realizar traspasos de puestos y suscribir convenios con otras instituciones de educación superior, nacionales o extranjeras (CES, 2013, art. 84).

Finalmente, se instruye que "las IES públicas podrán autorizar el traspaso de puestos de su personal académico, con o sin la respectiva partida presupuestaria, de una IES a otra, debidamente legalizada" (CES, 2013, art. 85).

En aras del desarrollo del sistema y la integración académica, el 14 de mayo de 2012, en la ciudad de Quito, se reunieron representantes de investigación de las universidades categoría A y constituyeron la Red Ecuatoriana de Universidades y Escuelas Politécnicas para Investigación y Posgrados, cuyo objetivo actuar para la integración del desarrollo científico y académico, basados en la práctica reflexiva, la innovación y el trabajo colaborativo, promoviendo el debate y la generación de soluciones para los problemas de la sociedad, mediante la vinculación entre la academia, la empresa, la comunidad y el Estado. ${ }^{9}$ En este contexto, las redes desarrolladas en este marco institucional, hasta 2017, son: robótica, telecomunicación, ingeniería química, biotecnología, lácteos derivados, ciencias de la educación, lenguaje y literatura, turismo y hospitalidad, energía, gestión del territorio y tecnología de la información geoespacial, economía y administración, materiales y nanotecnología, mecánica, bioproductos, ciencias de la computación e información, ciencias de la tierra y el ambiente, derecho, química, ciencias biológicas, hidrógenos y celdas de combustibles, arte-diseño y arquitectura. Un reto fuerte para esta red es desarrollar su integralidad para integrar a varios actores, de manera que todas las instituciones de educación superior - como es el caso de los institutos superiores - puedan participar y beneficiarse del trabajo de la red.

La SENESCYT acompaña gran parte de las redes académicas antes mencionadas. Las redes con mayor participación institucional son la de administración (50 IES), informática (30 IES), economía (26 IES) e idiomas (24 IES). Además, se debe mencionar que existen redes más pequeñas, constituidas recientemente, pero de gran importancia para el desarrollo na-

9 Se puede obtener más información en: https://goo.gl/dnc1vf/ 
cional como: mecatrónica, forestal, turismo, psicología, veterinaria y zootecnia, educación inicial, educación básica, odontología, pedagogía de las matemáticas, acuicultura y pedagogía de la historia (SENESCYT, 2015).

Dichas redes tienen ya importantes avances en la armonización de titulaciones (informática), rediseño de malla curricular (idiomas, turismo, acuicultura, ingeniería automotriz, veterinaria zootécnica), rediseño de la oferta académica (psicopedagogía) y constitución de nuevas subredes (administración).

A parte de las redes académicas, la SENESCYT ha creado Redes Transversales y Redes Interinstitucionales. En cada red participan unas u otras universidades. En cuanto a las Redes Transversales se han constituido tres: la Red Nacional de Prevención Integral del Consumo de Drogas, la Red de Educación Superior y Género, y la Red de Universidades Promotoras de Salud y Bienestar. Tres redes interinstitucionales también se han conformado: la Red de Biotecnología, la Red de Metalmecánica y Astilleros, y la Red de Agropecuaria, Agroindustria y Pesca. Cada una de estas redes busca generar conocimiento e investigación, tomando en cuenta las realidades locales y la pertinencia de la educación superior en el desarrollo del Ecuador.

Por otra parte, se deben señalar como un elemento de desarrollo del sistema al fortalecimiento de instituciones públicas de investigación ya existentes y a la creación de nuevas instituciones dedicadas ese fin, lo que hace que en la actualidad el país cuente con once institutos públicos especializados en investigación organizados de forma sistémica, los cuales son: Instituto Nacional de Investigación en Salud Pública (INSPI), Instituto Nacional de Investigación Geológico, Minero y Metalúrgico (INIGEMM), Instituto Nacional de Meteorología e Hidrología (INAMHI), Instituto Nacional de Patrimonio Cultural (INPC), Instituto Nacional de Eficiencia Energética y Energías Renovables (INER), Instituto Nacional de Investigaciones Agropecuarias (INIAP), Instituto Nacional de Pesca (INP), Instituto Antártico Ecuatoriano (INAE), Instituto Geográfico Militar (IGM), Instituto Oceanográfico de la Armada (INOCAR) e Instituto Espacial Ecuatoriano (IEE). ${ }^{10}$

Otro avance que se debe destacar en el marco del desarrollo nacional del sistema es el aumento porcentual de estudios de cuarto nivel en los docentes titulares en 20,7\% (20 puntos porcentuales) del 2012 al 2014. A continuación, se muestra la evolución de este dato desde el 2012 con su proyección de crecimiento hasta el 2017.

10 Se puede ampliar esta información en: https://goo.gl/QGckwM/ 
Tabla 5

Docentes titulares con título de cuarto nivel

\begin{tabular}{|l|c|c|}
\hline \multicolumn{1}{|c|}{ Año } & Dato real & Proyección \\
\hline 2012 & $54,9 \%$ & \\
\hline 2013 & $67,2 \%$ & \\
\hline 2014 & $75,6 \%$ & \\
\hline 2015 & & $78,7 \%$ \\
\hline 2016 & & $81,9 \%$ \\
\hline 2017 & & $85 \%$ \\
\hline
\end{tabular}

Fuente: los autores

El desarrollo del sistema en términos de producción científica también ha presentado una mejoría considerable. El Ecuador ha pasado de tener 313 publicaciones indexadas en Scopus en 2006, a 1237 en 2017, lo que significa aumentar cuatro veces su capacidad de publicación científica. Además, el 75\% de estas publicaciones han sido producto de investigaciones llevadas a cabo en las IES. Dicho esfuerzo por la publicación ha llevado a ubicar al país como el de mayor incremento porcentual en la región en los últimos años, alcanzando el 18\% de crecimiento interanual (SENESCYT, 2015).

\section{Figura 3}

\section{Total de publicaciones indexadas en Scopus}

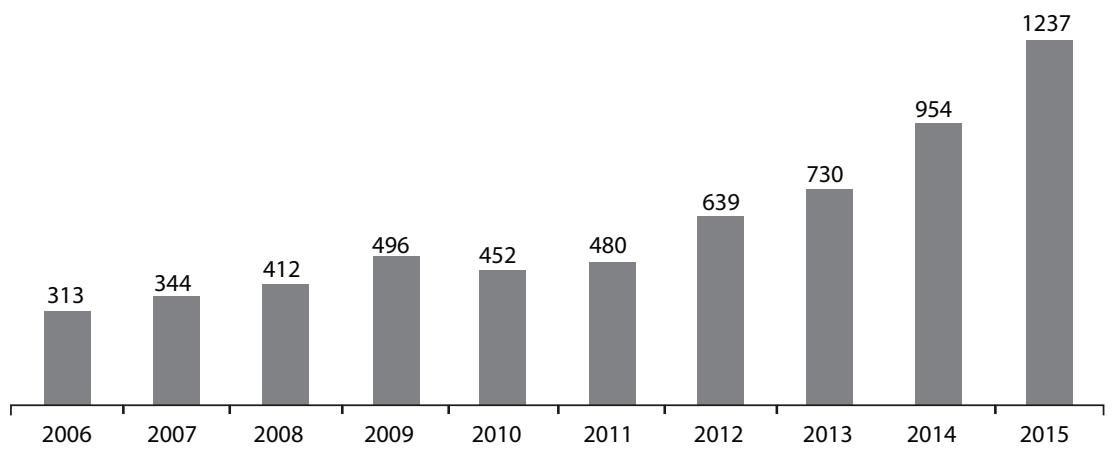

Fuentes: SENESCYT, 2015 
El sistema se ha diversificado, ampliando sus esfuerzos y resultados en los planos de investigación, producción y apropiación de conocimientos. En pro del desarrollo nacional ha venido avanzando, como puede verse, pero también son grandes los retos en este aspecto para que el desarrollo sea equilibrado, biocéntrico y para que más población tenga acceso a una educación superior de calidad y para que se haga ciencia de todo tipo en todo el país.

\section{Conclusiones}

Para finalizar este análisis es importante señalar algunas líneas de trabajo para seguir problematizando la realidad ecuatoriana en cuanto al sistema de educación superior. En este sentido, si la educación superior es un factor fundamental para el desarrollo general y equilibrado del Ecuador, ¿qué elementos hace falta trabajar para regionalizar la educación superior, basados en los principios de pertinencia y derecho social? Los modelos de desarrollo regional del sistema de educación superior se basan en la presencia de la educación superior en todo el país o en la movilidad de los estudiantes hacia los centros de formación, en este sentido: ¿qué modelo debe trabajar Ecuador?, ¿qué perspectiva sería la más idónea en términos de recursos y pertinencia?

Por otro lado, entendiendo a la educación superior como un factor de desarrollo y, por ende, a la generación de profesionales como un elemento de crecimiento social: ¿se podría pensar en una mayor sinergia entre la educación tecnológica y la educación de tercer nivel, facilitando la continuidad de estudios y la mayor profesionalización de la población, sin bajar la calidad?, ¿qué perspectivas se pueden construir en este sentido?

Por último, es necesario esbozar una interrogante central para el contexto social del Ecuador: ¿qué avances existen y qué retos debemos plantearnos para el estímulo de los elementos multiculturales, interculturales y biocéntricos en el desarrollo del sistema?

\section{Bibliografía}

Andersen, H. S. (2017). Udviklingen i unges fraflytning fra yderområder og den geografiske centralisering af uddannelserne. Lyngby, Dinamarca: Polyteknisk Forlag. 
Arnesen, A. L. y Lundahl, L. (2006). Still social and democratic? Inclusive education policies in the Nordic welfare states. Scandinavian Journal of Educational Research, 50(3), 285-300.

Asamblea Nacional. (2008). Constitución Política del Ecuador. Quito: Asamblea Nacional de la República del Ecuador.

Asamblea Nacional. (2010). Ley Orgánica de Educación Superior. Quito: Asamblea Nacional de la República del Ecuador.

Aupetit, S. (2006). Informe sobre la educación superior en América Latina y el Caribe (2000-2005): la metamorfosis de la educación superior. Panamá: IESALC/UNESCO.

Baena, M. D. (1999). El papel de la educación superior en el crecimiento y desarrollo de los países iberoamericanos. Scripta Nova, revista electrónica de geografía y ciencias sociales, 3 .

Bourdieu, P., Passeron, J. C., Melendres, J. y Subirats, M. (1981). La reproducción: elementos para una teoría del sistema de enseñanza. Barcelona: Laia.

Cedeño Ferrín, J. y Machado Ramírez, E. F. (2012). Papel de la extensión universitaria en la transformación local y el desarrollo social. Humanidades Médicas, 12(3), 371-390.

CES. (2013). Reglamento de Régimen Académico. Quito: Consejo de Educación Superior.

De Sousa Santos, B. (2008). La universidad en el siglo XXI: para una reforma democrática y emancipadora de la universidad. Caracas: CIM.

De Sousa Santos, B. (2010). Refundación del Estado en América Latina: perspectivas desde una epistemología del Sur. La Paz: Plural.

Díaz, E. G. V. (2000). Situación de la educación en el Ecuador. Educación, 23(11).

Fägerlind, I. y Strömqvist, G. (2004). Reforming higher education in the Nordic countries: studies of change in Denmark, Finland, Iceland, Norway and Sweden. UNESCO.

Horruitiner-Silva, P. (2007). La universalización de la educación superior. Revista Pedagogía Universitaria, 12(4).

Hounie, A., Pittaluga, L., Porcile, G. y Scatolin, F. (1999). La CEPAL y las nuevas teorías del crecimiento. Revista de la CEPAL, 68, 7-33.

INEC. (2016). Resultados de la Encuesta de Condiciones de Vida 2013-2014. Quito: INEC.

Ministry of Higher Education. (2016). The Danish Education System. Copenhagen: The Ministry of Higher Education and Science, the Ministry for 
Children, Education and Gender Equality and the Ministry of Culture, Copenhagen.

Muñoz, C. (2004). Educación y desarrollo socioeconómico en América Latina y el Caribe. México DF: Universidad Iberoamericana.

ONU. (2015). Objetivos de desarrollo del milenio. Nueva York: ONU.

Pereyra, M.A. (2006). Las universidades españolas y el proceso de construcción del Espacio Europeo de Educación Superior: limitaciones y perspectivas de cambio. Revista Española de Educación Comparada, 12, 113-143.

Rama, C. (2011). La educación superior en América Latina en el período 20002010: ocho ejes centrales en discusión. Revista Innovación Educativa, 15-20. México DF.

Ramírez, R. (2016). Universidad urgente para una sociedad emancipada. Quito: UNESCO/IESALC/SENESCYT.

Ramonet, I. (2016). Diez claves que explican el nuevo sistema mundial. Mimeografiado.

REDU. (s/f). Red Ecuatoriana de Universidades y Escuelas Politécnicas para Investigación y Posgrados. Recuperado de www.redu.edu.ec

SENESCYT. (2015). Rendición de cuentas. Quito: SENESCYT.

SENPLADES. (2009). Modo de desarrollo, organización territorial y cambio constituyente en Ecuador. Quito: SENPLADES.

SENPLADES. (2013). Buen Vivir: plan nacional 2013-2017. Quito: SENPLADES.

SENPLADES. (2017). Plan Nacional de Desarrollo: toda una vida. Quito: SENPLADES.

SNNA. (2015). Sistema Nacional de Nivelación y Admisión. Quito: SENESCYT.

SNIESE. (2016). Geo portal. Recuperado de https://bit.ly/24aC7te/

UNESCO. (2012). Global Education Digest. Montreal: Institute for Statistics.

Fecha de recepción: 2018/03/14; Fecha de aceptación: 2018/08/12;

Fecha de publicación: 2018/09/01 



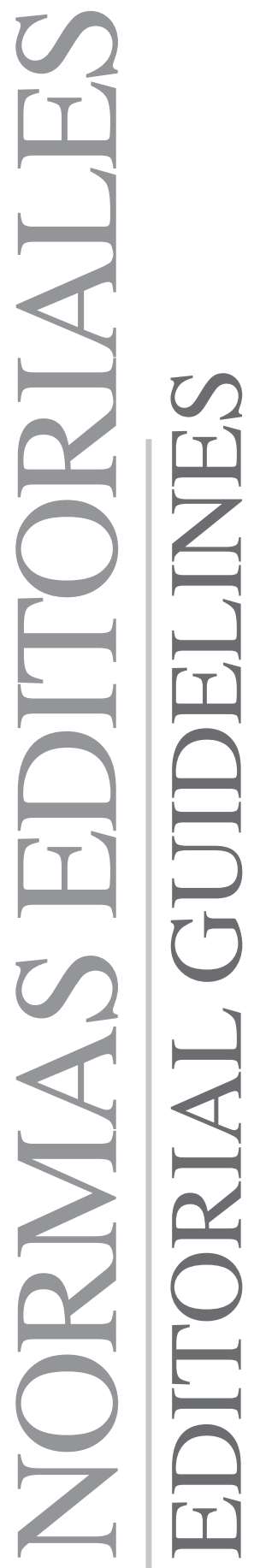





\section{NORMAS DE PUBLICACIÓN EN «UNIVERSITAS»}

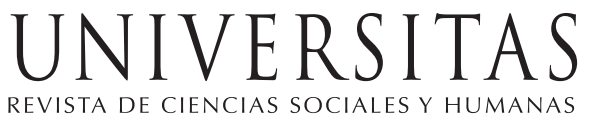

ISSN: 1390-3837 / e-ISSN: 1390-8634

\section{Información general}

«Universitas» es una publicación científica bilingüe de la Universidad Politécnica Salesiana de Ecuador, editada desde enero de 2002 de forma ininterrumpida, con periodicidad fija semestral, especializada en Ciencias Sociales y Humanas y sus líneas interdisciplinares como Sociología, Antropología, Psicología Social, Desarrollo Social, Comunidades, Estudios Latinoamericanos, Estudios Políticos, entre otras.

Es una revista científica arbitrada, que utiliza el sistema de evaluación externa por expertos (peer-review), bajo metodología de pares ciegos (doble-blind review), conforme a las normas de publicación de la American Psychological Association (APA). El cumplimiento de este sistema permite garantizar a los autores un proceso de revisión objetivo, imparcial y transparente, lo que facilita a la publicación su inclusión en bases de datos, repositorios e indexaciones internacionales de referencia.

«Universitas» se encuentra indexada en el directorio y catálogo selectivo del Sistema Regional de Información en Línea para Revistas Científicas de América Latina, el Caribe, España y Portugal (Latindex), en el Sistema de Información Científica REDALYC, en el Directorio de Revistas de Acceso Abierto DOAJ y en repositorios, bibliotecas y catálogos especializados de Iberoamérica.

La revista se edita en doble versión: impresa (ISSN: 1390-3837) y electrónica (e-ISSN: 1390-8634), en español e inglés, siendo identificado además cada trabajo con un DOI (Digital Object Identifier System). 


\section{Alcance y Política}

\subsection{Temática}

Contribuciones originales en materia de Ciencias Humanas y Sociales, así como áreas afines: Sociología, Antropología, Psicología Social, Desarrollo Social, Comunidades, Estudios Latinoamericanos, Estudios Políticos, y todas aquellas disciplinas conexas interdisciplinarmente con la línea temática central.

\subsection{Aportaciones}

«Universitas» edita preferentemente resultados de investigación empírica sobre Ciencias Humanas y Sociales, redactados en español y/o inglés, siendo también admisibles informes, estudios y propuestas, así como selectas revisiones de la literatura (state-of-the-art).

Todos los trabajos deben ser originales, no haber sido publicados en ningún medio ni estar en proceso de arbitraje o publicación. De esta manera, las aportaciones en la revista pueden ser:

- Investigaciones: 5.000 a 6.500 palabras de texto, incluyendo título, resúmenes, descriptores, tablas y referencias.

- Informes, estudios y propuestas: 5.000 a 6.500 palabras de texto, incluyendo título, resúmenes, tablas y referencias.

- Revisiones: 6.000 a 7.000 palabras de texto, incluidas tablas y referencias. Se valorará especialmente las referencias justificadas, actuales y selectivas de alrededor de unas 70 obras.

«Universitas» tiene periodicidad semestral (20 artículos por año), publicada en los meses de marzo y septiembre y cuenta por número con dos secciones de cinco artículos cada una, la primera referida a un tema Monográfico preparado con antelación y con editores temáticos y la segunda, una sección de Misceláneas, compuesta por aportaciones variadas dentro de la temática de la publicación.

\section{Presentación, estructura y envío de los manuscritos}

Los trabajos se presentarán en tipo de letra Arial 10, interlineado simple, justificado completo y sin tabuladores ni espacios en blanco entre párrafos. 
Solo se separarán con un espacio en blanco los grandes bloques (título, autores, resúmenes, descriptores, créditos y epígrafes). La página debe tener 2 centímetros en todos sus márgenes.

Los trabajos deben presentarse en documento de Microsoft Word (.doc o .docx), siendo necesario que el archivo esté anonimizado en Propiedades de Archivo, de forma que no aparezca la identificación de autor/es.

Los manuscritos deben ser enviados única y exclusivamente a través del OJS (Open Journal System), en el cual todos los autores deben darse de alta previamente. No se aceptan originales enviados a través de correo electrónico u otra interfaz.

\subsection{Estructura del manuscrito}

Para aquellos trabajos que se traten de investigaciones de carácter empírico, los manuscritos seguirán la estructura IMRDC, siendo opcionales los epígrafes de Notas y Apoyos. Aquellos trabajos que por el contrario se traten de informes, estudios, propuestas y revisiones podrán ser más flexibles en sus epígrafes, especialmente en Material y métodos, Análisis y resultados y Discusión y conclusiones. En todas las tipologías de trabajos son obligatorias las Referencias.

1) Título (español) / Title (inglés): Conciso pero informativo, en castellano en primera línea y en inglés en segunda. Se aceptan como máximo 80 caracteres con espacio. El título no solo es responsabilidad de los autores, pudiéndose proponer cambios por parte del Consejo Editorial.

2) Nombre y apellidos completos: De cada uno de los autores, organizados por orden de prelación. Se aceptarán como máximo 3 autores por original, aunque pudieren existir excepciones justificadas por el tema, su complejidad y extensión. Junto a los nombres ha de seguir la categoría profesional, centro de trabajo, correo electrónico de cada autor y número de ORCID. Es obligatorio indicar si se posee el grado académico de doctor (incluir Dr./Dra. antes del nombre).

3) Resumen (español) / Abstract (inglés): Tendrá como extensión máxima 230 palabras, primero en español y después en inglés. En el resumen se describirá de forma concisa y en este orden: 1) Justificación del tema; 2) Objetivos; 3) Metodología y muestra; 4) Principales resultados; 5) Principales conclusiones. Ha de estar escrito de manera impersonal "El presente trabajo analiza...". En el caso del abstract no se admitirá el empleo de traductores automáticos por su pésima calidad. 
4) Descriptores (español) / Keywords (inglés): Se deben exponer 6 descriptores por cada versión idiomática relacionados directamente con el tema del trabajo. Será valorado positivamente el uso de las palabras claves expuestas en el Thesaurus de la UNESCO.

5) Introducción y estado de la cuestión: Debe incluir el planteamiento del problema, el contexto de la problemática, la justificación, fundamentos y propósito del estudio, utilizando citas bibliográficas, así como la literatura más significativa y actual del tema a escala nacional e internacional.

6) Material y métodos: Debe ser redactado de forma que el lector pueda comprender con facilidad el desarrollo de la investigación. En su caso, describirá la metodología, la muestra y la forma de muestreo, así como se hará referencia al tipo de análisis estadístico empleado. Si se trata de una metodología original, es necesario exponer las razones que han conducido a su empleo y describir sus posibles limitaciones.

7) Análisis y resultados: Se procurará resaltar las observaciones más importantes, describiéndose, sin hacer juicios de valor, el material y métodos empleados. Aparecerán en una secuencia lógica en el texto y las tablas y figuras imprescindibles evitando la duplicidad de datos.

8) Discusión y conclusiones: Resumirá los hallazgos más importantes, relacionando las propias observaciones con estudios de interés, señalando aportaciones y limitaciones, sin redundar datos ya comentados en otros apartados. Asimismo, el apartado de discusión y conclusiones debe incluir las deducciones y líneas para futuras investigaciones.

9) Apoyos y agradecimientos (opcionales): El Council Science Editors recomienda a los autor/es especificar la fuente de financiación de la investigación. Se considerarán prioritarios los trabajos con aval de proyectos competitivos nacionales e internacionales. En todo caso, para la valoración científica del manuscrito, este debe ir anonimizado con XXXX solo para su evaluación inicial, a fin de no identificar autores y equipos de investigación, que deben ser explicitados en la Carta de Presentación y posteriormente en el manuscrito final.

10) Las notas (opcionales) irán, solo en caso necesario, al final del artículo (antes de las referencias). Deben anotarse manualmente, ya que el sistema de notas al pie o al final de Word no es reconocido por los sistemas de maquetación. Los números de notas se colocan en superíndice, tanto en el texto como en la nota final. No se permiten notas que recojan citas bibliográficas simples (sin comentarios), pues éstas deben ir en las referencias. 
11) Referencias: Las citas bibliográficas deben reseñarse en forma de referencias al texto. Bajo ningún caso deben incluirse referencias no citadas en el texto. Su número debe ser suficiente para contextualizar el marco teórico con criterios de actualidad e importancia. Se presentarán alfabéticamente por el primer apellido del autor.

\subsection{Normas para las referencias}

PUBLICACIONES PERIÓDICAS

Artículo de revista (un autor): Valdés-Pérez, D. (2016). Incidencia de las técnicas de gestión en la mejora de decisiones administrativas [Impact of Management Techniques on the Improvement of Administrative Decisions]. Retos, 12(6), 199-2013. https://doi.org/10.17163/ret.n12.2016.05

Artículo de revista (hasta seis autores): Ospina, M.C., Alvarado, S.V., Fefferman, M., \& Llanos, D. (2016). Introducción del dossier temático "Infancias y juventudes: violencias, conflictos, memorias y procesos de construcción de paz" [Introduction of the thematic dossier "Infancy and Youth: Violence, Conflicts, Memories and Peace Construction Processes"]. Universitas, 25(14), 91-95. https://doi.org/10.17163/uni.n25.\%25x

Artículo de revista (más de seis autores): Smith, S.W., Smith, S.L. Pieper, K.M., Yoo, J.H., Ferrys, A.L., Downs, E.,... Bowden, B. (2006). Altruism on American Television: Examining the Amount of, and Context Surronding. Acts of Helping and Sharing. Journal of Communication, 56(4), 707-727. https://doi.org/10.1111/j.1460-2466.2006.00316.x

Artículo de revista (sin DOI): Rodríguez, A. (2007). Desde la promoción de salud mental hacia la promoción de salud: La concepción de lo comunitario en la implementación de proyectos sociales. Alteridad, 2(1), 28-40. (https://goo.gl/zDb3Me) (2017-01-29).

LIBROS Y CAPÍTULOS DE LIBRO

Libros completos: Cuéllar, J.C., \& Moncada-Paredes, M.C. (2014). El peso de la deuda externa ecuatoriana. Quito: Abya-Yala.

Capítulos de libro: Zambrano-Quiñones, D. (2015). El ecoturismo comunitario en Manglaralto y Colonche. En V.H. Torres (Ed.), Alternativas de Vida: Trece experiencias de desarrollo endógeno en Ecuador (pp. 175-198). Quito: Abya-Yala. 
Medios EleCtrónicos

Pérez-Rodríguez, M.A., Ramírez, A., \& García-Ruíz, R. (2015). La competencia mediática en educación infantil. Análisis del nivel de desarrollo en España. Universitas Psychologica, 14(2), 619-630. https://doi.org.10.11144/ Javeriana.upsy14-2.cmei

Es prescriptivo que todas las citas que cuenten con DOI (Digital Object Identifier System) estén reflejadas en las Referencias (pueden obtenerse en http://goo.gl/gfruh1). Todas las revistas y libros que no tengan DOI deben aparecer con su link (en su versión on-line, en caso de que la tengan, acortada, mediante Google Shortener: http://goo.gl) y fecha de consulta en el formato indicado.

Los artículos de revistas deben ser expuestos en idioma inglés, a excepción de aquellos que se encuentren en español e inglés, caso en el que se expondrá en ambos idiomas utilizando corchetes. Todas las direcciones web que se presenten tienen que ser acortadas en el manuscrito, a excepción de los DOI que deben ir en el formato indicado (https://doi.org/XXX).

\subsection{Epígrafes, tablas y gráficos}

Los epígrafes del cuerpo del artículo se numerarán en arábigo. Irán sin caja completa de mayús-culas, ni subrayados, ni negritas. La numeración ha de ser como máximo de tres niveles: 1./ 1.1./ 1.1.1. Al final de cada epígrafe numerado se establecerá un retorno de carro.

Las tablas deben presentarse incluidas en el texto en formato Word según orden de aparición, numeradas en arábigo y subtituladas con la descripción del contenido.

Los gráficos o figuras se ajustarán al número mínimo necesario y se presentarán incorporadas al texto, según su orden de aparición, numeradas en arábigo y subtituladas con la descripción abreviada. Su calidad no debe ser inferior a 300 ppp, pudiendo ser necesario contar con el gráfico en formato TIFF, PNG o JPEG.

\section{Proceso de envío}

Deben remitirse a través del sistema OJS de la revista dos archivos:

1) Presentación y portada, en la que aparecerá el título en español e inglés, nombres y apellidos de los autores de forma estandarizada con nú- 
mero de ORCID, resumen, abstract, descriptores y keywords y una declaración de que el manuscrito se trata de una aportación original, no enviada ni en proceso de evaluación en otra revista, confirmación de las autorías firmantes, aceptación (si procede) de cambios formales en el manuscrito conforme a las normas y cesión parcial de derechos a la editorial (usar modelo oficial de portada).

2) Manuscrito totalmente anonimizado, conforme a las normas referidas en precedencia.

Todos los autores han de darse de alta, con sus créditos, en la plataforma OJS, si bien uno solo de ellos será el responsable de correspondencia. Ningún autor podrá enviar o tener en revisión dos manuscritos de forma simultánea, estimándose una carencia de cuatro números consecutivos (2 años). 



\section{Publication guidelines in "Universitas» \\ UNIVERSITAS

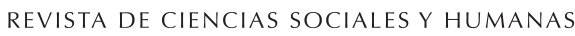

ISSN: 1390-3837 / e-ISSN: 1390-8634

\section{General Information}

«Universitas» is a bilingual scientific publication of the Universidad Politécnica Salesiana of Ecuador, published since January 2002 in an uninterrupted manner, with a semi-annual periodicity, specialized in Social and Human Sciences and its interdisciplinary lines such as Sociology, Anthropology, Social Psychology, Social Development, Communities, Latin American Studies, Political Studies, among others.

It is scientific journal, which uses the peer-review system, under double-blind review methodology, according to the publication standards of the American Psychological Association (APA). Compliance with this system allows authors to guarantee an objective, impartial and transparent review process, which facilitates the publication of their inclusion in reference databases, repositories and international indexing.

«Universitas» is indexed in the directory and selective catalog of the Regional Online Information System for Scientific Journals of Latin America, the Caribbean, Spain and Portugal (Latindex), in the Scientific Information System REDALYC, in the Directory of Journals of Open Access DOAJ and in repositories, libraries and specialized catalogs of Latin America.

The journal is published in a double version: printed (ISSN: 1390-3837) and digital (e-ISSN: 1390-8634), in English and Spanish, each work being identified with a DOI (Digital Object Identifier System). 


\section{Scope and Policy}

\subsection{Theme}

Original contributions in Humanities and Social Sciences, as well as related areas: Sociology, Anthropology, Social Psychology, Social Development, Communities, Latin American Studies, Political Studies, and all related interdisciplinary disciplines with the central theme.

\subsection{Contributions}

"Universitas" preferably publishes results of empirical research on $\mathrm{Hu}-$ man and Social Sciences, written in Spanish and / or English, as well as reports, studies and proposals, as well as selected state-of-the-art literature reviews.

All works must be original, have not been published in any medium or be in the process of arbitration or publication.

- Research: 5,000 to 6,500 words of text, including title, abstracts, descriptors, charts and references.

- Reports, studies and proposals: 5,000 to 6,500 words of text, including title, abstracts, charts and references.

- Reviews: 6,000 to 7,000 words of text, including charts and references. Justified references, would be specially valued. (current and selected from among 70 works)

"Universitas" has a biannual periodicity (20 articles per year), published in March and September and counts by number with two sections of five articles each, the first referring to a Monographic topic prepared in advance and with thematic editors and the Second, a section of Miscellaneous, composed of varied contributions within the theme of the publication.

\section{Presentation, Structure and Submission of the Manuscripts}

Texts will be presented in Arial 10 font, single line spacing, complete justification and no tabs or white spaces between paragraphs. Only large blocks (title, authors, summaries, descriptors, credits and headings) will 
be separated with a blank space. The page should be 2 centimeters in all its margins.

Papers must be submitted in a Microsoft Word document (.doc or .docx), requiring that the file be anonymized in File Properties, so that the author / $\mathrm{s}$ identification does not appear.

Manuscripts must be submitted only and exclusively through the OJS (Open Journal System), in which all authors must previously register. Originals sent via email or other interfaces are not accepted.

\subsection{Structure of the manuscript}

For those works that are empirical investigations, the manuscripts will follow the IMRDC structure, being optional the Notes and Supports. Those papers that, on the contrary, deal with reports, studies, proposals and reviews may be more flexible in their epigraphs, particularly in material and methods, analysis, results, discussion and conclusions. In all typologies of works, references are mandatory.

1) Title (Spanish) / Title (English): Concise but informative, in Spanish on the first line and in English on the second. A maximum of 80 characters with spaces are accepted. The title is not only the responsibility of the authors, changes being able to be proposed by the Editorial Board.

2) Full name and surnames: Of each of the authors, organized by priority. A maximum of 3 authors will be accepted per original, although there may be exceptions justified by the topic, its complexity and extent. Next to the names must follow the professional category, work center, email of each author and ORCID number. It is mandatory to indicate if you have the academic degree of doctor (include Dr./Dra before the name).

3) Abstract (Spanish) / Abstract (English): It will have a maximum extension of 230 words, first in Spanish and then in English. : 1) Justification of the topic; 2) Objectives; 3) Methodology and sample; 4) Main results; 5) Main conclusions. It must be impersonally written "This paper analyzes ...". In the case of the abstract, the use of automatic translators will not be accepted due to their poor quality.

4) Descriptors (Spanish) / Keywords (English): 6 descriptors must be presented for each language version directly related to the subject of the work. The use of the key words set out in UNESCO's Thesaurus will be positively valued. 
5) Introduction and state of the issue: It should include the problem statement, context of the problem, justification, rationale and purpose of the study, using bibliographical citations, as well as the most significant and current literature on the topic at national and international level .

6) Material and methods: It must be written so that the reader can easily understand the development of the research. If applicable, it will describe the methodology, the sample and the form of sampling, as well as the type of statistical analysis used. If it is an original methodology, it is necessary to explain the reasons that led to its use and to describe its possible limitations.

7) Analysis and results: It will try to highlight the most important observations, describing, without making value judgments, the material and methods used. They will appear in a logical sequence in the text and the essential charts and figures avoiding the duplication of data.

8) Discussion and conclusions: Summarize the most important findings, relating the observations themselves with relevant studies, indicating contributions and limitations, without adding data already mentioned in other sections. Also, the discussion and conclusions section should include the deductions and lines for future research.

9) Supports and acknowledgments (optional): The Council Science Editors recommends the author (s) to specify the source of funding for the research. Priority will be given to projects supported by national and international competitive projects. In any case, for the scientific evaluation of the manuscript, it should be only anonymized with XXXX for its initial evaluation, in order not to identify authors and research teams, which should be explained in the Cover Letter and later in the final manuscript.

10) The notes (optional) will go, only if necessary, at the end of the article (before the references). They must be manually annotated, since the system of footnotes or the end of Word is not recognized by the layout systems. The numbers of notes are placed in superscript, both in the text and in the final note. The numbers of notes are placed in superscript, both in the text and in the final note. No notes are allowed that collect simple bibliographic citations (without comments), as these should go in the references.

11) References: Bibliographical citations should be reviewed in the form of references to the text. Under no circumstances should references not mentioned in the text be included. Their number should be sufficient to 
contextualize the theoretical framework with current and important criteria. They will be presented alphabetically by the first last name of the author.

\subsection{Standards for references}

\section{Periodic Publications}

Journal article (author): Valdés-Pérez, D. (2016). Incidencia de las técnicas de gestión en la mejora de decisiones administrativas [Impact of Management Techniques on the Improvement of Administrative Decisions]. Retos, 12(6), 199-2013. https://doi.org/10.17163/ret.n12.2016.05

Journal Article (Up to six authors): Ospina, M.C., Alvarado, S.V., Fefferman, M., \& Llanos, D. (2016). Introducción del dossier temático "Infancias y juventudes: violencias, conflictos, memorias y procesos de construcción de paz" [Introduction of the thematic dossier "Infancy and Youth: Violence, Conflicts, Memories and Peace Construction Processes"]. Universitas, 25(14), 91-95. https://doi.org/10.17163/uni.n25.\%25x

Journal article (more tan six authors): Smith, S.W., Smith, S.L. Pieper, K.M., Yoo, J.H., Ferrys, A.L., Downs, E.,... Bowden, B. (2006). Altruism on American Television: Examining the Amount of, and Context Surronding. Acts of Helping and Sharing. Journal of Communication, 56(4), 707-727. https://doi.org/10.1111/j.1460-2466.2006.00316.x

Journal article (without DOI): Rodríguez, A. (2007). Desde la promoción de salud mental hacia la promoción de salud: La concepción de lo comunitario en la implementación de proyectos sociales. Alteridad, 2(1), 28-40. (https://goo.gl/zDb3Me) (2017-01-29).

\section{BOOKS AND BOOK CHAPTERS}

Full books: Cuéllar, J.C., \& Moncada-Paredes, M.C. (2014). El peso de la deuda externa ecuatoriana. Quito: Abya-Yala.

Chaprter of book: Zambrano-Quiñones, D. (2015). El ecoturismo comunitario en Manglaralto y Colonche. En V.H. Torres (Ed.), Alternativas de Vida: Trece experiencias de desarrollo endógeno en Ecuador (pp. 175-198). Quito: Abya-Yala. 


\section{Digital MEDIA}

Pérez-Rodríguez, M.A., Ramírez, A., \& García-Ruíz, R. (2015). La competencia mediática en educación infantil. Análisis del nivel de desarrollo en España. Universitas Psychologica, 14(2), 619-630. https://doi.org.10.11144/ Javeriana.upsy14-2.cmei

It is prescriptive that all quotations that have DOI (Digital Object Identifier System) are reflected in the References (can be obtained at http://goo. gl/gfruh1). All journals and books that do not have DOI should appear with their link (in their online version, if they have it, shortened by Google Shortened: http://goo.gl) and date of consultation in the format indicated.

Journal articles should be presented in English, except for those in Spanish and English, in which case it will be displayed in both languages using brackets. All web addresses submitted must be shortened in the manuscript, except for the DOI that must be in the indicated format (https://doi.org/XXX).

\subsection{Epigraphs, Figures and Charts}

The epigraphs of the body of the article will be numbered in Arabic. They should go without a full box of capital letters, neither underlined nor bold. The numbering must be a maximum of three levels: 1./ 1.1./ 1.1.1. A carriage return will be established at the end of each numbered epigraph.

The charts must be included in the text in Word format according to order of appearance, numbered in Arabic and subtitled with the description of the content.

The graphics or figures will be adjusted to the minimum number required and will be presented incorporated in the text, according to their order of appearance, numbered in Arabic and subtitled with the abbreviated description. Their quality should not be less than 300 dpi, and it may be necessary to have the graph in TIFF, PNG or JPEG format.

\section{Submission Process}

Two files must be sent through the OJS system of the journal:

1) Presentation and cover, in which the title in Spanish and English will appear, names and surnames of the authors in a standardized form with ORCID number, abstract in both Spanish and English, descriptors and ke- 
ywords and a statement that the manuscript is an Origina lcontribution, not sent or in the process of being evaluated in another journal, confirmation of the signatory authors, acceptance (if applicable) of formal changes in the manuscript according to the rules and partial transfer of rights to the publisher (use official cover model).

2) Manuscript totally anonymized, according to the norms referred in precedence.

All authors must register with their credits on the OJS platform, although only one of them will be responsible for correspondence.

No author can submit or have in review two manuscripts simultaneously, estimating an absence of four consecutive numbers (2 years). 



\section{INDICADORES PARA REVISORES EXTERNOS DE «UNIVERSITAS»}

El Consejo de Revisores Externos de «Universitas» es un órgano colegiado independiente cuyo fin es garantizar la excelencia de esta publicación científica, debido a que la evaluación ciega -basada exclusivamente en la calidad de los contenidos de los manuscritos y realizada por expertos de reconocido prestigio internacional en la materia- es la mejor garantía y, sin duda, el mejor aval para el avance de la ciencia y para preservar en esta cabecera una producción científica original y valiosa.

Para ello, el Consejo de Revisores Externos está conformado por diversos académicos y científicos internacionales especialistas en Ciencias Sociales, esenciales para seleccionar los artículos de mayor impacto e interés para la comunidad científica internacional. Esto permite a su vez que todos los artículos seleccionados para publicar en «Universitas» cuenten con un aval académico e informes objetivables sobre los originales.

Por supuesto, todas las revisiones en «Universitas» emplean el sistema estandarizado internacionalmente de evaluación por pares con «doble ciego» (doble-blind) que garantiza el anonimato de los manuscritos y de los revisores de los mismos. Como medida de transparencia, anualmente se hacen públicos en la web oficial de la revista (www. http://Universitas.ups.edu.ec/) los listados completos de los revisores.

\section{Criterios de aceptación/rechazo de evaluación manuscritos}

El equipo editorial de «Universitas» selecciona del listado de revisores del Consejo de Revisores a aquellos que se estiman más cualificado en la temática del manuscrito. Si bien por parte de la publicación se pide la máxima colaboración de los revisores para agilizar las evaluaciones y los informes sobre cada original, la aceptación de la revisión ha de estar vinculada a:

a. Experticia. La aceptación conlleva necesariamente la posesión de competencias en la temática concreta del artículo a evaluar.

b. Disponibilidad. Revisar un original exige tiempo y conlleva reflexión concienzuda de muchos aspectos. 
c. Conflicto de intereses. En caso de identificación de la autoría del manuscrito (a pesar de su anonimato), excesiva cercanía académica o familiar a sus autores, pertenencia a la misma Universidad, Departamento, Grupo de Investigación, Red Temática, Proyectos de Investigación, publicaciones conjuntas con los autores... o cualquier otro tipo de conexión o conflicto/cercanía profesional; el revisor debe rechazar la invitación del editor para su revisión.

d. Compromiso de confidencialidad. La recepción de un manuscrito para su evaluación exige del Revisor un compromiso expreso de confidencialidad, de manera que éste no puede, durante todo el proceso, ser divulgado a un tercero.

En caso que el revisor no pueda llevar a cabo la actividad por algunos de estos motivos u otros justificables, debe notificarlo al editor por la misma vía que ha recibido la invitación, especificando los motivos de rechazo.

\section{Criterios generales de evaluación de manuscritos}

\section{a) Tema}

La temática que se plantea en el original, además de ser valiosa y relevante para la comunidad científica, ha de ser limitada y especializada en tiempo y espacio, sin llegar al excesivo localismo.

\section{b) Redacción}

La valoración crítica en el informe de revisión ha de estar redactada de forma objetiva, aportando contenido, citas o referencias de interés para argumentar su juicio.

\section{c) Originalidad}

Como criterio de calidad fundamental, un artículo debe ser original, inédito e idóneo. En este sentido, los revisores deben responder a estas tres preguntas en la evaluación:

- ¿Es el artículo suficientemente novedoso e interesante para justificar su publicación? 
- ¿Aporta algo al canon del conocimiento?

- ¿Es relevante la pregunta de investigación?

Una búsqueda rápida de literatura utilizando repositorios tales como Web of Knowledge, Scopus y Google Scholar para ver si la investigación ha sido cubierta previamente puede ser de utilidad.

\section{d) Estructura}

Los manuscritos que se remiten a «Universitas» deben seguir obligatoriamente la estructura IMRyD, excepto aquellos que sean revisiones de la literatura o estudios específicos. En este sentido, los originales han de contener resumen, introducción, metodología, resultados, discusión y conclusión.

- El título, el resumen y las palabras clave han de describir exactamente el contenido del artículo.

- La revisión de la literatura debe resumir el estado de la cuestión de las investigaciones más recientes y adecuadas para el trabajo presentado. Se valorará especialmente con criterios de idoneidad y que las referencias sean a trabajos de alto impacto -especialmente en WoS, Scopus, Scielo, etc. Debe incluir además la explicación general del estudio, su objetivo central y el diseño metodológico seguido.

- En caso de investigaciones, en los materiales y métodos, el autor debe precisar cómo se recopilan los datos, el proceso y los instrumentos usados para responder a las hipótesis, el sistema de validación, y toda la información necesaria para replicar el estudio.

- En los resultados se deben especificar claramente los hallazgos en secuencia lógica. Es importante revisar si las tablas o cuadros presentados son necesarios o, caso contrario, redundantes con el contenido del texto.

- En la discusión se deben interpretar los datos obtenidos a la luz de la revisión de la literatura. Los autores deberán incluir aquí si su artículo apoya o contradice las teorías previas. Las conclusiones resumirán los avances que la investigación plantea en el área del conocimiento científico, las futuras líneas de investigación y las principales dificultades o limitaciones para la realización de la investigación.

- Idioma: Se valorará positivamente si el idioma utilizado facilita la lectura y va en favor de la claridad, sencillez, precisión y transpa- 
rencia del lenguaje científico. El Revisor no debe proceder a corrección, ya sea en español o inglés, sino que informará a los Editores de estos errores gramaticales u ortotipográficos.

- Finalmente, se requiere una profunda revisión de las referencias por si se hubiera omitido alguna obra relevante. Las referencias han de ser precisas, citando en la lógica de la temática a estudiar, sus principales obras así como los documentos que más se asemejen al propio trabajo, así como las últimas investigaciones en el área.

\section{Dimensiones relevantes de valoración}

«Universitas» utiliza una matriz de evaluación de cada original que responde a los criterios editoriales y al cumplimiento de la normativa de la publicación. En este sentido los revisores deberán atender a la valoración cuali-cuantitativa de cada uno de los aspectos propuestos en esta matriz con criterios de objetividad, razonamiento, lógica y experticia.

\begin{tabular}{|l|c|}
\hline \multicolumn{1}{|c|}{ INVESTIGACIONES } & \multicolumn{1}{|c|}{ Ítems valorables } \\
\hline \multicolumn{1}{|c|}{} & P. \\
\hline 01. Título y resumen (claridad y estructura) & $0 / 5$ \\
\hline $\begin{array}{l}\text { 02. Relevancia de la temática } \\
\text { 03. Originalidad del trabajo } \\
\text { 04. Revisión de la literatura }\end{array}$ & $0 / 10$ \\
\hline $\begin{array}{l}\text { 05. Estructura y organización artículo } \\
\text { 06. Capacidad argumental } \\
\text { 07. Redacción }\end{array}$ & $0 / 10$ \\
\hline $\begin{array}{l}\text { 08. Rigor metodológico } \\
\text { 09. Instrumentos de investigación }\end{array}$ & $0 / 10$ \\
\hline $\begin{array}{l}\text { 10. Resultados de investigación } \\
\text { 11. Avances } \\
\text { 12. Discusión } \\
\text { 13. Conclusiones }\end{array}$ & $0 / 10$ \\
\hline $\begin{array}{l}\text { 14. Citaciones (variedad y riqueza) } \\
\text { 15. Referencias }\end{array}$ & $0 / 5$ \\
\hline Total máximo & 50 \\
\hline
\end{tabular}


En caso de tratarse el original de una revisión de la literatura (estado de la cuestión) u otro tipo de estudio (informes, propuestas, experiencias, entre otras), el Consejo Editorial remitirá a los revisores una matriz distinta, comprendiendo las características propias de estructura de este tipo de originales:

\begin{tabular}{|l|c|}
\hline \multicolumn{1}{|c|}{ ESTUDIOS, INFORMES, PROPUESTAS, EXPERIENCIAS } \\
\hline \multicolumn{1}{|c|}{ Ítems valorables } & P. \\
\hline 01. Título y resumen (claridad y estructura) & $0 / 5$ \\
\hline 02. Relevancia de la temática & $0 / 10$ \\
\hline 03. Revisión de la literatura & $0 / 10$ \\
\hline $\begin{array}{l}\text { 04. Estructura y organización artículo } \\
\text { 05. Capacidad argumental y coherencia } \\
\text { 06. Redacción científica }\end{array}$ & $0 / 10$ \\
\hline $\begin{array}{l}\text { 07. Aportaciones originales } \\
\text { 08. Conclusiones }\end{array}$ & $0 / 10$ \\
\hline $\begin{array}{l}\text { 09. Citaciones } \\
\text { 10. Referencias }\end{array}$ & $0 / 5$ \\
\hline Total máximo & 50 \\
\hline
\end{tabular}

\section{Cuestiones éticas}

a) Plagio: Aunque la revista utiliza sistemas de detección de plagio, si el revisor sospechare que un original es una copia sustancial de otra obra, ha de informar de inmediato a los Editores citando la obra anterior con tanto detalle cómo le sea posible.

b) Fraude: Si hay sospecha real o remota de que los resultados en un artículo son falsos o fraudulentos, es necesario informar de ellos a los Editores.

\section{Evaluación de los originales}

Una vez realizada la evaluación cuanti-cualitativa del manuscrito en revisión, el revisor podrá realizar recomendaciones para mejorar la calidad 
del original. Sin embargo, se atenderá a la calificación del manuscrito de tres maneras:

a. Rechazo debido a las deficiencias detectadas, justificadas y razonadas con valoración cualitativa y cuantitativa. El informe ha de ser más extenso si obtiene menos de los 30 de los 50 puntos posibles.

b. Aceptación sin revisión.

c. Aceptación condicionada y por ende con revisión (mayor o menor). En este último caso, se ha de identificar claramente qué revisión es necesaria, enumerando los comentarios e incluso especificando párrafos y páginas en las que sugieren modificaciones. 


\section{GUIDELINES FOR EXTERNAL REVIEWERS OF «UNIVERSITAS»}

The Council of External Reviewers of «Universitas» is an independent collegiate body whose purpose is to guarantee the excellence of this scientific publication, because the blind evaluation - based exclusively on the quality of the contents of the manuscripts and carried out by experts of recognized International prestige in the field - is, without a doubt, the best guarantee for the advancement of science and to preserve in this header an original and valuable scientific production.

To this end, the Council of External Reviewers is made up of several scholars and international scientists specialized in Education, essential to select the articles of the greatest impact and interest for the international scientific community. This in turn allows that all the articles selected to publish in «Universitas» have an academic endorsement and objectifiable reports on the originals.

Of course, all reviews in «Universitas» use the internationally standardized system of double-blind peer evaluation that guarantees the anonymity of manuscripts and reviewers. As a measure of transparency, the complete lists of reviewers are published on the official website of the journal (www. http://Universitas.ups.edu.ec/) los listados completos de los revisores.

\section{Criteria for acceptance/rejection of manuscript evaluation}

The editorial team of «Universitas» selects those that are considered more qualified in the subject of the manuscript from the list of reviewers of the Council of Reviewers. While the publication requires the maximum collaboration of reviewers to expedite the evaluations and reports on each original, acceptance of the review must be linked to:

a. Expertise. Acceptance necessarily entails the possession of competences in the specific theme of the article to be evaluated.

b. Availability. Reviewing an original takes time and involves careful reflection on many aspects. 
c. Conflict of interests. In case of identification of the authorship of the manuscript (despite their anonymity), excessive academic or family closeness to their authors, membership in the same University, Department, Research Group, Thematic Network, Research Projects, joint publications with authors ... or any other type of connection or conflict / professional proximity; The reviewer must reject the publisher's invitation for review.

d. Commitment of confidentiality. Reception of a manuscript for evaluation requires the Reviewer to express a commitment of confidentiality, so that it cannot be divulged to a third party throughout the process.

In the event that the reviewer cannot carry out the activity for some of these reasons or other justifiable reasons, he/she must notify the publisher by the same route that he/she has received the invitation, specifying the reasons for rejection.

\section{General criteria for the evaluation of manuscripts}

\section{a) Topic}

In addition to being valuable and relevant to the scientific community, the topic that is presented in the original must be limited and specialized in time and space, without excessive localism.

\section{b) Redaction}

The critical assessment in the review report must be objectively written, providing content, quotes or references of interest to support its judgment.

\section{c) Originality}

As a fundamental criterion of quality, an article must be original, unpublished and suitable. In this sense, reviewers should answer these three questions in the evaluation:

- Is the article sufficiently novel and interesting to justify publication?

- Does it contribute anything to the knowledge canon? 
- Is the research question relevant?

A quick literature search using repositories such as Web of Knowledge, Scopus and Google Scholar to see if the research has been previously covered, may be helpful.

\section{d) Structure}

Manuscripts that refer to «Universitas» must follow the IMRDC structure, except those that are literature reviews or specific studies. In this sense, the originals must contain summary, introduction, methodology, results, discussion and conclusion.

- The title, abstract, and keywords should accurately describe the content of the article.

- The review of the literature should summarize the state of the question of the most recent and adequate research for the presented work. It will be especially evaluated with criteria of suitability and that the references are to works of high impact - especially in WoS, Scopus, Scielo, etc. It should also include the general explanation of the study, its central objective and the followed methodological design.

- In case of research, in the materials and methods, the author must specify how the data, the process and the instruments used to respond to the hypothesis, the validation system, and all the information necessary to replicate the study are collected.

- Results must be clearly specified in logical sequence. It is important to check if the figures or charts presented are necessary or, if not, redundant with the content of the text.

- In the discussion, the data obtained should be interpreted in the light of the literature review. Authors should include here if their article supports or contradicts previous theories. The conclusions will summarize the advances that the research presents in the area of scientific knowledge, the future lines of research and the main difficulties or limitations for carrying out the research.

- Language: It will be positively assessed if the language used facilitates reading and is in favor of the clarity, simplicity, precision and transparency of the scientific language. The Reviewer should not proceed to correction, either in Spanish or English, but will inform 
the Editors of these grammatical or orthographical and typographical errors.

- Finally, a thorough review of the references is required in case any relevant work has been omitted. The references must be precise, citing within the logic of the subject at study, its main works as well as the documents that most resemble the work itself, as well as the latest research in the area.

\section{Relevant valuation dimensions}

«Universitas» uses an evaluation matrix of each original that responds to the editorial criteria and to compliance with the publication normative. In this sense, the reviewers must attend to the qualitative-quantitative assessment of each of the aspects proposed in this matrix with criteria of objectivity, reasoning, logic and expertise.

\begin{tabular}{|l|c|}
\hline \multicolumn{1}{|c|}{ RESEARCHES } \\
\hline \multicolumn{1}{|c|}{ Valuable items } & P. \\
\hline 01. Title and abstract (clarity and structure) & $0 / 5$ \\
\hline $\begin{array}{l}\text { 02. Thematic relevance } \\
\text { 03. Originality of the work } \\
\text { 04. Review of the literature }\end{array}$ & $0 / 10$ \\
\hline $\begin{array}{l}\text { 05. Structure and organization of the article } \\
\text { 06. Argumentative capabilities } \\
\text { 07. Redaction }\end{array}$ & $0 / 10$ \\
\hline $\begin{array}{l}\text { 08. Methodological rigor } \\
\text { 09. Research instruments }\end{array}$ & $0 / 10$ \\
\hline $\begin{array}{l}\text { 10. Research results } \\
\text { 11. Advances } \\
\text { 12. Discussion } \\
\text { 13. Conclusions }\end{array}$ & $0 / 10$ \\
\hline $\begin{array}{l}\text { 14. Quotations (variety and richness) } \\
\text { 15. References }\end{array}$ & $0 / 5$ \\
\hline Total & 50 \\
\hline
\end{tabular}


If the original is a review of the literature (status of the subject) or other type of study (reports, proposals, experiences, among others), the Editorial Board will send to the reviewers a different matrix, including the characteristics of Structure of this type of originals:

\begin{tabular}{|l|c|}
\hline \multicolumn{2}{|c|}{ REPORTS, STUDIES, PROPOSALS, REVIEWS } \\
\hline \multicolumn{1}{|c|}{ Valuable items } & P. \\
\hline 01. Title and abstract (clarity and structure) & $0 / 5$ \\
\hline 02. Thematic relevance & $0 / 10$ \\
\hline 03. Review of the literature & $0 / 10$ \\
\hline $\begin{array}{l}\text { 04. Structure and organization of the article } \\
\text { 05. Argumentative capabilities and coherence } \\
\text { 06. Scientific redaction }\end{array}$ & $0 / 10$ \\
\hline $\begin{array}{l}\text { 07. original contributions } \\
\text { 08. Conclusions }\end{array}$ & $0 / 10$ \\
\hline $\begin{array}{l}\text { 09. Quotations } \\
\text { 10. References }\end{array}$ & $0 / 5$ \\
\hline Total & 50 \\
\hline
\end{tabular}

\section{Ethical Considerations}

a) Plagiarism: Although the journal uses plagiarism detection systems, if the reviewer suspects that an original is a substantial copy of another work, he must immediately inform the Editors citing the previous work in as much detail as possible.

b) Fraud: If there is real or remote suspicion that the results in an article are false or fraudulent, it is necessary to inform them to the Editors.

\section{Evaluation of the originals}

After the quantitative-qualitative evaluation of the manuscript under review, the reviewer may make recommendations to improve the quality of the manuscript. However, the manuscript will be graded in three ways: 
a. Acceptance without review

b. Conditional acceptance and therefore review (greater or lesser). In the latter case, it is necessary to clearly identify which review is necessary, listing the comments and even specifying paragraphs and pages suggesting modifications.

c. Rejection due to detected deficiencies justified and reasoned with quantitative and quantitative assessment. The report should be longer if a score of less than 40 of the 50 possible points is obtained. 


\section{PROTOCOLO DE EVALUACIÓN DE MANUSCRITOS PARA REVISORES EXTERNOS}

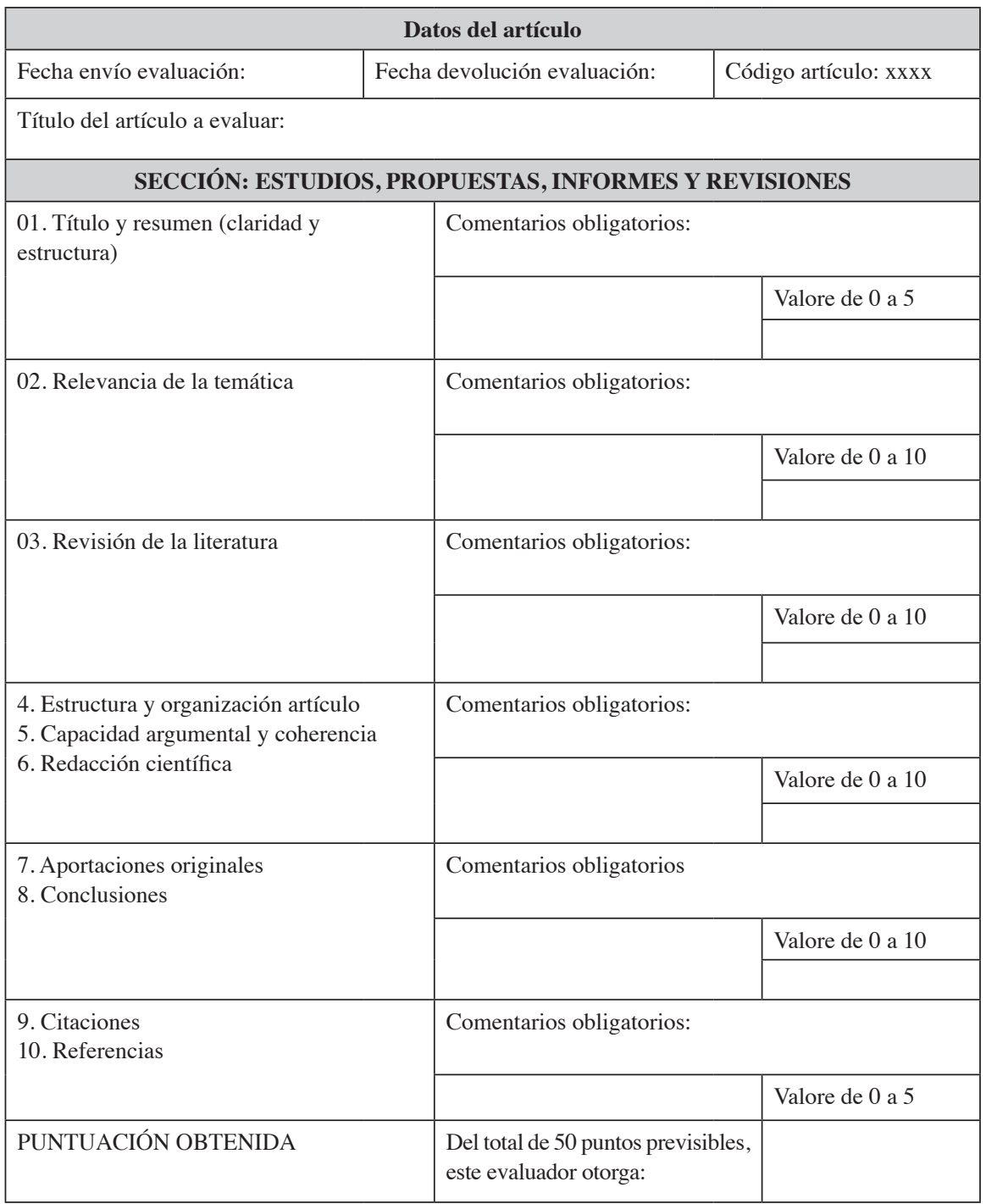




\begin{tabular}{|l|l|l|l|l|}
\hline OPINIÓN & \multicolumn{5}{|l|}{} \\
REDACTADA \\
(Más detallada si el \\
trabajo no obtiene 40 \\
puntos, para informar al \\
autor/es).
\end{tabular}




\section{PROTOCOL OF MANUSCRIPT EVALUATION FOR EXTERNAL REVIEWERS}

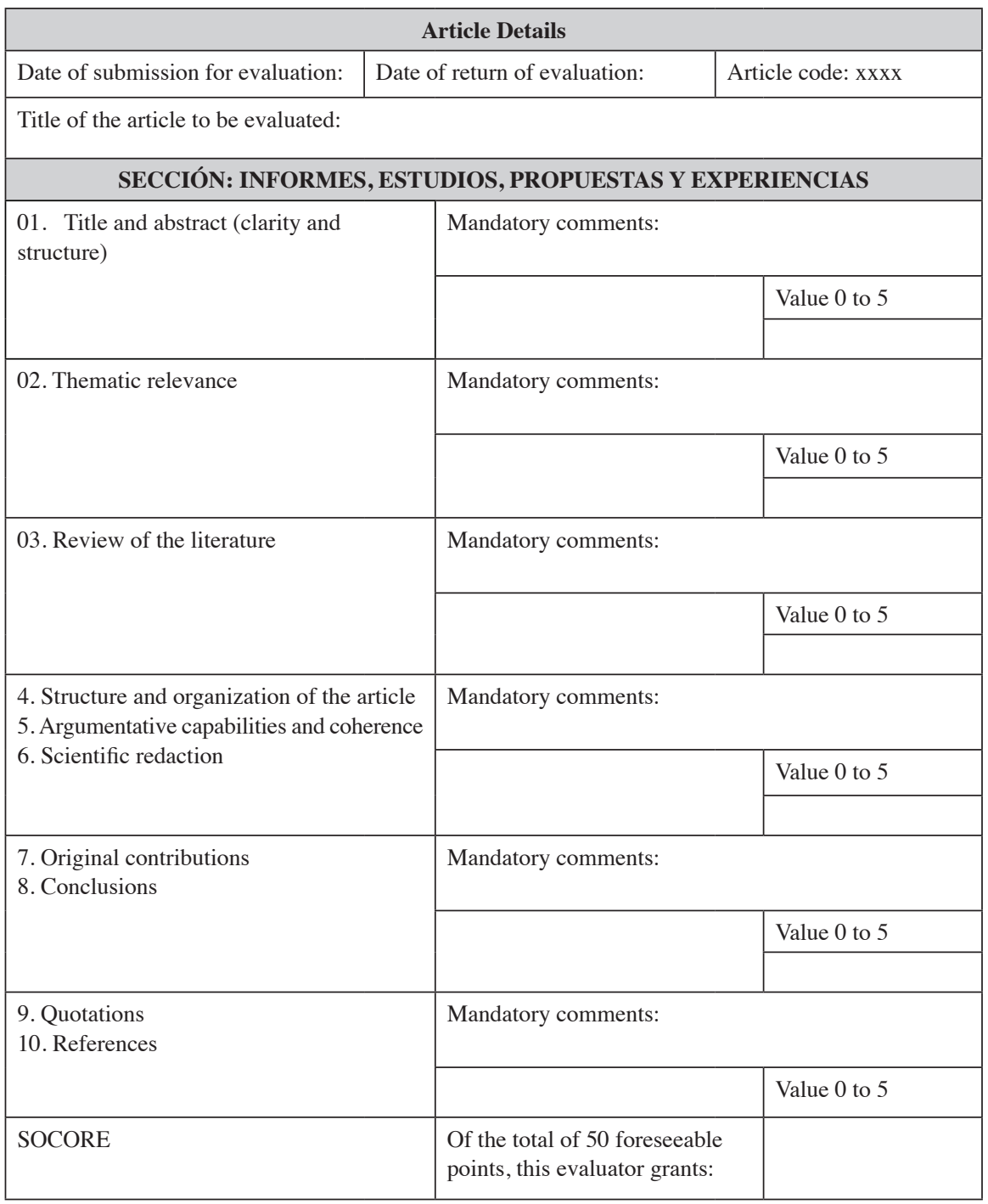




\begin{tabular}{|c|c|c|c|}
\hline $\begin{array}{l}\text { REDACTED OPINION } \\
\text { (More detailed if the work } \\
\text { does not get } 40 \text { points, to } \\
\text { inform the author(s) } \\
\text { This text is sent verbatim } \\
\text { to the author (s) } \\
\text { anonymously. }\end{array}$ & & & \\
\hline WORTH PUBLISHING & No & Yes & $\begin{array}{l}\text { Yes, with minor } \\
\text { changes }\end{array}$ \\
\hline $\begin{array}{l}\text { PROPOSED CHANGES } \\
\text { (In case of "Yes, with } \\
\text { conditions") }\end{array}$ & & & \\
\hline
\end{tabular}




\title{
Cover Letter
}

Sección (Marcar)

Dossier Monográfico

Miscelánea

\section{Título en español: Arial 14 negrita y centrado. Máximo 80 caracteres con espacios}

\author{
Title in English: Arial 14 cursiva. \\ Máximo 80 caracteres con espacios
}

Nombre autor 1 (estandarizado)

Categoría profesional, Institución, País

Correo electrónico institucional

ORCID

Nombre autor 2 (estandarizado)

Categoría profesional, Institución, País

Correo electrónico institucional

ORCID

Nombre autor 3 (estandarizado)

Categoría profesional, Institución, País

Correo electrónico institucional

ORCID

\section{Resumen}

Mínimo 210 y máximo 230 palabras. Debe incluir 1) Justificación del tema; 2) Objetivos; 3) Metodología y muestra; 4) Principales resultados; 5) Principales conclusiones. Ha de estar escrito de manera impersonal "El presente trabajo analiza..." 


\begin{abstract}
Mínimo 210 y máximo 230 palabras cursiva. Debe incluir 1) Justificación del tema; 2) Objetivos; 3) Metodología y muestra; 4) Principales resultados; 5) Principales conclusiones. Ha de estar escrito de manera impersonal “El presente trabajo analiza..." No utilizar sistemas de traducción automáticos.
\end{abstract}

\title{
Descriptores
}

6 términos estandarizados preferiblemente de una sola palabra y del Thesaurus de la UNESCO separados por coma (,).

\section{Keyword}

Los 6 términos referidos en inglés separados por coma (,). No utilizar sistemas de traducción automáticos.

\section{Apoyos y soporte financiero de la investigación (Opcional)}

Entidad:

País:

Ciudad:

Proyecto subvencionado:

Código de proyecto: 


\section{PRESENTACIÓN}

\section{Cover Letter}

Sr. Editor de «Universitas»

Leída la normativa de la revista «Universitas» y analizada su cobertura, área temática y enfoque, considero que esta revista es la idónea para la difusión del trabajo que le adjunto, por lo que le ruego sea sometida a la consideración para su publicación. El original lleva por título “ ", cuya autoría corresponde a

El autor/es certifican que este trabajo no ha sido publicado, ni está en vías de consideración para su publicación en ninguna otra revista u obra editorial.

El autor/es se responsabilizan de su contenido y de haber contribuido a la concepción, diseño y realización del trabajo, análisis e interpretación de datos, y de haber participado en la redacción del texto y sus revisiones, así como en la aprobación de la versión que finalmente se remite en adjunto.

Se aceptan la introducción de cambios en el contenido si hubiere lugar tras la revisión, y de cambios en el estilo del manuscrito por parte de la redacción de «Universitas».

\section{Cesión de derechos y declaración de conflicto de intereses}

La editorial Abya-Yala (editorial matriz de las obras de la Universidad Politécnica Salesiana de Ecuador) conserva los derechos patrimoniales (copyright) de las obras publicadas y favorecerá la reutilización de las mismas. Las obras se publican en la edición electrónica de la revista bajo una licencia Creative Commons Reconocimiento / No Comercial-Sin Obra Derivada 3.0 Ecuador: se pueden copiar, usar, difundir, transmitir y exponer públicamente.

El autor/es abajo firmante transfiere parcialmente los derechos de propiedad (copyright) del presente trabajo a la editorial Abya-Yala (Ecuador) (RUC: XXXXXX), para las ediciones impresas. 
Se declara además haber respetado los principios éticos de investigación y estar libre de cualquier conflicto de intereses.

En ___ (ciudad), a los ___ días del mes de de 201

Firmado. (Por el autor o en su caso, todos los autores)

Nombre y apellido de los autores

Documento de Identidad

Firma

Nombre y apellido de los autores

Documento de Identidad

Firma

Nombre y apellido de los autores

Documento de Identidad

Firma

Nota: Una vez haya guardado el documento cumplimentado y firmado, deberá consignarlo a través del sistema OJS en la sección "Ficheros Complementarios". 


\title{
Cover Letter
}

Section (Mark)

Mnographic Dossier

Miscellany

\section{Title in Spanish: Arial 14 bold and centered. Maximum 80 characters with spaces}

\author{
Title in English: Arial 14 cursive. \\ Maximum 80 characters with spaces
}

\begin{abstract}
Name author 1 (standardized)
Professional category, Institution,

Country Institutional email

ORCID
\end{abstract}

Name author 2 (standardized)

Professional category, Institution, Country

Institutional email

ORCID

Name author 3 (standardized)

Professional category, Institution, Country

Institutional email

ORCID

\section{Abstract (Spanish)}

Minimum 210 and maximum 230 words. It must include 1) Justification of the topic; 2) Objectives; 3) Methodology and sample; 4) Main results; 5) Main conclusions. It must be impersonally written "The present paper analyzes ..." 


\section{Abstract (English)}

Minimum 210 and maximum 230 words. It must include 1) Justification of the topic; 2) Objectives; 3) Methodology and sample; 4) Main results; 5) Main conclusions. It must be impersonally written "The present paper analyzes ..." Do not use automatic translation systems.

\section{Descriptors (Spanish)}

6 standardized terms preferably of a single word and of the UNESCO Thesaurus separated by commas (,).

\section{Keywords}

The 6 terms referred to in English separated by commas (,). Do not use automatic translation systems.

\section{Financial Support of Research (Optional)}

Entity:

Country:

City:

Subsidized project:

Code of the project: 


\title{
PRESENTATION
}

\author{
Cover Letter
}

Mr. Editor of «Universitas»

Having read the regulations of the journal «Universitas» and analyzed its coverage, thematic area and approach, I consider that this journal is the ideal one for the dissemination of the work that I hereby attach, for which I beg you to be submitted for consideration for publication. The original has the following title " ", whose authorship corresponds to

The authors (s) certify that this work has not been published, nor is it under consideration for publication in any other journal or editorial work.

The author (s) are responsible for their content and have contributed to the conception, design and completion of the work, analysis and interpretation of data, and to have participated in the writing of the text and its revisions, as well as in the approval of the version which is finally referred to as an attachment.

Changes to the content are accepted if they occur after the review process, and also changes in the style of the manuscript by the editorial process of «Universitas».

\section{Transfer of Copyright and Declaration of Conflict of Interest}

The Universidad Politécnica Salesiana of Ecuador preserves the copyrights of the published works and will favor the reuse of the same. The works are published in the electronic edition of the journal under a Creative Commons Attribution / Noncommercial-No Derivative Works 3.0 Ecuador license: they can be copied, used, disseminated, transmitted and publicly displayed.

The undersigned author partially transfers the copyrights of this work to the Universidad Politécnica Salesiana of Ecuador, for the printed editions. 
It is also declared that they have respected the ethical principles of research and are free from any conflict of interest.

In ___ (city), by the___ days of the month of ___ of 201_

Signed. (By the author or in the case, all the authors)

Authors' first and last name

Identification document

Signature

Authors' first and last name

Identification document

Signature

Authors' first and last name

Identification document

Signature

Note: Once saved the completed and signed document, it must be register through the OJS system in the section "Complementary Files". 


\title{
Convocatoria del dossier "Problemáticas, prácticas y sujetos educativos en América Latina: balances y perspectivas a futuro en tiempos de cambio"
}

\section{Coordinadores del Dossier}

\author{
Dra. Marina Larrondo, (IDES - CONICET, Argentina) \\ Dra. Liliana Mayer (UNAM - CONICET, Argentina) \\ Dra. Pedro Núñez (FLACSO - CONICET/UBA, Argentina) \\ Mg. Sebastián Granda (UPS, Ecuador)
}

\section{Convocatoria}

Desde sus inicios, las ciencias sociales mostraron su interés por la realidad educativa, reflexionando respecto de sus recursos, normas, agentes, instituciones y las prácticas que allí tienen lugar. Más allá de este interés fundacional, los últimos años fueron testigo de la diversificación del campo educativo, cobrando fuerza nuevos objetos de estudio y ampliando los ya existentes, también, a través de disciplinas y puntos de vista diversos.

De manera concomitante, la ampliación de la obligatoriedad y cobertura educativa también colaboraron en la determinación de nuevos ejes al identificar los cambios en los sistemas y políticas educativas. En efecto, los últimos veinte años en la región registraron modificaciones en las legislaciones educativas en casi todos sus países, que fueron determinantes en estos procesos, al mismo tiempo que el ideario del Estado Nación agenciado por los propios sistemas educativas entró muchas veces en crisis. En este sentido, podemos mencionar en particular los procesos de diferenciación socioeconómica expresados principalmente en la privatización creciente de la educación básica u obligatoria, tensionando el ideal de igualdad que pretende por un lado la escuela en su formación ciudadana frente a proyectos que producen simultáneamente fisuras y fragmentaciones en tal proyecto unitario. Estas fragmentaciones no han tenido solamente efectos en la segregación socioeconómica inicial, sino también en términos pedagógicos. Así, los procesos de ampliación de derechos que ocuparon un lugar principal en la agenda educativa de la región, muchas veces impulsados por los "gobiernos progresistas", otras por organismos internacionales, reconocen el lugar 
central de la institución escolar en la aspiración a la constitución de sociedades equitativas -sino igualitarias- e incorporan referencias a la convivencia, la paz, los derechos sexuales y reproductivos o la educación intercultural bilingüe -por mencionar sólo algunos- se enfrentan y conviven con la conformación de espacios escolares que muchas veces tienden a expresar o reflejar diferenciaciones socioeconómicas o su pretensión de distinción social, incidiendo en la generación y ampliación de la desigualdad social y o fragmentaciones culturales. Asimismo, la vocación de ampliar saberes legítimos y prácticas (por ejemplo, el derecho a participar y reconocer la voz de los estudiantes) ha encontrado resistencias en la práctica cotidiana así como muestra las dificultades para que los enunciados legislativos y el diseño de las políticas públicas se plasmen en las instituciones. Estos procesos que inicialmente fueron analizados por los cientistas sociales como propios de la educación secundaria o media, se extendieron al resto de los niveles, mostrando nuevas formas de producción y reproducción de las desigualdades sociales y con ellas, de habitar las instituciones en términos de trayectorias e itinerarios educativos.

La fecha límite para el envío de artículos a través del OJS de la revista es el 10 de noviembre de 2017:. http://revistas.ups.edu.ec/pdf/docs/ universitas/NORMATIVAUNIVERSITAS.pdf 


\section{Call for the dossier "Problems, practices and educational subjects in Latin America: balances and future perspectives in times of change"}

\section{Dossier Coordinators}

Dra. Marina Larrondo, (IDES - CONICET, Argentina)

Dra. Liliana Mayer (UNAM - CONICET, Argentina)

Dra. Pedro Núñez (FLACSO - CONICET/UBA, Argentina)

Mg. Sebastián Granda (UPS, Ecuador)

\section{Theoretical basis}

From its beginnings, the social sciences showed their interest in the educational reality, reflecting on their resources, norms, agents, institutions and the practices that take place there. Beyond this foundational interest, the last years witnessed the diversification of the educational field, gaining strength new objects of study and expanding existing ones, also, through diverse disciplines and points of view. At the same time, the expansion of compulsory education coverage also helped to identify new axes in identifying changes in education systems and policies. In fact, the last twenty years the region registered changes in educational legislation in almost all of its countries, which were decisive in these processes, at the same time as the ideology of the Nation State, which was brokered by the educational systems themselves, often went into crisis. In this sense, we can mention in particular the processes of socioeconomic differentiation expressed mainly in the increasing privatization of basic or compulsory education, stressing the ideal of equality that seeks on the one hand the school in its citizenship formation against projects that simultaneously produce fissures and fragmentations in such a unitary project. These fragmentations have not only had an effect on the initial socioeconomic segregation, but also on pedagogical terms. Thus, the processes of extending rights that have occupied a major place in the educational agenda of the region, often driven by "progressive governments", others by international organizations, recognize the central 
place of the school institution in the aspiration to the constitution equitable societies - and incorporate references to coexistence, peace, sexual and reproductive rights or intercultural bilingual education - to mention only a few - face and coexist with the conformation of school spaces that often tend to express or reflect socioeconomic differentiations or their claim to social distinction, affecting the generation and expansion of social inequality and cultural fragmentation. Likewise, the vocation to extend legitimate and practical knowledge (for example, the right to participate and to recognize the voice of students) has found resistance in daily practice as well as shown the difficulties for legislative statements and the design of public policies to be reflected in the institutions. These processes that were initially analyzed by social scientists as belonging to secondary or secondary education, extended to the other levels, showing new forms of production and reproduction of social inequalities and with them, to inhabit institutions in terms of trajectories and educational itineraries.

The deadline for sending articles through the OJS of the journal is November 10, 2017. It appends the publication rules: http://revistas.ups. edu.ec/pdf/docs/universitas/NORMATIVAUNIVERSITAS. pdf 